\title{
Mending Women's \\ Health \\ through Invisible Quilts
}

by

\begin{abstract}
Alisha Kapoor
A thesis submitted to the Faculty of Graduate and Postdoctoral Affairs in partial fulfillment of the requirements for the degree of
\end{abstract}

Master of Architecture

in

Azrieli School of Architecture

Carleton University

Ottawa, Ontario

(C) 2019

Alisha Kapoor 


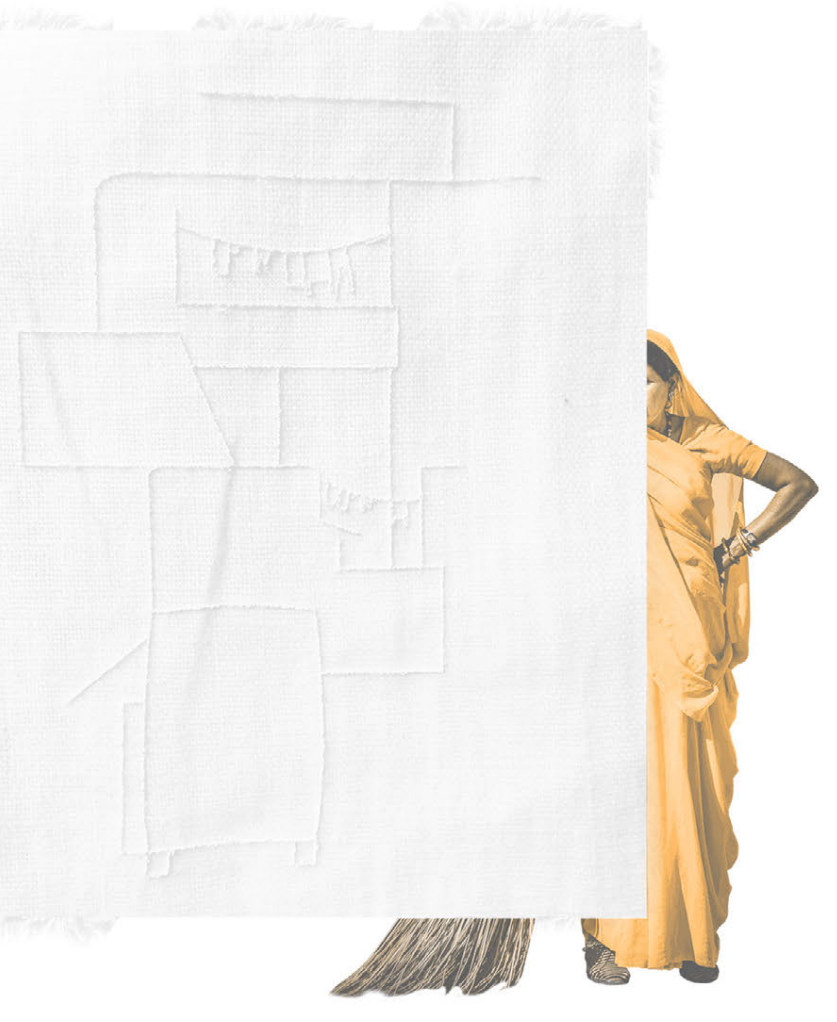


Abstract

Dharavi, one of Asia's largest urban, low-income settlements faces many sanitary and public health concerns making the residents especially vulnerable to infectious diseases. The health concerns are exacerbated for women living in Dharavi, as social, cultural, and gendered norms are compounded with the poor living standards to further barricade women from receiving adequate care. Many women cited expenditure, distrust, lack of integration, misinformation, and social pressures as some of the reasons for not attending health facilities or delaying treatment.

This proposal sets out to engage and socialize women in Dharavi through a two-fold approach; a mobile sewing facility to empower women-led industry and adhering to social norms, and a discrete preventative-health laundry clinic inside to help women with hygienic practices during menstruation. The thesis is grounded in a magical realist framework to situate opposing gendered systems to one another and transgress the normative boundaries that affect women's safety and health. As such, by employing magical realist objectives, the proposal is a critique on the current social climate and a method for imagining new possibilities. 


\section{Acknowledgement}

I wish to express my sincere thanks to my thesis supervisor, Professor Federica Goffi, for her support and contribution to my project. This thesis would not be possible without her consistent efforts to improve my work through edits, insightful suggestions, and words of encouragement. I am deeply grateful to have had the opportunity to spend an entire year working closely with her. I could not have imagined a better advisor and mentor for this project. 


\section{Table of Contents}

01 1. Introduction: The Urban Slum Condition

04 2. Health and the Urban Slum

2.1 The Health Care System

2.2 Women's Health in the Urban Slum

2.2.1 Urban Specific Health Concerns: Sanitation and the Spread of Disease

2.2.2 Menstrual Health

17 3. Understanding the Shortcomings of Health Care Services

3.1 Prevailing Social Norms

3.2 Economic Barriers

3.3 Poor Living Standards

3.4 Dominant Social Structures for Health-Related Support

294 4. Site: Dharavi

4.1 History

4.2 Morphology

4.2.1 Site Neighbourhoods

4.2.2 Building and Site Typology

4.2.3 Transportation

4.2.4 Industry

4.3 Health Structure: Facilities and Use

4.31 Sanitation Services

$54 \quad$ 5. A Magical Realist Framework

5.1 Introducing Magical Realism

5.2 Decoding Magical Realism

5.3 Magical Realism and Dharavi 


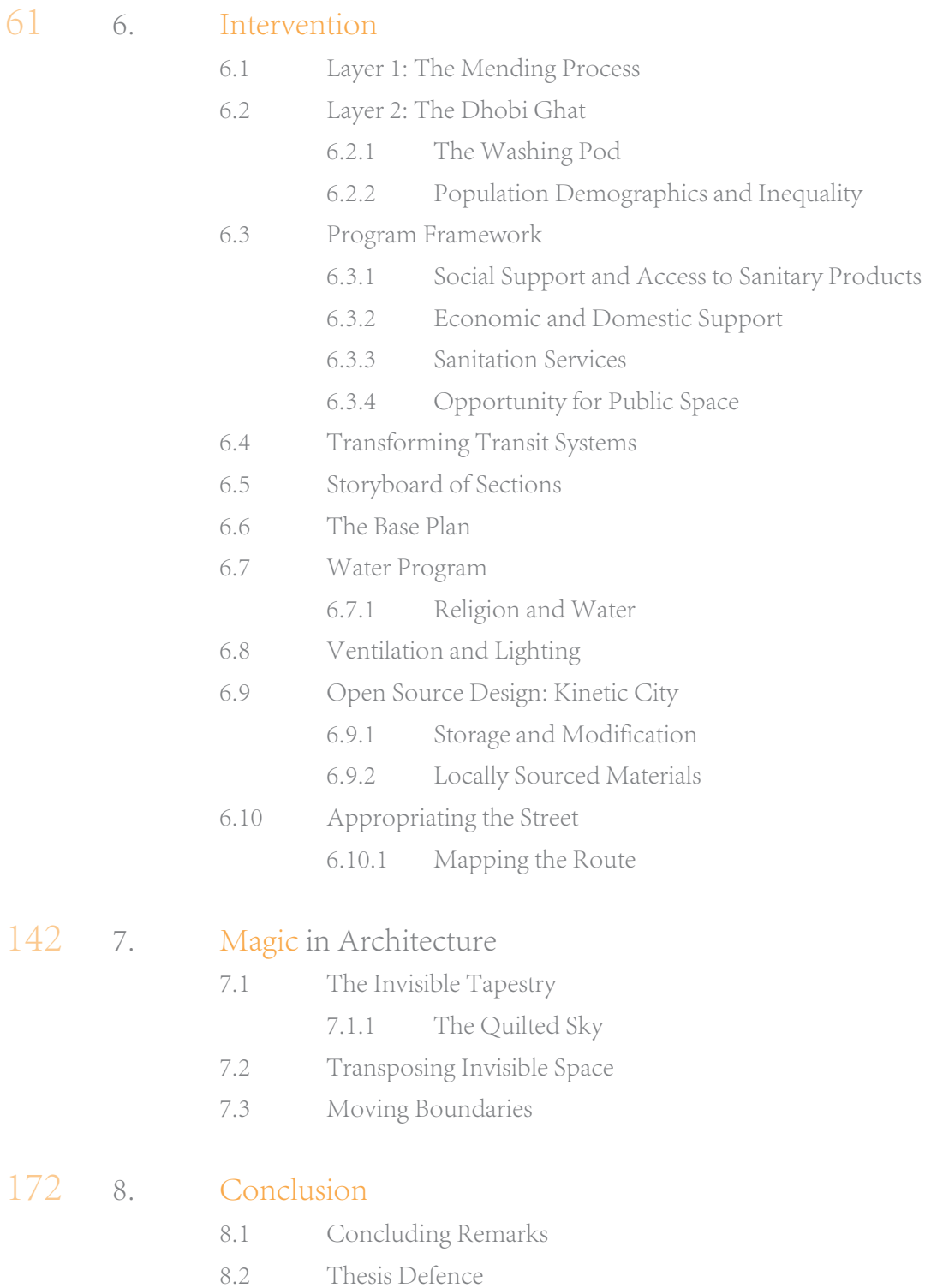

$1809 . \quad$ Sources




\section{List of Illustrations}

Fig 2.0 Health Expenditure Amongst Newly Industrialized Nations 2015

Fig 2.1 Public versus Private Healthcare Systems in India 2014

Fig 2.2 Representation of the Social Fabric Revealing Male Hygiene Practices as Women Remain Hidden Behind the Cloth

Fig 2.3 Representation of Current Social Fabric that Makes Invisible Women's Health and Hygiene

Fig 2.4 Representation of an Ideal Future whereby Women's Health Reveals Itself from the Social Fabric

Fig 2.5 Representation of Women's Health

Fig 4.0 Map of Bombay from the Times of India c. 1895 Source: Geographicus Rare Antique Maps

Fig 4.1 Pictorial Timeline of Dharavi's Major Industries

Fig 4.2 Map of Five Major Districts in Dharavi

Fig 4.3 Typical Street and Building Construction in Dharavi

Fig 4.4 Map of Accessible Railroads and Highways and Major Roads in Dharavi

Fig 4.5 Map of Kumbharwada and its marked kilns Source: URBZ

Fig 4.6 Map of the Major Economic Industries in Dharavi

Fig 4.7 Routes by which Women in Crisis Approached the Centre 2003-2006

Fig 4.8 Map of Flood Planes, Water Supply and Public Toilets in Dharavi

Fig 5.0 Dr Franz Roh, “The Candle Duel of the Literary Man,” c. 1930 Source: UBU Gallery

Fig 6.0 Laundry at Dhobi Ghat in Mumbai, India 2009 
Photographed by: Veronika Roosimaa

Fig 6.1 Population and Social Structure of the Dhobi Ghat, Mumbai 2014

Fig 6.2 Map of Population Demographics Between the Two Sites and Laundry Facilities in Dharavi

82 Fig 6.3 Mumbai's BEST Double Decker Bus

83 Fig 6.4 Typical Programmatic Organization based on Assigned Visibility

Fig 6.5 Program Arrangement Based on Water Zone and Requirements

Fig 6.6 Programmatic Dimensions and Allocated Space

Fig 6.7 Main Level Bus Plan

Fig 6.8 Level 01Bus Plan

Fig 6.9 Water System Diagram

Fig 6.10 Water System Section during Monsoon

Fig 6.11 Water System Section Printed on Fabric and Hand-Washed

Fig 6.12 Sanitation Section near Police Station

Fig 6.13 Sanitation Section Printed on Fabric and Hand-Washed

Fig 6.14 A 17-Year-Old Nepali Woman Banished to a Chaupadi Hut during Menstruation 2018

Photographed by: Tara Todras-Whitehill

104 Fig 6.15 Bath Section during Ramadan

105 Fig 6.16 Bath Section Printed on Fabric and Hand-Washed

109 Fig 6.17 Drying Section during Holi

110 Fig 6.18 Drying Section Printed on Fabric and Hand-Washed

112 Fig 6.19 Immersion of the Ganesh Idol

114 Fig 6.20 Town Hall of Mumbai transformed of Independence Day Photographed by: Rahul Mehrotra

116 Fig 6.21 Ambulance Service Stations Near Dharavi

118 Fig 6.22 Longitudinal Section at Storage Garage

119 Fig 6.23 Section at Storage Printed on Fabric and Hand-Washed

121 Fig 6.24 Health Space Section near Sai Hospital

122 Fig 6.25 Health Space Section Printed on Fabric and Hand-Washed

125 Fig 6.26 Bus Material Locations in Dharavi

127 Fig 6.27 Local Material Wall Section during Diwali

128 Fig 6.28 Material Wall Section Printed on Fabric and Hand-Washed 132 Fig 6.29 Sewing Workspace Section at Dharavi Market 
Fig 6.30 Sewing Workspace Section Printed on Fabric and Hand-

Washed

136 Fig 6.31 Driver Seat Section at Dharavi Bus Depot

137 Fig 6.32 Driver Seat Section Printed on Fabric and Hand-Washed

138 Fig 6.33 Map of Mobile Clinic Route Based on Concentration of Four Key Transportation Layers

139 Fig 6.34 First Bus Route Scale the Bus Depot

140 Fig 6.35 Second Bus Route Scale Major Arterial Roads for Vehicular Traffic

141 Fig 6.36 Third Bus Route Scale Interior Pedestrian Streets Near Bus Stop

146 Fig 7.0 Lee Mingwei, “The Mending Project,” c. 2017 Photographed by: Anna Wu

149 Fig 7.1 Cotton Fabric Drying in the Sun in Jaipur, Rajasthan 2016 Photographed by: Yann Arthus-Bertrand

150 Fig 7.2 The Bus Tethered to the Narrative Quilt

151 Fig 7.3 The Bus Tethered to the Narrative Quilt

152 Fig 7.4 The Bus and Narrative Quilt Tethered Together

153 Fig 7.5 The Bus Tethered to the Narrative Quilt

154 Fig 7.6 Narrative Quilt of the Tethered Buses

155 Fig 7.7 Narratives from Hapur District Imagined as the Magical Quilt

156 Fig 7.8 Magical Representation of Women Sewing Messages to the Narrative Quilt

157 Fig 7.9 Women Sewing Messages to the Narrative Quilt

161 Fig 7.10 Magical Representation of the Bus's Space and Visibility

162 Fig 7.11 Magical Representation of the Bus's Space and Visibility

163 Fig 7.12 Magical Representation of the Bus's Space and Visibility

164 Fig 7.13 Magical Representation of the Bus's Space and Visibility

165 Fig 7.14 Magical Representation of the Bus Moving through a Bazaar

166 Fig 7.15 Bus Moving through a Bazaar in Dharavi

170 Fig 7.16 Magical Representation of Path Moving through Places of Exclusion

171 Fig 7.17 Women Excluded from Commerce Activity

176 Fig 8.0 Thesis Defence

177 Fig 8.1 Thesis Defence Drawings

178 Fig 8.2 Thesis Defence Main Floor Installation 


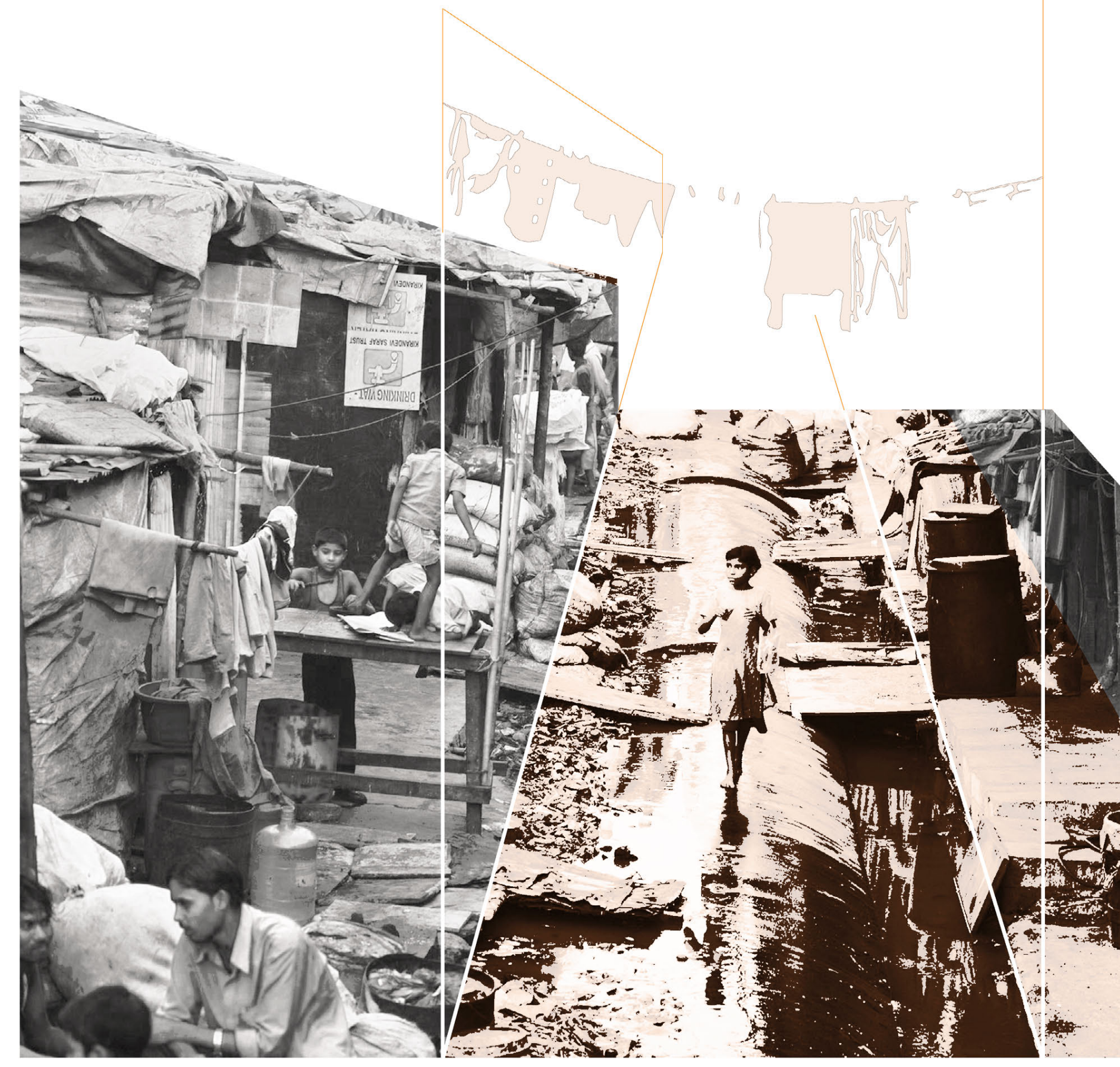




\section{Introduction/ The Urban Slum Condition}

The UN-Habitat published a report in 2006 defining slums as, "areas of people lacking one or more of the following indicators: durable housing of permanent nature, sufficient living space, easy access to safe water, access to adequate sanitation and security of tenure." According to a recent study, $32 \%$ of the world's urban population live in slums, and that number is expected to steadily rise. ${ }^{2}$ Of this number, approximately 60-70\% are women and girls, who are often excluded or restricted from economic, social and political realms. ${ }^{3}$

India's largest city, Mumbai, is particularly vulnerable to proliferated and unregulated slum growth as already $55 \%$ of the current population live in slums and yet only occupy $12.9 \%$ of the city. ${ }^{4}$ Of the multiple slums in Mumbai, Dharavi is especially noteworthy, as it is regarded as Asia's largest slum with population estimates anywhere between 600,000-1,000,000 people within $2 \mathrm{~km}$ squared. ${ }^{5}$

Of this population, women are at higher risk of crime, disease, conflict and instability because of their inequitable burden in the

\footnotetext{
1 Taubenbock and Kraff 2014:18

2 Taubenbock and Kraff 2014:15

3 Meleis, Birch, and Wachter 2011: 79

4 Taubenbock and Kraff 2014:16

5 Saglio-Yatzimirsky 2013: 2
} 
household and disproportionate health needs. Women's life expectancy in the developed world is 79.8 years, however, it drastically drops to 66.2 in the less developed world and to 53.2 in the least developed world. ${ }^{6}$ Even when latrines, hospitals, and health facilities are constructed, there is still a dissonance between services and use. The nuanced social structures, gendered roles, and cultural practices greatly impact a woman's decision to seek formal health services.

This thesis seeks to develop a preventative healthcare space for feminine hygiene and reproductive health for women in low-income settlements. The project's intent is to engage, mobilize, and autotomize women through the dissemination of accurate information and products, offering a financial return while addressing the poor sanitary conditions and offering female-led gathering spaces.

Dharavi, the chosen site for this intervention, is highly diverse with an intricate and lucrative artisan industry. However, due to its high population density, intimate living quarters, and a ratio of 40 inhabitants to one water tap, Dharavi residents are more susceptible to disease. ${ }^{7}$ In addition, some low-income settlements like Dharavi subscribe to traditional and cultural traditions that may stigmatize menstrual health, leading to misinformation and isolation. Further, issues of visibility and safety can obstruct women from socializing and accessing services within the community.

To overcome the stigmatization, the thesis will employ magical elements to emphasize the gendered systems at play while maintaining traditional customs. This will be achieved through the interplay between

6 Meleis, Birch, and Wachter 2011: 79

7 Saglio-Yatzimirsky 2013: 48 
visibility and safety, and language and communication. The project will find magical ways to maneuverer visibility and use language in a way that is strictly accessible to the women. In doing so, the magical elements will avoid attracting unwanted attention that could compromise the project's success. It will also bring the reader's attention to the long-standing customary practices, which influence a woman's understanding of her body. Time, education, and changing attitudes, will dismantle these customary beliefs, however, this project is set in the present landscape and hopes to be a catalyst for the change.

The proposal will transform a double decker bus into a preventative female healthcare space with laundry, garment sewing, and sanitation programs. The sewing spaces will act as an economic incentive for women to perform household chores outside of the home, which in turn will promote community-building. The laundry will borrow inspiration from the largest open-air laundromat, Dhobi Ghat, located a few kilometers from Dharavi. The Dhobi Ghat workers are 95\% male and so, the end goal is to offer similar laundry and drying services for women's menstrual cloths.

The project will offer women-specific health consultations, the opportunity to privately wash clothes and garments used during menstruation, availability of reproductive and menstrual health products, and a community space for shared perspectives and narratives to build a more holistic understanding of women's health. 


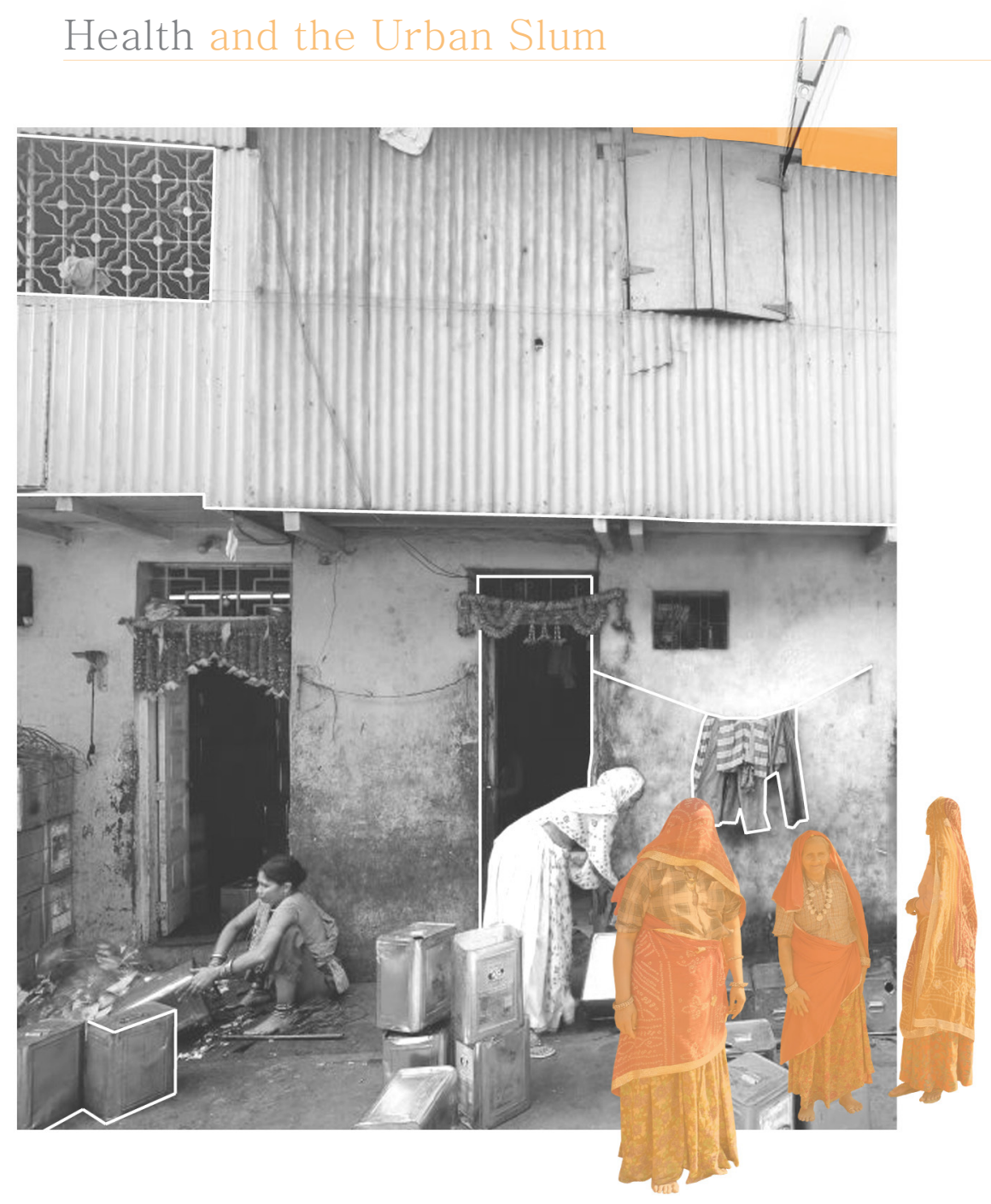


India has a two-tiered healthcare system--public and private-however, there is a significant imbalance between the quality of care and patient use. ${ }^{8}$ Private healthcare services are on average four times more expensive than their public counterparts. ${ }^{9}$ For public facilities, the state subsidizes the cost of treatment, so the services are more affordable. However, government funding for healthcare is amongst the lowest in comparison to low-income countries. ${ }^{10}$

Patient spending and capital can greatly influence the quality of treatment. Public clinics are severely understaffed and patients may still be expected to pay for basic medical and surgical items due to the shortage. Further, health professionals working at public hospitals may harbour prejudiced opinions and an overall apathetic attitude towards the patients. A common misconception is that the patients "are being done a favour by the state, and such patients are perceived as learning material." ${ }^{11}$ This paternalistic attitude can raise issues concerning privacy, consent, patient autonomy, and communication throughout the

8 International Health Care System Profiles 2017

9 International Health Care System Profiles 2017

10 Last year, only about $5 \%$ of the country's total annual expenditure was allocated to healthcare (International Health Care System Profiles 2017). In 2014, the government's expenditure was approximately $1.1 \%$ of India's domestic gross product (International Health Care System Profiles 2017).

11 Ghoshal 2016: 25 
health and the urban slum

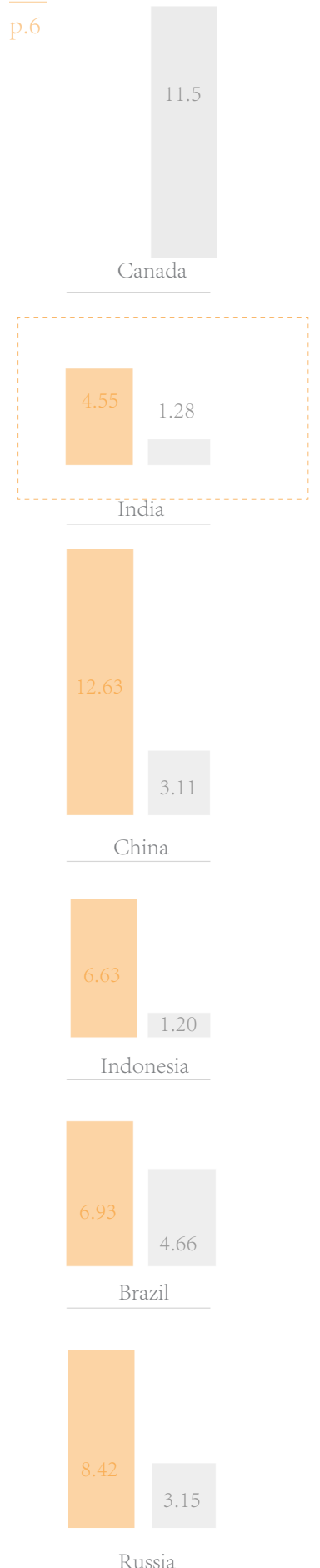

Govt Health Expenditure:

$\%$ of Budget

$\%$ of GDP

Figure 2.0: Health Expenditure Amongst Newly Industrialized Nations 2015 decision-making process. Consequently, many patients are intimidated to access public health services.

In contrast, private clinics have experienced a positive economic growth trend. The rise in domestic income levels across India and the influx of medical tourism have helped funnel billions of dollars annually into the private sector. ${ }^{12}$ As such, the facilities are equipped with cleaner amenities and less overcrowding. In addition, private healthcare physicians are paid more than their public counterparts, which may explain the lower occurrence of abusive or patronizing behaviour. ${ }^{13}$

Geographic barriers also directly impact patient use. Urban areas typically have higher concentrations of private clinics, as they are dependent on more affluent neighbourhoods for profit. ${ }^{14}$ Thus, there is a lack of private health facilities in lower socio-economic areas.

What emerges from the current system is a class and socioeconomic divide between patients and healthcare. Medical personnel's attitudes, geographic isolation, and funding are all contributing factors that impact the schism between private and public healthcare. Of the country's total healthcare clinics and amenities, $80 \%$ of them are private institutions. ${ }^{15}$ This is despite the fact that more than half the population relies on public healthcare. ${ }^{16}$ Evidently, there is a discord between supply and demand, whereby the economically disadvantaged are negatively affected.

\footnotetext{
12 Sengupta 2005: 1157

13 Ghoshal 2016: 25

14 Ghoshal 2016: 25

15 Ghoshal 2016: 25

16 International Health Care System Profiles 2017
} 


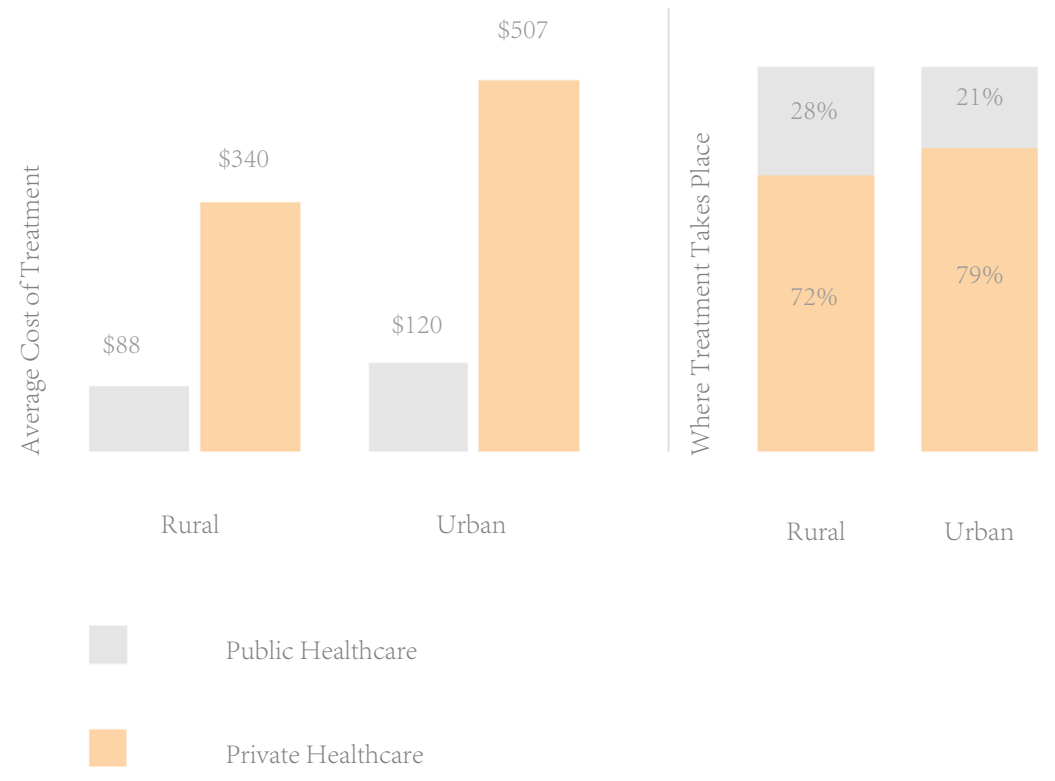

Figure 2.1: Public versus Private Healthcare Systems in India 2014 


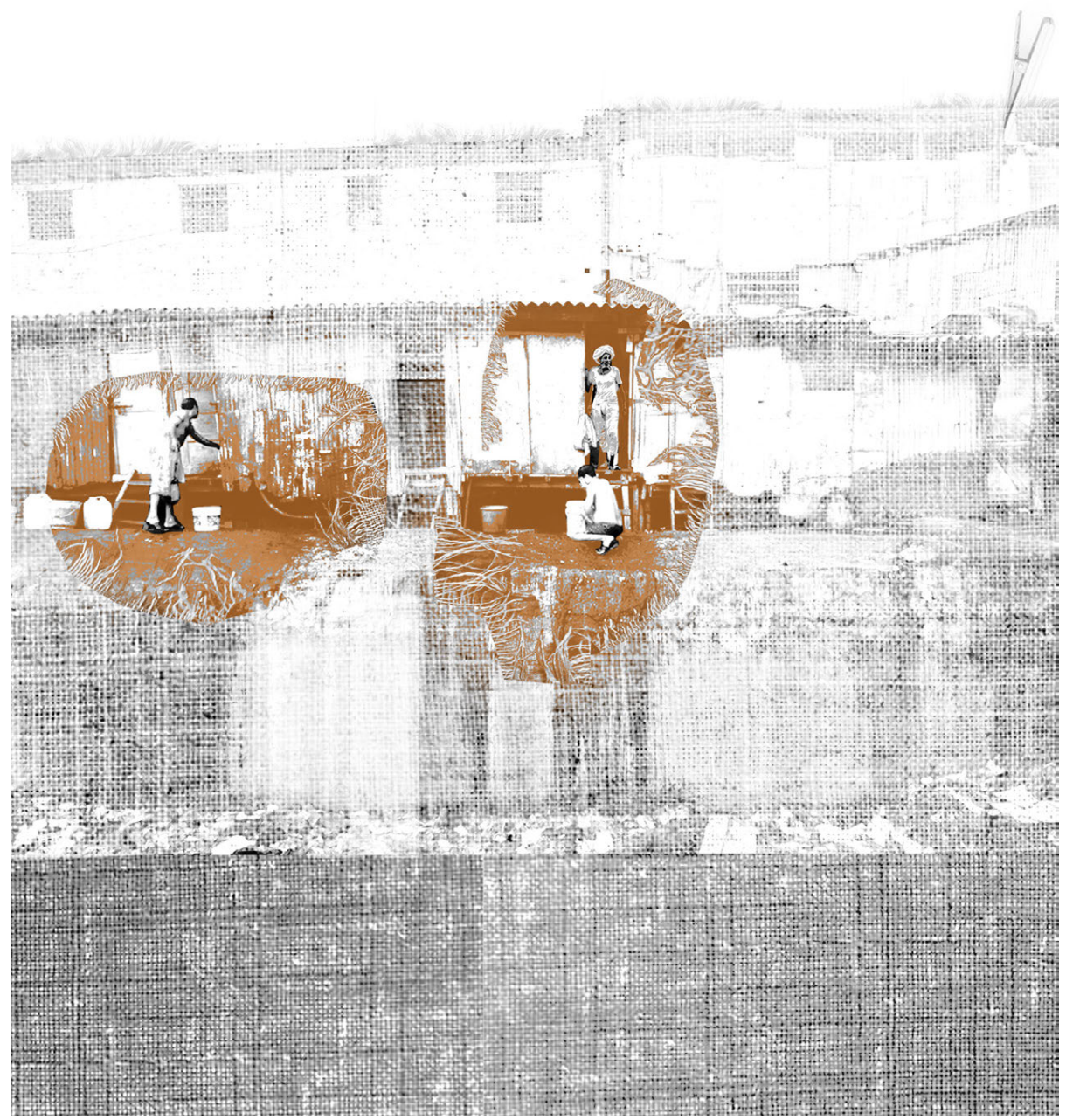

Figure 2.2: Representation of the Social Fabric Revealing Male Hygiene Practices as Women Remain Hidden Behind the Cloth 


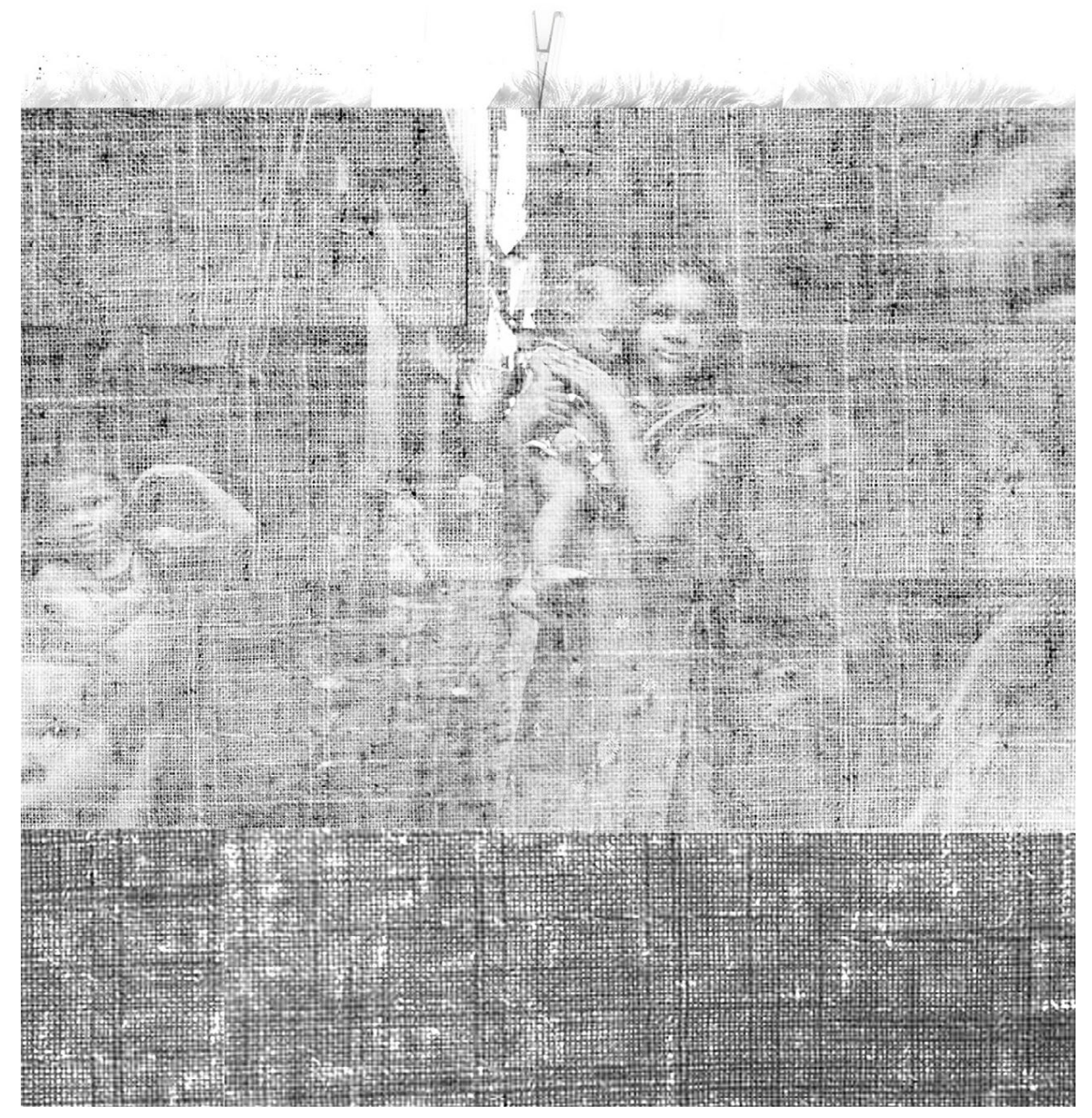

Figure 2.3: Representation of Current Social Fabric that Makes Invisible Women's Health and Hygiene 


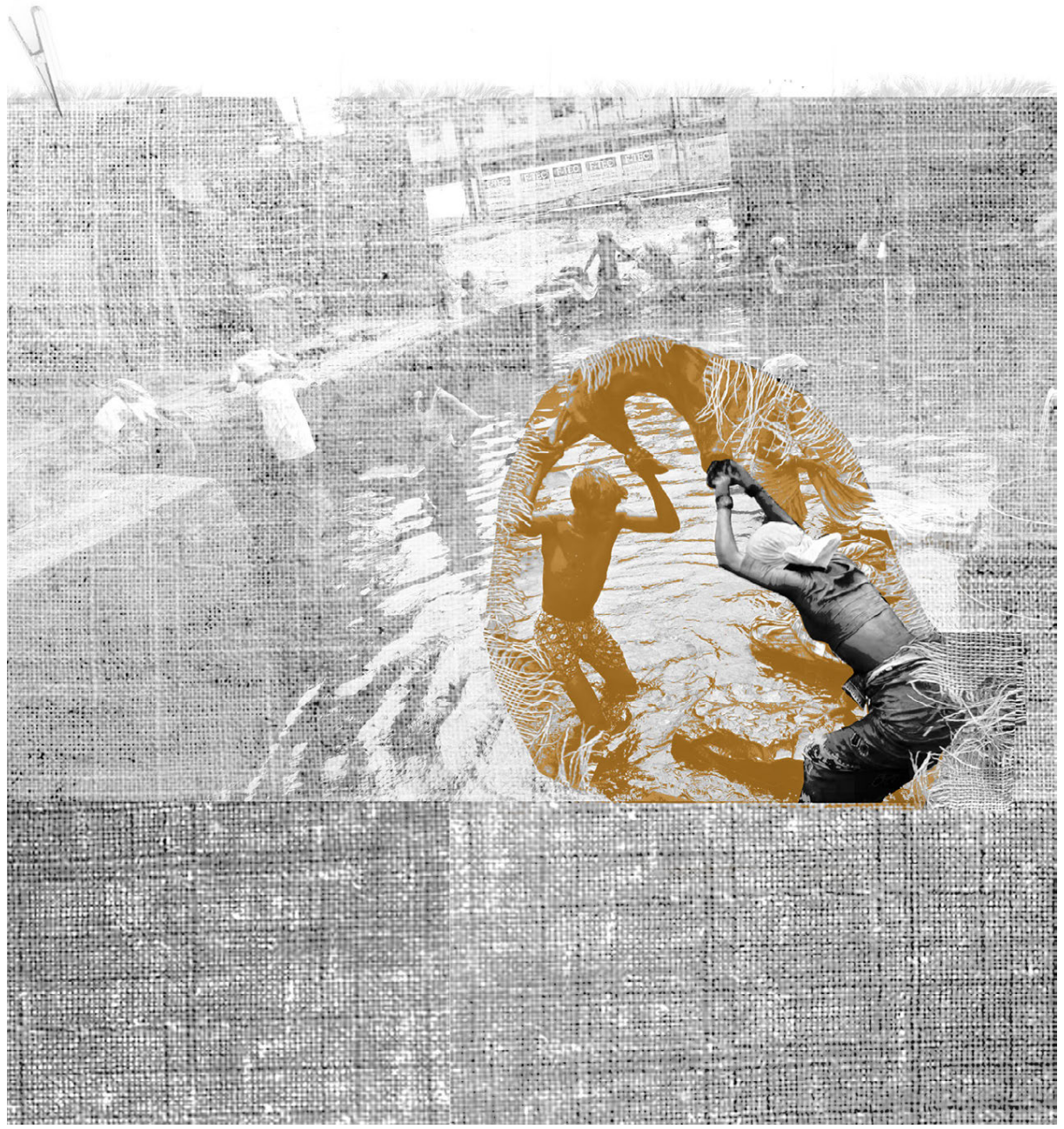

Figure 2.4: Representation of an Ideal Future whereby Women's Health Reveals Itself from the Social Fabric 

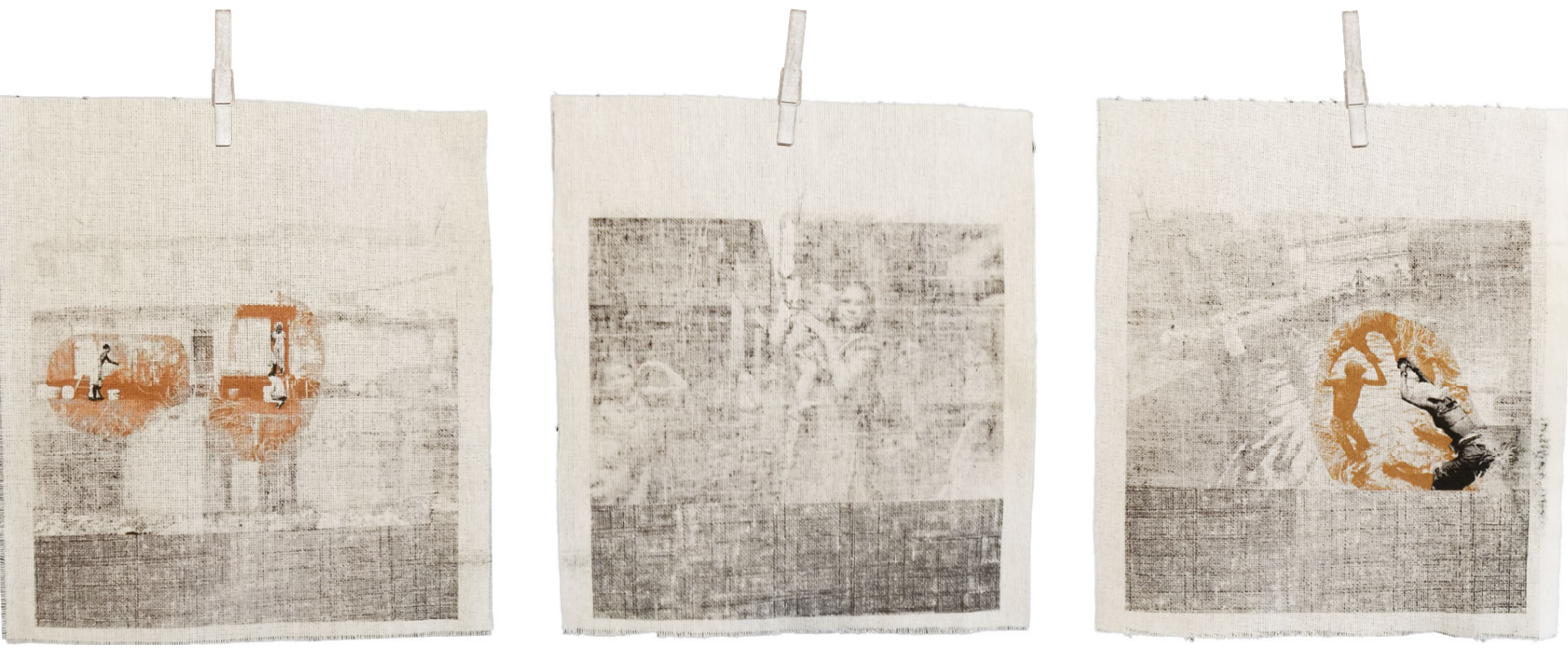

Figure 2.5: Representation of Women's Health Medium: Substrate Printed on Cotton 
Accessibility, supply, and quality of water are fraught with complications within low-income settlements, which worsen health conditions. As such, water-borne and vector-borne diseases, such as dengue, diarrhea, and malaria are statistically higher and more fatal

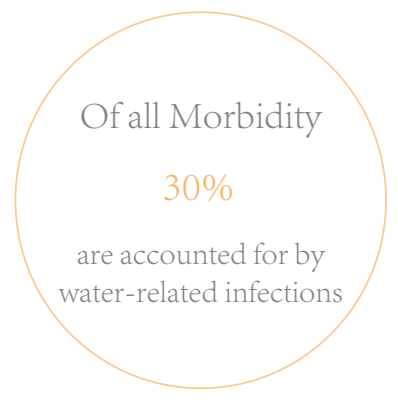
in urban slums. In 2017, water-related infections due to poor sanitary conditions amounted to an estimated $30 \%$ of all morbidity cases within Mumbai urban slums. ${ }^{17}$ The issue of water accessibility and sanitation are of particular importance, in part, because of their larger social and gendered ramifications.

With respects to water supply, Greater Mumbai relies on its surrounding reservoirs and six major lakes. ${ }^{18}$ In 2011, Mumbai reported a shortage of 656 million litres per day (MLD), which would largely affect the informal communities. ${ }^{19}$

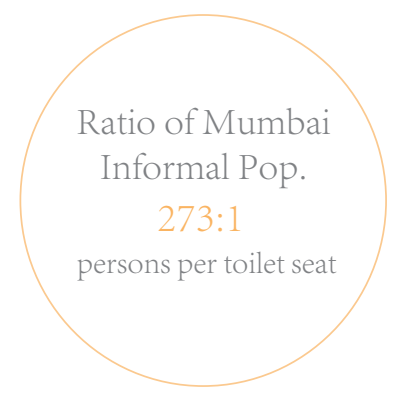

During times of expected use, the slum population relies on four major sources for drinking water; neighbour's tap (33\%), community tap (27\%), private truck/tanker (16\%), and municipality truck/tanker 17 Ansari 2017: 444

18 The city of Mumbai has over 3,000,000 water connections, which helps to situate the monumentality of the city's water demand (US AID 2016: 13). Despite the massive water infrastructure, many areas, especially informal settlements, are excluded from stable water access, thereby pressuring some to partake in illegal water diversions.

19 In times of water shortages, some low-income residents may have to resort to retrieving groundwater, despite the Government of Maharashtra's ban due to its unhygienic properties and contamination (US AID 2016: 14). 


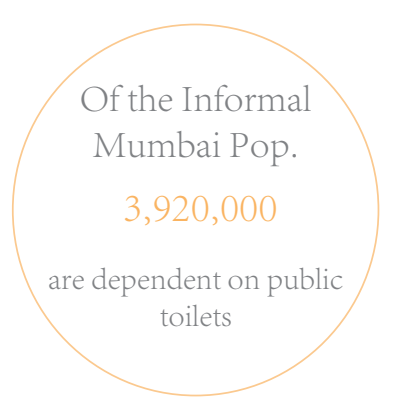

(14\%). ${ }^{20}$ However, those with a tap tend to only have $2-5$ hours of accessible water per day and pressure variability depending on the home's proximity to the water pipe. ${ }^{21}$

For Mumbai's informal population, 3.92 million rely exclusively on public toilets and the ratio of persons to toilet seat are upwards of 273:1. ${ }^{22}$ Of those public toilets, $78 \%$ of them lack water supply, which means water must be collected from bore wells, which are unregulated. ${ }^{23}$ Some $58 \%$ of public toilets have no electricity, which restricts the occupiable time during daylight hours. ${ }^{24}$ Lastly, only $31 \%$ are connected to the sewage system, which can lead to frequent blockage, due to the high pressure, and accumulation of waste. ${ }^{25}$

The poor sanitation services disproportionately affect women in urban slums. Women are vulnerable to harassment, sexual violence or intimidation by their male community members when accessing public toilets. This is because the toilets are highly visible, making it easier for men to congregate and track the women's movement. Further, men tend to get preference in the mornings to use the toilet blocks, whereas women often limit water and food intake to suppress their toilet use. ${ }^{26}$ There is social shame around using the toilet blocks in full public view, as many lack proper locks, and very few, if any, have adequate disposal systems for sanitary napkins or other feminine hygiene products. ${ }^{27}$

\footnotetext{
20 US AID 2016: 28

21 US AID 2016: 13

22 McFarlane 2007: 94

23 McFarlane 2007: 94

24 McFarlane 2007: 94

25 McFarlane 2007: 94

26 McFarlane 2007: 94

27 McFarlane 2007: 94
} 
health and the urban slum

P.14

\section{Menstrual Health}

The issue of poorly operable toilet blocks and lack of menstrual disposal strategies have been discussed but the scope of the problem is far greater and deeply entrenched in normative social orders.

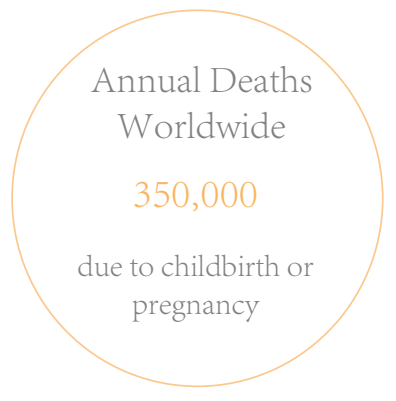

The language surrounding menstruation reveals a serious schism between fact and perceived reality. A common misconception is that menstruation is a flow of waste or $\operatorname{dirt}^{28}$ culminating into a highly shameful perception of self and social isolation during menstruation. ${ }^{29}$ Much of this low self-worth comes from lack of information, isolation, and in cases where girls communicate with relatives or peers, they often receive medically inaccurate information. ${ }^{30}$ There is a direct correlation between knowledge and healthy menstrual practices, as evidenced by a cross-sectional study conducted in a Mumbai slum; $94.9 \%$ of

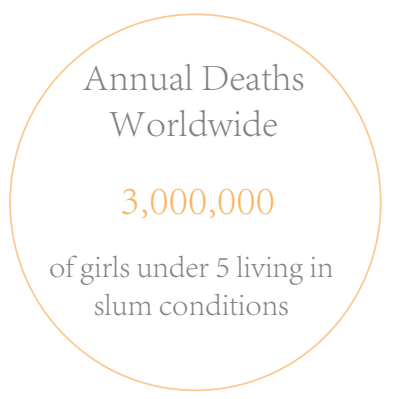
girls educated up to secondary school and above had good menstrual practices compared to $35.7 \%$ of illiterate girls. ${ }^{31}$

28 Rajagopal and Mathur 2017: 306

29 In a study conducted in Rajasthan, 88\% of school-aged girls upheld a negative feeling towards menstruation and so, impacted their sense of belonging within the community (Rajagopal and Mathur 2017: 309).

30 A cross-sectional descriptive study conducted in an urban slum in Mumbai found that of the 240 girls surveyed, only $20.3 \%$ were aware of menstruation prior to menarche (Bobhate, and Shrivastava.2011: 118). Those with prior knowledge received information from their mother or other relatives.

31 Bobhate and Shrivastava 2011:120 


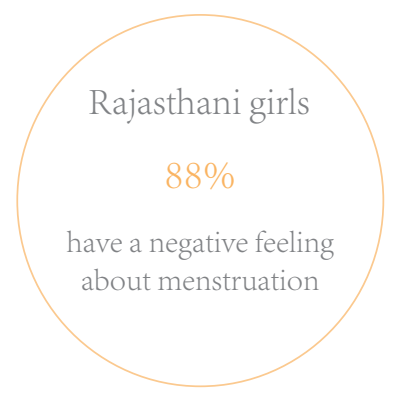

The stigma around menstruation can affect a woman's decision and/or ability to use feminine hygiene products. In the same Mumbai cross-sectional study, $72.2 \%$ of participants were aware that sanitary pads should be used during menstruation but only $59.8 \%$ reported using pads. ${ }^{32}$ Instead of sanitary napkins, some low-income communities use cloth during menstruation, in part because of socialized shame, cost, accessibility, acute sanitary napkin disposal. ${ }^{33}$ Cloth can lead to lacerations and discomfort, however, many reject medication or consultation with health-care facilities due to shame and/or embarrassment with talking to medical practitioners.

The issue with using cloth rather than sanitary napkins-other than the lacerations and discomfort--is the need for spaces to conduct laundry before re-use or safe disposal. In a Rajasthani study, $40 \%$ of participants reported drying their menstrual cloths in secluded areas away from the male gaze, however, within the dense and highly integrated spatial organization of urban neighbourhoods, the cleaning and drying process proved difficult. ${ }^{34}$ A majority of women in the study disclosed that they use old or worn cloth, which could pose serious health ramifications. ${ }^{35}$ The cross-sectional study re-iterated this point, as researchers found women would change their sanitary pad or cloth anywhere from 0-3 times a day. ${ }^{36}$ Part of the reasoning for such infrequent changes could be the lack of facilities or spaces that support

32 Bobhate and Shrivastava 2011:121

33 Typically, old, ragged cloth or low-cost, old, cotton sarees were bought and used, as it would not alert other community members when a girl started menstruating (Bobhate and Shrivastava.2011: 119). Furthermore, using cloth means girls avoid purchasing sanitary napkins at local pharmacies, where, again, community members may discover the girl's menstruation.

34 Rajagopal and Mathur 2017: 311

35 Rajagopal and Mathur 2017: 311

36 Bobhate and Shrivastava 2011:119 
menstrual hygiene and safety concerns when accessing public toilets in full view of the male community members.

Another concern is shortage of water contributes to infrequent and poor hygiene practices. A majority of participants were aware that poor hygiene makes one more susceptible to infections--i.e. reproductive tract and urinary tract infections--thus, perhaps the dissonance between knowledge and practice comes from lack of resources or support. ${ }^{37}$

37 Bobhate and Shrivastava 2011:119 


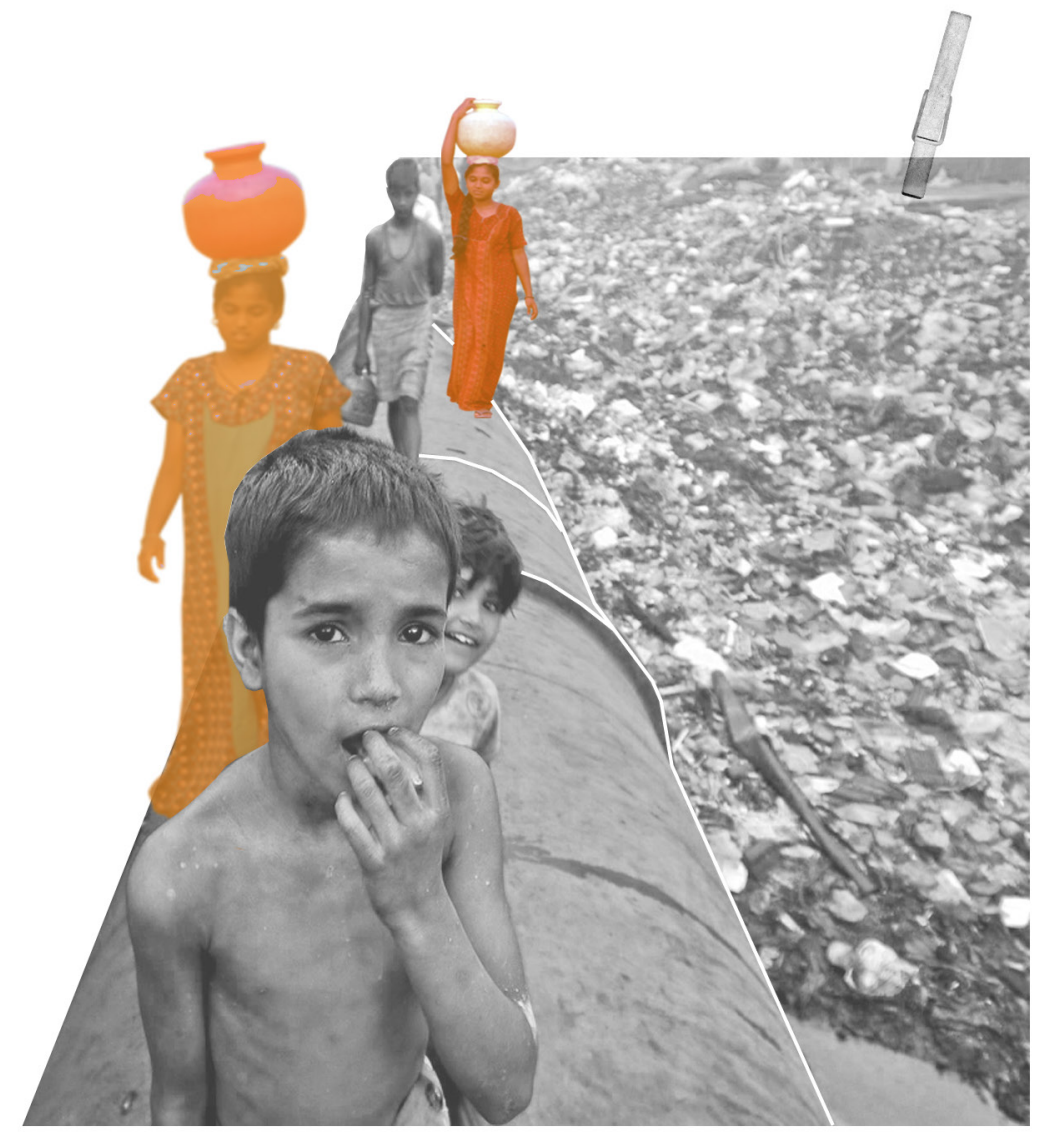


This section examines ethnographic studies interviewing women in urban slums on themes of menstruation, perceptions of female health, and patterns of illness disclosure. Evidently, women's health is a serious matter and yet, there appears to be some obstacles between identifying a health concern and visiting or consulting a healthcare professional. Based on ethnographic research conducted by the BMC International Health and Human Rights and Reproductive Health Matters, four major themes emerged that uncovered key reasonings for avoiding traditional healthcare amenities. 

vessel has to come out."

"When I started menstruating I thought that I must have been hurt and told this to my mother. I am bleeding from this place. My mother said there may be some wound and she gave me a cloth and told me to keep it inside my underwear...No, my mother did not tell me the actual thing. She must have thought that once I started menstruating I would come to know about it automatically. My mother must have been feeling hesitant." 
Topics related to female health are considered taboo and often suppressed in urban slums. One way in which this is accomplished is through the charged language used to describe the symptoms, such as dirt or waste, which elicits feelings of shame or fear. ${ }^{38}$ As a consequence of the socialization, many women decline antenatal or gynecological consultation because they consider them unnecessary or do not have the adequate knowledge to access the services since conversation around those topics is often censored. ${ }^{39}$

Within the social structure, any female-related illnesses or health concerns are considered direct threats against marriage eligibility, security, and stability. Thus, it is not uncommon for women to remain silent and ignore the symptoms as a way of preserving their status in society. ${ }^{40}$

So, accurate information and adequate healthcare need to be disseminated into the community but should be done in a culturally-

38 Research conducted by the Institute of Health Management in 27 slums near Pune found that $68 \%$ of women harboured negative attitudes against themselves, which was a direct result of the slum's socialization (Kapadia-Kundu and Kanitkar 2002: 5086). 39 Thapan 1997: 83

40 Through socialization some women uphold the belief that "their biological composition is responsible for their morbidity and even puts them at risk of death," and so, poor female-health is deemed unavoidable and simply a way of life (Das, Angeli, Krumeich, and Schayck 2018: 11). 
sensitive manner. To accomplish this, women should be included at every stage of development. Hopefully, by including women and involving their opinions on the highly stigmatized topics, it will lead to higher engagement and sustained use.

Further, offering safe spaces for women to orate their experiences and information, away from male community members, could start to promote open dialogue among women. The safe spaces could help women begin to identify and define symptoms and illnesses, rather than live in fear of the unknown. 
shortcomings of health care

$$
\text { p.22 }
$$

"I have four daughters and all of them have their monthly cycles. I cannot afford to buy napkins; so I tell them to use cloth. I know it is not hygienic as I have suffered due to infection myself but I have little choice."

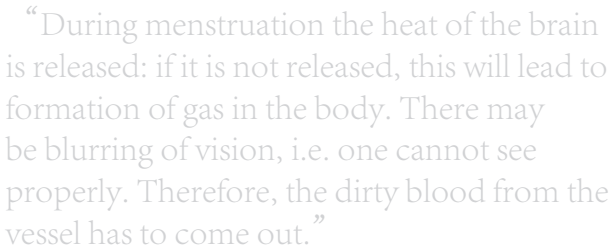

"Where will we wash where will we put it for drying. You stay in a big house. You must be washing in one corner of the house. Here sometimes a man is passing, sometimes a young boy is passing, then how can we wash." 


\section{Economic Barriers}

Some women cite financial constraints as a reason for delaying or rejecting healthcare services. ${ }^{41}$ Economic constraints can refer to the inability to sacrifice work or other responsibilities to visit a clinic or expensive treatment and medication costs. Women occupy subordinate positions, both in the household and in the workforce, and are often expected to take on secondary work to compensate for the inequity in pay and opportunity. ${ }^{42}$

Many existing health facilities do not consider how their hours of operation may conflict with the women's work schedules. Women are expected to work during the day while meeting their family and household needs, and so it is unreasonable to expect women to leave their homes or places of work to visit a health facility. There needs to be flexible hours and/or financial incentive within the facility to compensate for their time off. In doing so, perhaps women would be more apt to seek medical assistance or treatment and male family members would be more inclined to allow women to leave the home knowing there would be some financial return that would benefit the family.

According to a study conducted by the BMC International

41 Das et al. 2018: 10

42 Das et al. 2018: 10 
Health and Human Rights, a common belief amongst women in urban slums is that "their livelihood and the everyday financial struggle which they face prevent them from promptly disclosing their illness to anyone." ${ }^{43}$ The hesitation in disclosing an illness or symptom, thereby leading to a delay in treatment potentially leads to higher costs, as the course of action becomes more complicated or specialized. ${ }^{44}$ Thus, preventative care may be a missing component within the current health structure.

43 Das et al. 2018: 10

44 In 2006, the United Nations Development Program surveyed the urban poor in India to better understand the issues or barriers around access to health-care. In the survey, $37 \%$ of women cited high expenditure as the primary reason for refusing health-care support during labour (Gupta and Guin 2015: 250). 
shortcomings of health care

$$
\text { p.25 }
$$

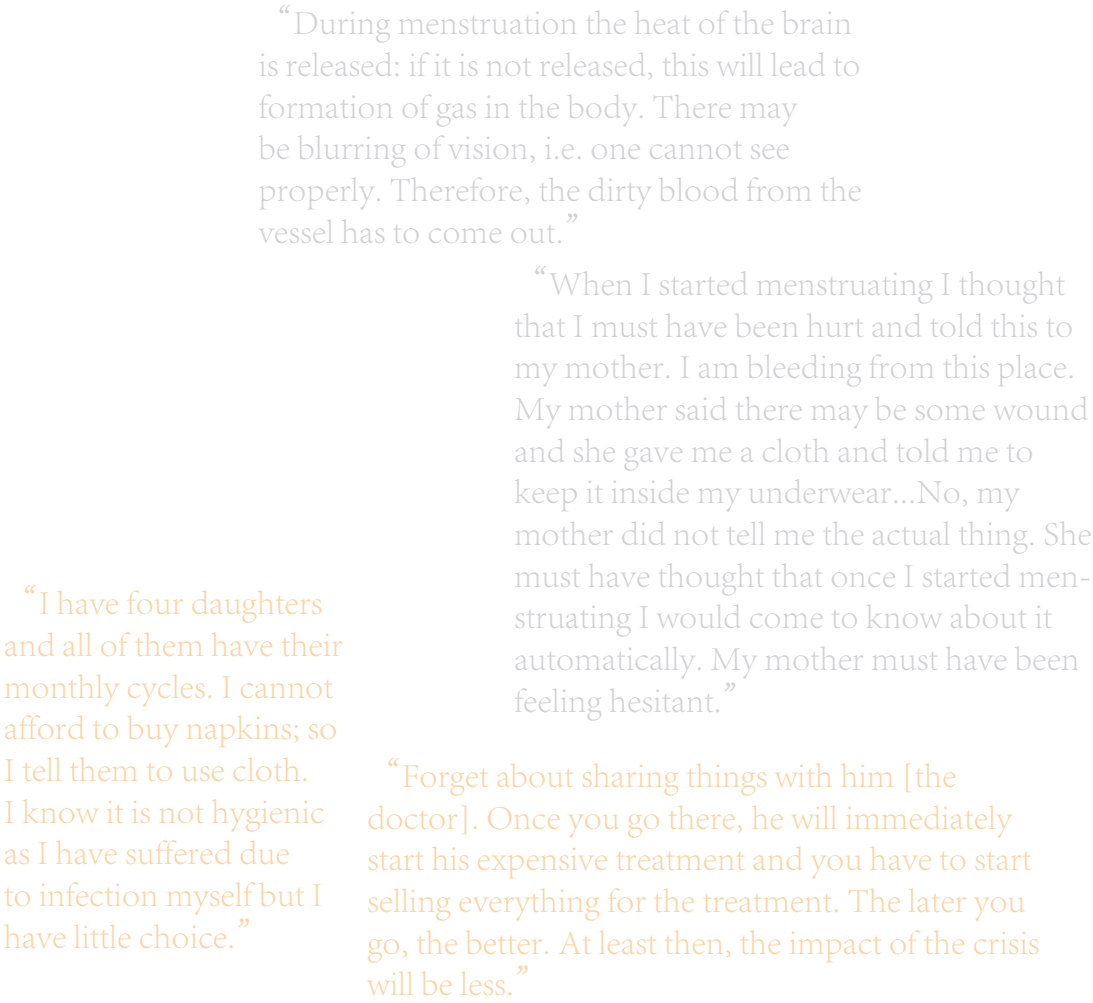

"If there are no proper water and toilet facilities, it is obvious that we will get ill...so there is no question of talking about illness and wasting time until and unless these problems get sorted."

"The toilets are not clean. In such a situation we try and avoid using the toilets. We also refrain from drinking too much water" 
The residents in urban slums are cognizant of the poor sanitation conditions and are acutely aware that their health issues stem from the slum environment. ${ }^{45}$

Some of the ethnographic interviews, particularly by the BMC International Health and Human Rights, reveal an apathetic attitude towards their health. As discussed earlier, sanitation, water, and hygiene practices are compromised within urban slums. Thus, for the residents, it would be seemingly futile to pursue health services when the cause of said health concerns is their environment, which has worsened over time.

Although health facilities do offer sanitary services, the services are only accessible through consultation visits and are otherwise not integrated with the larger community. Further, their services and do not address the poor, unsafe toilet blocks and living standards that women return to after consultation.

45 Das et al. 2018: 13 
"When I started menstruating I thought that I must have been hurt and told this to my mother. I am bleeding from this place. My mother said there may be some wound and she gave me a cloth and told me to keep it inside my underwear...No, my mother did not tell me the actual thing. She must have thought that once I started men-

"I have four daughters and all of them have their monthly cycles. I cannot afford to buy napkins; sc I tell them to use cloth. I know it is not hygienic as I have suffered due to infection myself but I have little choice." struating I would come to know about it automatically. My mother must have been feeling hesitant."

"Forget about sharing things with him [ the doctor]. Once you go there, he will immediately start his expensive treatment and you have to start selling everything for the treatment. The later you go, the better. At least then, the impact of the crisis will be less."

\footnotetext{
"I use old ragged clothes from the children, my own pantaloons, whatever; I try my best to use cottor but if it is not available then in an emergency I use any cloth that is available.
}

\begin{abstract}
"Where will we wash where will we put it for drying. You stay in a big house. You must be washing in one comer of the house.
\end{abstract} Here sometimes a man is passing, sometimes a young boy is passing, then how can we wash."

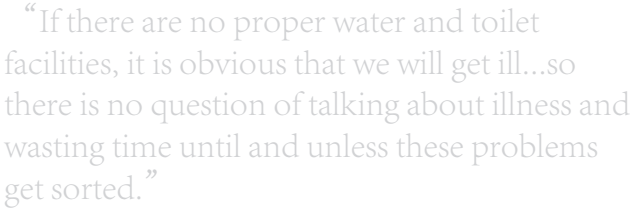

"The toilets are not clean. In such a situation we try and avoid using the toilets. We also refrain from drinking too much water"

"We tell our distress only to hear from others about women whom they know, who led a healthy life and died due to old age. By listening to all these accounts, we actually try to create hope in ourselves that we can also live in the same way and die due to old age rather than from female-related problems."
"I went to him [the doctor], not with the intention to start treatment immediately but first to share my suffering and feel relieved. I expected him to comfort me by saying good and positive things and to give me the mental strength to deal with the illness, but he was focusing more on treatment than on listening to me and my feelings." 


\section{2 \\ Dominant Social Structures for Health-Related Support}

Firstly, women turn to one another to discuss their health and treatment options. According to the BMC International Health and Human Rights, women will then contact informal healers because they "generally reside in the neighbourhood and are well acquainted with all the households in the area, health habits, practices and behaviours." ${ }^{46}$ In comparison, treatment options or expectations at health facilities are grossly ill-suited for the reality of women living in urban slums ${ }^{47}$ Consequently, health professionals can appear paternalistic and far removed from the community's social structure, which can aggravate stress and discomfort. So, relying on social groups helps to alleviate the severe anxiety women harbour towards their illnesses. $^{48}$

The healthcare amenities should be better integrated within the community to make women feel more comfortable in accessing the services. Further, utilizing the practice of female gathering spaces could transform health from an individualistic to a collectivist attitude, thereby creating a system to disarm anxiety and fear.

46 Das et al. 2018: 6

47 Meleis et al. 2011: 103

48 Women should be receiving accurate information from medically-trained personnel, however, this section seeks to highlight the problem with how the information is communicated. 
Site: Dharavi

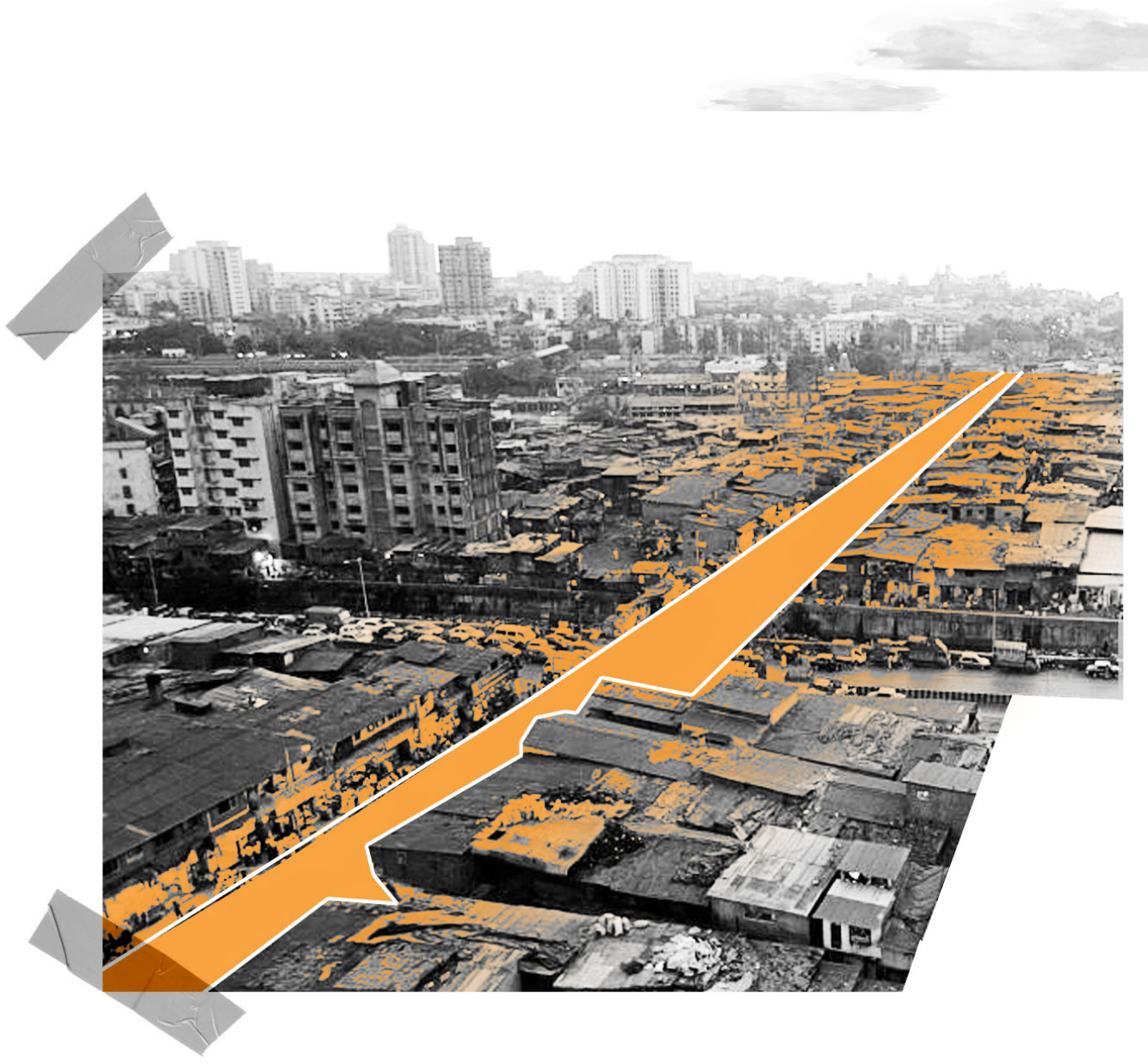


Dharavi is an urban slum located in Mumbai, situated between two major railway lines, south of the Mahim river and to the west lies the highly affluent Bandra neighbourhood. It is considered one of the largest slums in Asia, with a population anywhere between 600,000-1,000,000 residents within a $2 \mathrm{~km}$ squared radius. 


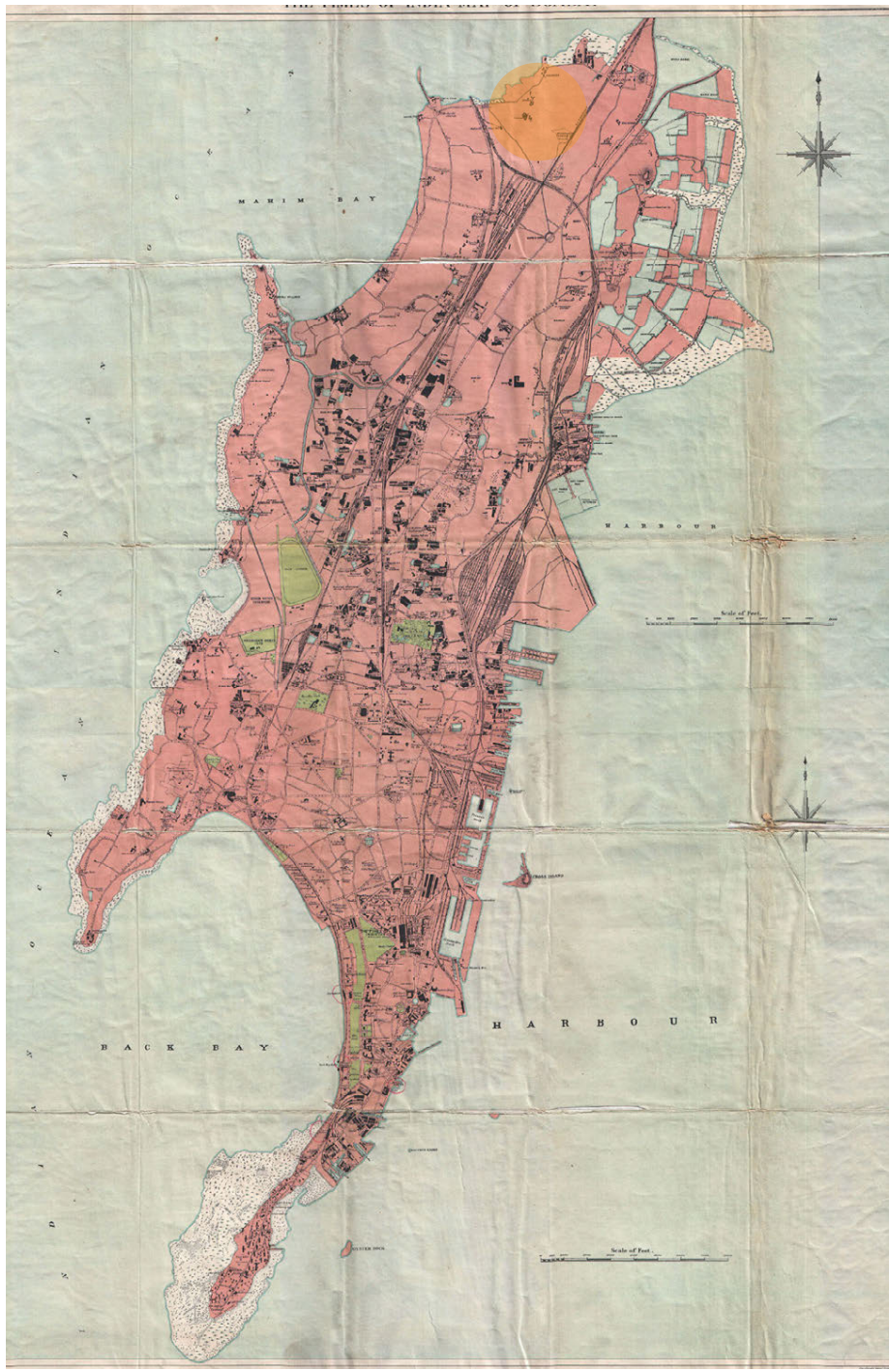

Figure 4.0: Times of India Map of Bombay, India c. 1895 
Dharavi is not a transitory settlement, rather the area has a considerably long history dating back to the 19th century. Today, the slum is home to a large migrant population--many living in Dharavi for a couple of generations--from diverse ethnic, linguistic and religious backgrounds.

In the nineteenth century, Dharavi was situated on a marshy mangrove swamp, thereby making the site largely uninhabitable. ${ }^{49}$ However, the conditions and proximity to Mithi River and Mahim Bay attracted the Koli fishing community, who are considered the oldest residents..$^{50}$

In 1869, due to the poor land conditions and distance from the British Empire's station in Bombay, many plague victims were condemned to Dharavi. ${ }^{51}$

Over the next decades, Gujarati potters known as the Kumbharwada class began to migrate to Bombay. ${ }^{52}$ They initially settled around the southern tip of the city before being relocated to the largely unoccupied northern region, current-day Dharavi, by municipal

\footnotetext{
49 Saglio-Yatzimirsky 2013: 2

50 Saglio-Yatzimirsky 2013: 40

51 Gandy 2008: 114

52 URBZ 2018
} 
authorities. ${ }^{53}$ Dharavi was ideal for the pottery and ceramics industry as a way to conceal the smokestacks and expel the pollution associated with the craft away from the main city.

Thus, the site has always had a deep-rooted association with displaced and disadvantaged populations.

Today, Dharavi has grown into a stable community that boats a highly profitable, informal industry with an estimated annual revenue of $\$ 700$ million- $\$ 1$ billion. ${ }^{54}$ There is a generous migratory population, however, many people are second or third generation residents and consider Dharavi a long-standing home with a deeply woven cultural and social fabric. 


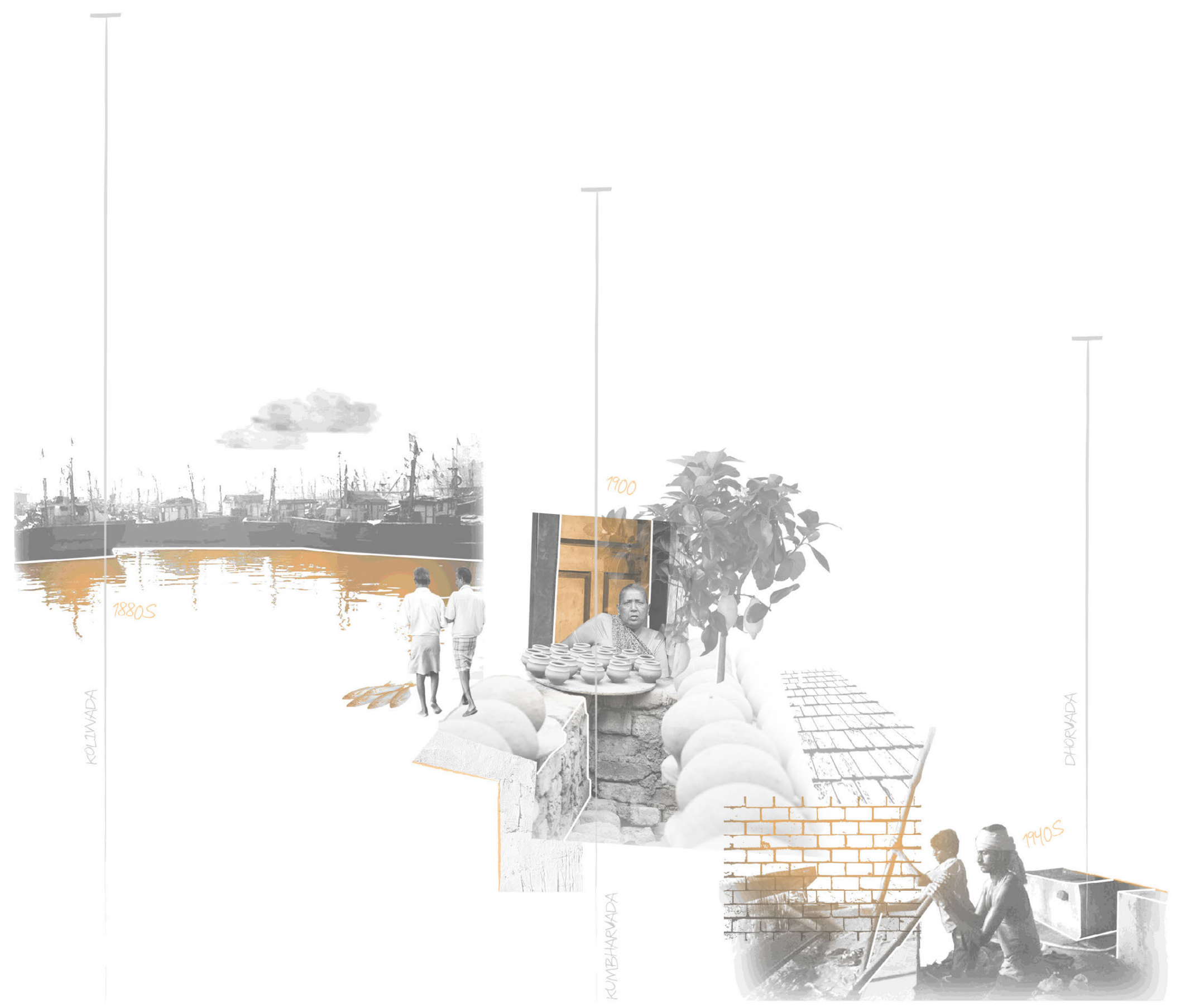

Figure 4.1: Pictorial Timeline of Dharavi's Major Industries 


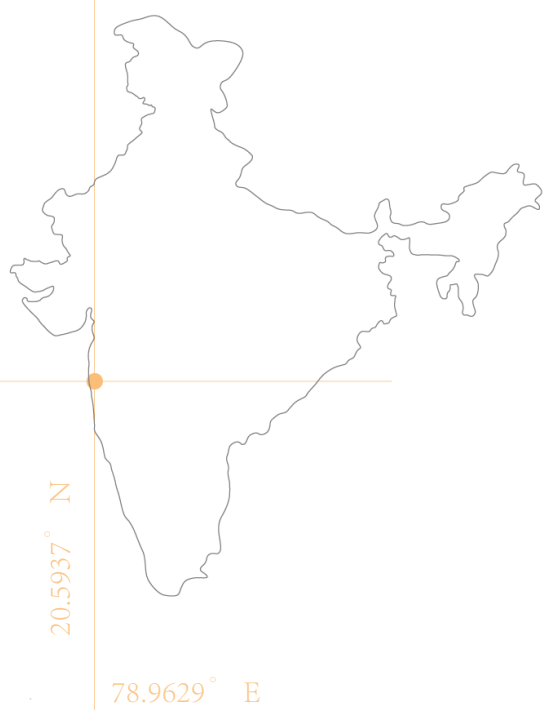

$78.9629^{\circ} \mathrm{E}$

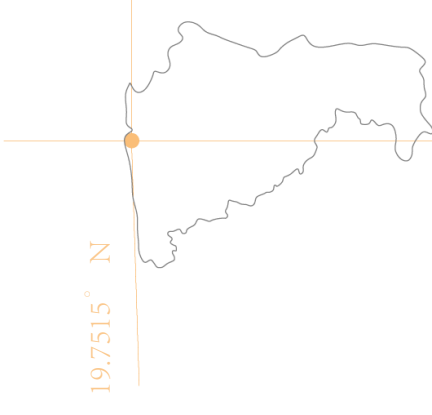

75.7139

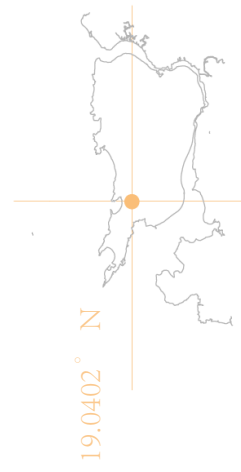

$72.8509^{\circ} \mathrm{E}$ 
In general, Dharavi can be divided into five main areas based on industry and working class. They are Dhorwada, Kumbharwada, Matunga Labour Camp, Transit Camp, and Koliwada.

01 Koliwada is considered the original district; it was established by the Koli fishing community in the nineteenth century. ${ }^{55}$ The area is still largely occupied by the Kolis who continue their trade by the Mithi River, just north of the site.

02 Dhorwada--which quite literally translates to "tanners" in Marathi--is one of Dharavi's oldest area. ${ }^{56}$ It is located in the heart of Dharavi with arguably the highest population density and narrow, winding streets. The district is predominantly run by the large-scale leather industry.

03 Matunga Labour Camp is located in the southern region of Dharavi and borders the Matunga Railway Station. It is relatively cleaner than the other districts with cement roads and more permanent housing accommodations..$^{57}$ The area is organized around the main road where much of its mechanical and recycling production is situated. ${ }^{58}$

55 Saglio-Yatzimirsky 2013: 52

56 Saglio-Yatzimirsky 2013: 56

57 The New York Times 2011

58 The New York Times 2011 
04 Kumbharwada quite literally means 'potters district' and is largely inhabited by those who moved there in the early twentieth century. ${ }^{59}$ Unlike the rest of Dharavi, this district has a high spatial unity and homogeneity. ${ }^{60}$ The site is situated near 90 Feet Road that acts as a major commercial hub for shops and commerce.

05 The Transit Camp was one of the last established settlements in Dharavi, intended for temporary housing. ${ }^{61}$ Despite being a late settlement, the area looks particularly disorganized because of the dense housing, congested alleys, and continued development. ${ }^{62}$

\footnotetext{
59 Saglio-Yatzimirsky 2013: 76

60 Most homes have a production space within the one-floor, brick and earth architecture and courtyard space for the kilns (URBZ 2018).

61 The New York Times 2011

62 The New York Times 2011
} 


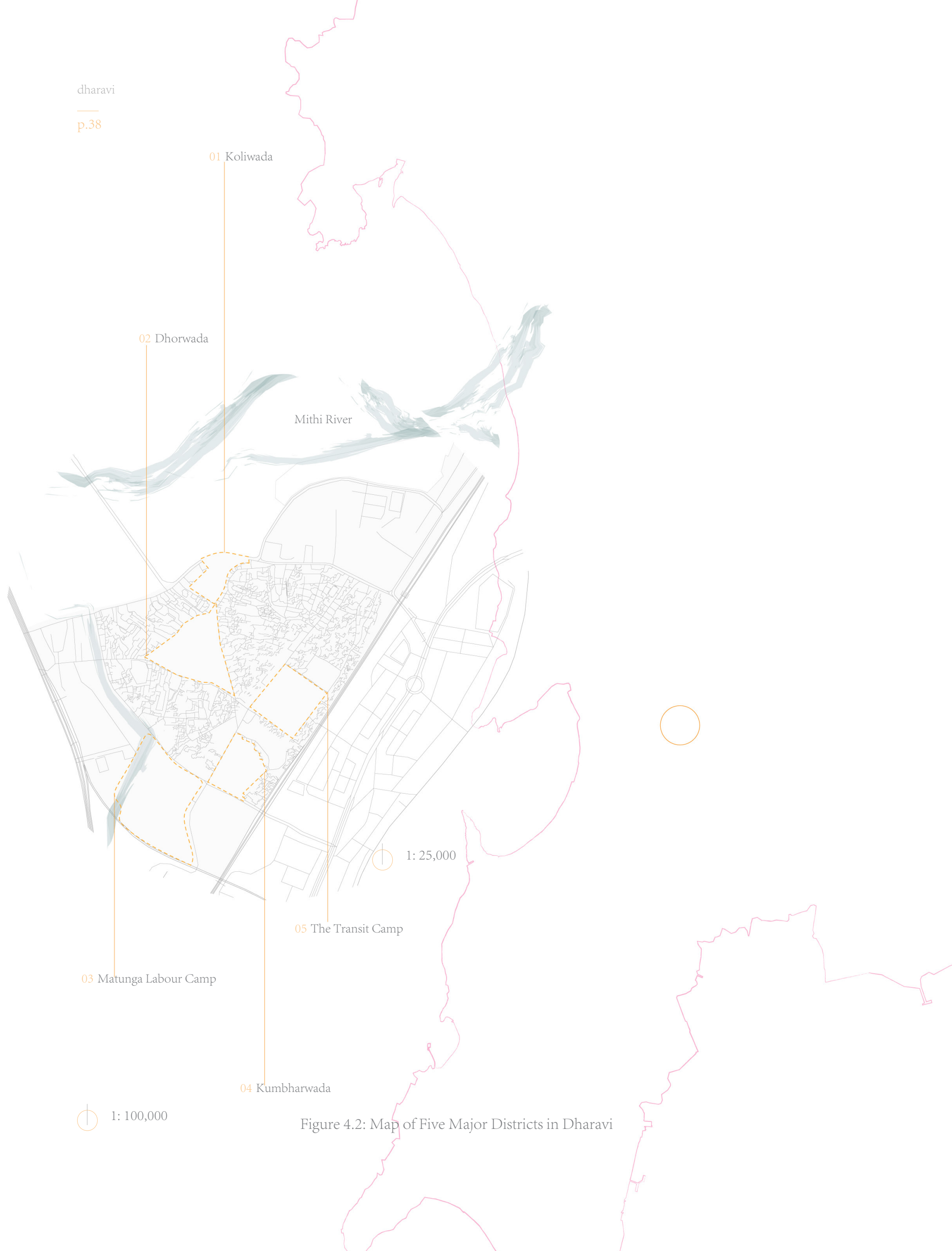




\section{Building and Site Typology}

The structural type in slums is often characterized by a high level of homogeneity. The building typology is usually highly dense with one to two storeys in height. ${ }^{63}$ Dharavi is no different, as its 80 districts follow the same homogenous construction and building typology. ${ }^{64}$

Open space is scarce in Dharavi and is usually only found in interstitial spaces or an occasional wider laneway. ${ }^{65}$ The dwellings are usually too small to accommodate all the residential or production needs, so residents tend to spill onto the laneways for additional space. As such, the narrow laneways become social spaces, and residents often set up seating along the edges for gatherings.

Along with the pedestrian-dominated streets, there are vehicular streets for transportation and industry on site. ${ }^{66}$

In Dharavi, dwellings are typically a combination of residential, industrial and commercial units distributed in no particular order, except that commercial activity tends to occupy the first-floor layout. ${ }^{67} \mathrm{~A}$

63 Taubenbock and Kraff 2014: 30

64 Dovey and Tomlinson 2012: 4

65 A typical laneway is far too narrow for vehicular use, and designated open space is only about 4 meters wide (Dovey and Tomlinson 2012: 15).

66 The vehicular streets are wider, approximately 6-8 meters, and run along the perimeter of the site, connecting to the city (Dovey and Tomlinson 2012:3).

67 Dovey and Tomlinson 2012: 11 
typical building is between 2-4 storeys high and each room inside varies from $10-30$ m squared. ${ }^{68}$ The dwellings are generally made of affordable, accessible materials. ${ }^{69}$

Generations of additive design have created dense building blocks, where the upper floors cantilever and often meet across narrow lanes consequently, blocking natural light.

68 The homes in Dharavi are unregulated, however, a government edict specifies that no building should be taller than 2 storeys. And yet, a survey conducted on site approximates that $35 \%$ of buildings are 3 storeys and $10 \%$ are 4 storeys, which typically peak at $11 \mathrm{~m}$ high (Dovey and Tomlinson 2012: 12).

69 The ground floors are usually constructed with concrete and a ceramic or stone finish. Brick or concrete block are typically used for the first floor walls, while upper floors may use timber framing or steel I beam construction to support the metal roof cladding (Dovey and Tomlinson 2012: 18). 

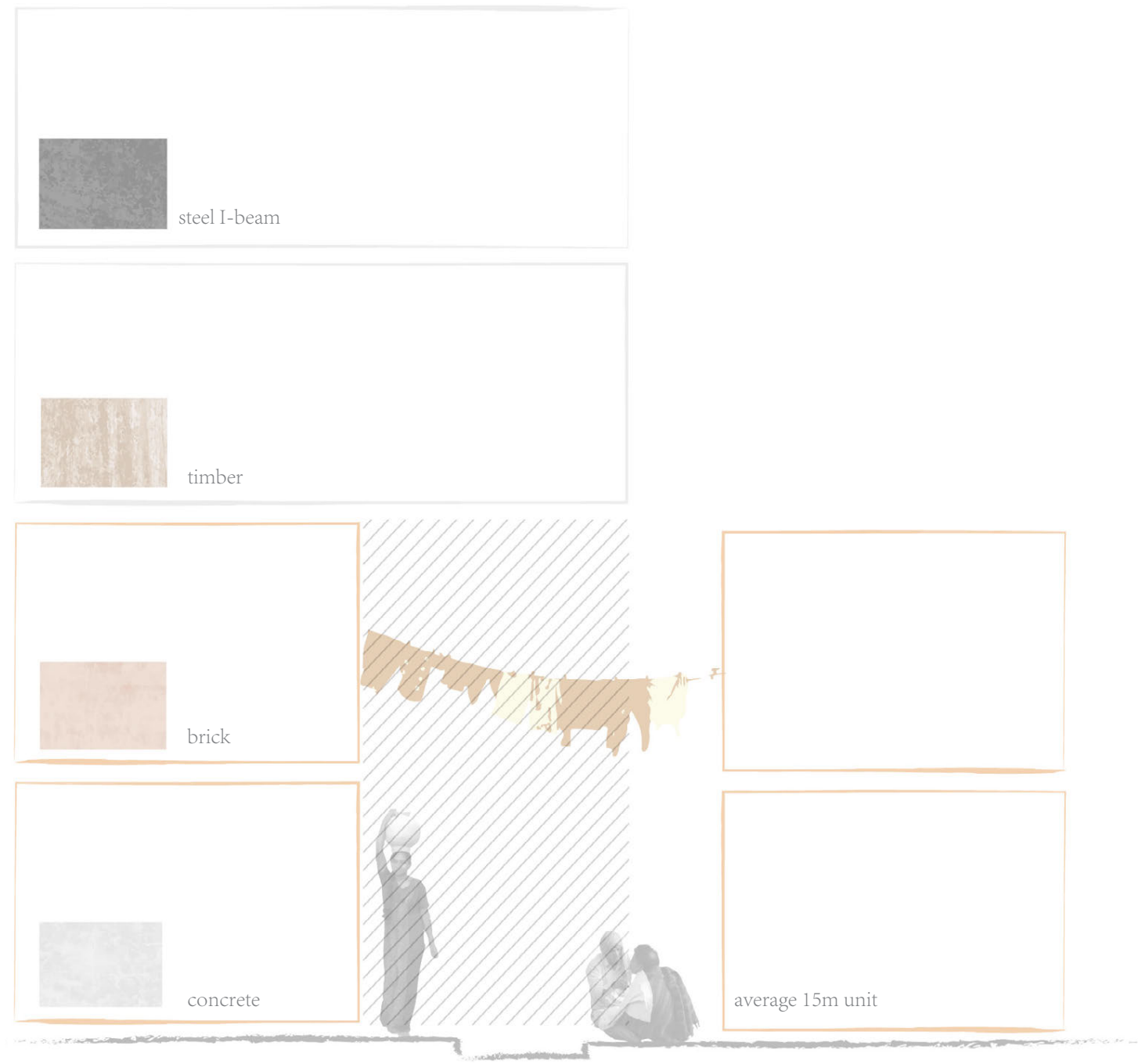

Figure 4.3: Typical Street and Building Construction in Dharavi 

extended city. Along with the railway system, Dharavi has an extended bus transit throughout the site. There is a bus depot, highlighted in pink, where multiple bus routes pass through each day. Lastly, there are major arterial roads that line the perimeter of the site and connect back to the city's major highways. ${ }^{70}$

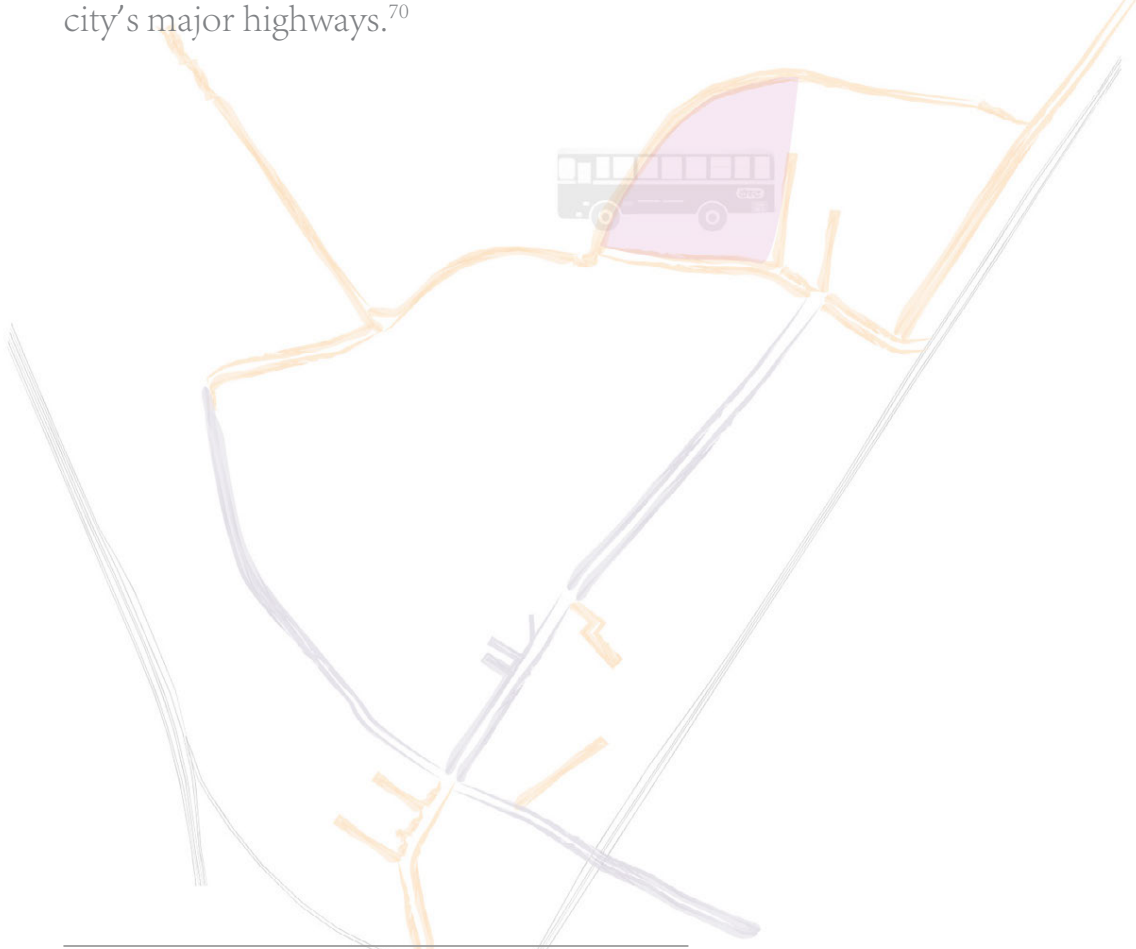

70 The two largest arterial roads, the 90 Feet Road and the 60 Feet Road, were developed in 1971 as a government initiative to improve the site and make it more habitable following the Maharashtra Slums Area Act--they are marked in purple on the map (Saglio-Yatzimirsky 2013: 77). 


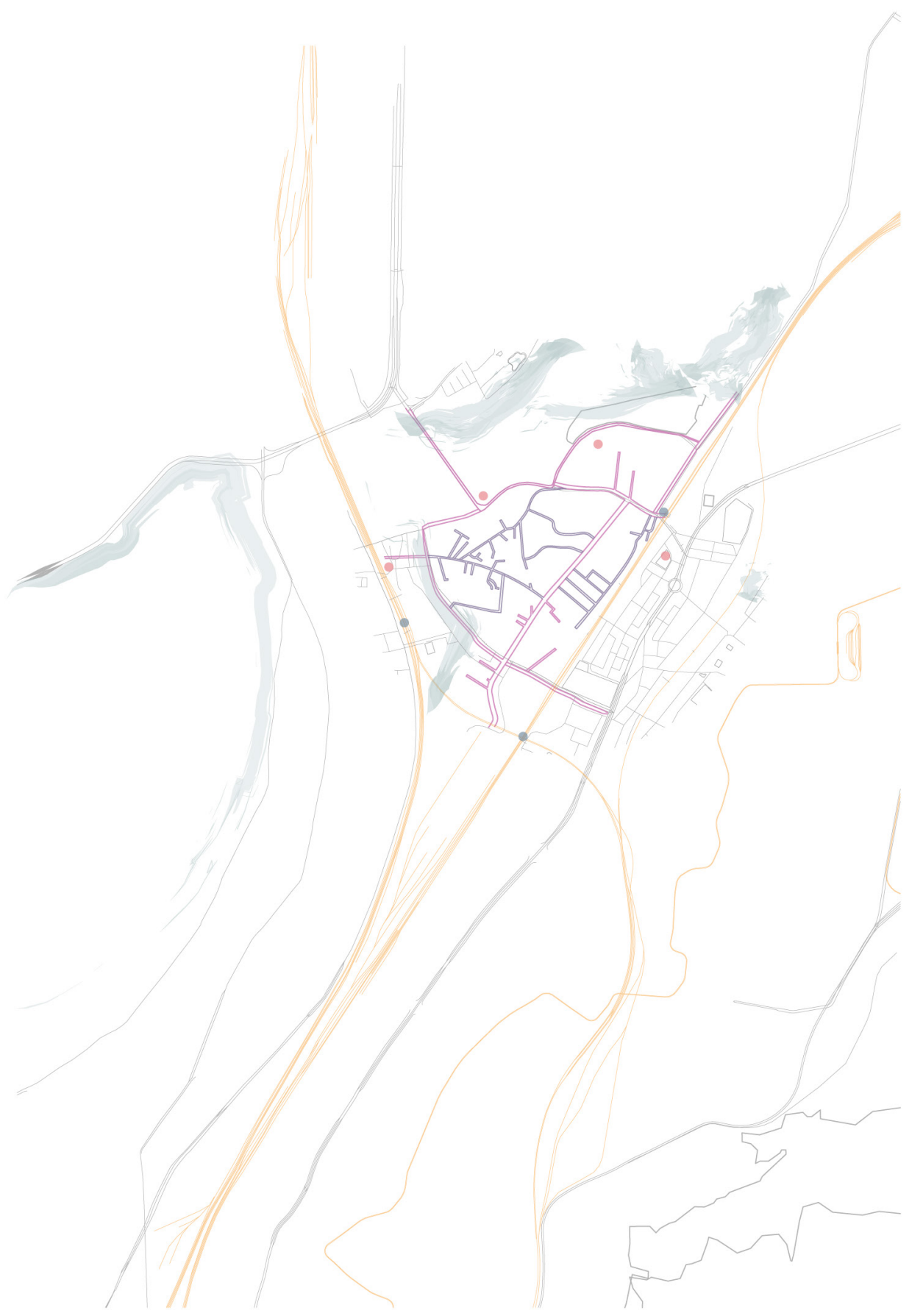

- Bus Stop

- Train Station

- Mumbai Railway

— Mumbai Highways

— Main Dharavi Roads

— Side Dharavi Roads 


\section{Industry}

In Dharavi, $80 \%$ of employed residents work in the area. ${ }^{71}$ Much of the production is done through a decentralised process that operates from small homes across the site. ${ }^{72}$

As stated, the Kumbharwada is home to the pottery industry and one of Dharavi's most sought after crafts. ${ }^{73}$ The neighbourhood is densely packed with homes, workshops and 120 kilns spread across five lanes. ${ }^{74}$ The potters produce a wide range of ceramic goods from small diya candles to larger ornamental vases.

Latest government data shows that Maharashtra produces 15\% of the country's leather goods; Dharavi's leather industry is a large share of the state total. ${ }^{75}$ Since the mid 20 th century, tanneries proliferated, rather than amalgamating, meaning Dharavi was saturated with many small leather workshops with an estimated 20,000 manufacturing units. ${ }^{76}$

The recycling industry, which dominates the 13th compound bordering Mahim-Sion Link Road, employs more than 120,000

71 Dovey and Tomlinson 2012: 4

72 Dovey and Tomlinson 2012: 4

73 At present, an average potter family unit is 6-8 people working and living within a production space of $55 \mathrm{~m}$ squared (URBZ 2018).

74 URBZ 2018

75 Phadke 2017

76 Saglio-Yatzimirsky 2013: 59 


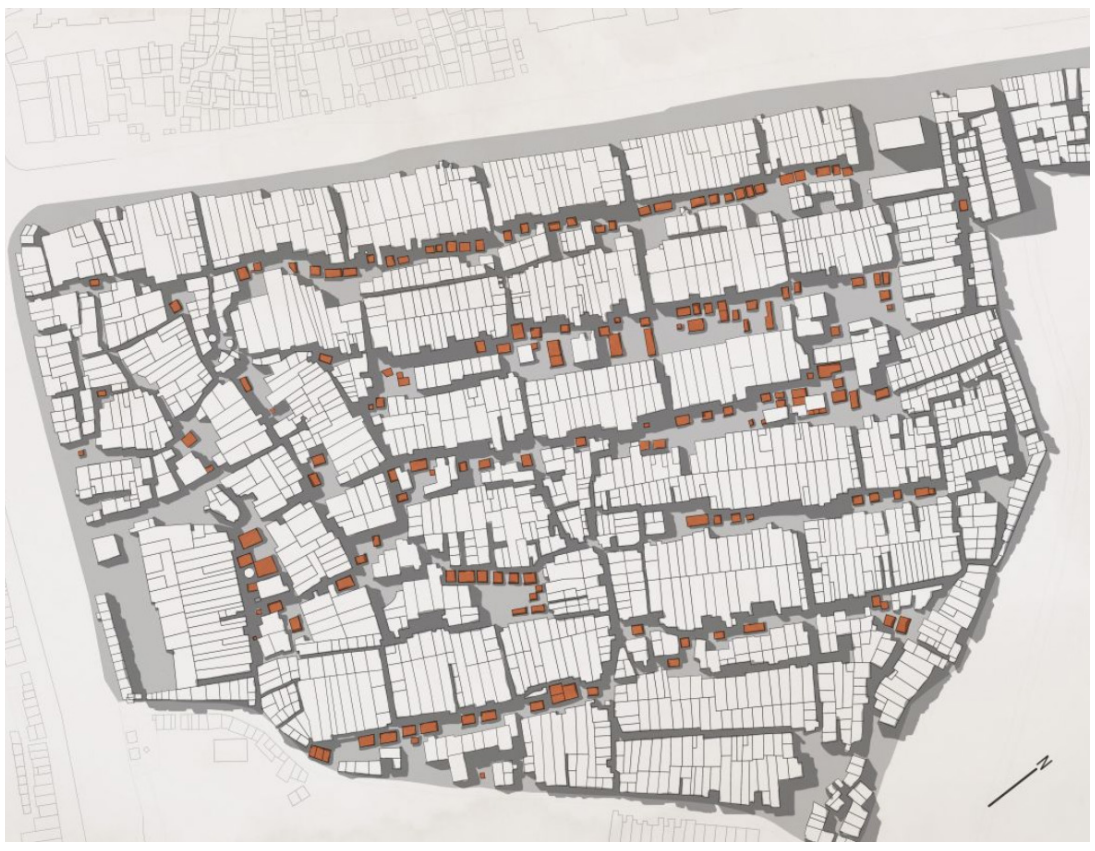


dharavi

p.46

"... the day we stop functioning,

Mumbai, or as a matter of fact any

Indian city, will drown in its own

filth."

Scrap Dealer unofficial waste collectors. ${ }^{77}$ The district sorts and recycles $80 \%$ of the

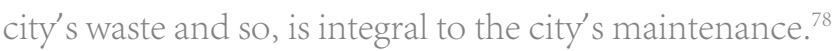

Despite the highly diverse and engaged economy, it is

worthwhile to note that women often perform domestic chores without financial compensation. In addition to domestic work, women may seek other employment options, the most viable being home-based work. ${ }^{79}$ Much of home-based work receives considerably lower wages ${ }^{80}$ and pay is often seasonal during weddings or festivities. ${ }^{81}$
77 Brown 2017

78 Brown 2017

79 Some home-based work includes mess work--providing cooked meals--garment tailoring or sewing, leather belt braiding, and home-based tuition (Gartenberg 2011: 15). 80 Saglio-Yatzimirsky 2013: 189

81 A survey conducted by a Mumbai-based NGO, the Labour Education and Research Network (LEARN), estimates that majority of home-based workers, which are predominantly women, earn less than \$18 per month (Gartenberg 2011: 15). 
dharavi

$\overline{p .47}$

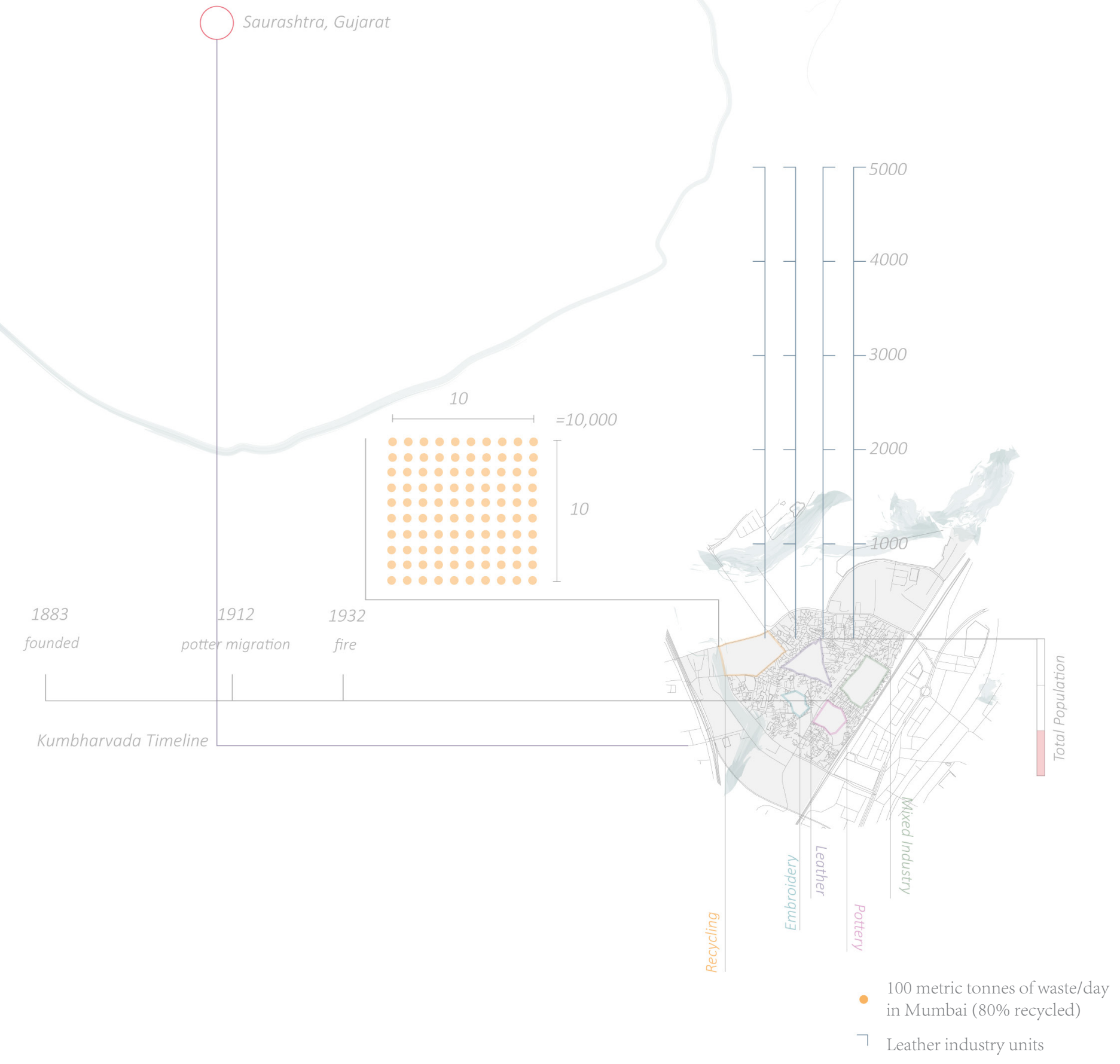




\section{Health Structure: Facilities and Use}

There is a combination of private and public health facilities across Dharavi. Despite the steeper medical costs within private care, the Mumbai based NGO, LEARN, found that a little more than half of Dharavi residents surveyed, still used private clinics. ${ }^{82}$

Even for public facilities, participants may incur medical fees that could cause financial strain. Sion hospital, one of the most recognized public hospitals in Dharavi, has additional costs associated with certain procedures, surgeries, and medication. ${ }^{83}$

In addition to the medical costs, patriarchy could possibly deter residents from visiting the facilities, especially for preventative diseases. For example, Sion medical staff noted that most patients were admitted with severe symptoms from preventable or curable conditions; the sickness worsened due to delayed treatment. ${ }^{84}$ One of the highest rates of admittance was for children suffering from tetanus after home deliveries. ${ }^{85}$

82 Of the small sample group surveyed by LEARN, 63\% spent approximately $\$ 20$ per month on healthcare expenses, whereas $24 \%$ spent approximately $\$ 36$, and the rest of the participants spent up to $\$ 90$ (Gartenberg 2011: 15).

83 Carr 2015

84 Carr 2015

85 Home deliveries and relying on traditional birth attendants still supersedes medical personnel for many Dharavi residents. Consequently, in the 1970s and 1980s, sick children admitted to Sion Hospital had a mortality rate of $77 \%$ because medical facilities were understaffed, underfunded and patients would delay treatment until severely ill (Carr 2015). 
Under staffing and overcrowding is a significant factor that reduces the quality of care for medical facilities. In the 1970s, it was not uncommon for medical staff at Sion Hospital to see 3,000 patients a day ${ }^{86}$ Resources and time are limited under these conditions, which could be another barrier towards accessing medical care.

For women, there is the added layer of adhering to traditional customs and not drawing attention to their reproductive health concerns. Women's subordinate role typically means they often confide in other community members regarding their medical concerns. Below is a graph that outlines the different routes women took before attending a centre for vulnerable women and children in Dharavi. ${ }^{87}$ The graph clearly demonstrates that advice from community members is the main catalyst for seeking treatment and personal initiative is less common.

86 Carr 2015

87 Daruwalla, Fernandez, Salam, Shaikh, and Osrin 2009: 6 


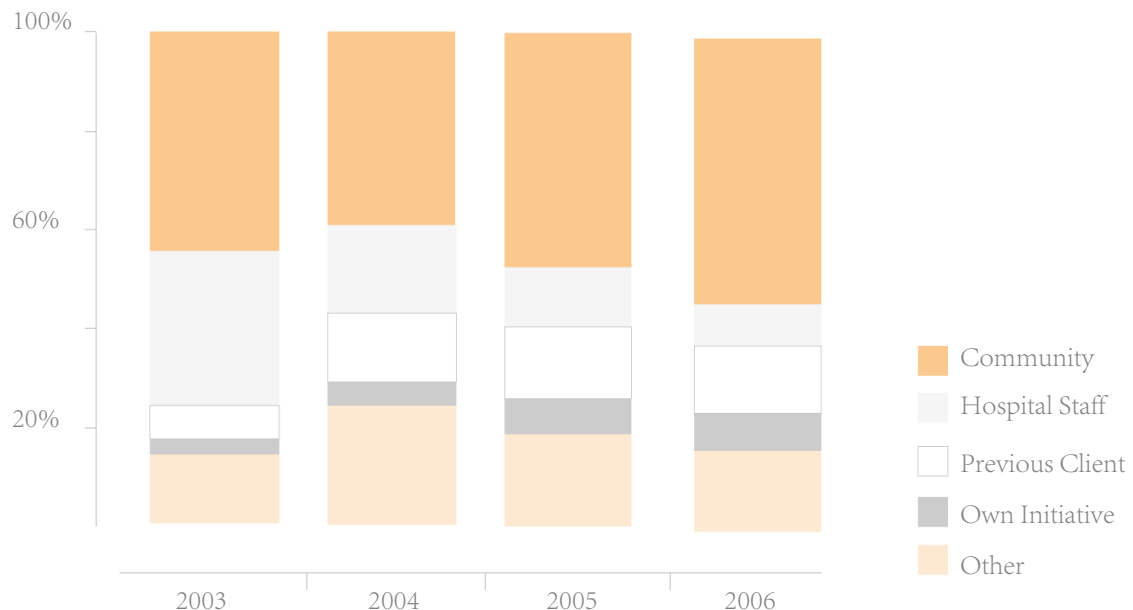

Figure 4.7: Routes by which Women in Crisis Approached the Centre 2003-2006 

of poor sanitation control. There is a lack of accurate documentation and census on site--most housing and 90\% of commercial units in Dharavi are illegal--which makes it difficult to account for the necessary infrastructure ${ }^{88}$ As a result, there is a severe shortage of sanitation facilities for the largely undocumented population. ${ }^{89}$

Individual water connections are rare and so, typically one tap is shared by 40 residents. ${ }^{90}$ The government has made attempts to extend infrastructure in the hopes of overcoming the barrier to accessible water. ${ }^{91}$ However, the fact remains that Mumbai has water shortages and vulnerable communities are the first groups affected.

In addition to the water accessibility issues, sanitation is also negatively impacted by the flooding and monsoon seasons. Dharavi is situated near a flooding plane and so, during heavy rainfall water lies

88 Yardley 2011

89 In 2006 the United Nations Development Program reported that the ratio of toilets to a person in Dharavi was a staggering 1:1440 (United Nations Human Settlements Programme 2006:26).

90 Yardley 2011

91 In 2010, the Municipal Corporation installed pipes in Northern Dharavi that extended into each home. Residents paid a monthly expenditure of $\$ 1.82$ for three to four hours of water each morning (US AID 2016: 13). 
stagnant while sewage collects within the open drains.$^{92}$ Designated trash collection sites are generally off-site thus, there is often a collection of waste along the streets. These conditions facilitate breeding grounds for waterborne diseases like cholera, jaundice, typhoid, and diarrhea. ${ }^{93}$ 


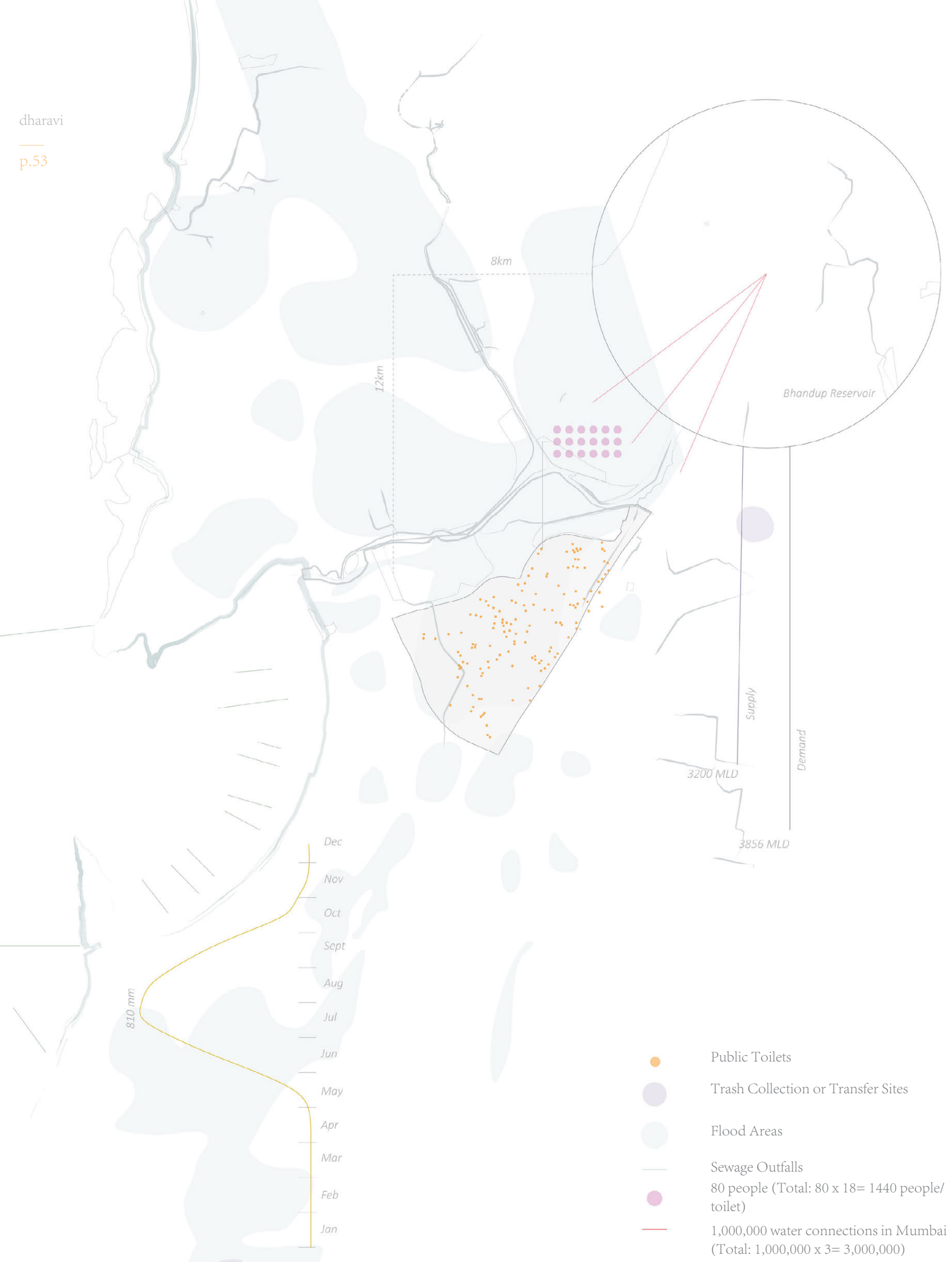




\section{A Magical Realist Framework}

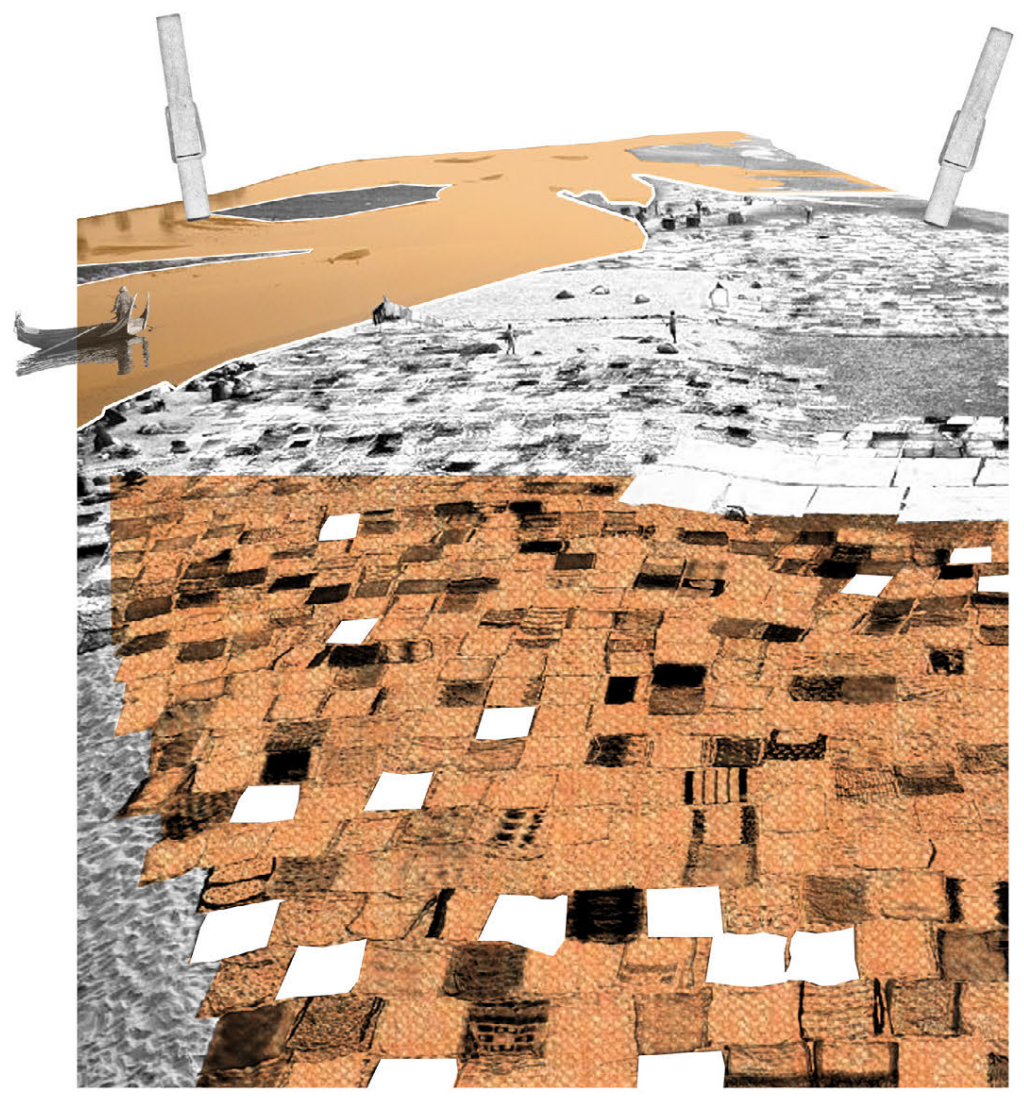


magical realism

p.55

\footnotetext{
"Magical realism is a mode suited

to exploring--and transgressing-

-boundaries, whether the

boundaries are ontological,

political, geographical, or generic.

Magical realism often facilitates the

fusion, or coexistence, of possible

worlds, spaces, systems that would

be irreconcilable in other modes of fiction"
}

(Zamora and Faris 1995: 5)
ए.

\section{Introducing Magical Realism}

The Oxford Dictionary of Art attributes magical realism to German art critic Franz Roh, who coined the phrase to describe the aesthetic of the New Objectivity art movement in Germany during the 1920s. ${ }^{94}$ Later, the term was used to " cover various types of painting in which objects are depicted with photographic naturalism but which because of paradoxical elements or strange juxtapositions convey a feeling of unreality, infusing the ordinary with a sense of mystery." 95 Since then, magical realism has been most closely related to Latin American and Caribbean culture during the 1940s and 1950s. ${ }^{96}$ The term spread to Latin America by the French-Russian Cuban writer and diplomat, Alejo Carpentier. ${ }^{97}$ He used the term lo realismo maravilloso, or marvellous realism, to "describe a concept that could represent for him the mixture of differing cultural systems and the variety of experiences that create an extraordinary atmosphere, alternative attitude and differing appreciation of reality in Latin America." 98

94 Slemon 1995: 407

95 Zamora and Faris 1995: 3

96 Slemon 1995: 407

97 Slemon 1995: 407

98 Slemon 1995: 407 


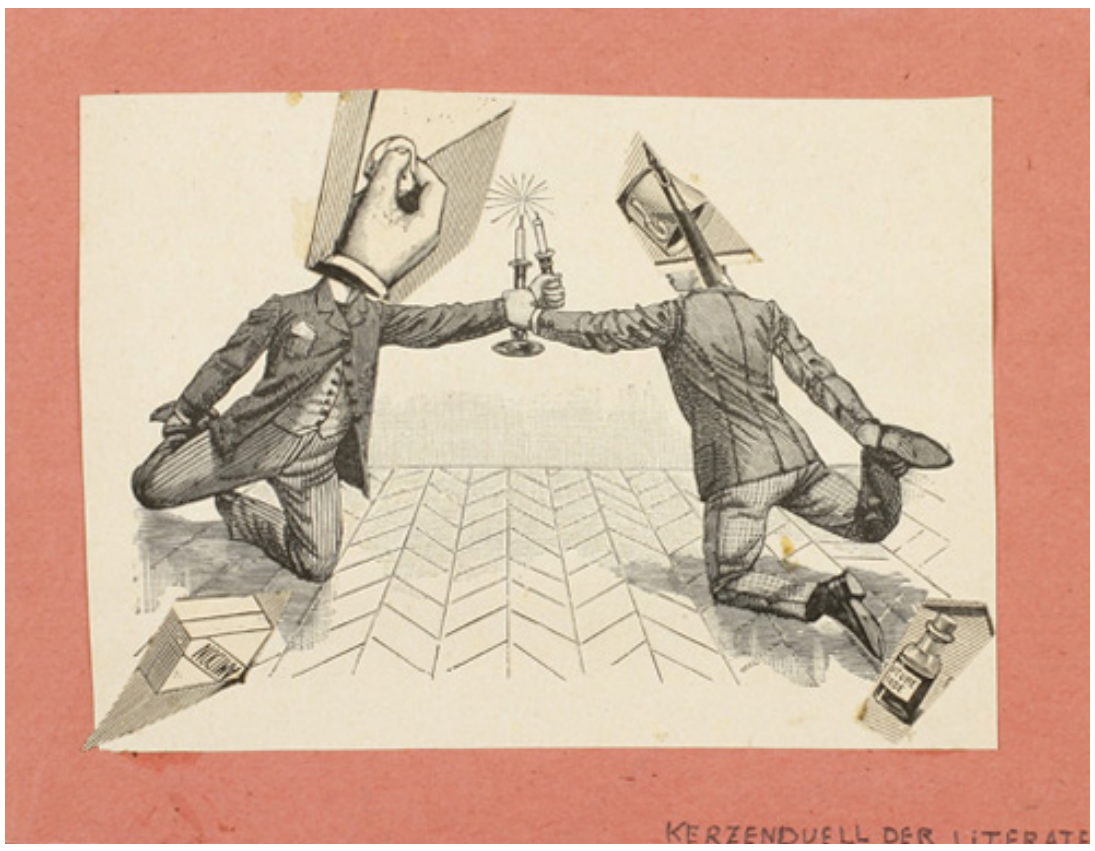

Figure 5.0: Dr Franz Roh, “The Candle Duel of the Literary Man,” c. 1930 
magical realism

p. 57
"Magical realism, in contrast to the realism upon which it builds,

may encode the strengths of communities even more than the struggle of individuals. Societies, rather than personalities tend to rise and fall in magical realist fiction"

(Zamora and 1995: 10)

\section{Decoding Magical Realism}

The term magical realism is in itself an oxymoron, two binary opposites in relation to one another. ${ }^{99}$ This translates in literature, as two oppositional systems that work against one another through very different fictional worlds. In Stephen Slemon's essay, “Magical Realism as Postcolonial Discourse" he writes about these two opposing systems and argues that "since the ground rules of these two worlds are incompatible, neither one can fully come into the "other," a situation which creates disjunction within each of the separate discursive systems, rendering them with gaps, absences, and silences." 100

Working within this concept, magical realism operates to inhibit either separate system from arranging itself into a type of hierarchy by suspending the text from an "established system of representation." 101 Thus, magical realism, within a literary context, is well suited for marginalized cultures and groups located on the fringes of society since their narratives are often underrepresented. As stated, there is no hierarchy or subordination between the opposing systems, which works to the marginalized groups' advantage. So, magical realism tends to draw on cultural systems and overcoming boundaries, whether political,

99 Slemon 1995: 409

100 Slemon 1995: 410

101 Slemon 1995: 410 
geographical or ontological by situating the opposing systems within equal standing. ${ }^{102}$ 
magical realism

p. 59

\section{Magical Realism and Dharavi}

Magical realism is a tool to strengthen communities, transgress boundaries, situate opposing systems in relation to one another, and allow multiple narratives and systems to co-exist.

Dharavi has a long history of hosting marginalized communities and being a site located on the fringes of society. Within the community, there are many political, social, gendered systems in place that position different groups in opposition to one another. The gendered roles and patriarchal society negatively affect women's relation to their health and hygiene.

Thus, because of the gendered boundaries on site the thesis will use a magical realist framework to contextualize the concerns with respect to women's health and aid the design process to overcome said concerns.

Using magical realism is a way to highlight the limitations within the current conditions and acknowledging the complexity of the problem. The site has a layered history along with a long-standing socialization process and so, magical realism can be a tool to reveal these concerns while also curbing a singular design approach.

This can be accomplished by creating a space and communicative language that exists on the threshold of visibility and 


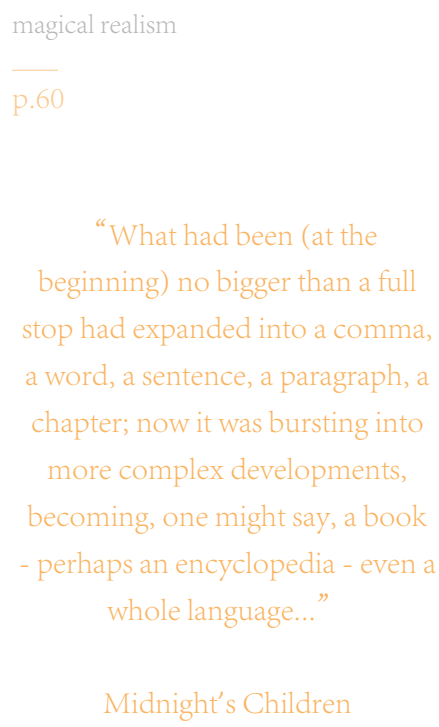

"What had been (at the beginning) no bigger than a full stop had expanded into a comma, a word, a sentence, a paragraph, a chapter; now it was bursting into more complex developments, becoming, one might say, a book - perhaps an encyclopedia - even a whole language..."

Midnight's Children

invisibility. The project's visibility has a direct connection to its safety and acceptability within the site and so, through magical realism the project can defy the rational to adjust its perceptibility. This can help transgress gendered boundaries and allow the project freely exist within the current social climate.

Invisibility and adaptability are significant themes that can give rise to the female voice and the ability to communicate sensitive topics with one another while safeguarded against unwanted attention. The hope is to create a method of communication for the participants that allows expressibility and collectivity of experiences to establish a shared truth and understanding. 
Intervention

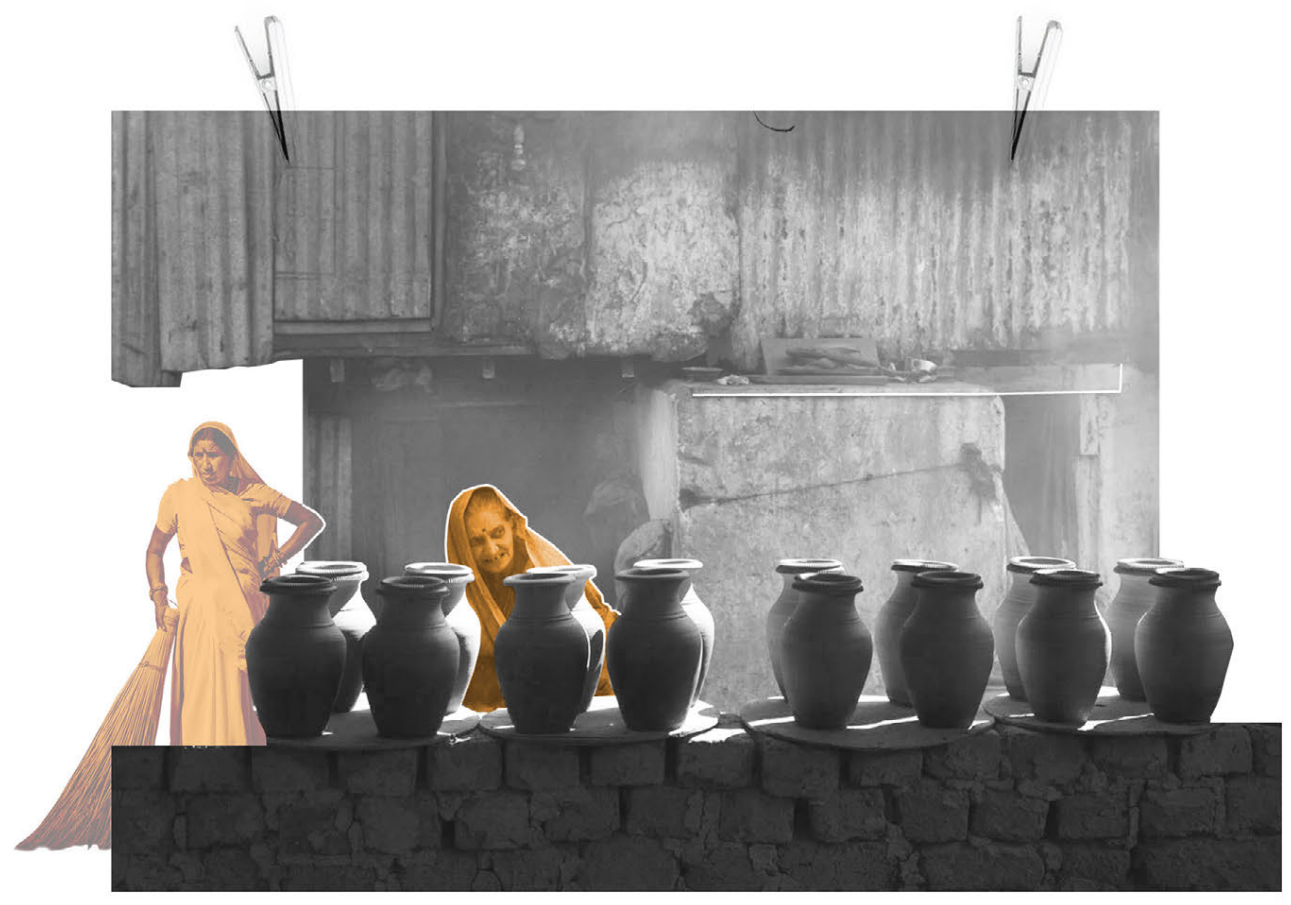




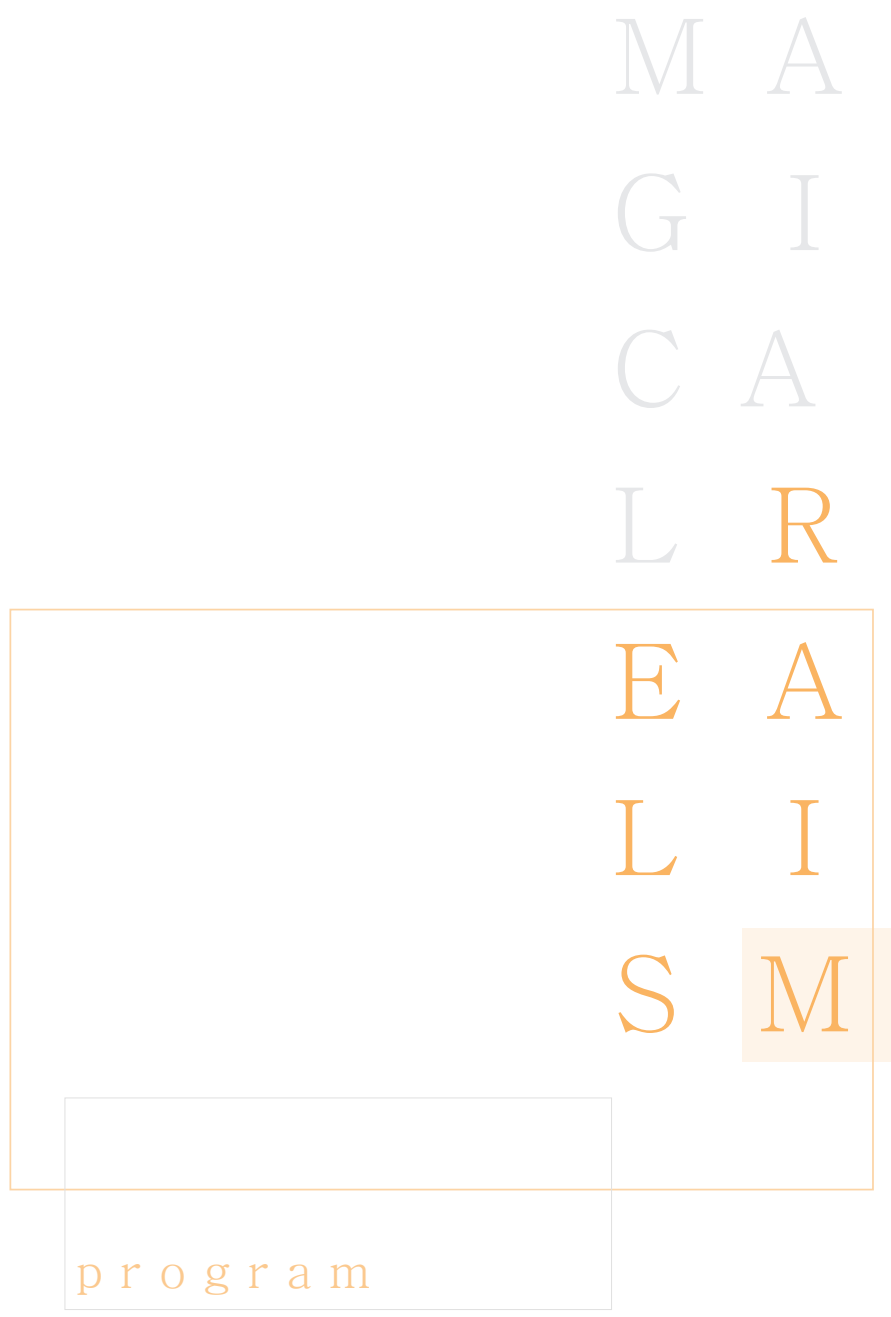


design intervention

p.63

"Research indicates that garment work... has an impact by delaying marriage, reducing the number of children women have, increasing education, and increasing women's decision-making powers at home and in the community."

(Svarer et al. 2017: 7)

\section{Layer 1: The Mending Process}

Globally, the apparel sector is one of the largest industries for female employment. ${ }^{103}$ Herein lies a potential opportunity to engage women's economic empowerment by offering garment workspaces for women to access alongside their medical council.

As discussed in chapter four, many women in Dharavi

participate in home-based garment work such as, embellishment, thread cutting, tailoring, and sewing. The women are often crosslegged, performing repetitive tasks by hand in the same position for long hours. This along with the lack of private toilet facilities, and the stress of working in isolation could lead to serious health concerns like hypertension, arthritis, urinary tract infection and spinal degeneration. ${ }^{104}$

The intervention hopes to minimize some of the stressors caused by home-based garment work through private sanitation services and inclusive workspaces to promote a sense of community and support. ${ }^{105}$ The hope is that integration and strength in numbers among women can help thwart isolation and possible exploitation. ${ }^{106}$ Women may also

103 India is no exception as its garment industry employs approximately 8 million women, which amounts to $60 \%$ of the workforce within the sector (CARE 2017).

104 Svarer, Meiers, and Rothmeier 2017: 7

105 A study conducted by the humanitarian agency CARE found that $60 \%$ of garment production in Asia is conducted at home (CARE 2017). In India alone, an estimated 5 million garment workers conduct their business at home (CARE 2017).

106 According to the Fair Wear Foundation, 60\% of female workers in the garment 

project is not to divide women and men in the workplace but to provide some respite for women and foster uncensored communication. ${ }^{107}$ Through open dialogue, women can learn more from one another and build a more holistic understanding of various issues that affect them such as, feminine health.

Moreover, cutting and sewing fabric for menstruation are not uncommon in some communities across India. Thus, the garment workspace could be used to sew or repair menstrual cloths or to even offer templates and fabrics to reduce lacerations or discomfort from unkempt or misshapen cloth.

Lastly, the ethnographic study revealed that financial constraints deterred some women from seeking health-related care. The study looked at the financial cost of medication and treatment and also the Amounts to $\$ 42$ Billion lost domestic capital or income from taking time off to visit the health

industry have experienced some form of harassment (CARE 2017).

107 One of CARE's fundamental goals is to see more women in the garment industry "organize and work collectively" in "trade unions, on committees and in community associations” (CARE 2017). 
care facility and attend medical care. Thus, the proposal seeks to overcome the latter financial concern by providing workstations for women to use. This may encourage women to participate in informal discussions around health and other taboo topics while being able to complete some domestic chores at the sewing workstation. Additionally, the workstations are an effective ploy for women to use when seeking medical council without alerting male community members or garnering unwanted attention. 
design intervention

p.66

/ dhobi/ a washerman

/ ghat/ a flight of steps leading down to a river

\section{Layer 2: The Dhobi Ghat}

The world's largest open-air laundromat, the Dhobi Ghat, will serve as a case study for washing practices in Mumbai. The term dhobi translates to washerman, a working caste within India. ${ }^{108}$ The Dhobi Ghat is located approximately 7 kilometers south-west from Dharavi, in the old city known as Mahalaxmi. ${ }^{109}$ The Dhobi Ghat services a wide range of industries and institutions from hospitals, restaurants and garment factories all across Mumbai.

The dhobi's operations are as follows:

1. Collect the garments from the client or institution

2. Steep the clothes in washing soda for 20 minutes

3. Use a bar of soap and brush scrub to clean the collars or edges of the garments

4. Beat the clothes on the stone slab to loosen the dirt

5. Rinse in clean water several times

6. Hang the garments to dry--each dhobi is assigned one or two drying lines per service station

7. Steam and press the garments using either a charcoal or electric flat iron

108 Souza 1998: 142

109 It was first established in 1890 by the British East Indian Company and used as a mass laundry site to clean military uniforms (Das 2017). 
The Dhobi Ghat's washing pods will inform the project's laundry space. In addition, the uneven population demographics within the Dhobi Ghat will further support the argument that women face geographic barriers with respect to cleaning menstrual cloths. 


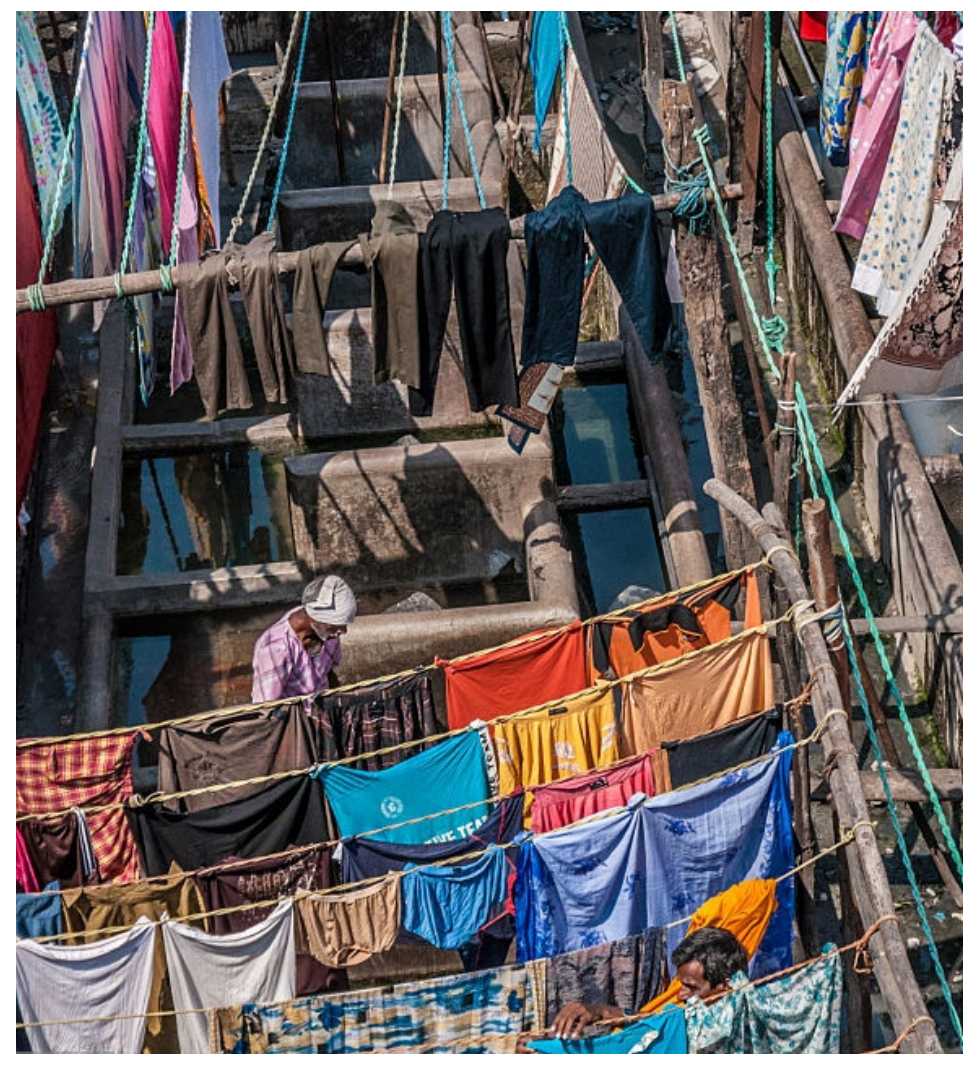


design intervention

p.69

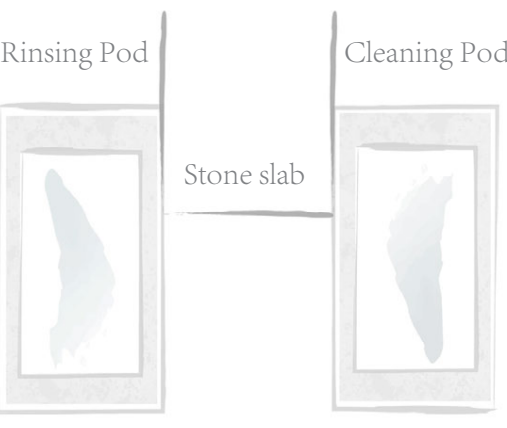

$4 \mathrm{~m}$ squared

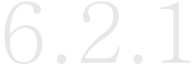

The Washing Pod

The washing pods used at the Dhobi Ghat will be translated into the project primarily for its low-tech approach and familiarity among locals. ${ }^{110}$

Currently, the Dhobi Ghat spreads across four acres of land with 731 washing pods organized throughout the site. ${ }^{111}$

With respect to the design, the washing station has the following: two large cement tanks--one with washing soda, the other with water for rinsing--and a flogging stone to beat the clothes onto to loosen the soil and dirt. ${ }^{112}$
110 The success of the project is partly contingent on its approachability and considering only $10 \%$ of homes in India have a washing machine, it would seem logical to employ a long-withstanding, recognizable mode of laundry within the project (BBC 2017). 111 Each dhobi rents a washing pod for $\$ 5.40$ per month and work within an approximate space of $4 \mathrm{~m}$ squared (Souza 1998: 142).

112 Troublingly, the washing pods receive water from the Tala Pumping Station, unmetered, which is a designated drinking water tap (Mitra 2016). 


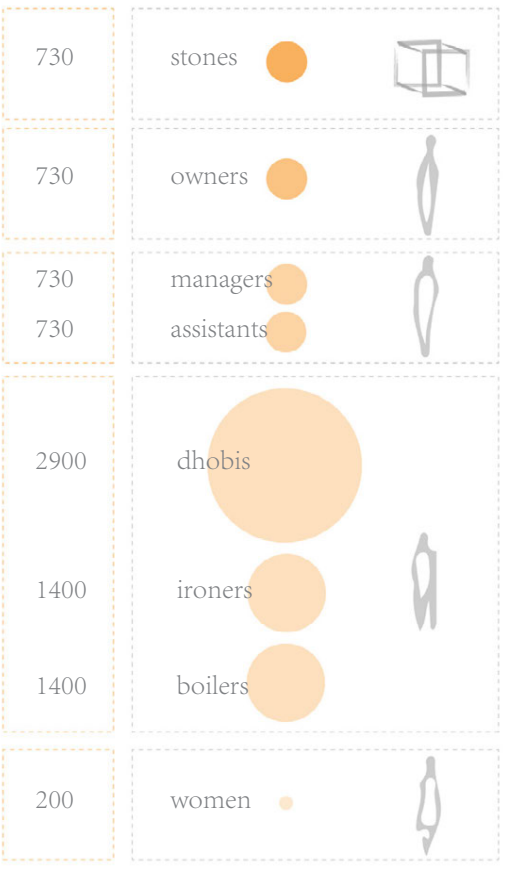

Figure 6.1: Population and Social Structure of the Dhobi Ghat, Mumbai 2014
The Dhobi Ghat employs approximately 7500 workers who live and work on site. ${ }^{113}$ There are three dominant tiers of workers; the stone owners, the managers, and the dhobis. ${ }^{114}$ The stone owners live off-site and are responsible for inspection and management. The manager lives within the community and monitors the dhobis, sorts and distributes the goods, and dispatches the clean garments. As previously discussed, the dhobis are responsible for the soaking, washing, and drying of the clothes.

However, there is a significant group that is largely absent from the workforce, the women. Only $3 \%$ of the population is female, which amounts to approximately 200 workers. ${ }^{115}$

As previously mentioned, studies show that there is a shortage of space for women to conduct menstrual cloth cleaning and drying within their neighbourhoods. In addition, the lack of representation within the Dhobi Ghat could discourage women from using laundry services for their sensitive washing needs. Thus, the women-led washing initiative

113 Many of the workers are migrants from across India who relocated to the Dhobi Ghat, in part because of its continuous, stable work for almost 150 years (Pandey and Bajpai 2014).

114 Pandey and Bajpai 2014

115 This is despite that the government census approximates the national gender ratio is $52 \%$ male and $48 \%$ female, and 56\% male and $44 \%$ female in Dharavi (Ministry of Home Affairs 2001). 
within the project could be one of the few viable options for women in the area. 


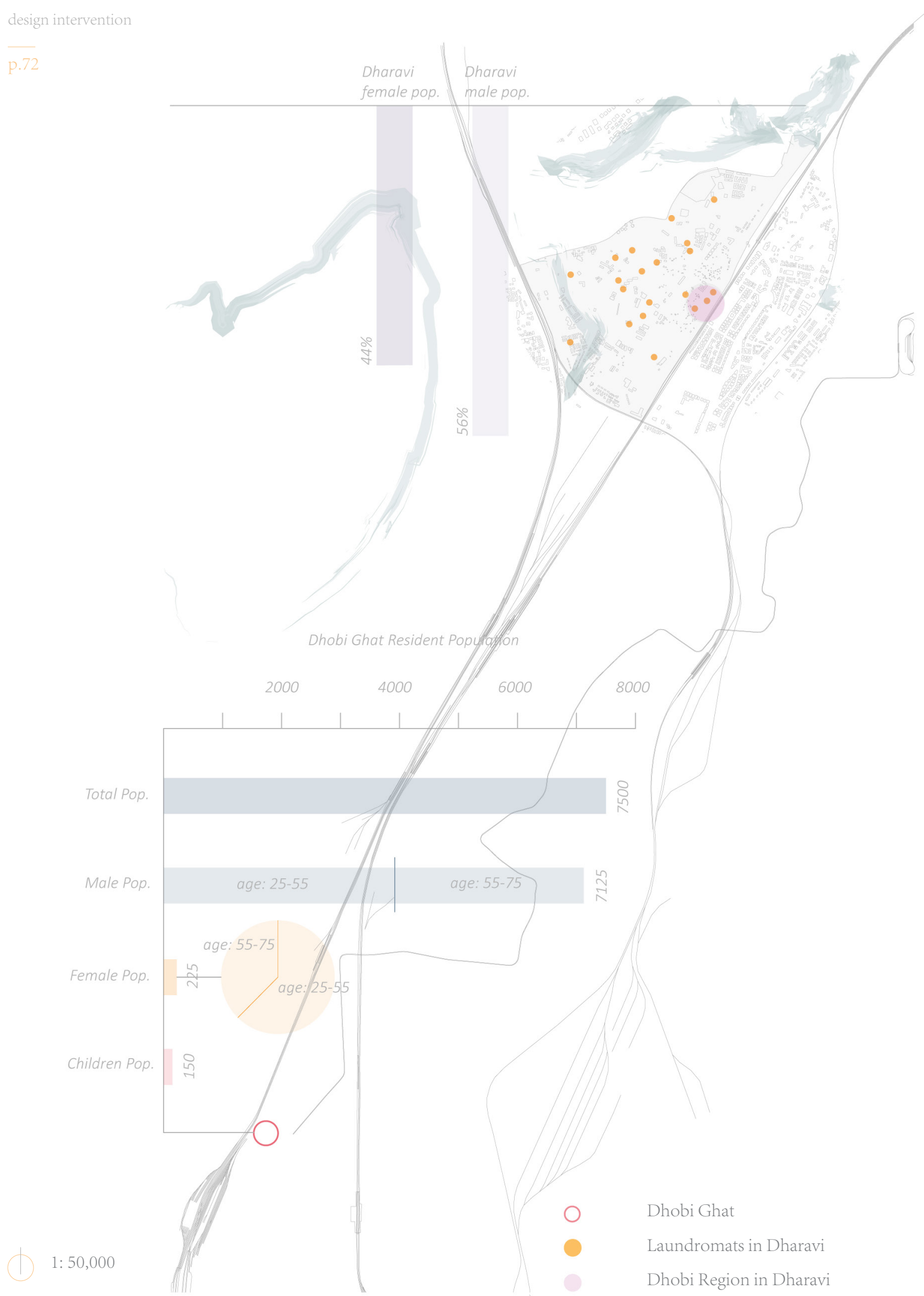

Figure 6.2: Map of Population Demographics Between the Two Sites and Laundry Facilities in Dharavi 
design intervention

p. 73

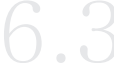

Program Framework

The intervention seeks to incorporate four major components and program that are considered missing from many healthcare facilities, as per the ethnographic research; dissemination of accurate information and products to transform social norms, providing a service that has financial return to overcome economic barriers, meeting basic sanitation and hygiene needs to address the poor living standards, and offering public space and open forums for female discussion and support. 
design intervention

p.74

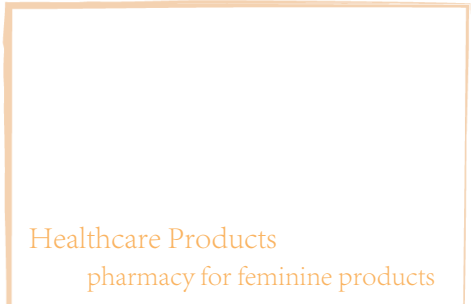

pharmacy for feminine products

\section{0.7 \\ Social Support and Access to Sanitary Products}

Urban slums have statistically lower levels of immunization coverage than their rural counterparts. ${ }^{116}$ A possible explanation could be that in urban areas immunization services are largely provided at hospitals or other clinical facilities. In contrast, rural areas offer community-based services where an auxiliary nurse midwife (ANM) attends to the patients within the home or common space. ${ }^{117}$ Women participating in the Mumbai-based community group "Mahila Milan” expressed that they were "able to explore stories and experiences related to health that they might not have felt comfortable sharing in an atmosphere dominated by professionals." ${ }^{118}$ Thus, community-level programs and collectivist environments help disarm women's fears of accessing health facilities or speaking on their personal health.

The project should be well integrated into the site and accessible, similar to traditional healers. There should be communal spaces to promote a more collectivist approach to women's health; although some private rooms should be offered for personal counsel.

As mentioned, purchasing sanitary napkins poses a considerable challenge for women in Dharavi. So, the project should include spaces

116 Kapadia-Kundu and Kanitkar 2002: 5087

117 Kapadia-Kundu and Kanitkar 2002: 5087

118 Meleis et al. 2011: 104 
where sanitary napkins can be stored, sewn, taught how to use, and distributed. 
design intervention

p.76

\section{Economic and Domestic Support}

Economic and domestic incentives are key hallmarks of this project to encourage community participation. As discussed, the garment industry has a considerable female presence and is an apt opportunity for women to enter the workforce. So, the project will look to incorporate sewing stations with seating and storage for threads, sequins, needles and other handicraft utensils. Another possible use could be for women to sew or repair personal hygiene cloths within a protected space outside of the home. 
design intervention

p.77
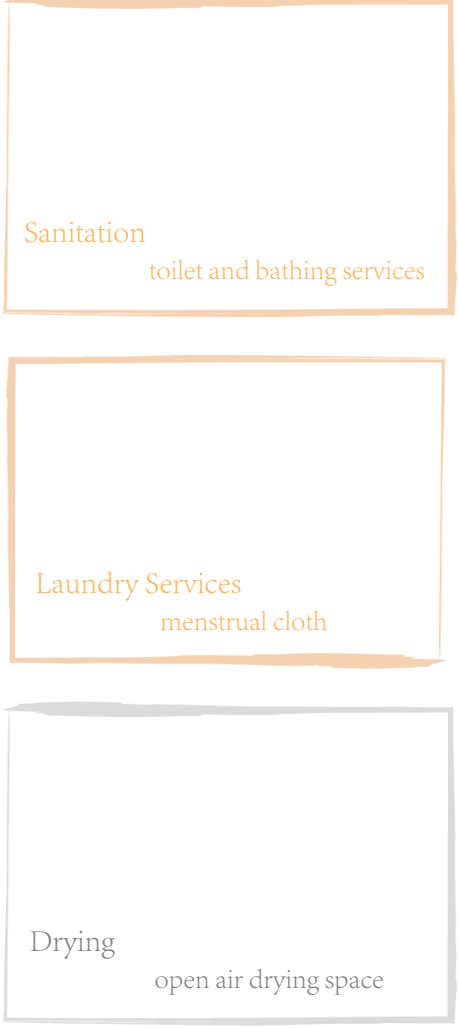

Having toilets, personal baths, and spaces for cleaning and drying menstrual cloths or other private garments will help improve personal hygiene and healthy practices. ${ }^{119}$

In addition, there should be washing pods--inspired by the Dhobi Ghat--as a means for women to conduct menstrual cloth cleaning in a space away from male community members. Space will also be allocated on the upper floor for drying the fabric.
119 The toilets should also have storage with sanitary pads and their designated disposal bins while the personal baths should be equipped with a shower and sink for personal hygiene. 
design intervention

p.78
6.3 .4 Opportunity for Public Space

Public spaces in economically disadvantaged areas or informal settlements can offer many positive contributions to the community. ${ }^{120}$ For example, they provide active and social interaction outside of the home and temporary respite from domestic chores. ${ }^{121}$ Further, a majority of the population occupy job positions within the informal economy leading to job insecurity, thus having stable, community spaces can be a valuable asset. ${ }^{122}$

Thus, part of the project's intent is to provide a femaledominated "public" space as an open forum for discussion, and connectivity; ideally in the more engaged programs such as the sewing, washing, and drying stations. The idea is to provide the same sense of community and temporary relief that traditional public spaces offer.

Public Forum

gathering space for discussions
120 Unfortunately, public space is a rarity within highly dense and marginalized communities and many of the community members do not have the "luxury of patronizing the public spaces of upper middle class and rich Indians, such as malls and public parks with admission fees" (Pyati and Kamal 2012: 341).

121 Pyati and Kamal 2012: 341

122 Pyati and Kamal 2012: 340 


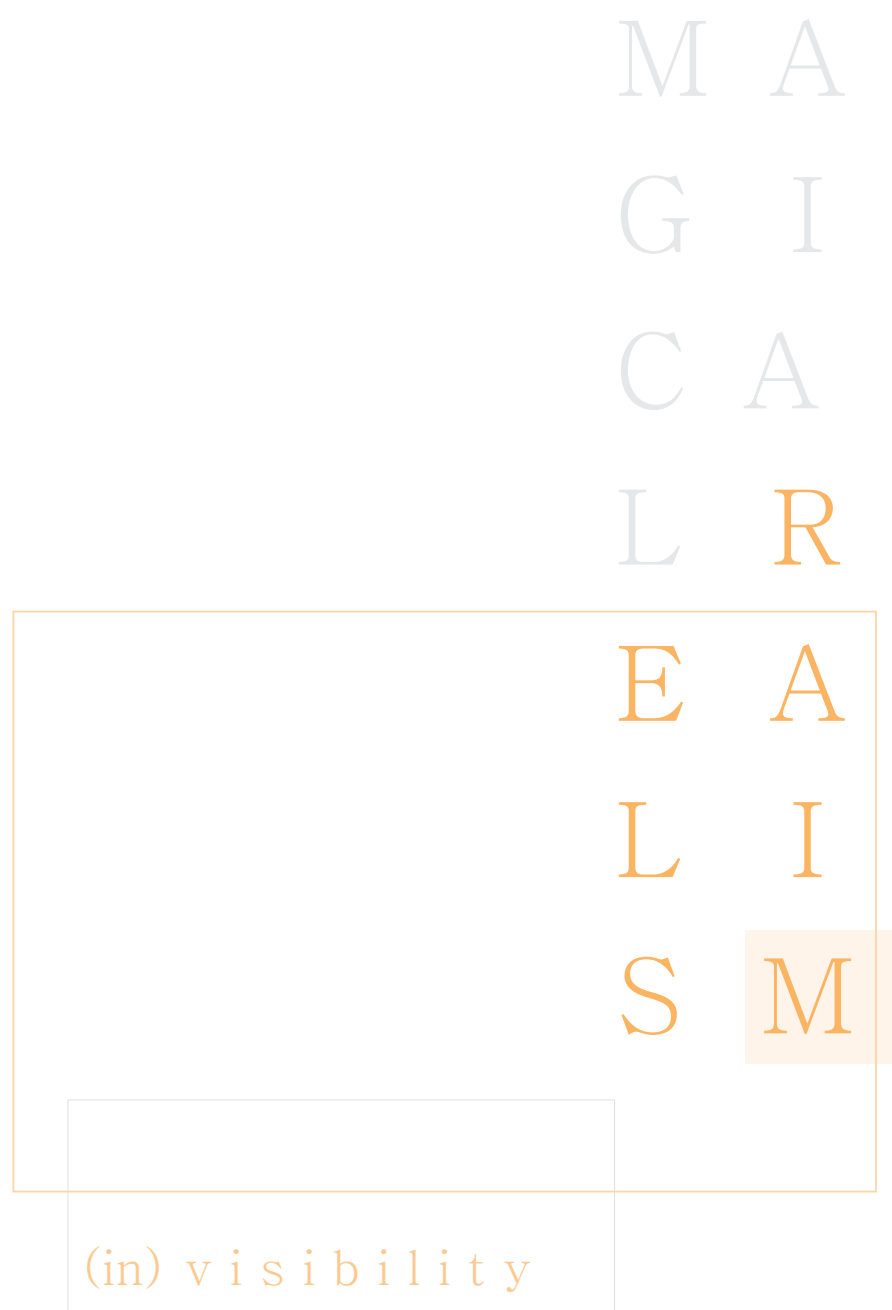



modify the bus. ${ }^{123}$

Buses have become one of the most used modes of transportation and yet, in the last couple years, BEST has been reporting annual revenue losses. ${ }^{124}$ To relieve some of the loss, BEST reportedly cancelled some services and sold 100 buses. ${ }^{125}$

Herein lies an opportunity for the project to re-salvage some of the lost fleets by purchasing the decommissioned buses and restoring them into the preventative health clinics. Further, BEST buses are easily recognizable to the locals and so, will be less conspicuous to male members in Dharavi.

From the entire fleet, the project will procure the double decker

123 The Myna Mahila Foundation, located in Mumbai, is an organization that works to "employ women from urban slums in Mumbai to manufacture and sell affordable sanitary pads back into their communities, improving menstrual hygiene, providing stable employment, and building a trusted network." Profits from the sales of sanitary pads are re-distributed in the community and health institutions. They reach over 10,000 women per month and have established connections in Dharavi, which would serve well for this thesis (Myna Mahila Foundation 2018).

124 In 2017, reports claimed that the number of BEST buses have fallen 21\% in the last 5 years and are down to 3,300 buses across the city (Press Trust of India 2017).

125 Press Trust of India 2017 
bus, as it has enough space to accommodate all the programmatic needs.

The double decker buses are also steadily declining and will likely be phased out in the coming years. ${ }^{126}$ Thus, it will be easier to acquire and re-use the obsolete fleet.

126 Since the 1980s, there has been a steady decrease in the number of double decker buses from 864 in 1982 to 122 in 2013. This is partly because there is a minimal difference in seating capacity, an additional 32 seats, and yet the buses require two operating conductors, which is an additional cost (Press Trust of India 2017). 


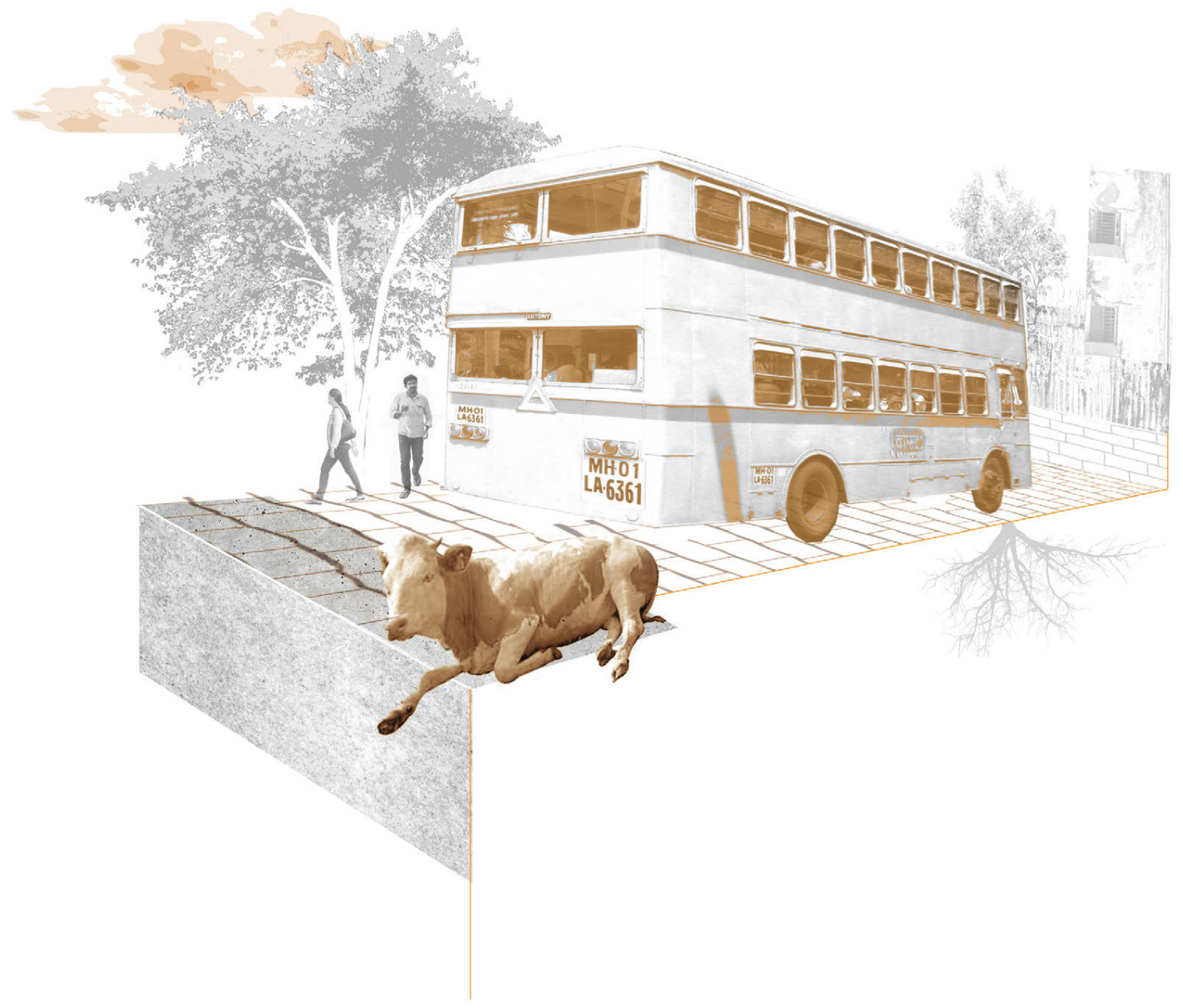

Figure 6.3: Mumbai's BEST Double Decker Bus 


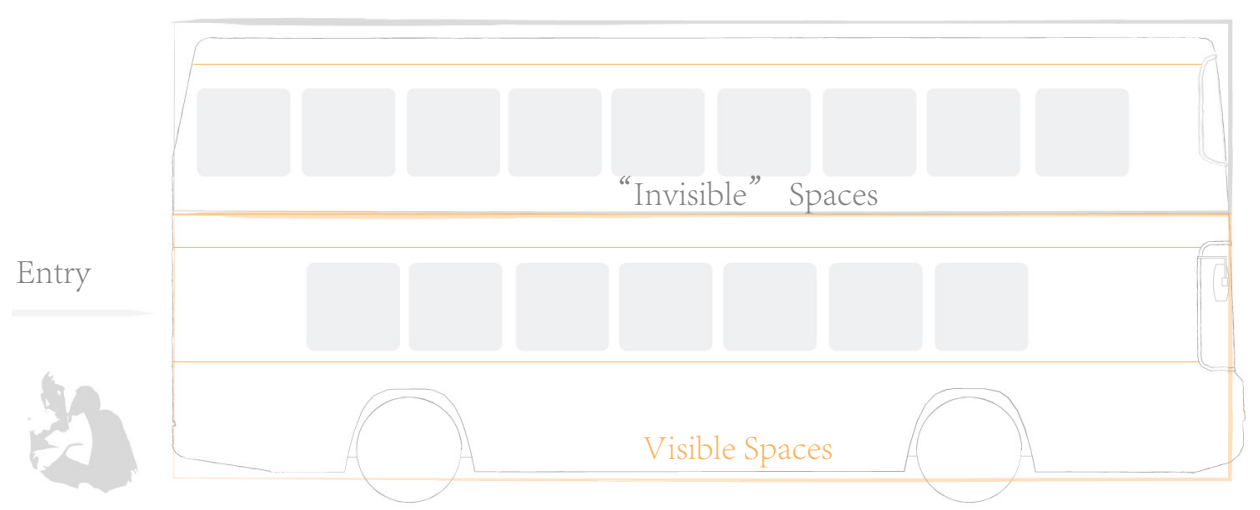




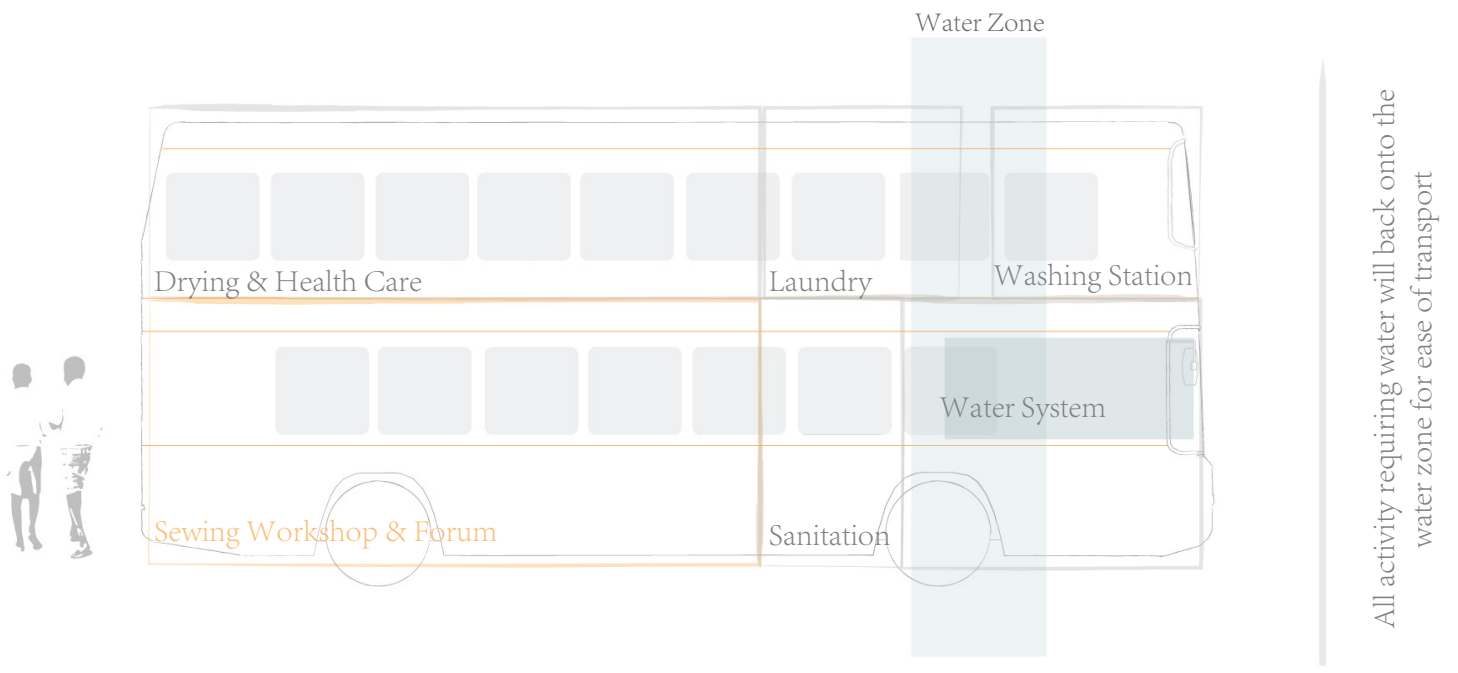

Figure 6.5: Program Arrangement Based on Water Zone and Requirements 


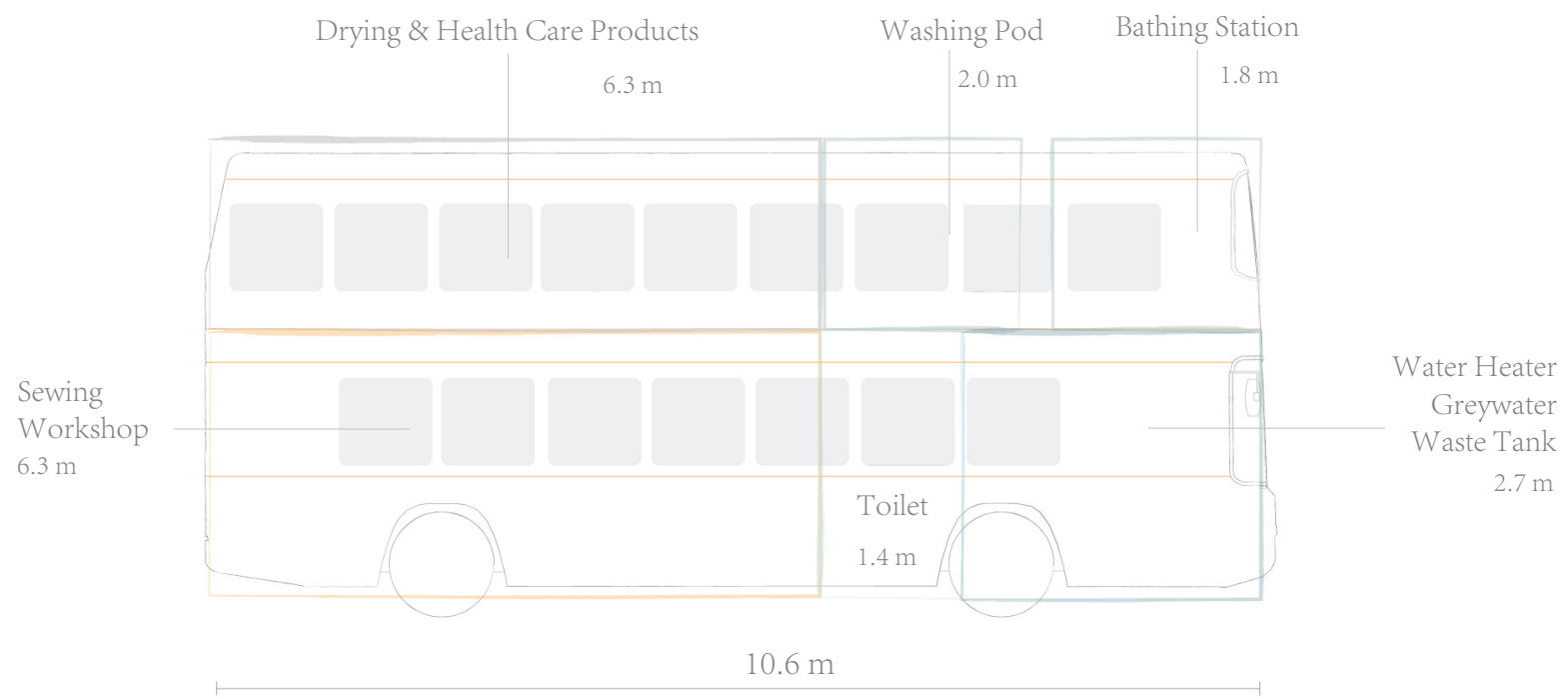

Figure 6.6: Programmatic Dimensions and Allocated Space 


\section{Storyboard of Sections}

The bus will be drawn as a series of sections to represent the project moving through space and time.

The sections of the bus have been organized as a storyboard, revealing different social, cultural and religious narratives at play in relation to the bus.

The storyboard is attempting to create a collection of lived experiences that are recognizable to the women on site. In each section, larger social structures are represented in the background and are related to the activity within the bus. The section is cut at a particular program in the bus that seeks to address, support, question, or illuminate the larger social structures at play.

And yet, the sections are meant to be further customized by the local women and not enforce a definiteness or finality within the project. ${ }^{127}$

The series of sections undergo a process of translation to relate to different viewers. The sections are first represented as sketch drawings, meant to offer some spatial qualities that can be read by designers or NGOs willing to participate in the project. Note, the sections are not overly designed in order to give equal importance to the social structures

127 In the previous section, the bus and program were defined to act as the exoskeleton and give the project a framework, whereby further design considerations and spatial arrangements can build upon. 
represented in the background and allow some freedom for changes. The sections are then printed onto fabric to represent the idea of conversion. The intent of translating the drawing onto fabric is to discourage a level of definiteness that is associated with printed design drawings. The fabric invites a level of engagement and participation, either through stitching, sewing or tailoring directly onto the fabric. Then, the fabric is handwashed, which leads to wrinkles, fading, and fraying, making them even less precious.

In essence, the drawings are working in reverse, moving away from architectural conventions. In doing so, the project starts to become more real. This is because the drawings are meant to be a point of reference that supports further conversation and adaptation by local women until a collective understanding of the bus is achieved. The drawings propose an initial concept rooted in some form of reality but must be activated by the community to become real.

If the drawings maintain its architectural conventions on paper, the work is being privileged for the designers and inaccessible to the local women. As such, the project is making an effort to be less prescriptive through the representation and conversion process to encourage conversation and shared perspectives to piece together a more holistic reality. 
design intervention

p.88

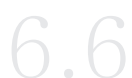

The Base Plan

The sections are based off an initial plan drawn from personal reflection and understanding of architectural efficiency. The plans and sections are just initial concepts, which can be read by architects or designers willing to participate in the project. However, this thesis is also proposing a representation process from drawing to washed fabric, so the images can be circulated on site and receive revisions and feedback by the local women

Throughout the chapter, research and thought has been put into the logistical and operational considerations for the project, as a means to demonstrate the project's feasibility and materiality. This is to ground the project in reality and justify the work to an NGO or architectural committee. 


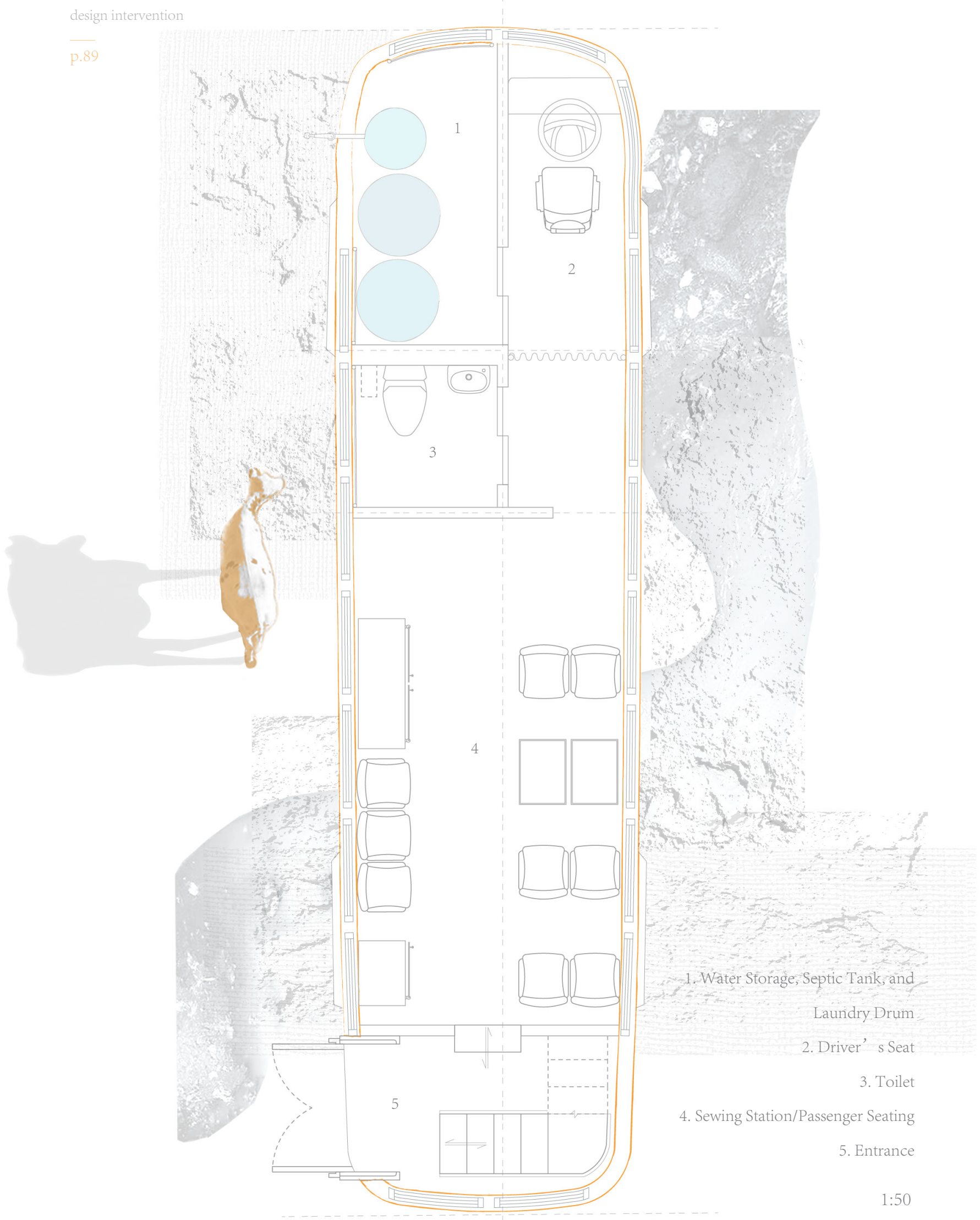

Figure 6.7: Main Level Bus Plan 


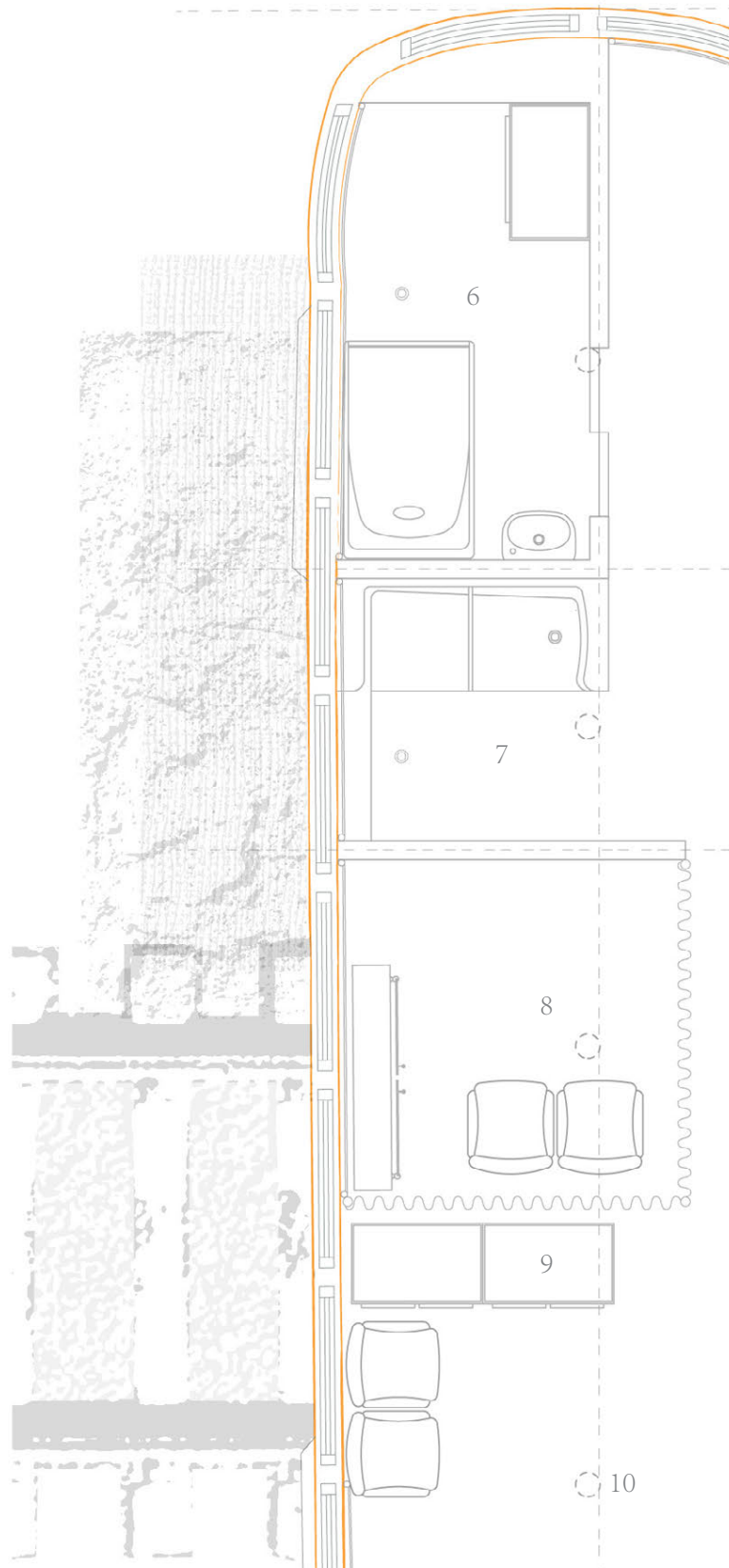

6. Bathing Station

7. Laundry Pod

8. Health Consultation Space

9. Additional Storage for Feminine

Products

10. Rotary Fan Ventilator

11. Drying Racks

$1: 50$

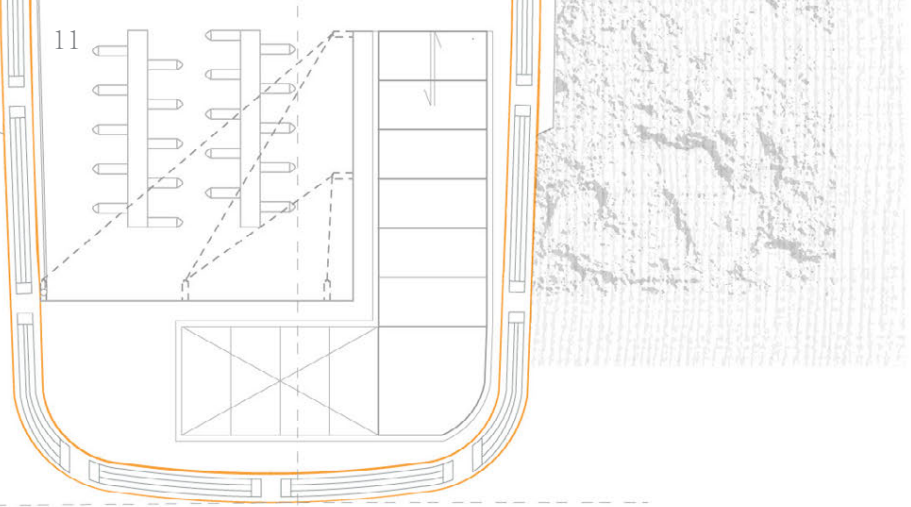

Figure 6.8: Level 01 Bus Plan 
Prior to use, a water system would need to be installed and managed by an appointed team. For ease of water supply and drainage, all the water-based program would be organized adjacent to the water system. The system would have the following components: septic storage, water heater storage, and greywater collection.

The septic tank collects waste from the toilet and stores it until the tank can be attached to a service vehicle, where it can be emptied at a waste-disposal site. A waste storage system between 373-416 L would be appropriate for the bus's system. According to a container capacity chart the septic tank would need to be $0.91 \mathrm{~m}$ in height and $0.76 \mathrm{~m}$ in diameter.

The water is supplied through a hot water storage tank, most likely a propane system. The three main components of the storage tank are supply lines made of cross-linked polyethylene, drain lines made of polyvinyl chloride, and ventilation pipes to maintain the suitable pressure. ${ }^{128}$ Based on the suggested single person use of water, $65-100 \mathrm{~L} /$ day, for all household activities, the water tank dimensions would be 1.22 $\mathrm{m}$ in height and $0.76 \mathrm{~m}$ in diameter for a $550 \mathrm{~L}$ capacity tank. ${ }^{129}$

128 US Department of Energy 2019

129 This is also considering residential water heaters can store $300 \mathrm{~L}$ and the occupancy on the bus would be greater than a standard family home (USGS 2016). 
The project could benefit from a greywater collection system since much of the water use in the project comes from washing and laundry. The collected greywater can be re-used to irrigate plants, so long as it deeply penetrates the soil and does not run off into nearby bodies of water. The most economical option would be to use a laundry drum; wash water is pumped inside and then drained out from the bottom into a hose that can be used for irrigation. The laundry drum has an approximate capacity of $400 \mathrm{~L}$, to accommodate the multiple loads of laundry per day, which may range from 20-100 L depending on the number of menstrual cloths. ${ }^{130}$ 
Septic Tank System

Water Storage System
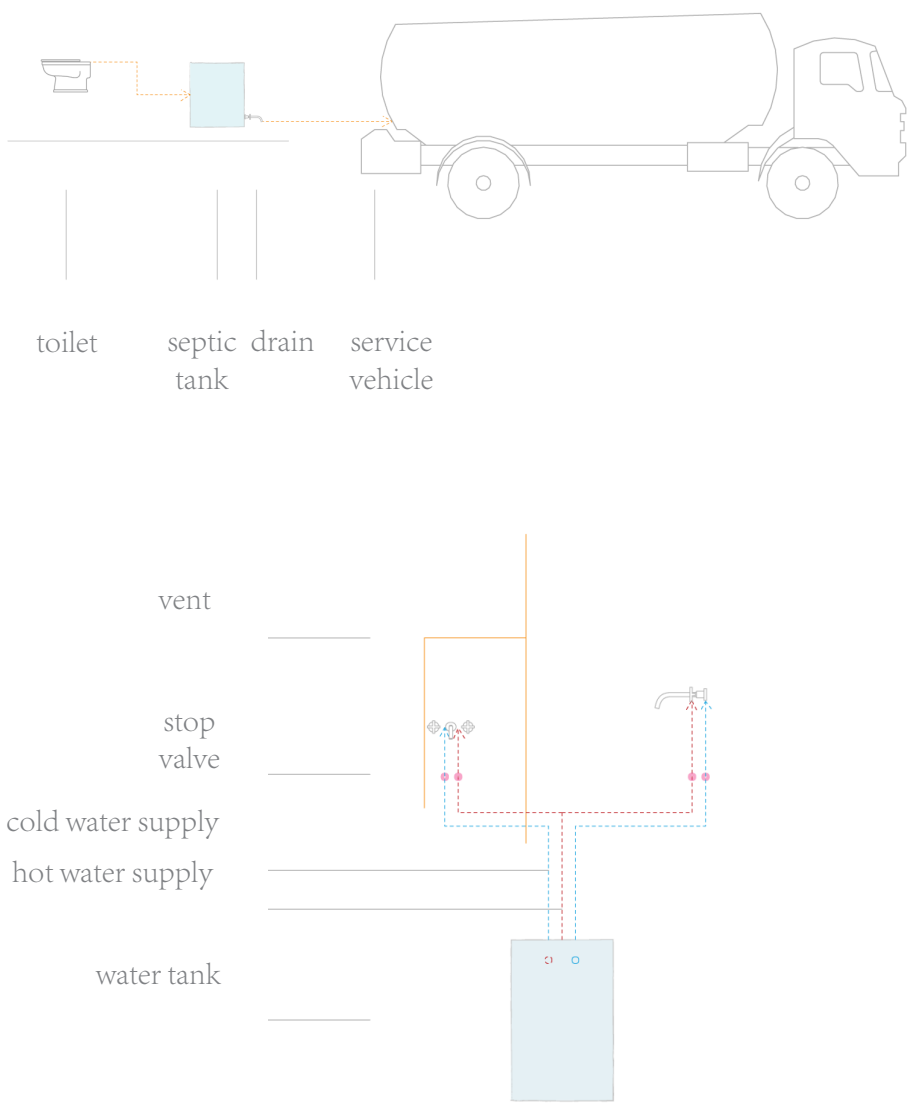

wash water lines
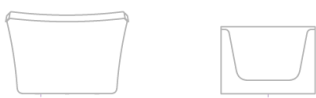

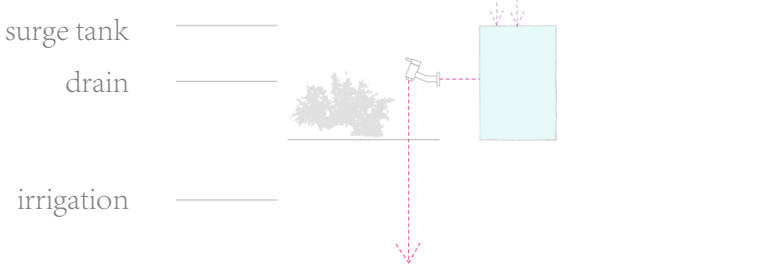

irrigation

Greywater System

Figure 6.9: Water System Diagram 


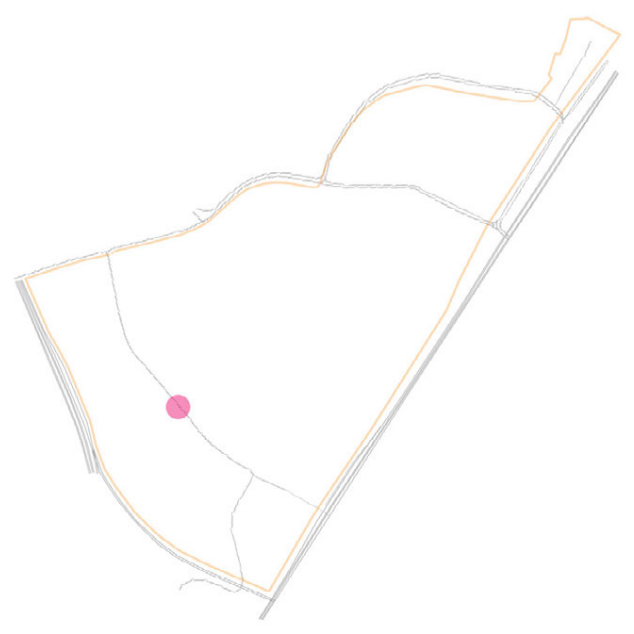

[Water]

Section through the water system of the bus

Time: During the monsoon season, which is typically between June-September where rainfall can reach $1800 \mathrm{~mm}$.

Location: Near the above ground water sewer pipes, approximately $2 \mathrm{~m}$ in diameter

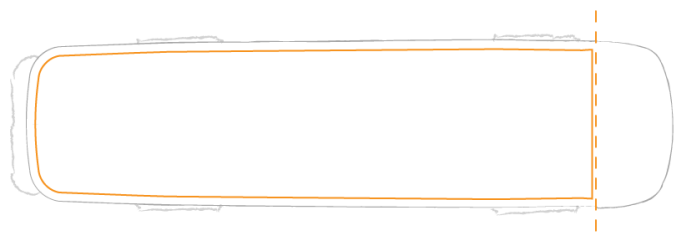



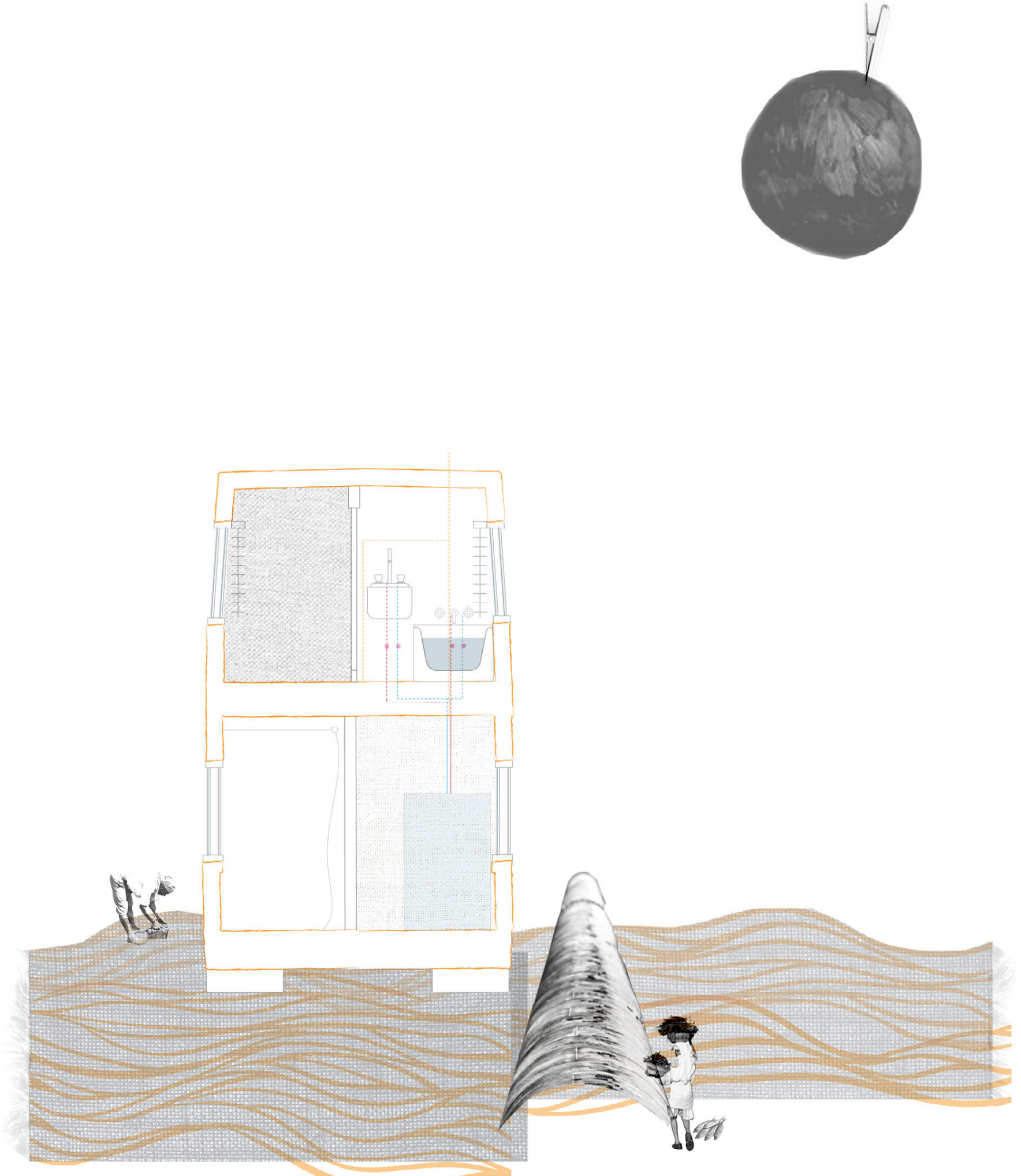

Figure 6.10: Water System Section during Monsoon 


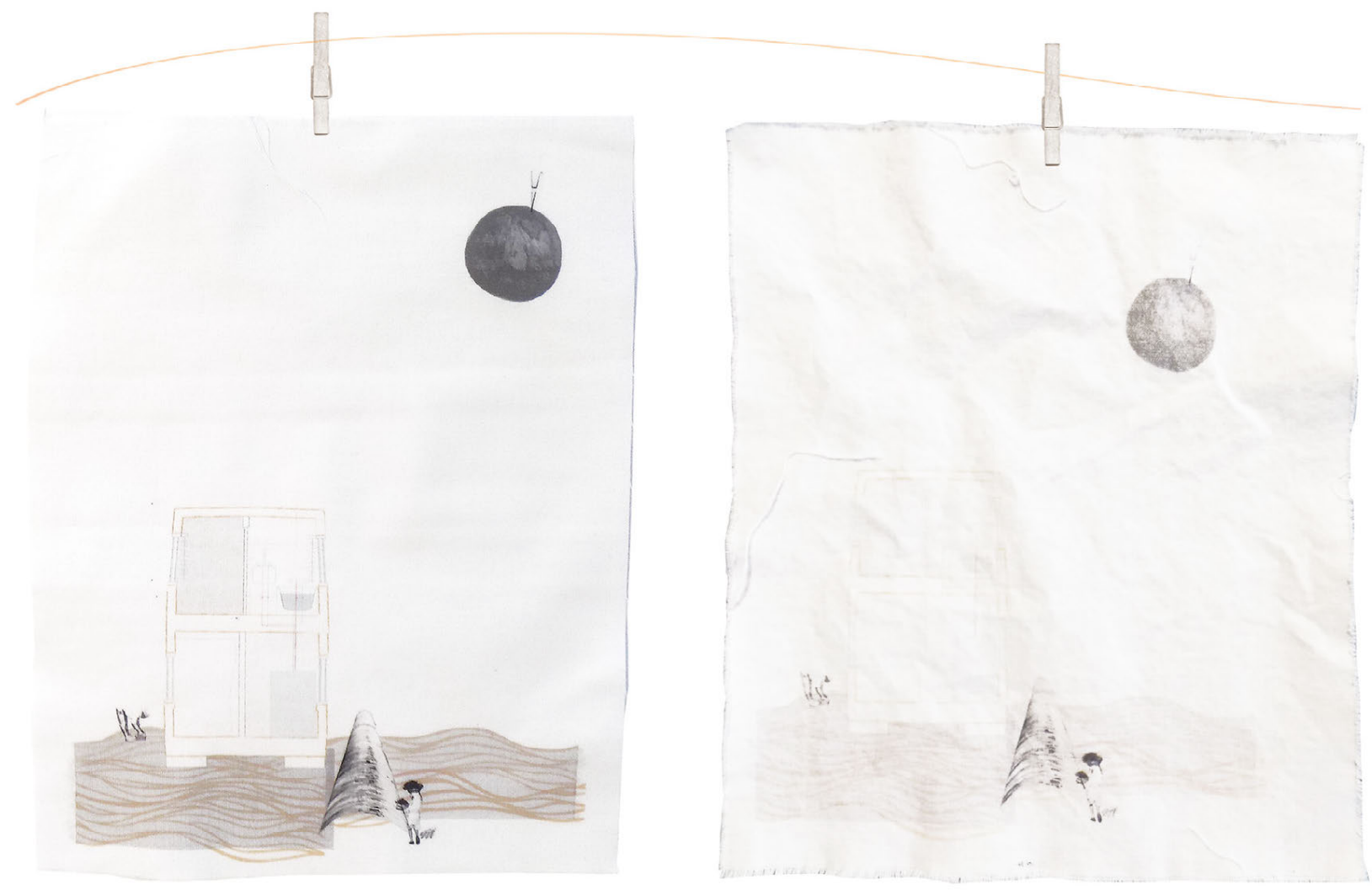

Figure 6.11: Water System Section Printed on Fabric and Hand-Washed Medium: Substrate Printed on Cotton 


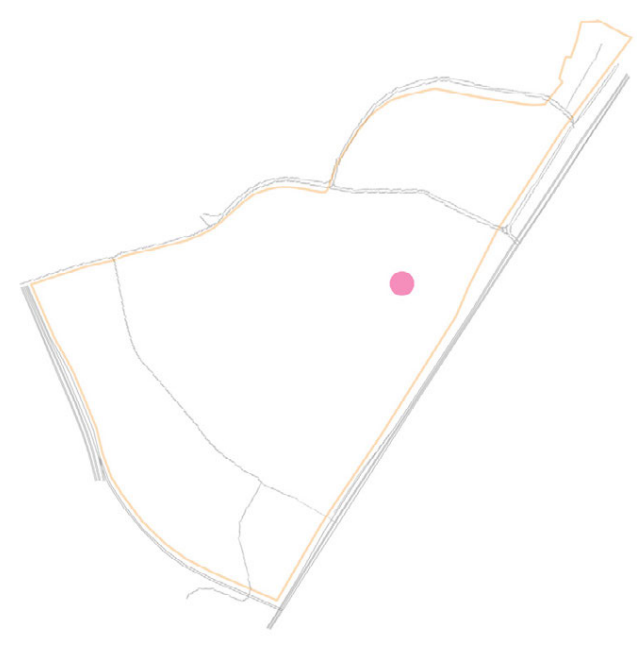

\section{[Sanitation and Safety]}

Section through the toilet facility

Time: Sometime in the late evening, when the sun has set and women may be vulnerable to unwanted attention when accessing the public toilets

Location: On 90 Feet Road outside the police station

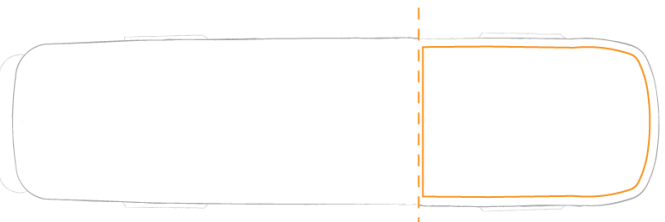



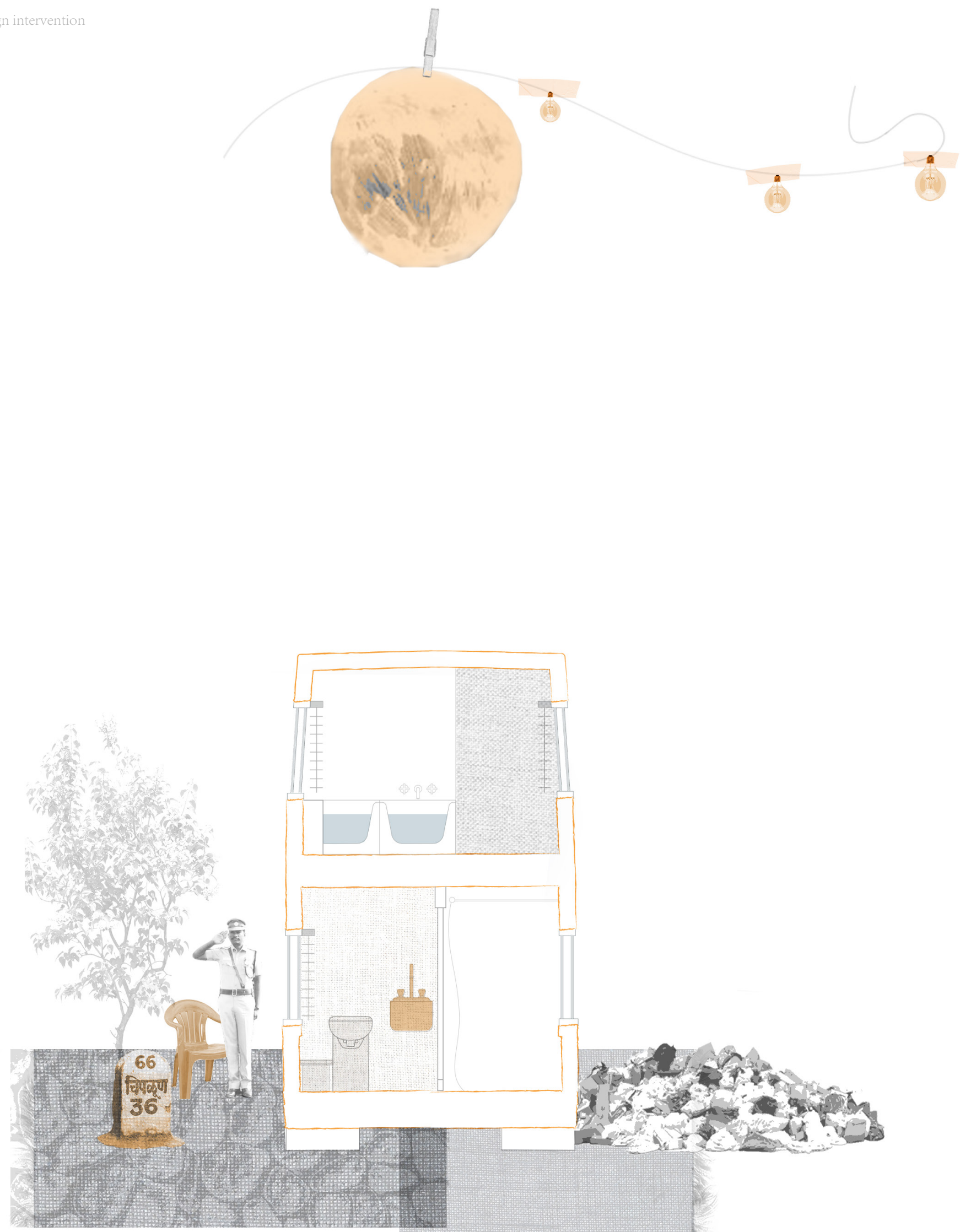

Figure 6.12: Sanitation Section near Police Station 


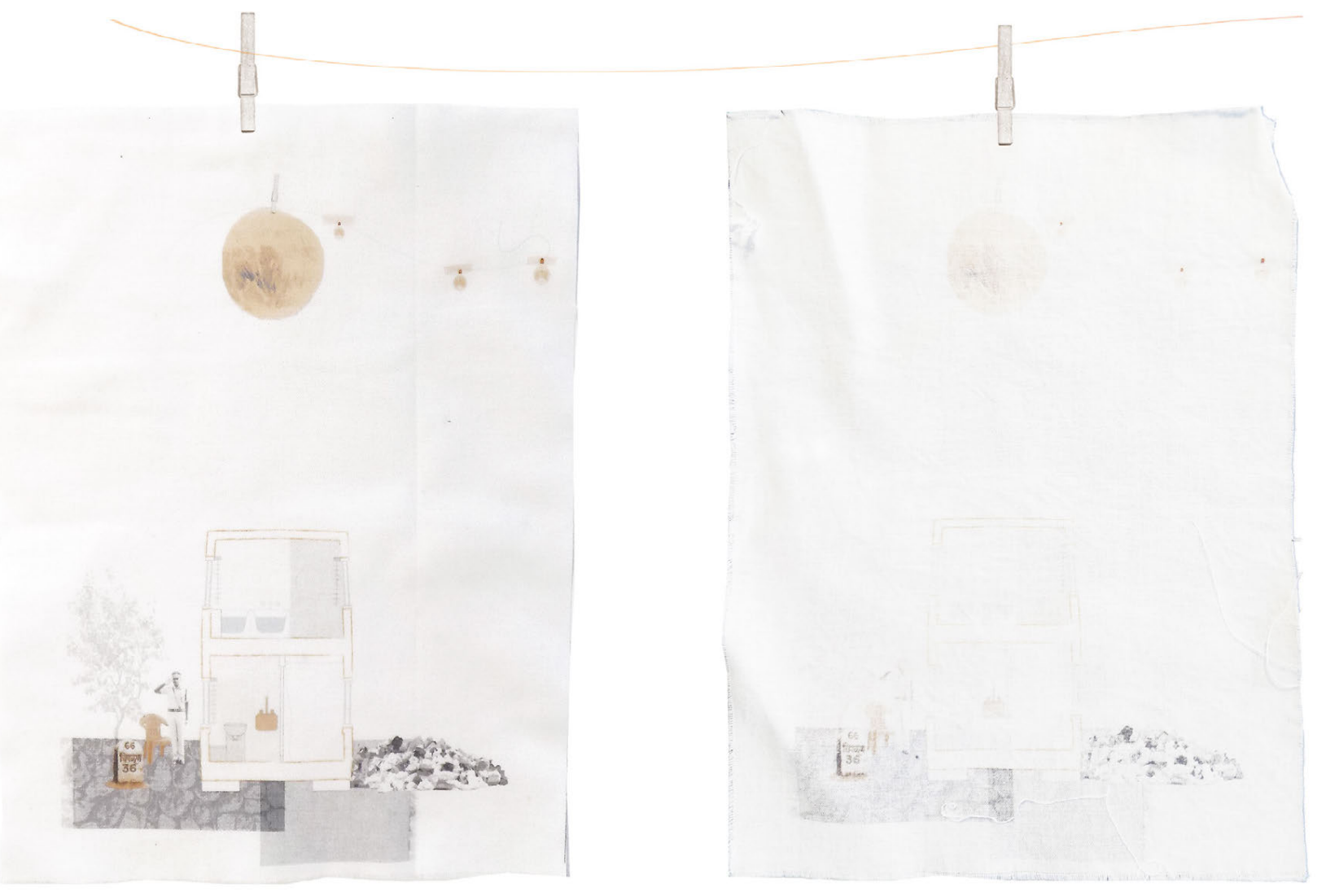

Figure 6.13: Sanitation Section Printed on Fabric and Hand-Washed Medium: Substrate Printed on Cotton 
In India, the most practiced religions are Hinduism (80.5\%) and Islam (13.4\%). ${ }^{131}$ Each religion has some writing or common belief that affects women's participation during menstruation.

For some traditional Hindus, touching a menstruating woman is deemed inappropriate, as the menstrual blood is thought to be toxic. ${ }^{132}$ In other cases, some women are not allowed to enter kitchens or temples, bathe or touch other people.

Some Hindu communities across India and Nepal banish menstruating women to clay sheds--known as chaupadi huts--located 10-15 meters from the main residence. ${ }^{133}$ Women are expected to reside in the chaupadi hut, along with any children they may have, for the duration of their menstrual cycle. ${ }^{134}$ Once their menstrual cycle is completed, they receive an oil bath to become ritually clean again. ${ }^{135}$

The Quran 2:222 says menstruation is "an impurity, so keep away from women during it and do not approach them until they are cleansed; when they are cleansed you may approach them as God

132 Bhartiya 2013: 524

133 Bhartiya 2013: 525

134 Bhartiya 2013: 525

135 The Nepal Supreme Court abolished this practice in 2005 because there are reports of women dying due to snake bites, severe cold, rape or smoke inhalation. However, it is reported that $85 \%$ of women still continue the practice (Bhartiya 2013: 525). 
has ordained." ${ }^{136}$ Some religious interpreters have further restricted menstruating women from touching the Quran or entering a mosque. ${ }^{137}$ During religious events such as Ramadan, women are disallowed from prayers and fasting until they complete their menstrual cycle. ${ }^{138}$ They are expected to complete a washing at the end of the cycle to become clean and return to ritual activity.

Thus, the project's bathing facilities are meant to promote hygienic practices during menstruation to reverse the religious stigmatization and misconceptions of agency. Some religions limit women's activity and movement, and require a ritual cleaning before integrating back into one's routine and places of worship. The bathing and products on the bus are meant to demonstrate that women can still partake in everyday activities with absorptive products and hygienic care.

The washing coupled with more medically accurate information can hopefully help women understand the agency they have over their bodies during menstruation and not feel limited by cultural and religious taboos.

136 Bhartiya 2013: 524

137 Bhartiya 2013: 524

138 Bhartiya 2013: 524 


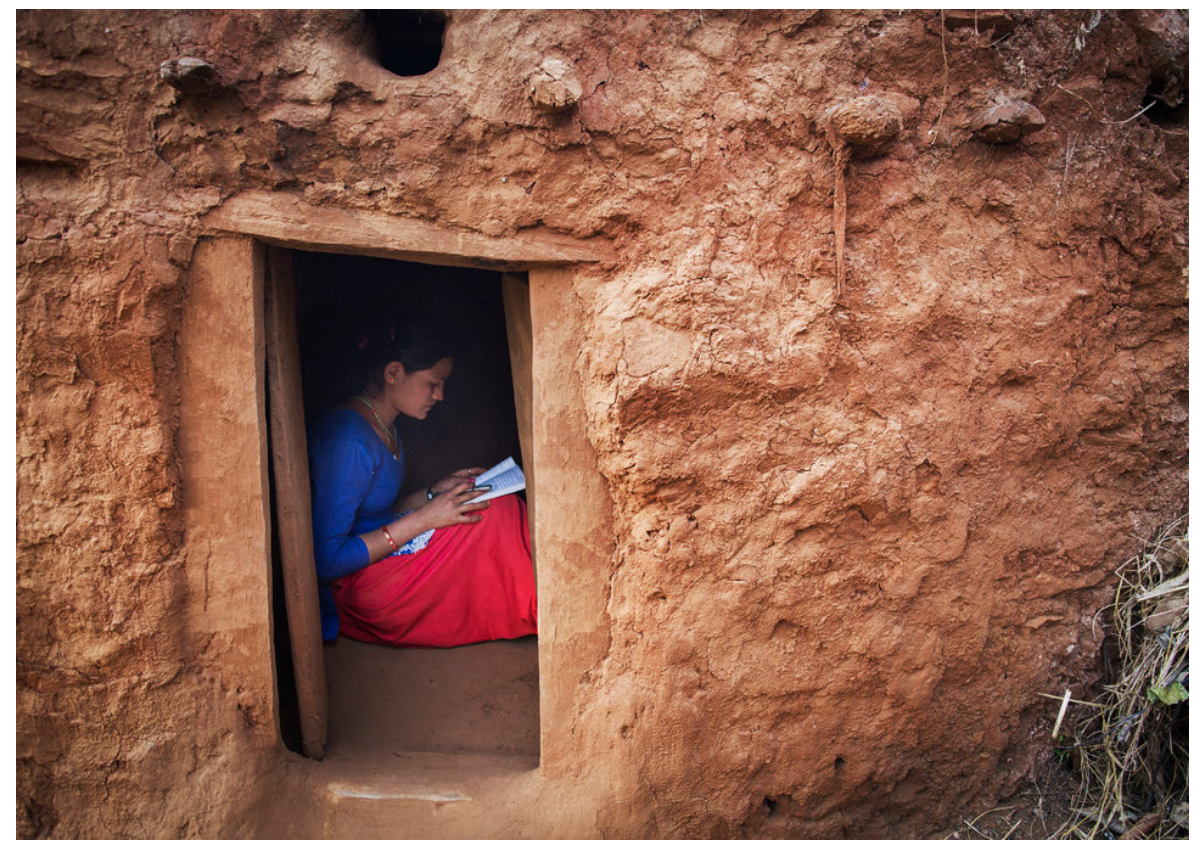

Figure 6.14: A 17-Year-Old Nepali Woman Banished to a Chaupadi Hut during Menstruation 2018 


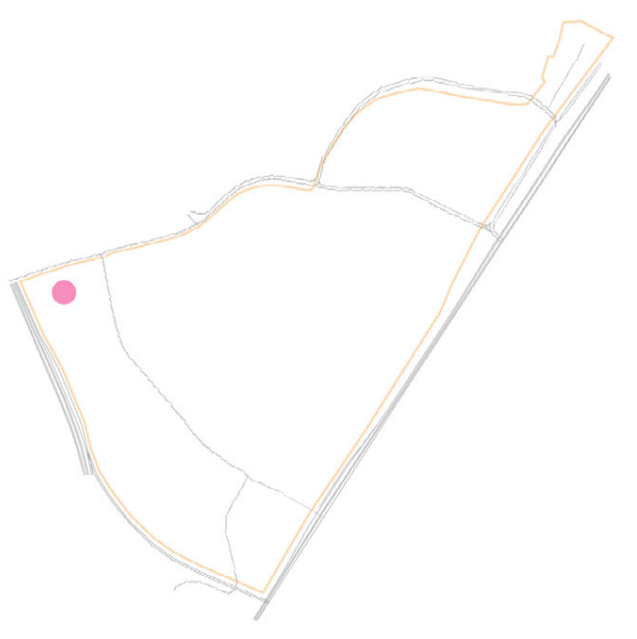

\section{[Water and Religion]}

Section through the bathing and personal hygiene spaces

Time: In May, during the religious fasting month of Ramadan when menstruating women are disallowed from prayers Location: Moiniya Jama Masjid

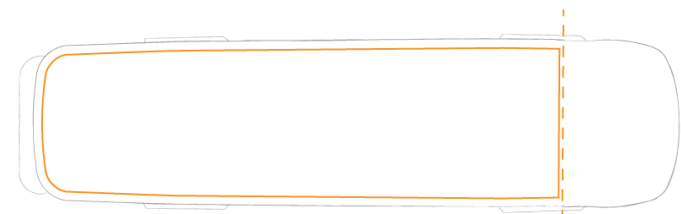



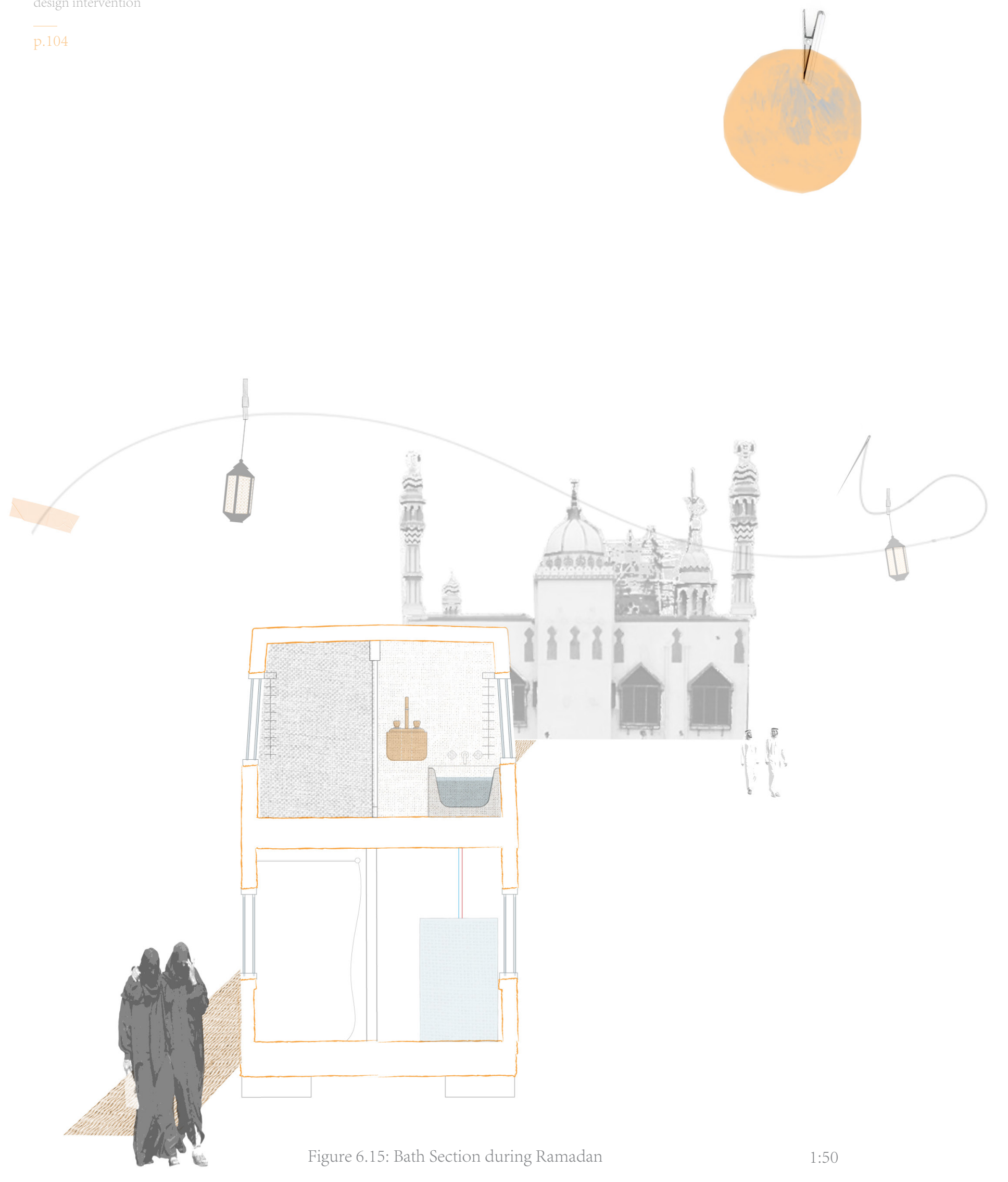


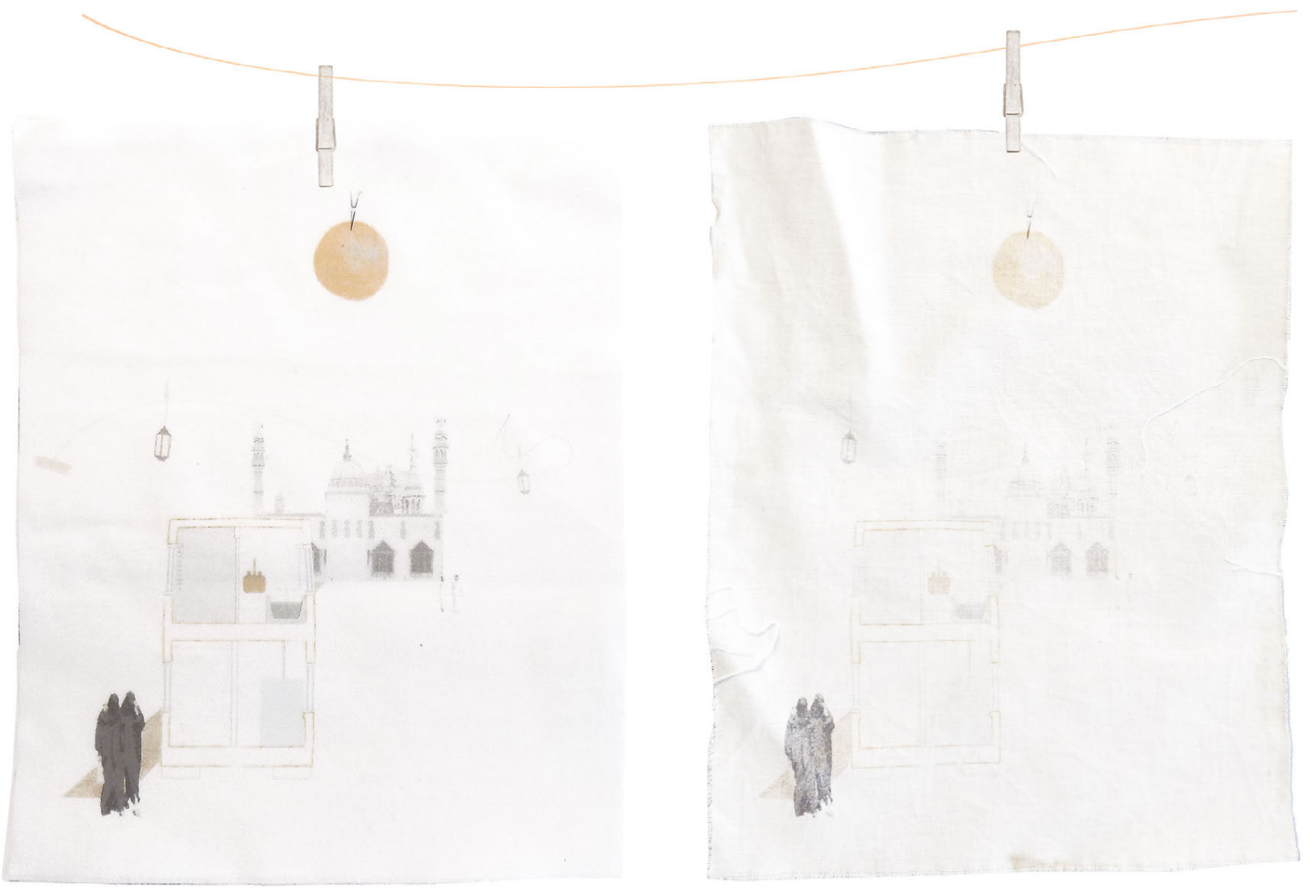

Figure 6.16: Bath Section Printed on Fabric and Hand-Washed Medium: Substrate Printed on Cotton 


\section{Ventilation and Lighting}

The double decker is non-air-conditioned, thus majority of the fresh air would come from cross ventilation and open windows. However, there is a level of privacy that needs to be maintained for the safety of the participants, so hanging fabric can help obstruct the view from the outside and provide shading.

The lower level would primarily use cross ventilation from the windows for central air. The upper level, which has more sensitive spaces like laundry and drying, would also use cross ventilation but there is the issue of visibility. The hanging fabric would most likely need to be partially closed to limit visibility into the spaces, and hopefully, the elevated height would deter pedestrian view. However, in case the fabric limits some natural air flow, the bus could install low profile rotary van ventilators for additional circulation. The rotary vent is a cost-effective solution with a minimally invasive installation--a small $130 \mathrm{~mm}$ hole for the vent and a suitable adhesive to seal in place. ${ }^{139}$ The system is windoperated and extracts stale air while the bus is in motion. ${ }^{140}$

In addition to natural lighting, there needs to be LED interior lighting, so the bus can operate even after sunset; this is an important consideration when the sun sets at 4:16 pm in Mumbai during the winter 
solstice. ${ }^{141}$ There would be a combination of panel LEDs in the corridors, and individual LEDs to direct light onto the workspaces. 


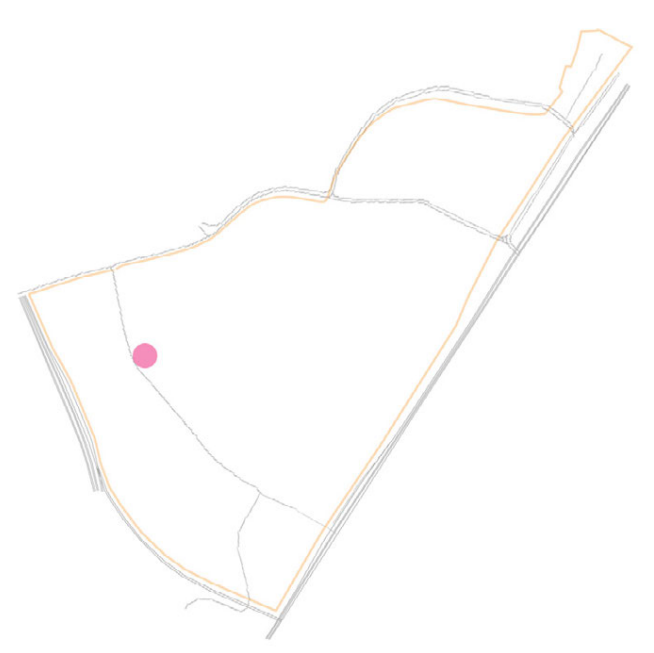

\section{[Drying]}

Section through the menstrual cloth drying room

Time: In March, during the Hindu Spring Festival Holi; a celebration of colour, followed by washing and laundry

Location: Intersection between 60 Feet Road and the narrower, pedestrian street Bhatiya Nagar Dharavi Road, where residences are congested and stacked upon one another and difficult for drying

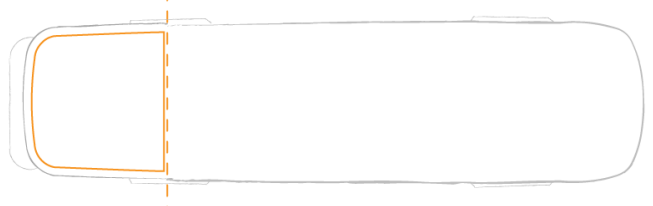



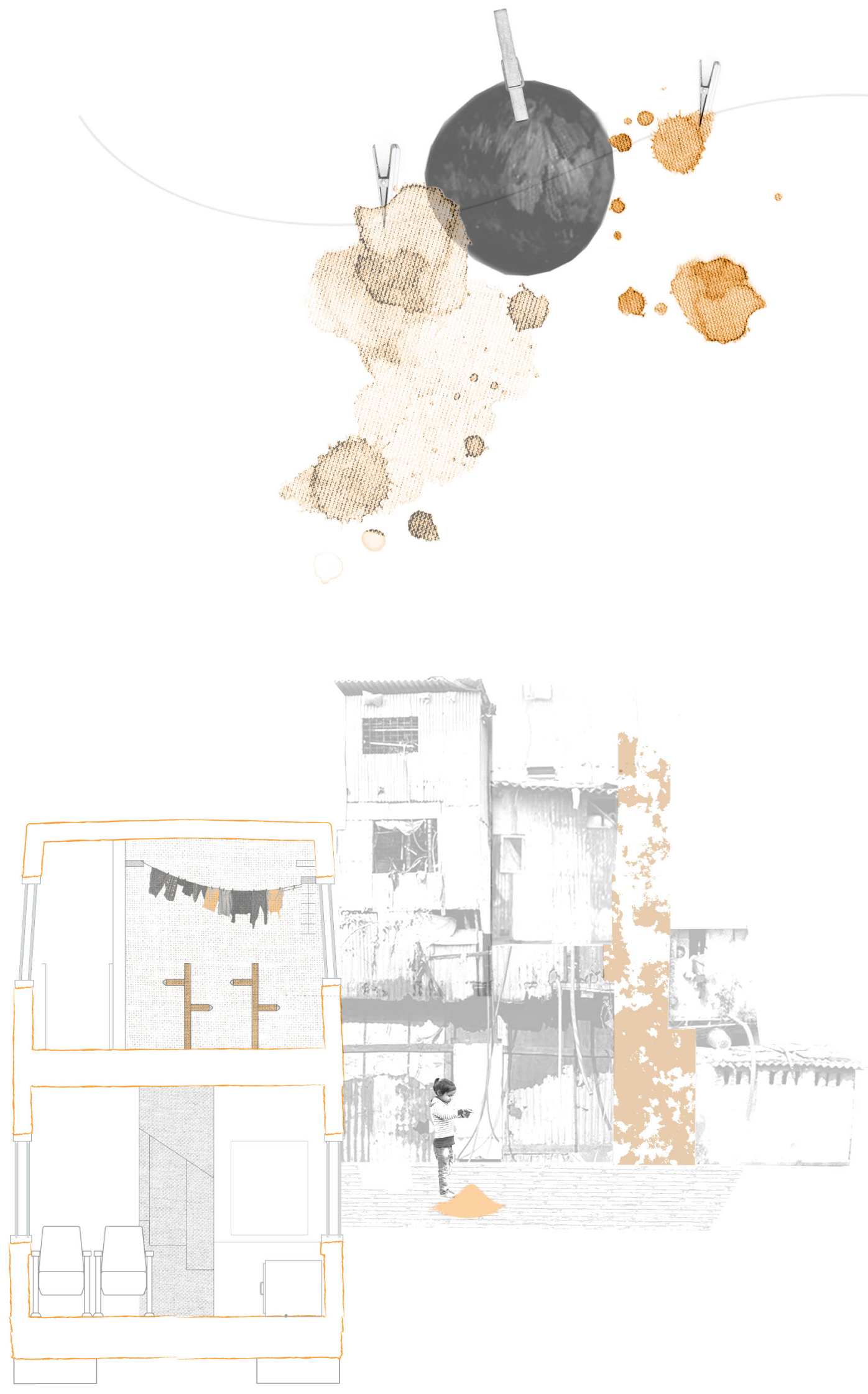

Figure 6.17: Drying Section during Holi 


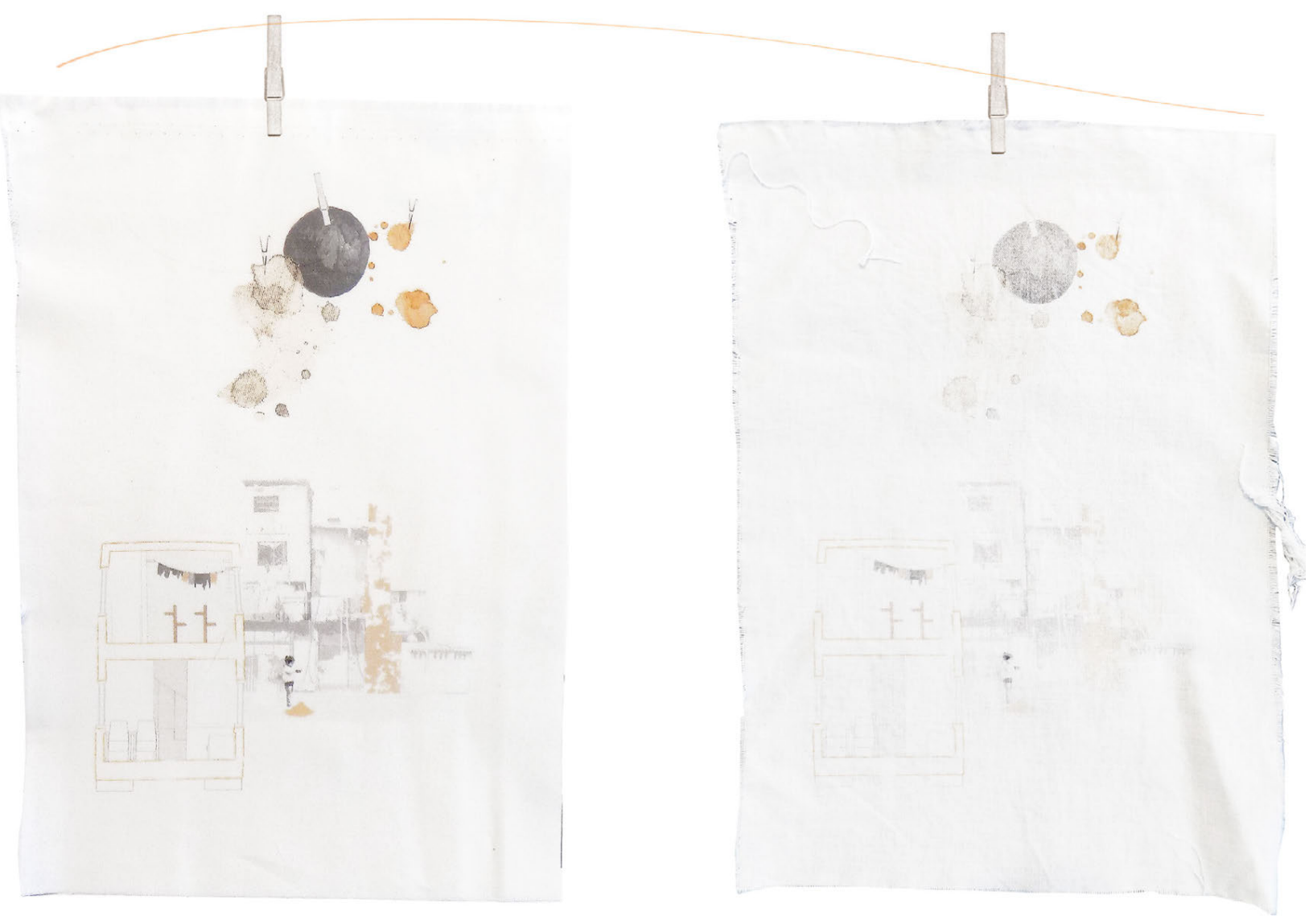

Figure 6.18: Drying Section Printed on Fabric and Hand-Washed Medium: Substrate Printed on Cotton 
design intervention

P.111

"Historically, particularly during

the period of British colonization,

the different worlds--whether

economic, social or cultural--that

were contained within these cities

occupied different spaces and

operated under different rules, the

aim being to maximize control

and minimize conflict between

opposing worlds. Today although

these worlds have come to share

the same space, they understand

and use it differently"

\section{Open Source Design: Kinetic City}

The project's open source design, whereby women can offer feedback and participate in the design of the multiple buses, could be considered a form of dynamic design, which is a way of life for Mumbai residents. Rahul Mehrotra's “Negotiating the Static and Kinetic Cities: The Emergent Urbanism of Mumbai," is a good framework to understand dynamic design and its integration into the city. Mehrotra identifies two separate systems, the static and kinetic, which occupy different social spaces within Indian cities. ${ }^{142}$

The static city is the more conventional, permanent architecture that is often found in maps. Then, there are the "everyday spaces" that "have been largely excluded from the cultural discourses on globalization." ${ }^{143}$ This is known as the kinetic city, which is often built from recycled materials and has a malleable quality as "patterns of occupation determine its form and perception.” ${ }^{144}$

According to Mehrotra, kinetic spaces and its architecture cannot be synonymous or contain a singular meaning. He writes that

"within the Kinetic City, meanings are not stable; spaces get consumed, reinterpreted, and recycled. The Kinetic City recycles the Static City to

142 Mehrotra 2008: 206

143 Mehrotra 2008: 206

144 Mehrotra 2008: 206 


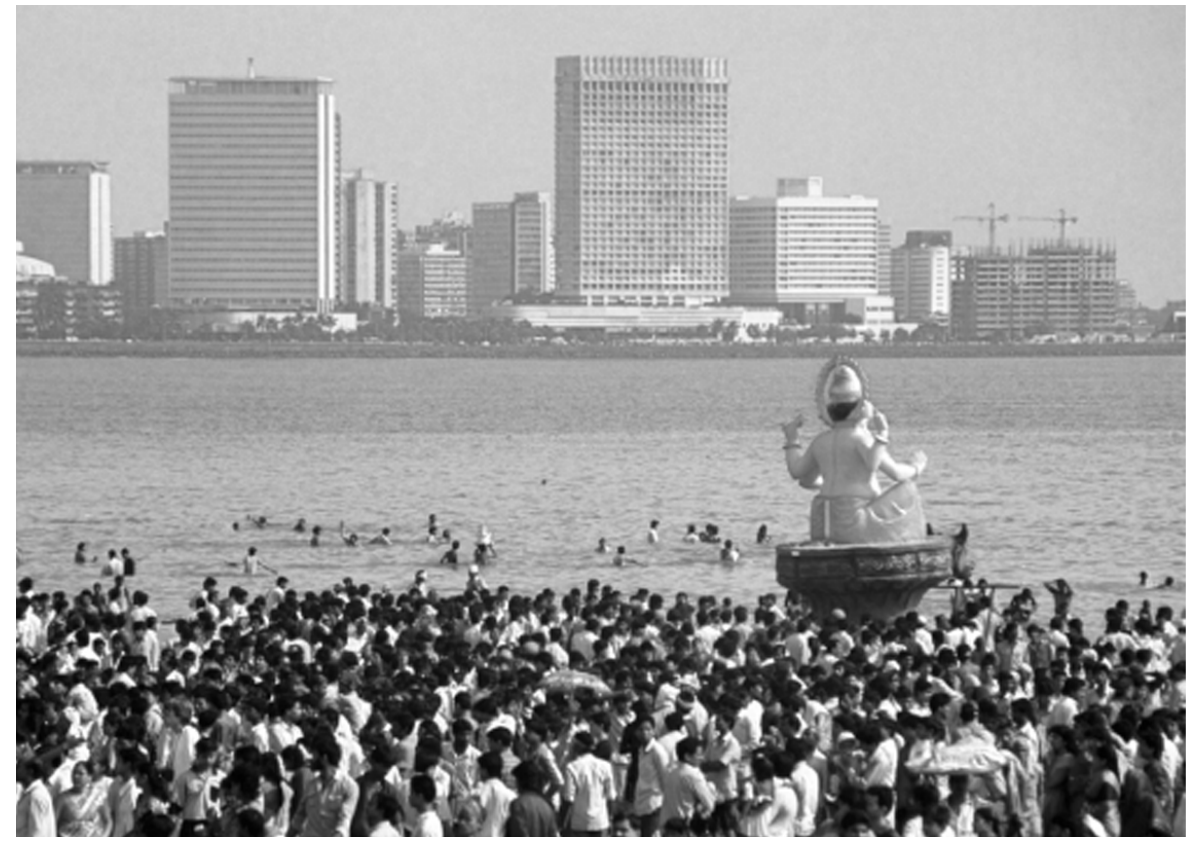


design intervention

P.113

create a new spectacle." 145

Through Mehrotra's reading, using open source, dynamic design seems like an appropriate technique because it captures the spirit of Mumbai and its residents. In the text, Mehrotra writes how every Independence Day, the Public Works Department builds a bamboo and

The Kinetic City is perceived not as architecture, but in terms

of spaces which hold associative values and support lives. Patterns of occupation determine its form and perception." cloth structure off the town hall to protect the crowd from monsoon rains. ${ }^{146}$ At the moment where the town hall and its extension meet is where, "the intended image of this symbol of colonial power, a celebrated asset of the Static City, is subverted and recolonized by the Kinetic City.” ${ }^{147}$ The subversion of one symbol through conversion is the similar intent behind the representation process of translating the sections into cloth and then further abstracted through washing. The process is re-interpreting the static, and often privileged, architectural drawings into a dynamic, additive form of representation.

Further, the idea of dynamism is reflective in the project's program and design. The bus, a recognizable symbol, is assigned a different meaning by re-interpreting its spatial function. Even the program serves multiple meanings; the washing pods can be a laundry facility and simultaneously a space for menstrual hygiene, or the workshop as a sewing studio as well as for sanitary napkin repair.

The following sections look at the logistical considerations to support an open-source design initiative for this project in Dharavi.

145 Mehrotra 2008: 208

146 Mehrotra 2008: 209

147 Mehrotra 2008: 209 

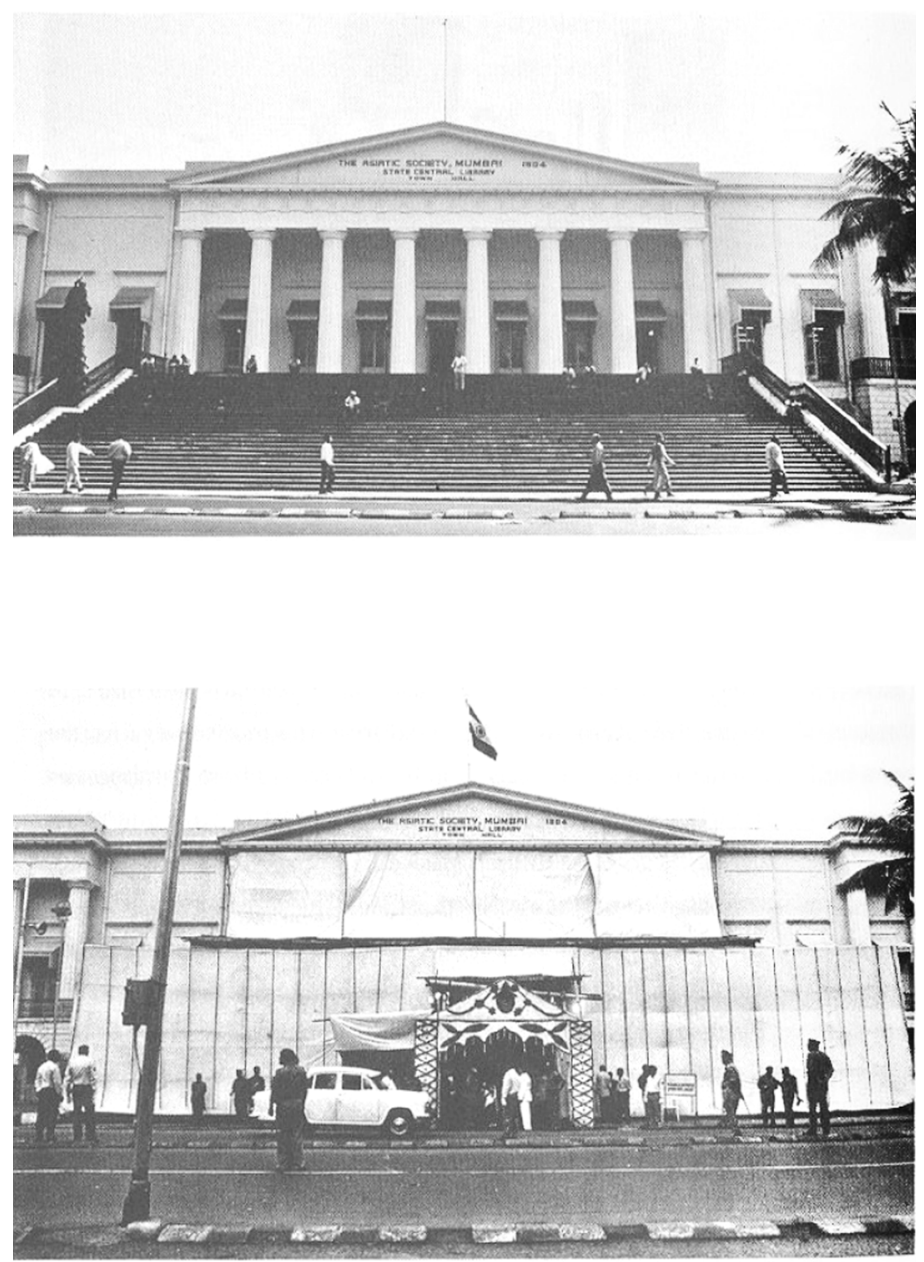

Figure 6.20: Town Hall of Mumbai transformed of Independence Day 
design intervention

P.115

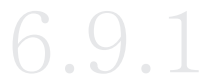

Storage and Modification

The bus will require a garage space for storage, repair, and modification. A possible solution could be ambulance garages because the project could partner with local hospitals to improve medical-patient relations and visitation. There are a few ambulance stations near Dharavi but the Mumbai Health Care Ambulance Services would be the initial point of contact for its proximity and larger building size. The garage is approximately $2.5 \mathrm{~km}$ away from the Dharavi bus depot, which is the first stop on the bus route. The Salvation Ambulance Mumbai and Ekvira Mauli Ambulance Services are other locations that could be consulted via the hospital staff or NGOs.

Prior to use, the decommissioned bus could be repaired and modified at the ambulance garage. Once in operation, the bus could park in the ambulance garage overnight. 

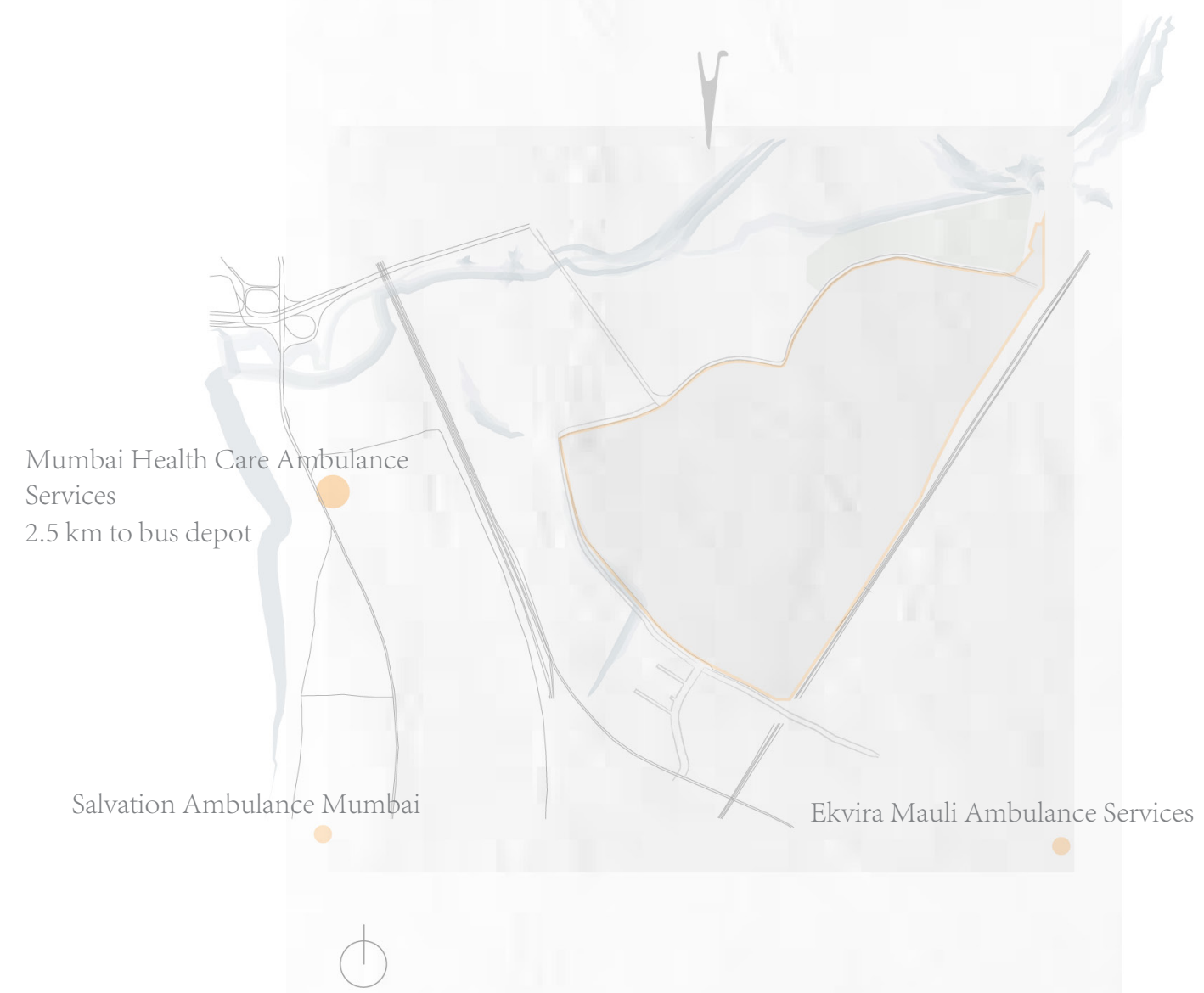

Figure 6.21: Ambulance Service Stations Near Dharavi 


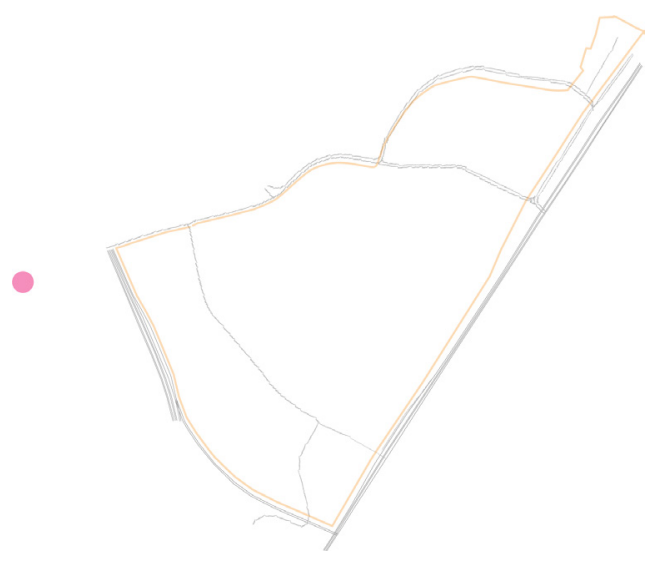

\section{[Storage]}

Longitudinal Section to show added program

Time: At night, after hours of operation

Location: Mumbai Health Care

Ambulance Services where the bus is stored and modified

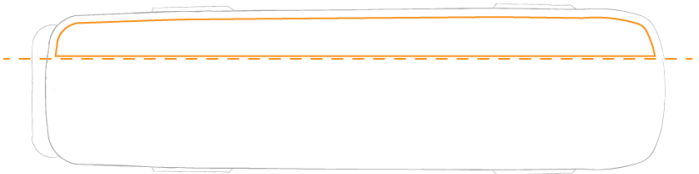



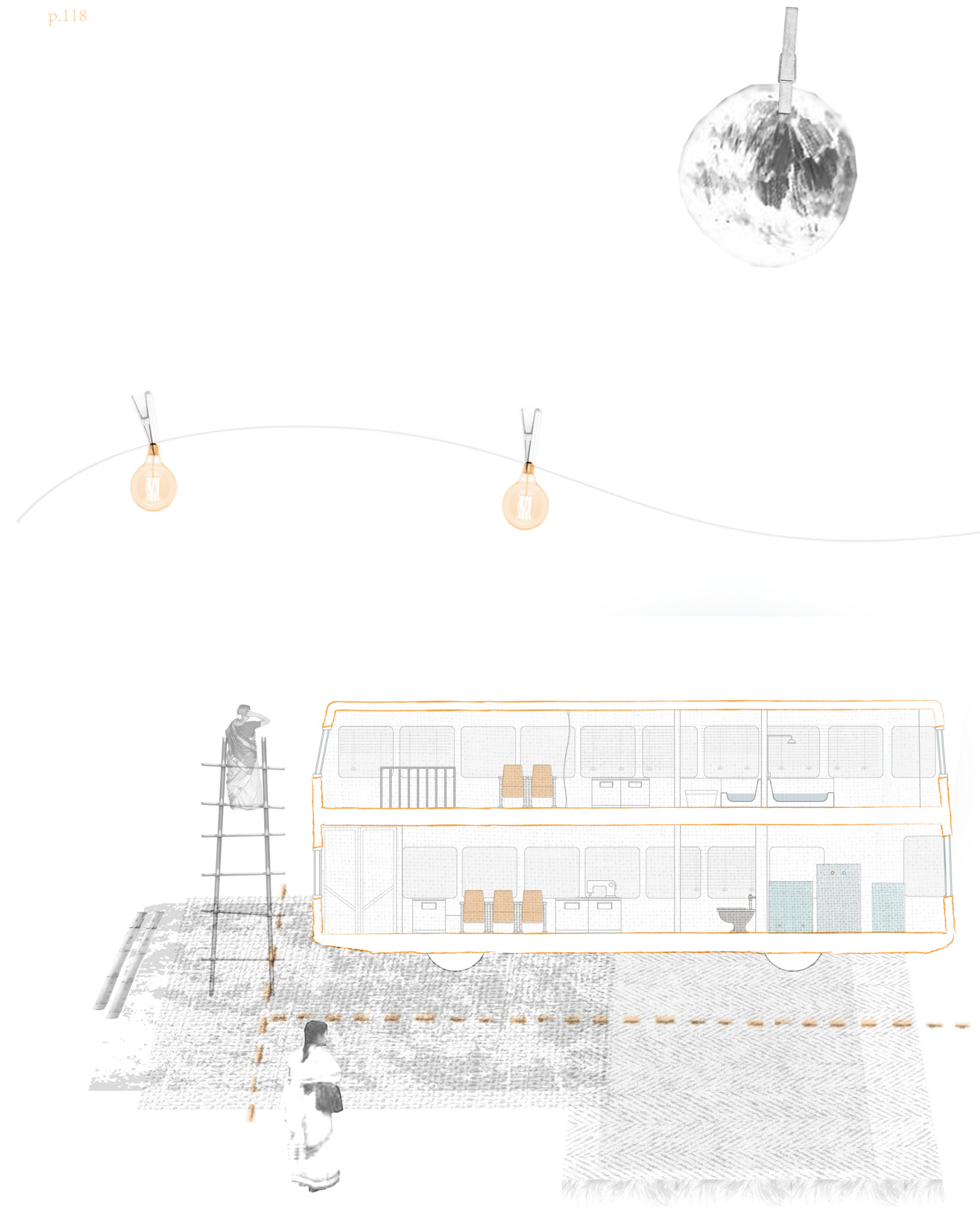

Figure 6.22: Longitudinal Section at Storage Garage 


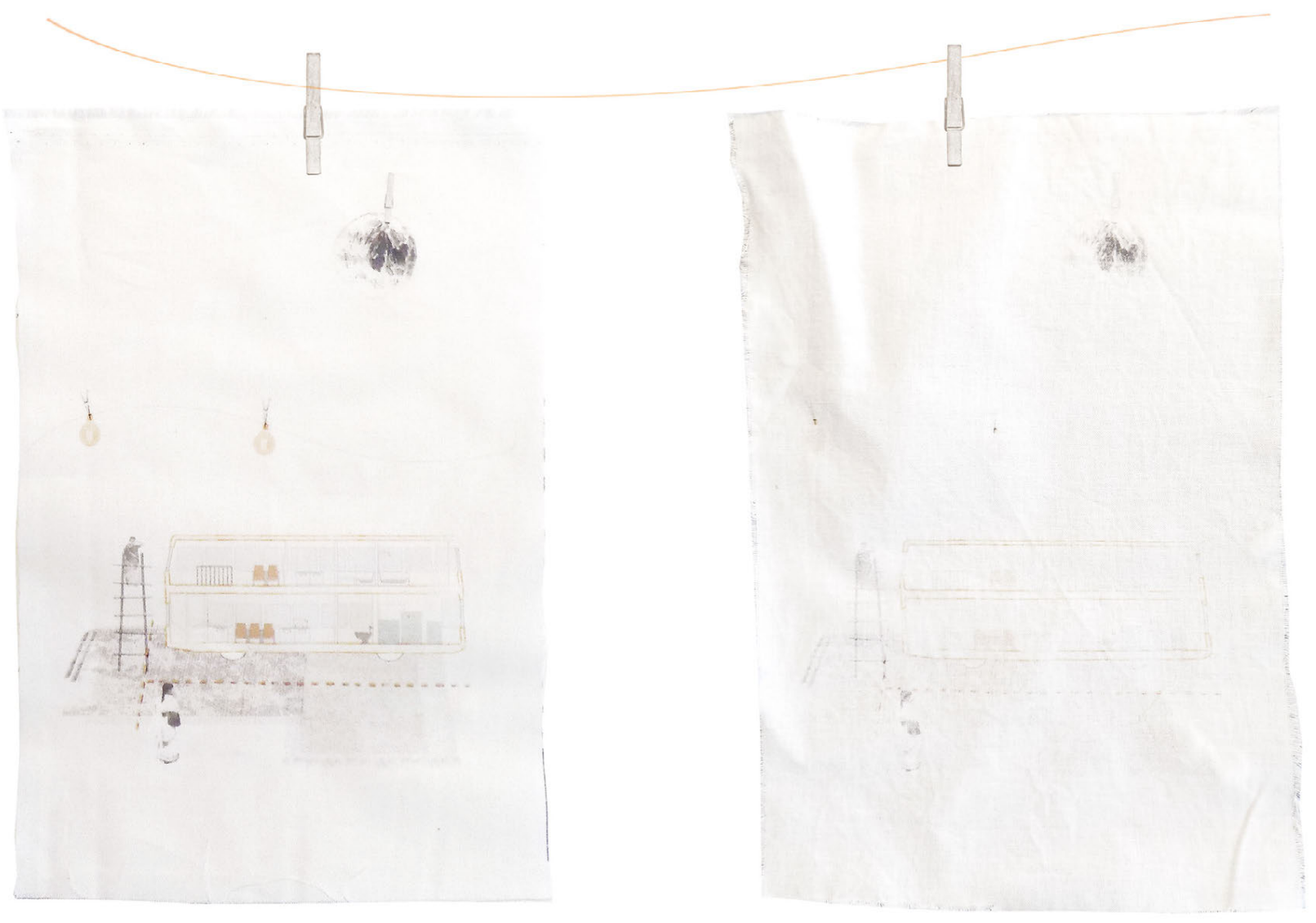

Figure 6.23: Section at Storage Printed on Fabric and Hand-Washed Medium: Substrate Printed on Cotton 


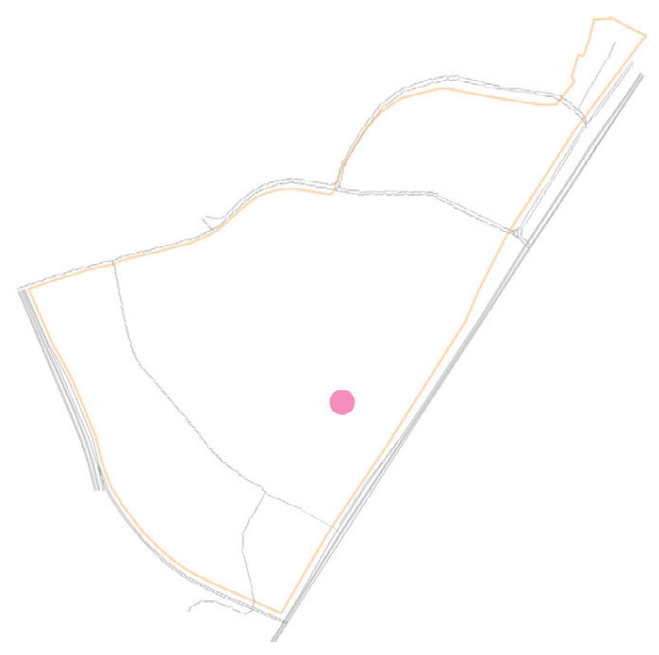

\section{[Health Care]}

Section through the private consultation room and storage space for feminine hygiene products

Time: Early morning when men are bathing before work. However, the water supply could possibly be contaminated by nearby waste pipes, thereby further exacerbating health concerns

Location: Near Sai Hospital

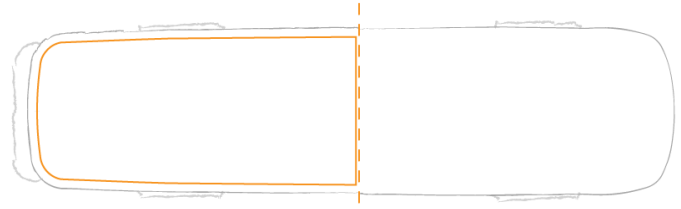



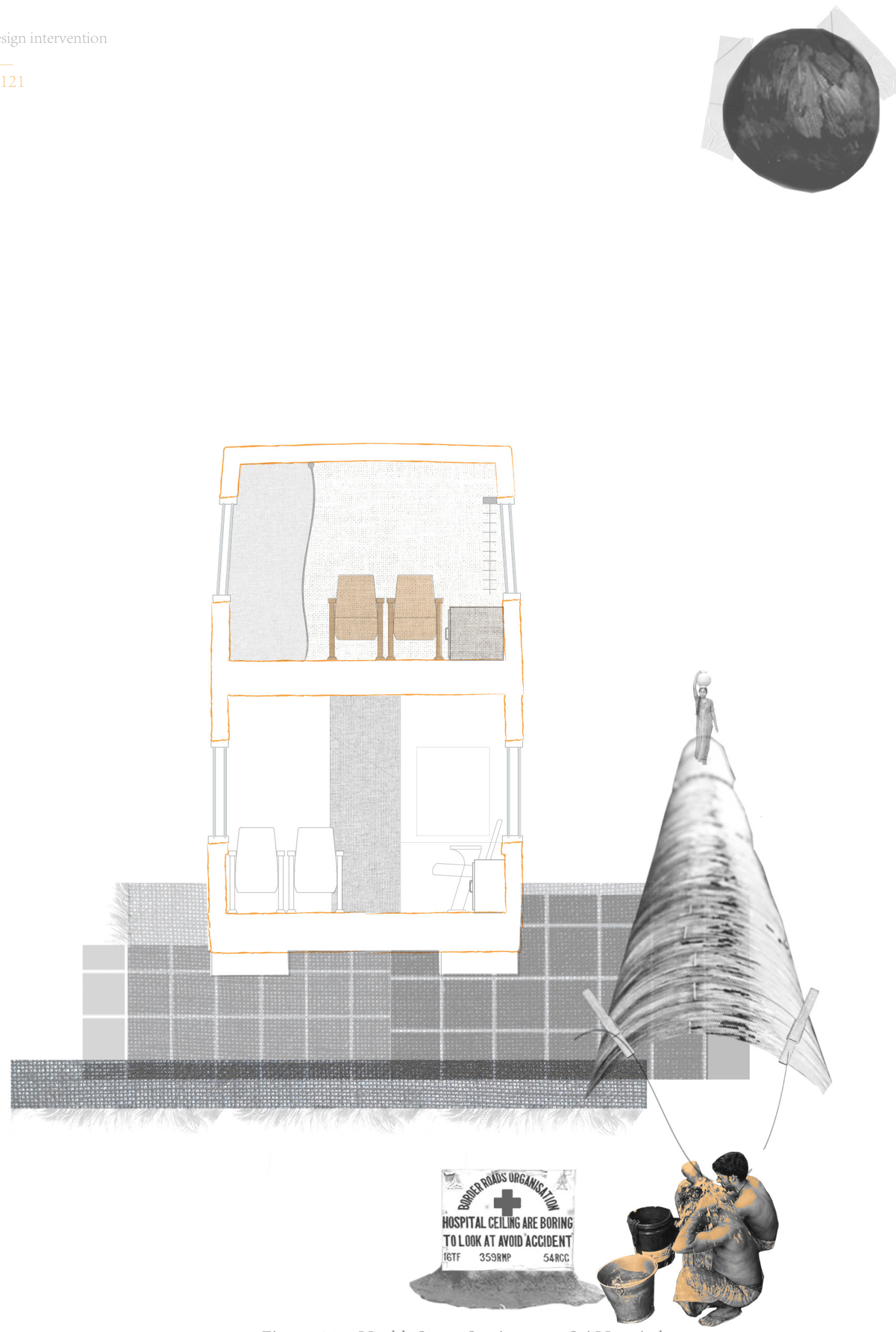

Figure 6.24: Health Space Section near Sai Hospital 


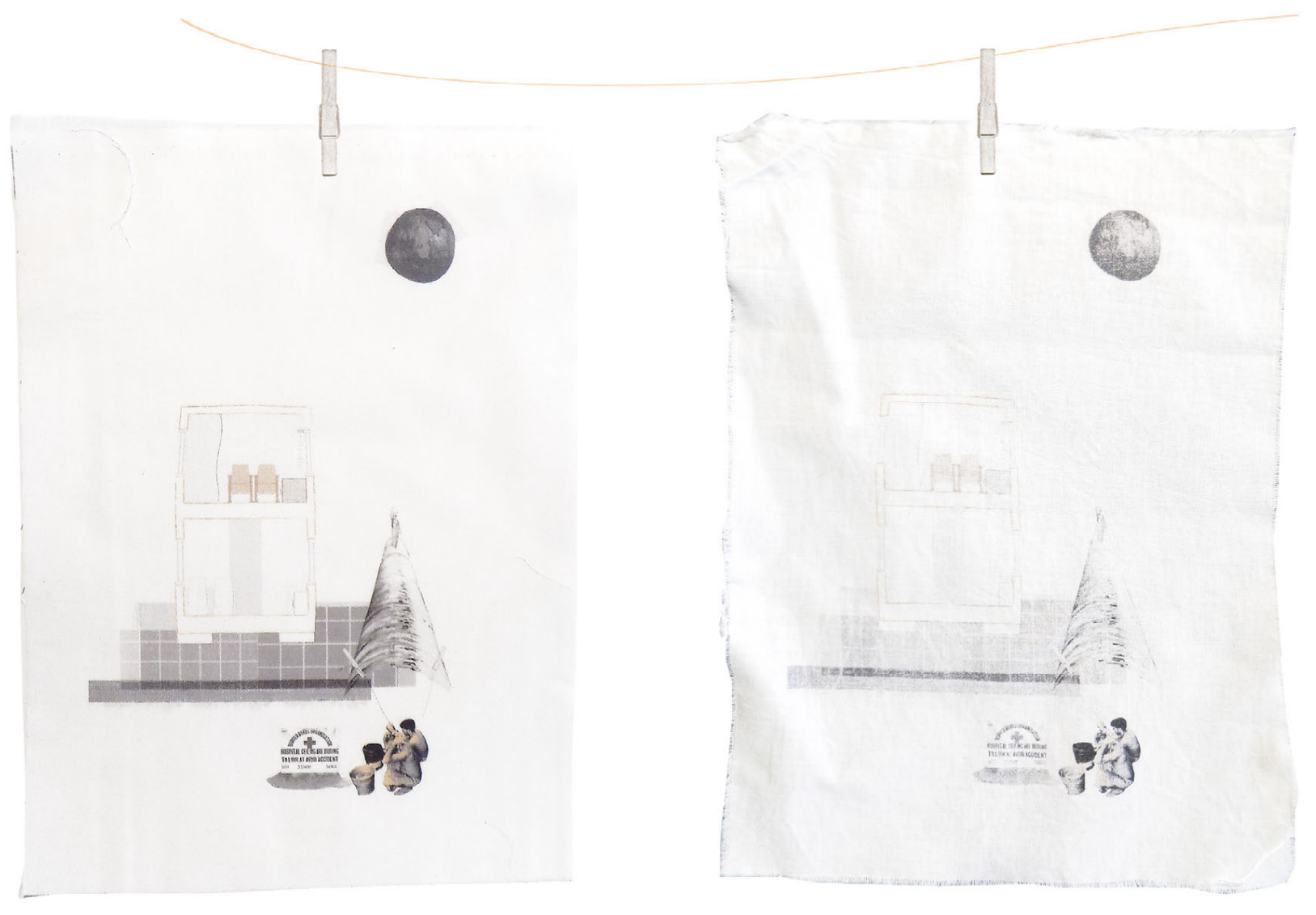

Figure 6.25: Health Space Section Printed on Fabric and Hand-Washed Medium: Substrate Printed on Cotton 
In order to achieve a sustainable project, the bus will need to source local materials for construction. Fortunately, Dharavi boasts a rich collection of industries and artisans that can sustain the bus.

On Tulsi Pipe Road, near Mahim Station, there is a group of bamboo basket weavers. ${ }^{148}$ Perhaps, the bus could employ the bamboo workers to weave the partition walls in the project, as a way to harness local material and provide an added economic return to the local community. Additionally, the level of weave could correlate to the level of privacy needed for each program. ${ }^{149}$

Furthermore, Dharavi has a substantial recycling industry and so, the project could benefit from re-using scrap material like plastic and glass, which are sorted on a daily basis.

Plastic is one of the most commonly sorted materials in the recycling industry. As such, plastic can be an integral source for many building materials like lumber and tiles. Plastic lumber could be an alternative construction material to steel I-beams, as they are lighter,

148 Raw bamboo costs approximately $\$ 1.88 /$ stick and is a renewable resource that also supports a largely female-dominant industry (Fernando 2014).

149 Many of the workers are women and they tend to sell their baskets for approximately $\$ 0.50$ each (Fernando 2014). So, although the partition walls are larger and require more material, they could also be sold at a higher cost than the baskets. This would also allow the female weavers to work in public and not disrupt their regular routine. 
which is easier to assemble and transport. ${ }^{150}$ Low-density plastic can also be transformed into tiles, at a lower cost, and are waterproof and thermally resistant. ${ }^{151}$

For recycled glass, there is an economic recycling process that fuses together different glass composites, using a bio-resin binder, into glass tiles. ${ }^{152}$ The process does not expend a lot of manual labour and circumvents the high-energy process of melting glass. ${ }^{153}$ The tiles could be a suitable building material for floors and backsplashes within the bus for easy cleaning and maintenance.

150 Dey 2018: 71

151 The plastic is shredded, washed, melted and then compressed into the tile mold. The product is best-suited as wall tiles, which would work for the bathing and toilet envelope (Dey 2018: 74).

152 Dey 2018: 89

153 Dey 2018: 89 
Tulsi Pipe Road (Bamboo Basket Weavers)

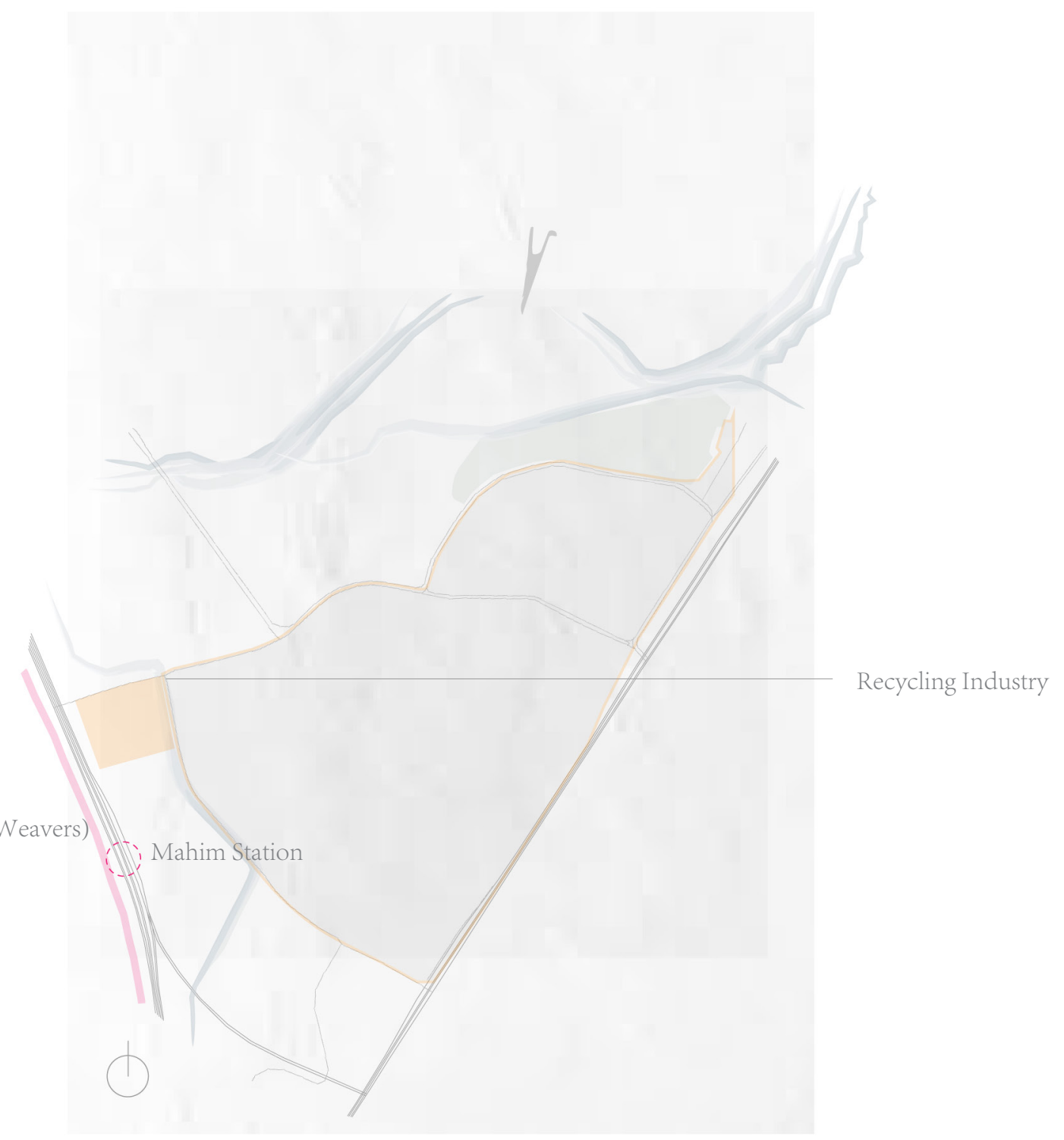

Figure 6.26: Bus Material Locations in Dharavi 


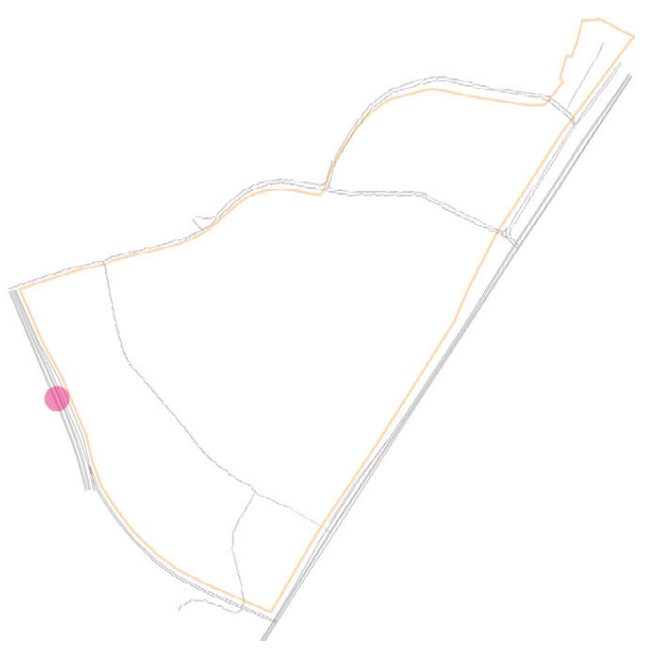

[Open-Source Design]

Section that shows the locally crafted facade that conceals the private program

Time: The Hindu holiday, Diwali, during October when home-based craft work surges

Location: Past the bamboo basket weavers near Mahim Station

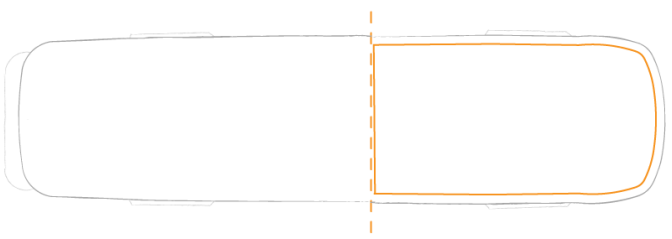




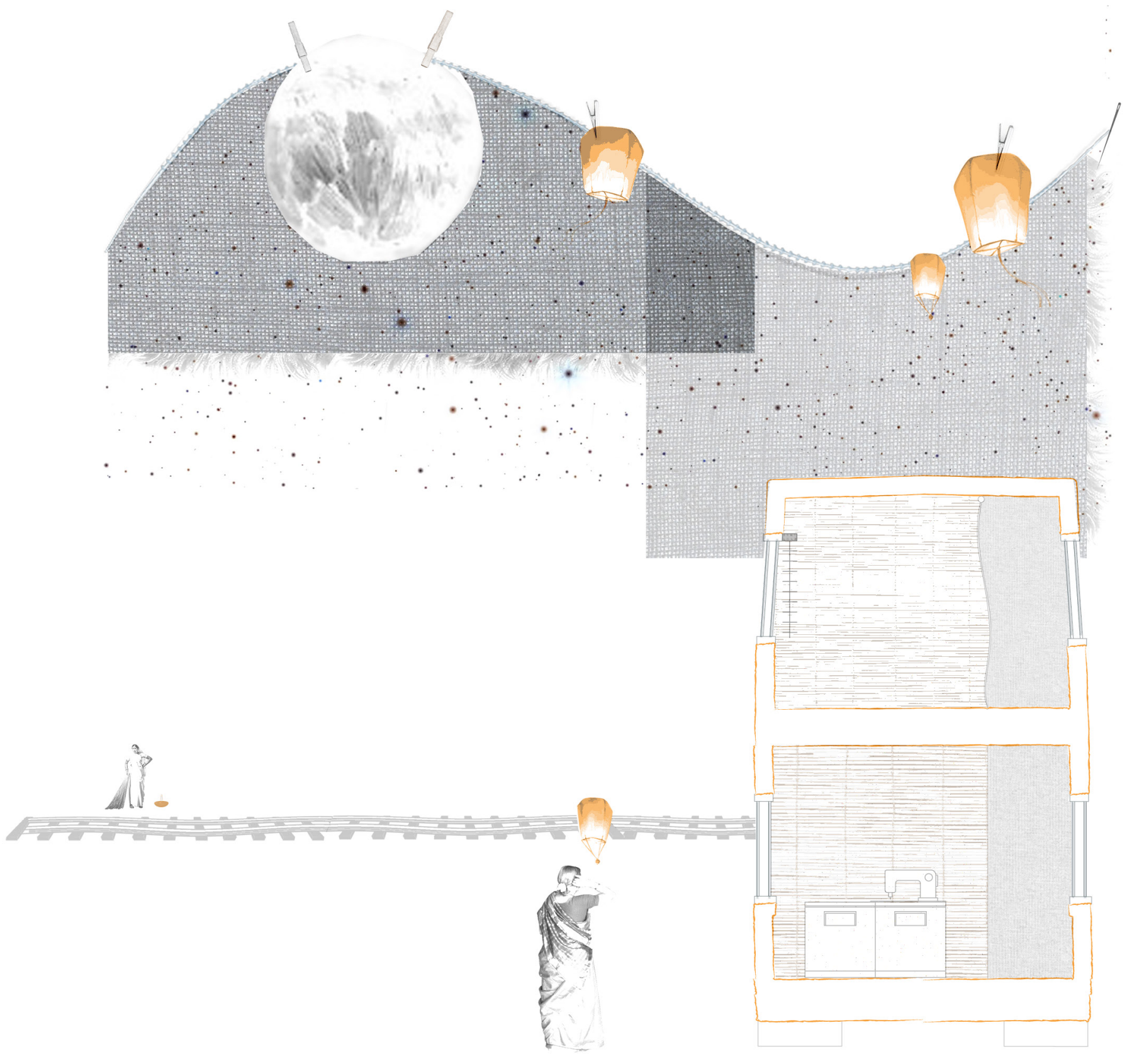




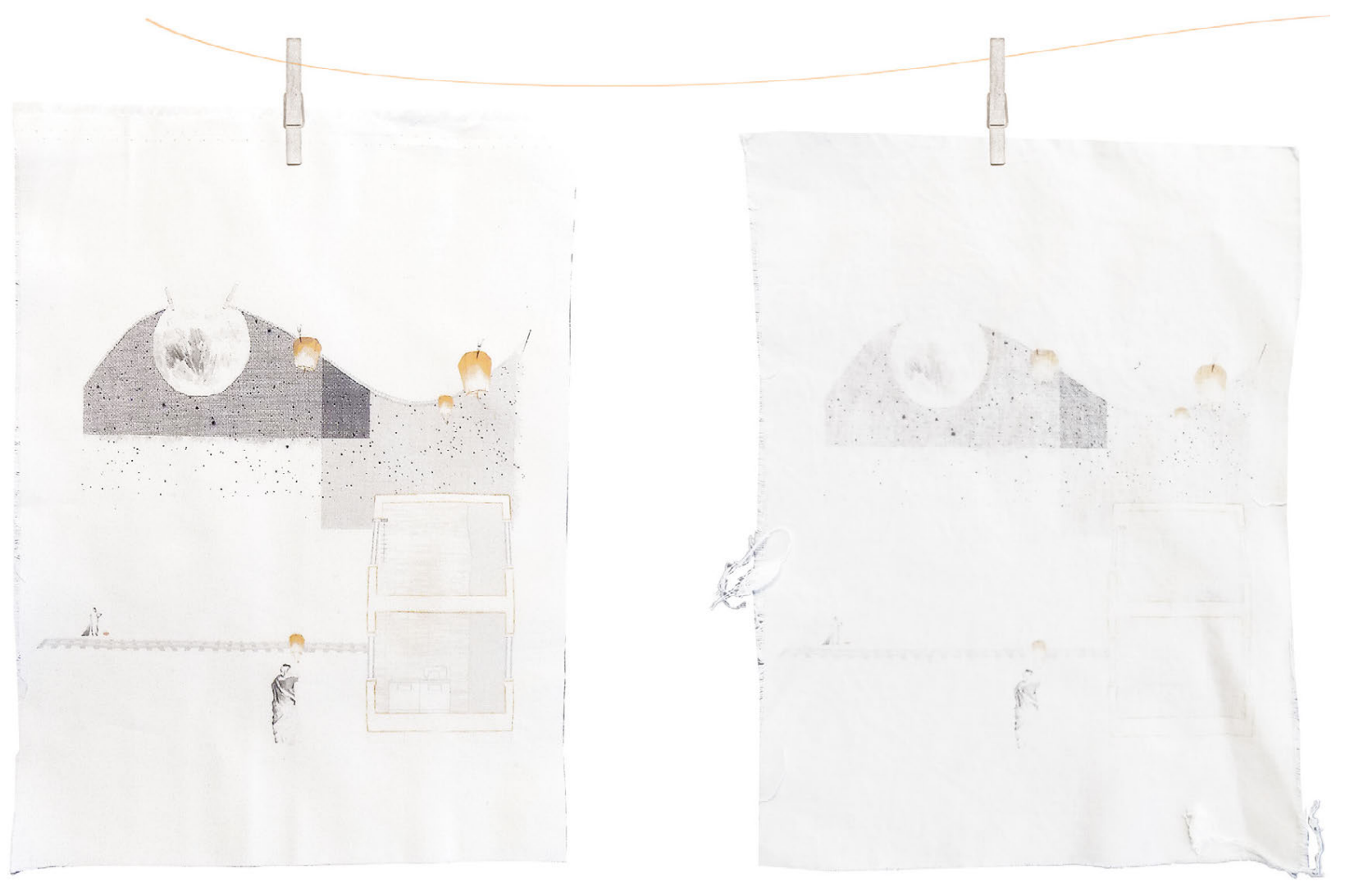

Figure 6.28: Material Wall Section Printed on Fabric and Hand-Washed Medium: Substrate Printed on Cotton 


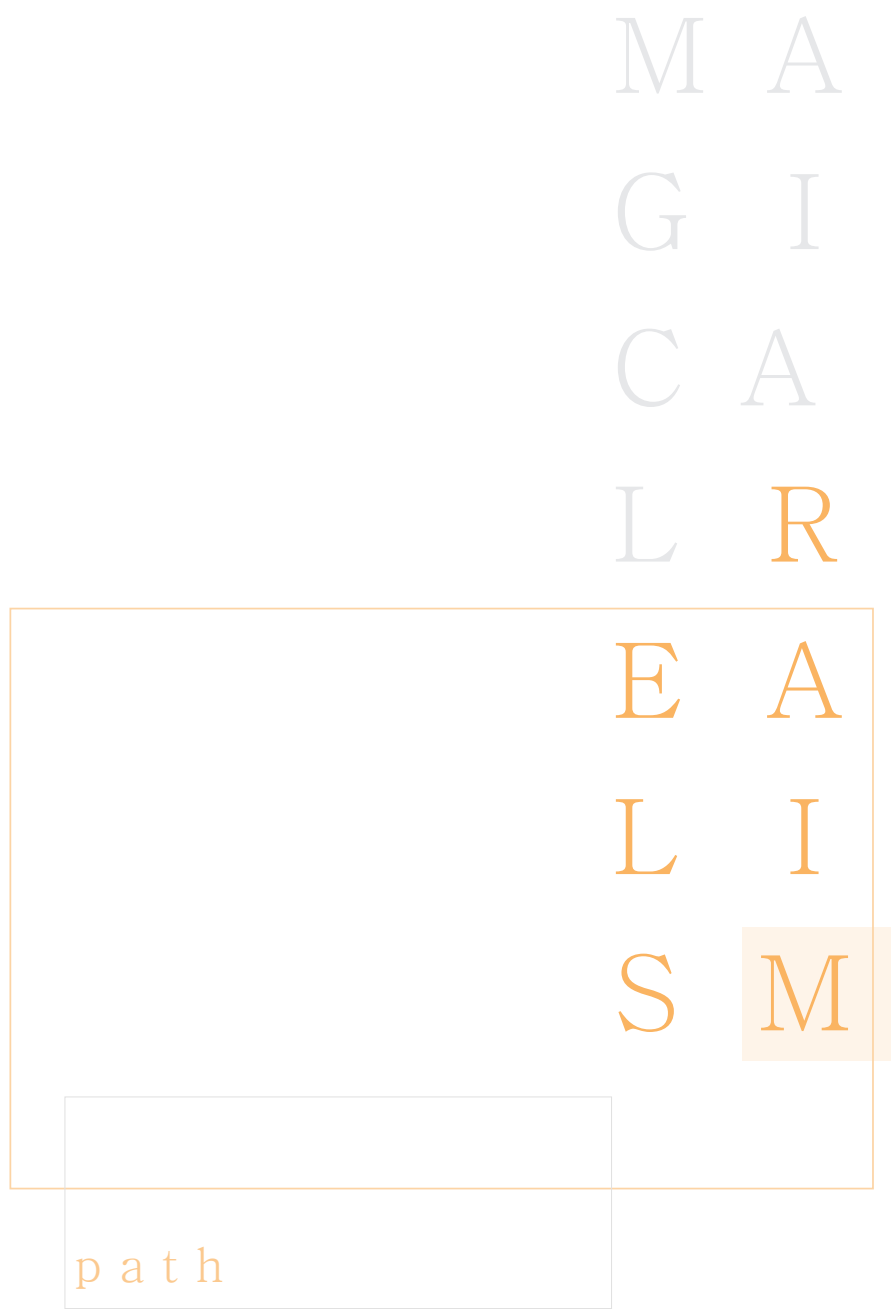




\section{Appropriating the Street}

In Dharavi, the sense of community is strengthened by that fact that most people live part of their lives around their doorways or by the streets and alleys. As previously discussed, many residents in Dharavi appropriate the narrow streets since the dwellings tend to be too small to house all the domestic, commercial or production needs. What emerges is a public space devoted to the community and a primary source of contact for news, information, and socialization.

Women, especially, partake in the street socialization, as they prefer walking to public transportation due to safety concerns. ${ }^{154}$ The intent behind proposing a mobile design is to engage with the women at the street level as a point of outreach. ${ }^{155}$ By moving through the site, the bus is more visible and accessible to women sitting or working just outside their homes. Further, the bus can be an alternative mode of transportation that women can access, and deter men from tracking their movement, which is a concern with the current toilet blocks.

154 Meleis et al. 2011: 88

155 Studies show that higher engagement at the street level reduces crime rates, as there are more eyes for surveillance and creating a sense of security (Meleis et al. 2011:88). 


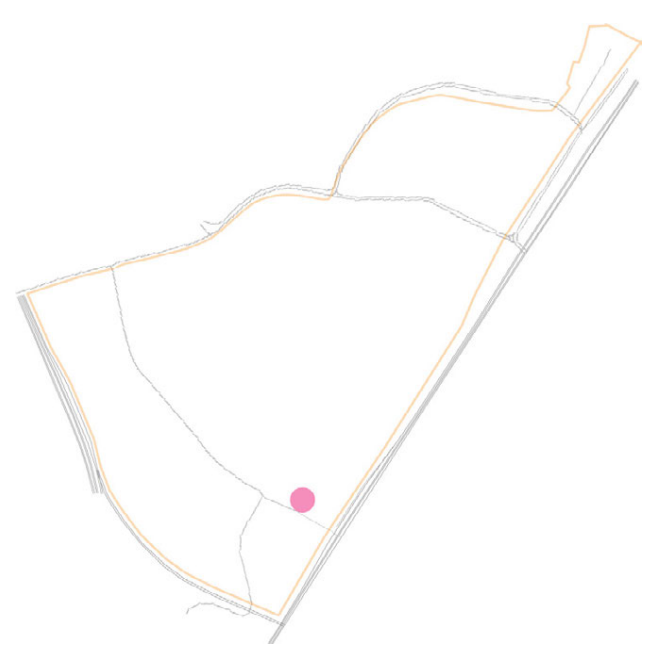

[Industry]

Section through the sewing workshop

Time: Mid-day office hours when men are typically at work

Location: Kumbharwada, pottery market and workshops

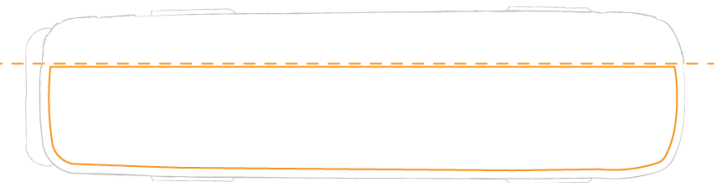


design intervention
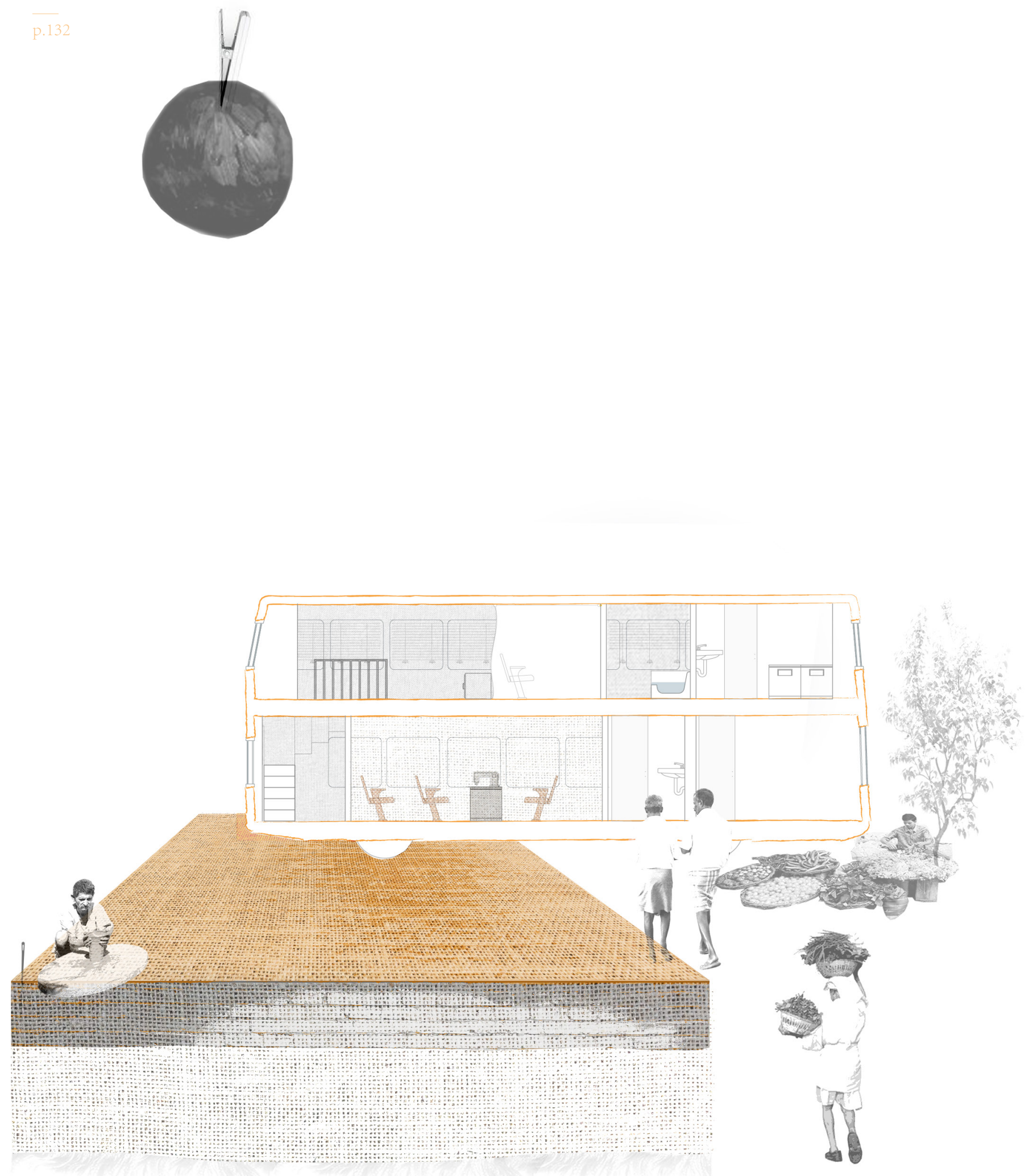

Figure 6.29: Sewing Workspace Section at Dharavi Market 


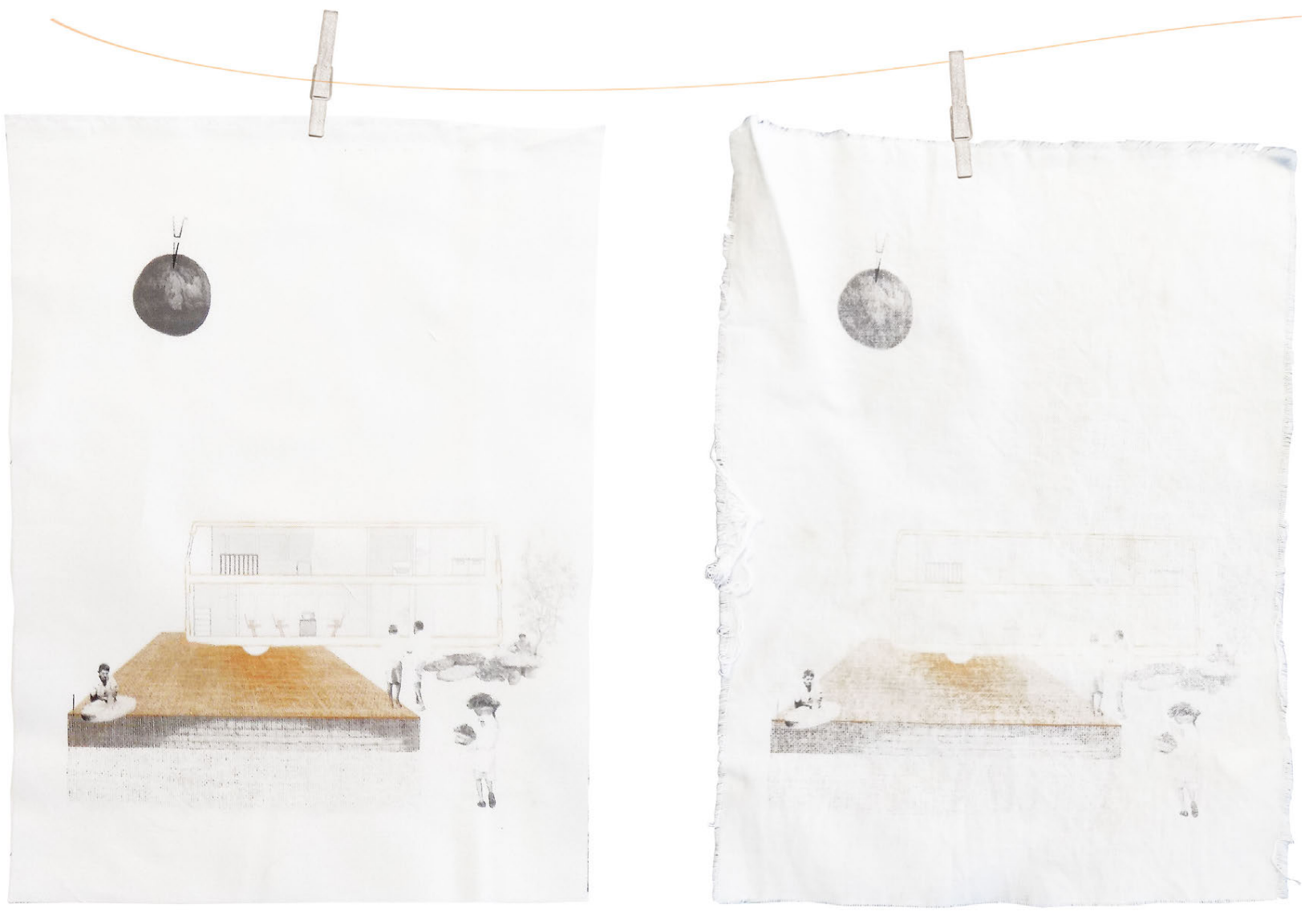

Figure 6.30: Sewing Workspace Section Printed on Fabric and Hand-Washed Medium: Substrate Printed on Cotton 
One bus may follow the subsequent timeline:

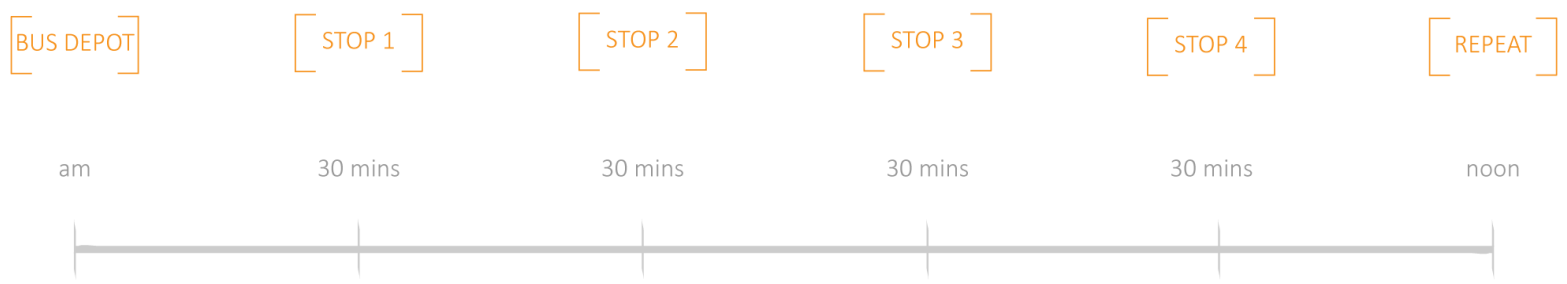

The project supposes there would be multiple buses deployed, so the route timings may differ depending on the bus. The route would largely remain the same--with room for minor variations--because the bus is restricted to only the vehicular roads.

Since Dharavi is a relatively small site, the bus would likely repeat the route multiple times within a day. ${ }^{156}$

The main bus stops were determined after plotting four key elements, hospitals and nursing homes, schools, public space, and bus stops. A master map of all the key elements layered upon one another helped determine the location of the bus stops. Each stop would also have a hospital affiliate in close proximity where a medical personnel could be available for consultations on the bus.

156 The route is marked by the major arterial roads on site; the 60 Feet Road and 90 Feet Road. 


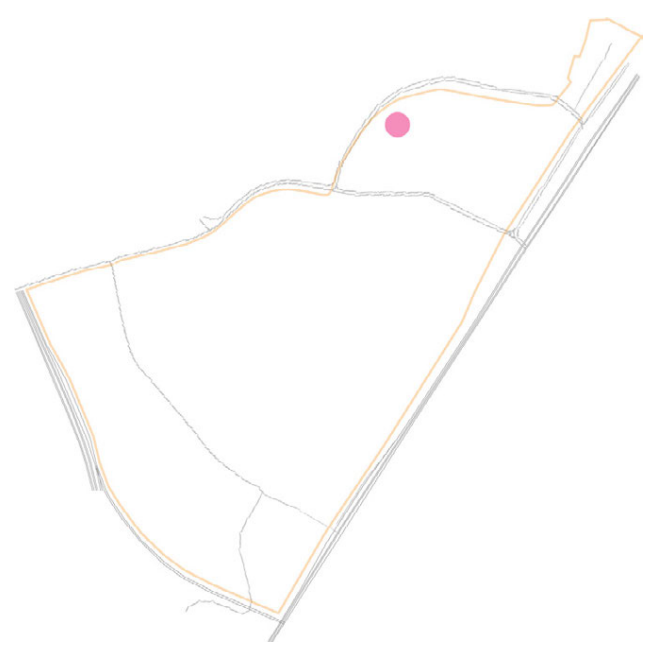

\section{[Starting Point]}

Section through bus entrance and driver's seat

Time: Early morning, during hours of operation

Location: Bus Depot

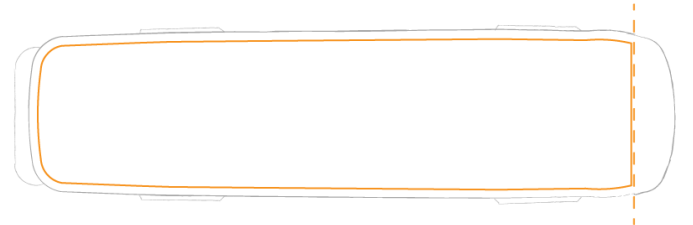



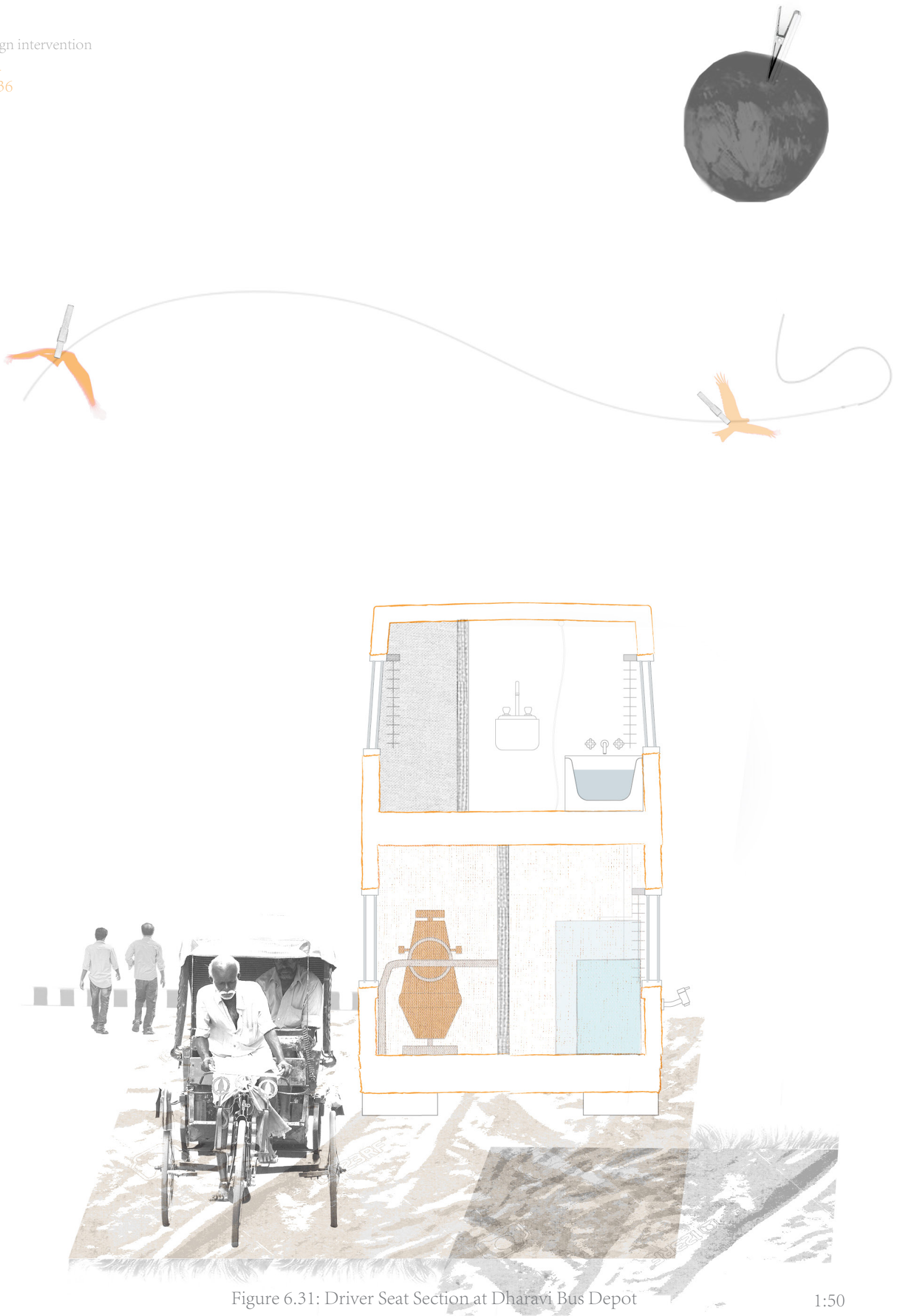


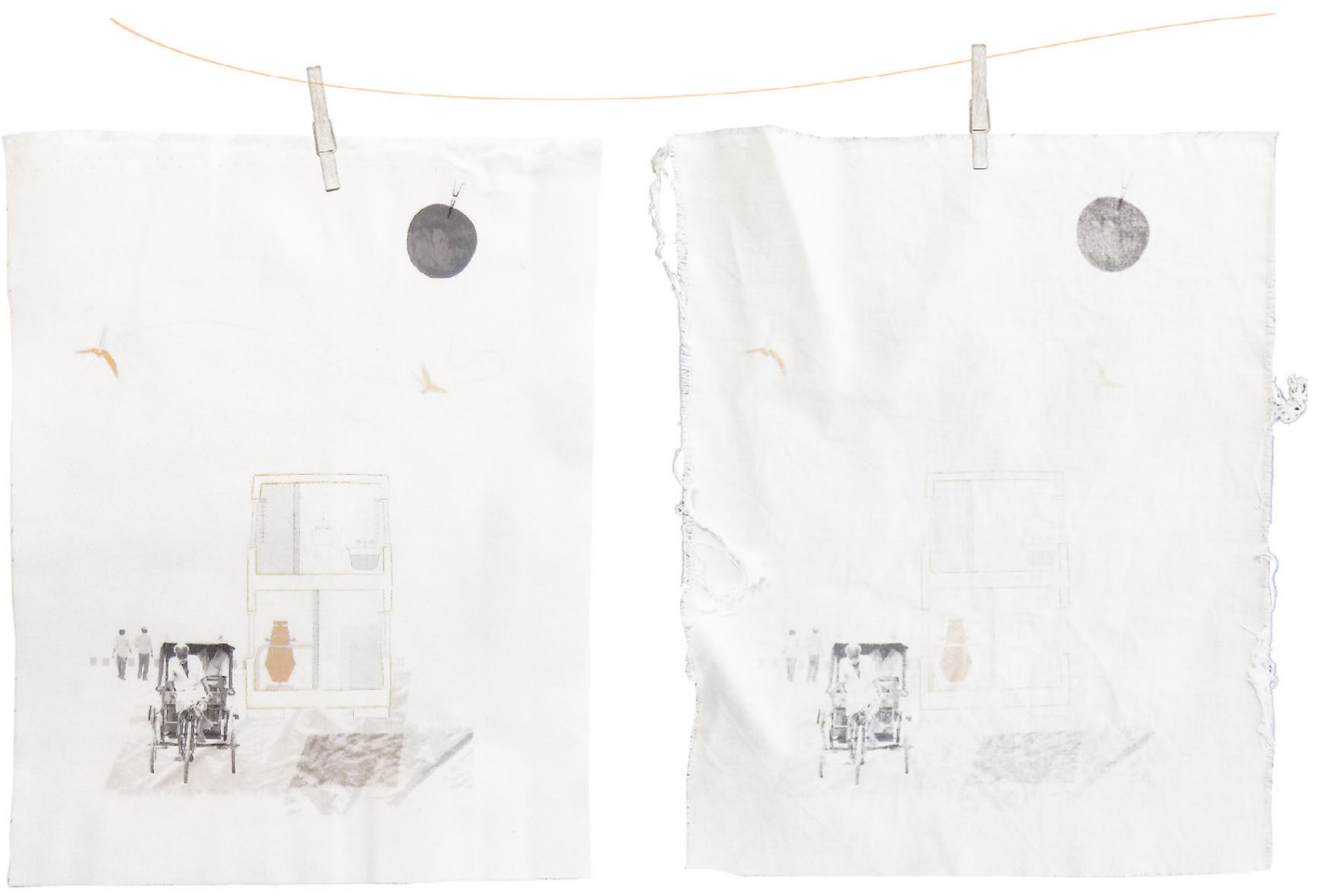

Figure 6.32: Driver Seat Section Printed on Fabric and Hand-Washed Medium: Substrate Printed on Cotton 


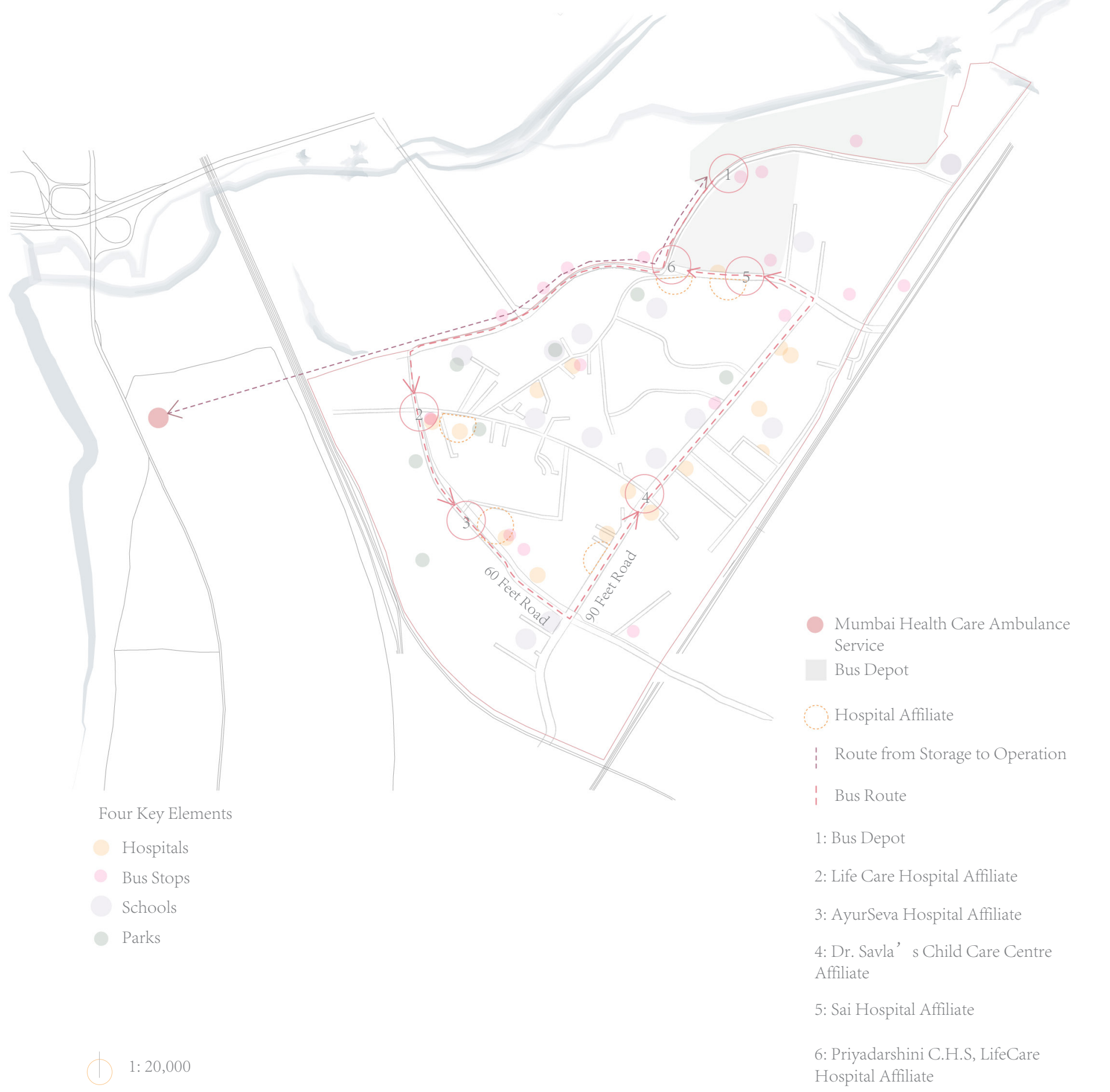

Figure 6.33: Map of Mobile Clinic Route Based on Concentration of Four Key Transportation Layers 


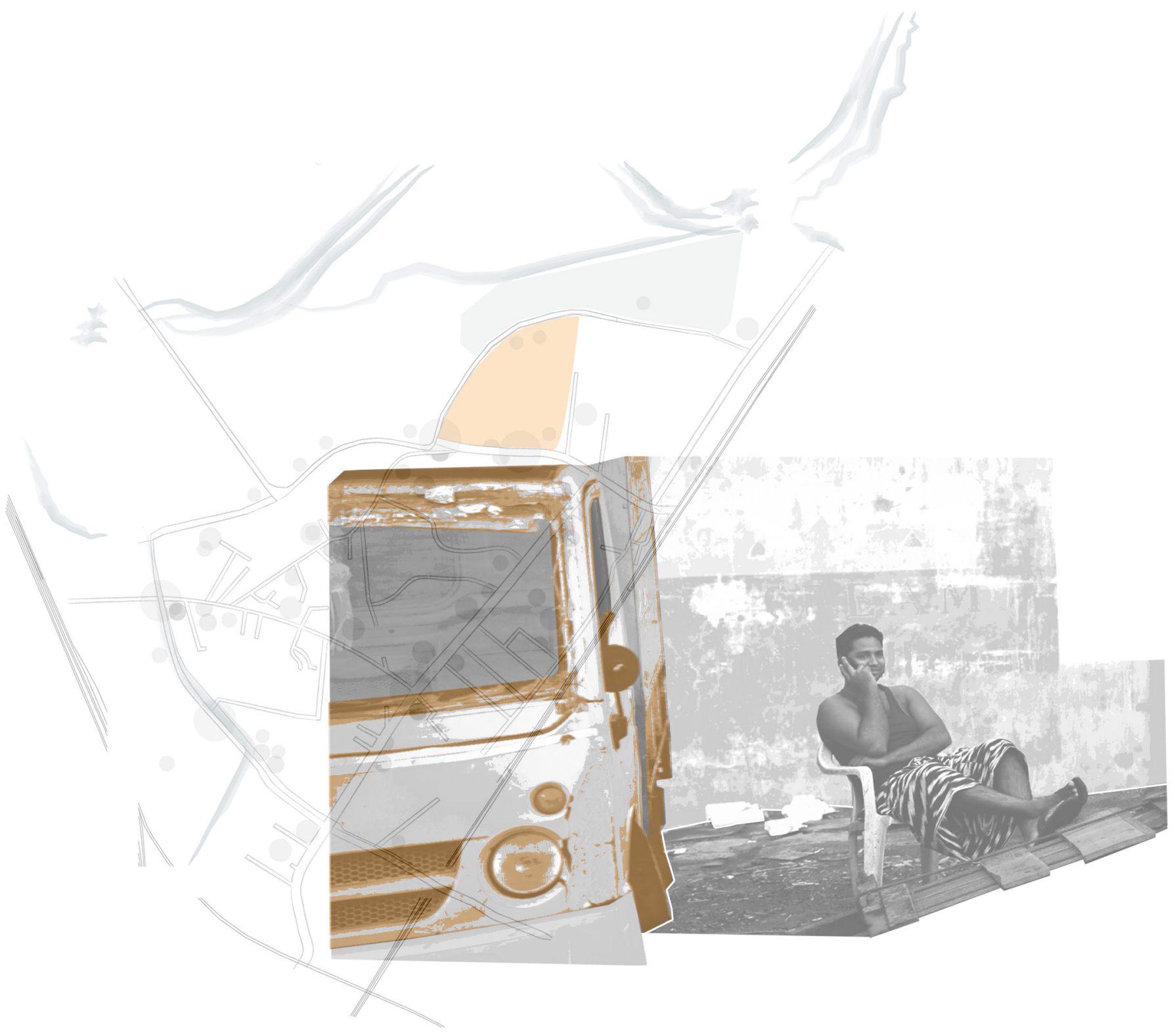

Figure 6.34: First Bus Route Scale the Bus Depot 


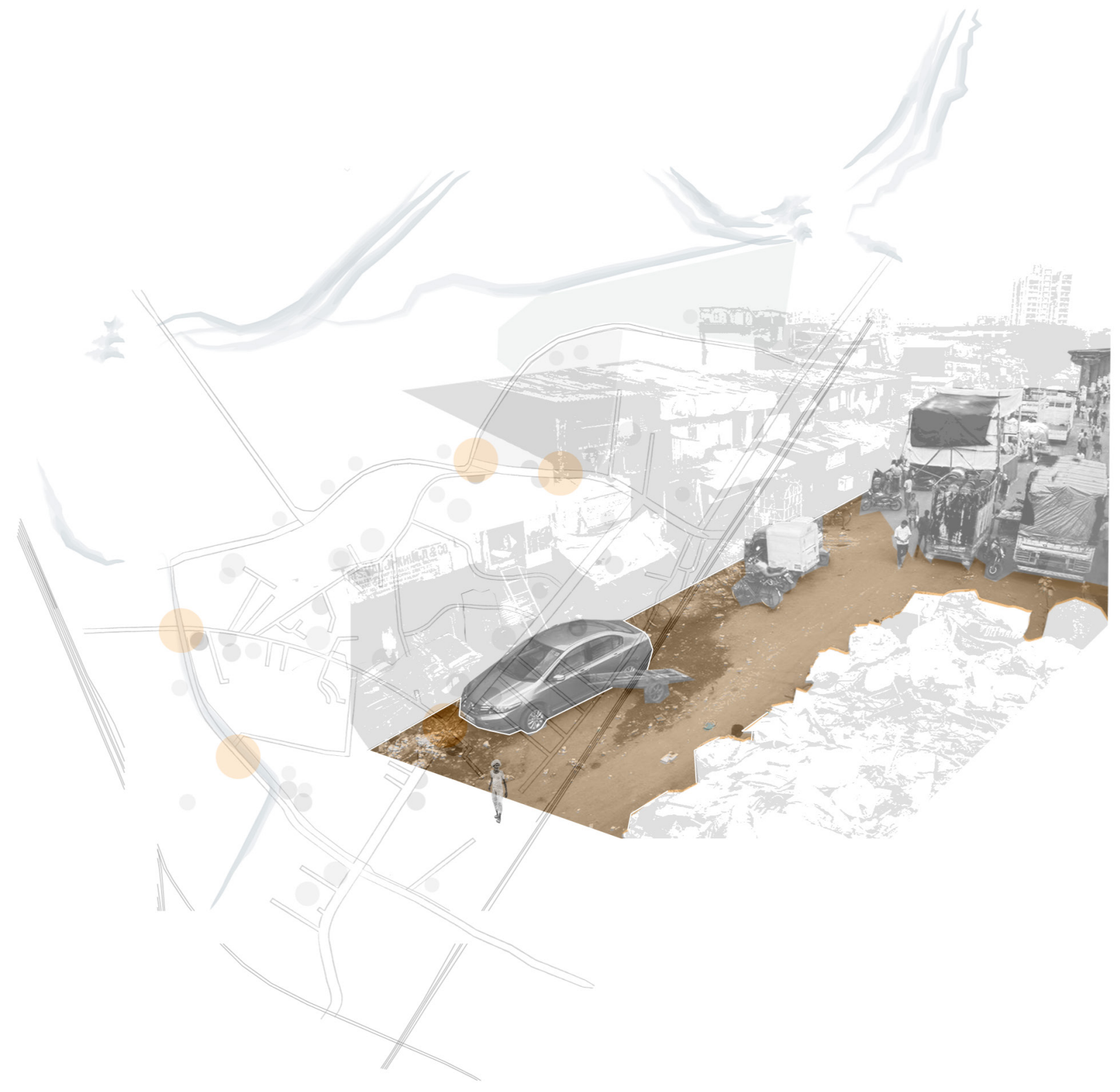

Figure 6.35: Second Bus Route Scale Major Arterial Roads for Vehicular Traffic 


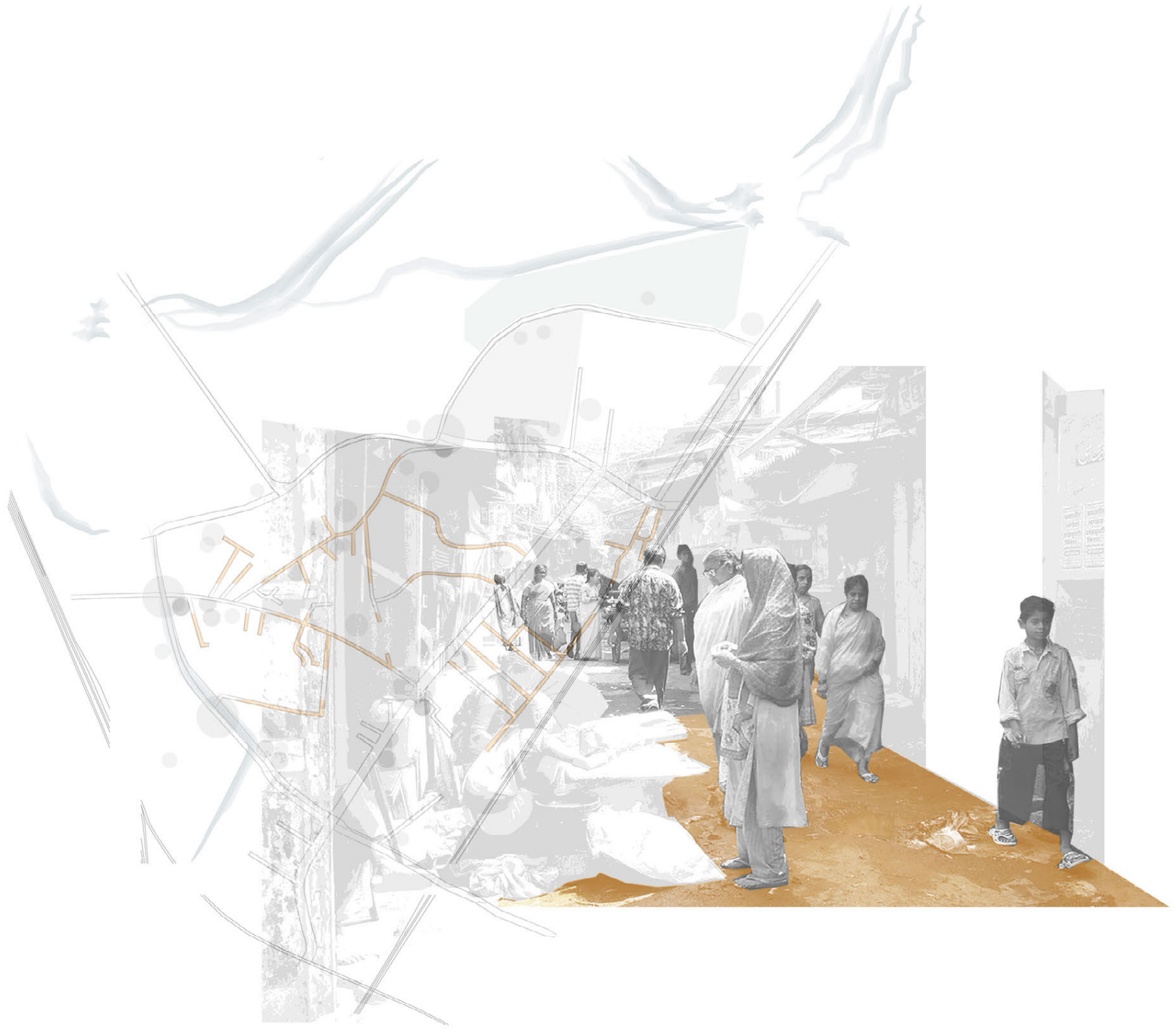

Figure 6.36: Third Bus Route Scale Interior Pedestrian Streets Near Bus Stop 


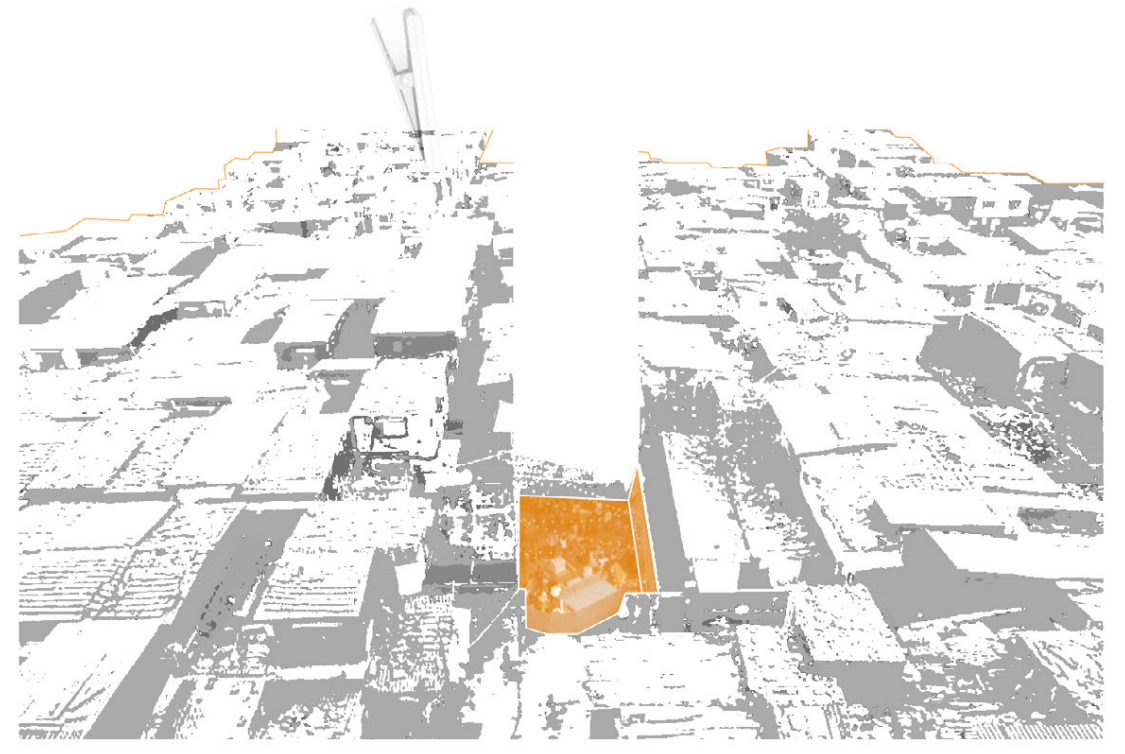




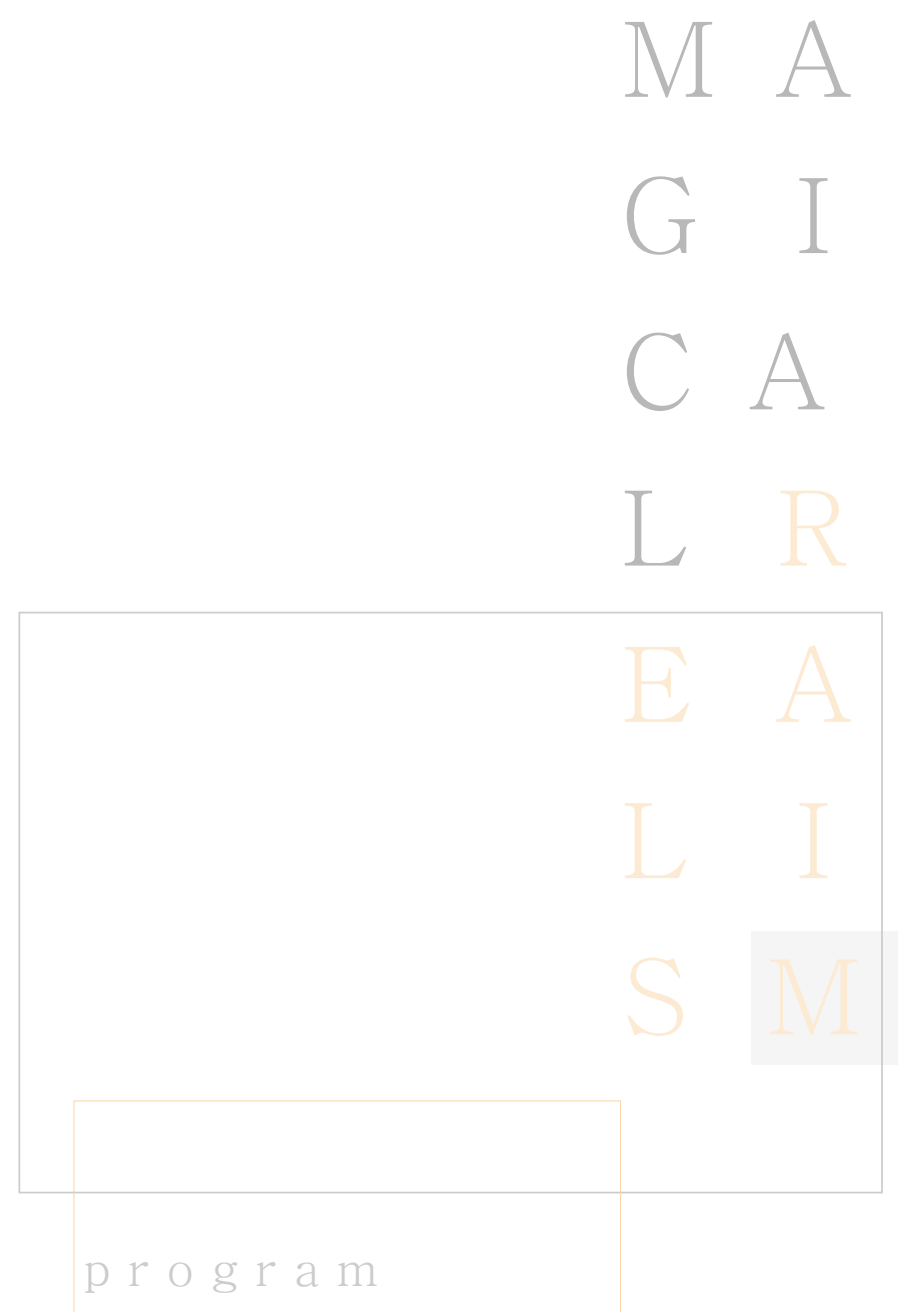


magic in architecture

P.144

Unlike a tailor, who will try to hide the fact that the fabric was once

damaged, my mending was done with the idea of celebrating the repair, as if to say, "something good was done here, a gift was given, this fabric is even better than before."

Lee Mingwei

\section{The Invisible Tapestry}

In 2017, the Venice Biennale featured “The Mending Project" by Lee Mingwei. ${ }^{157}$ The premise of the project was for visitors to bring an article of clothing for Mingwei, or a volunteer, to mend using the thread within the room. ${ }^{158}$ The owners could then return on the last day of the exhibition to retrieve their mended articles. The mended pieces were not meant to be restored, instead, the intent of the project was the art of conversation and connectivity through the pieces of fabric. ${ }^{159}$

This is a compelling sentiment that could apply well to this thesis through magical realism. Perhaps, the women can stitch messages, stories or instructions pertaining to women's health into textiles or articles of clothing. Similar to "The Mending Project," garments could be brought to the mobile clinic for other women to sew messages onto, not as a means of repair but with the intention to stitch the women's social fabric tighter. Within a magical sense, the thread may be only visible to the women, as a way of maintaining the project's discreteness. Similar to "The Mending Project," the thesis is also attempting to "commemorate the repair," however, the level of visibility might be

157 The installation included a long table, two chairs and a wall covered with spools of thread (Mingwei 2017).

158 Mingwei 2017

159 Mingwei 2017 
less obvious to those who do not participate in the clinic. ${ }^{160}$ 


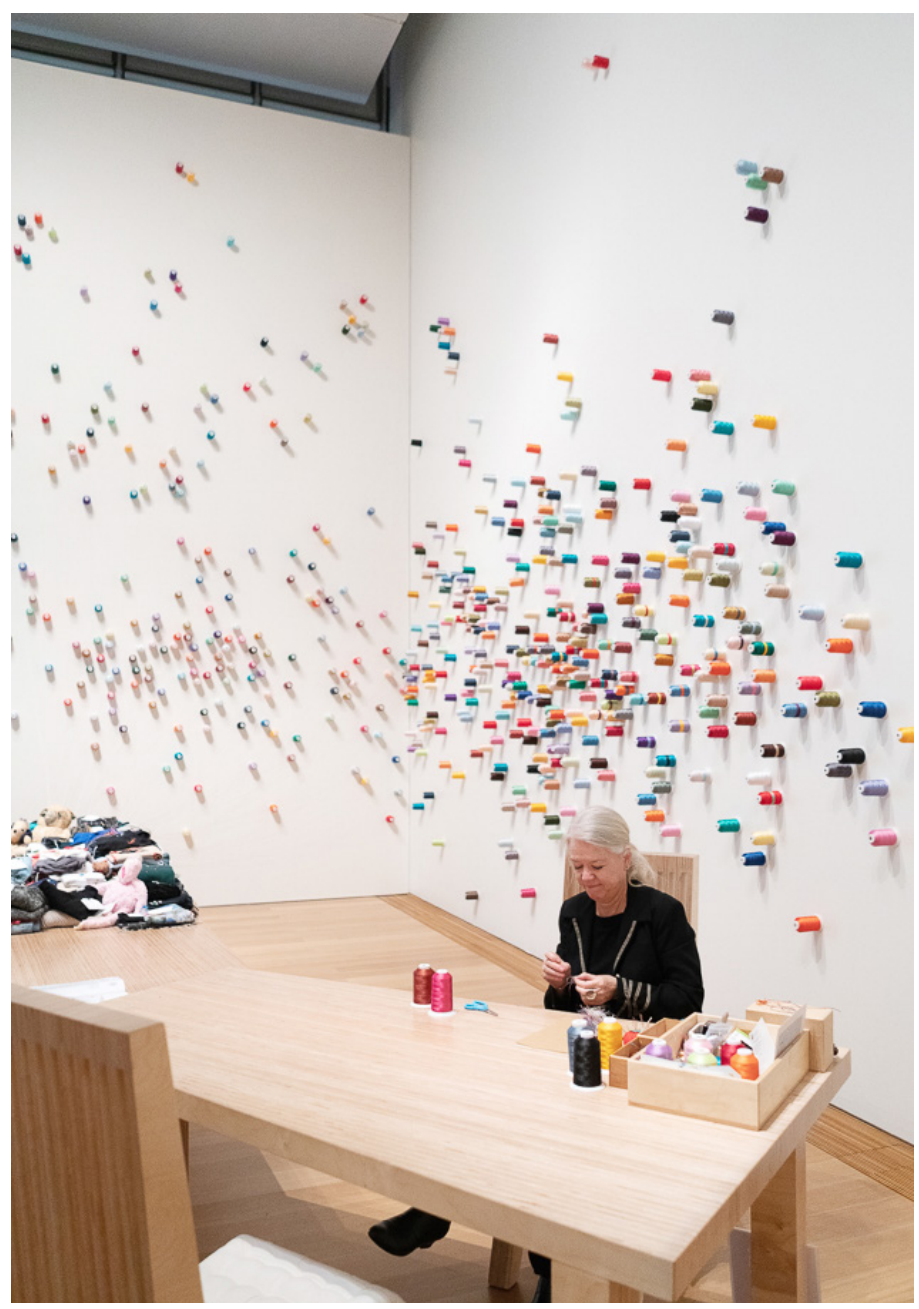

Figure 7.0: Lee Mingwei, “The Mending Project,” c. 2017 
In India, washed garments are sometimes laid adjacent to one another in an open field to dry. Aerial photography shows the scale of the drying fabric, which can stretch over an entire plot of land. Despite the vast space and numerous articles of clothing, there is a level of organization to the placement. The varied clothing items, shapes, and colours, somehow piece together into a larger, unified mosaic or quilt.

This is an apt metaphor for the project's use of narratives being sewn together so, the imagery of the drying cloth could be re-interpreted in a magical sense. As discussed, there is a level of communicative stitching at the person-to-person scale, however, the project can take on another scale of communication from bus-to-bus.

The buses could communicate the occupants' different perspectives and experiences while being tethered to a magical quilt network. Rather than piecing together the narrative quilt on the ground, like the drying fabric, the quilt could be woven into the sky, like a canopy. Using the sky as a plane to build the quilt upon represents a neutral, genderless, unoccupied territory whereby, women can claim and connect with one another. The quilted sky could loom over Dharavi and asserts women's health and the scale of the problem, as a literal representation of mending the social fabric. It also creates a level of 
collective visibility for the women and an organization of a more holistic, shared experience.

In the following series of patchwork, the quilted sky was embroidered onto the fabric to represent the stitching of different narratives. The gold embroidery also creates a language that reads differently from the photo images of the site to demonstrate a distinction in visibility from the real elements and the magical or the male viewer and the female perspective.

Then, the quilted sky was represented as a canopy of narratives using quotes from interviews conducted in the documentary "Period. End of Sentence." In the film, the women of Hapur District were asked questions regarding menstruation and the socialization within their community. It was imperative that the narratives used throughout the thesis were collected from women in India because the project necessitated the female voice to advance conversations around women's health. Their voices are the agent for change and thus, must be accurately represented and not assumed by a third party speaking on their behalf. 


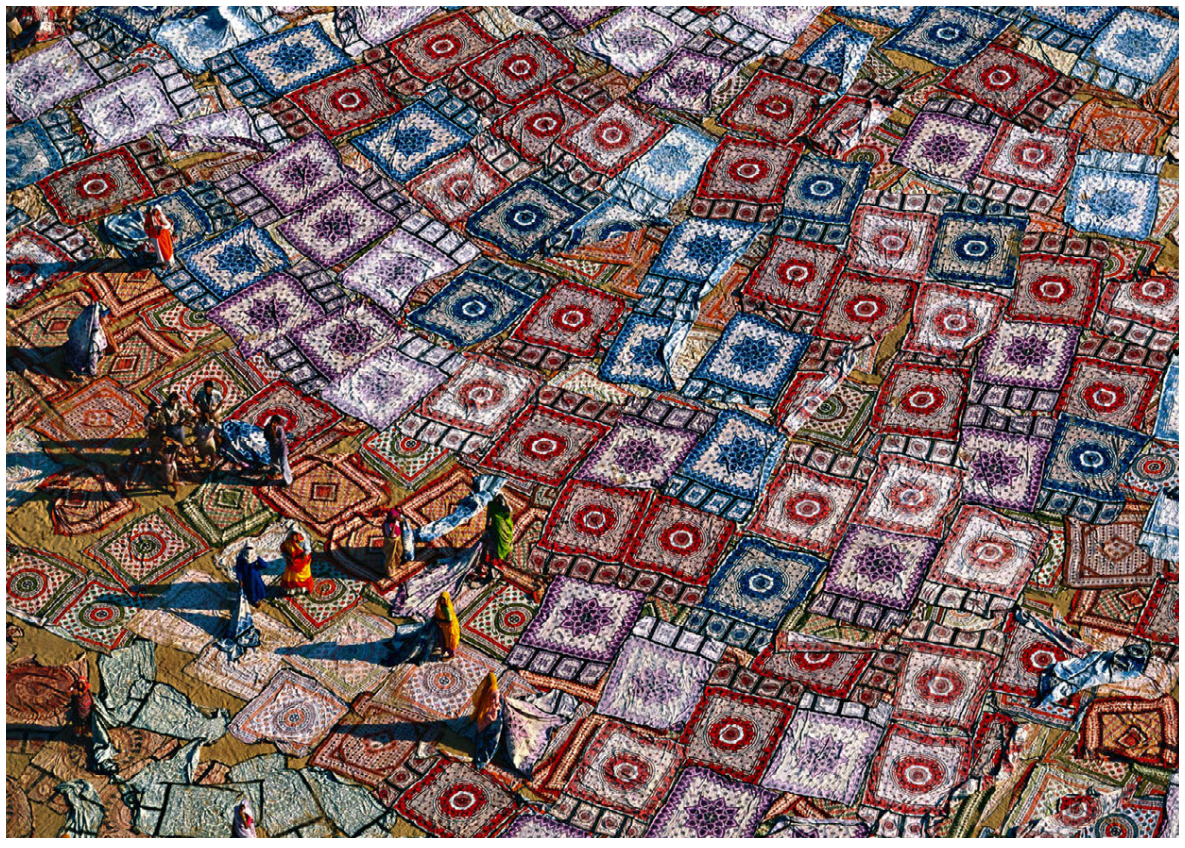




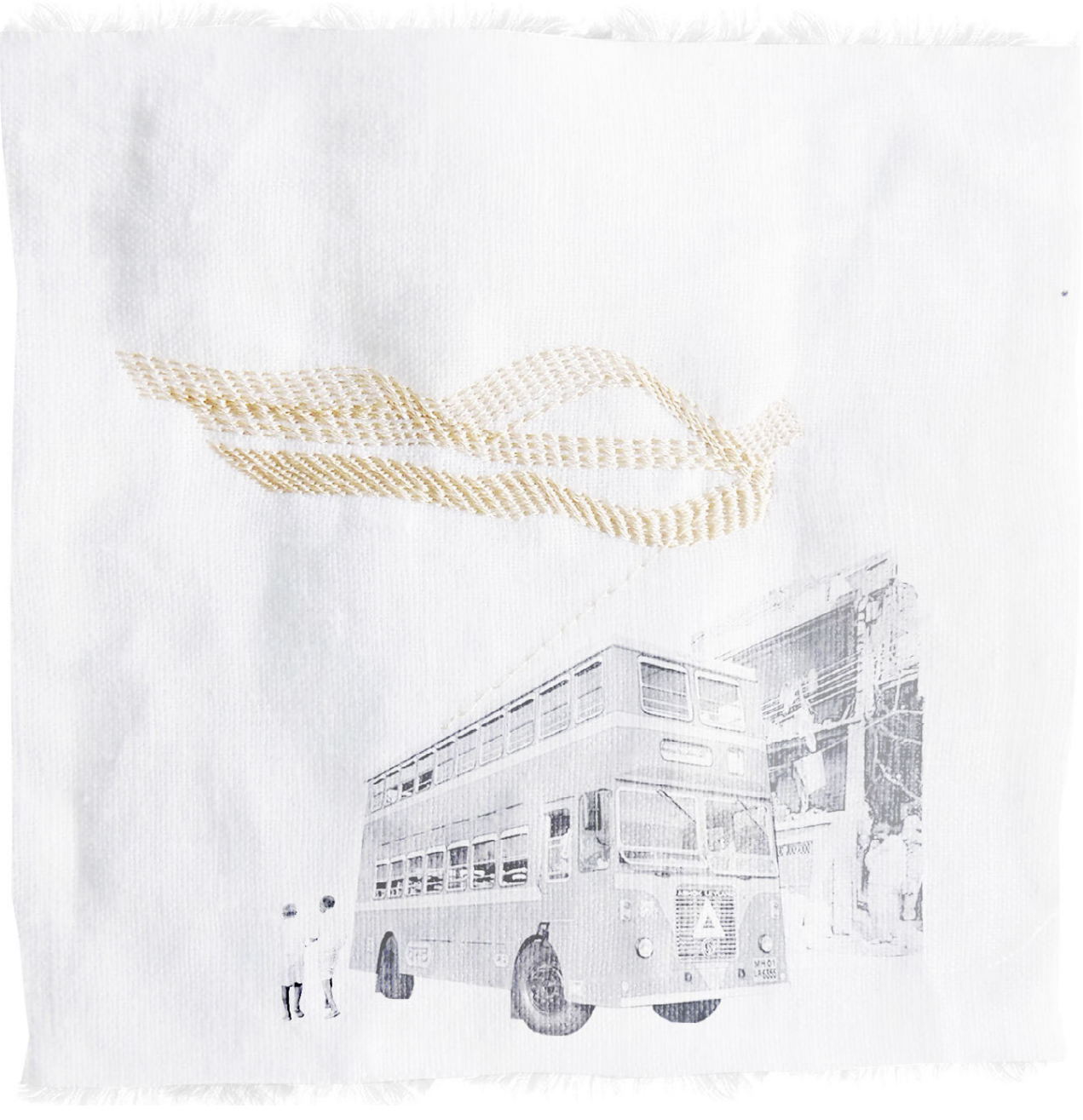

Figure 7.2: The Bus Tethered to the Narrative Quilt Medium: Embroidery on Linen Scanned and Layered on Photo Images 


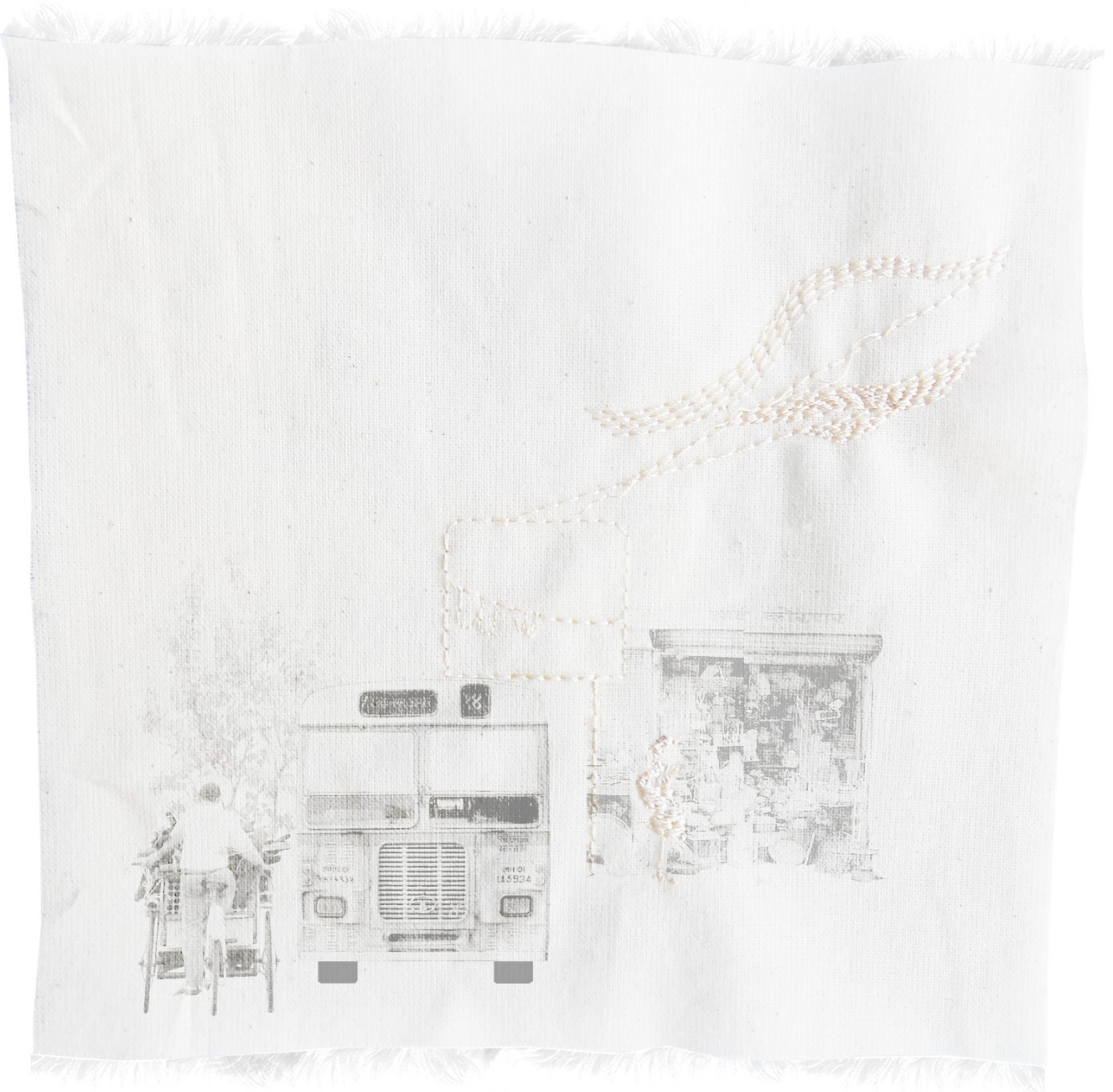

Figure 7.3: The Bus Tethered to the Narrative Quilt Medium: Embroidery on Cotton Scanned and Layered on Photo Images 


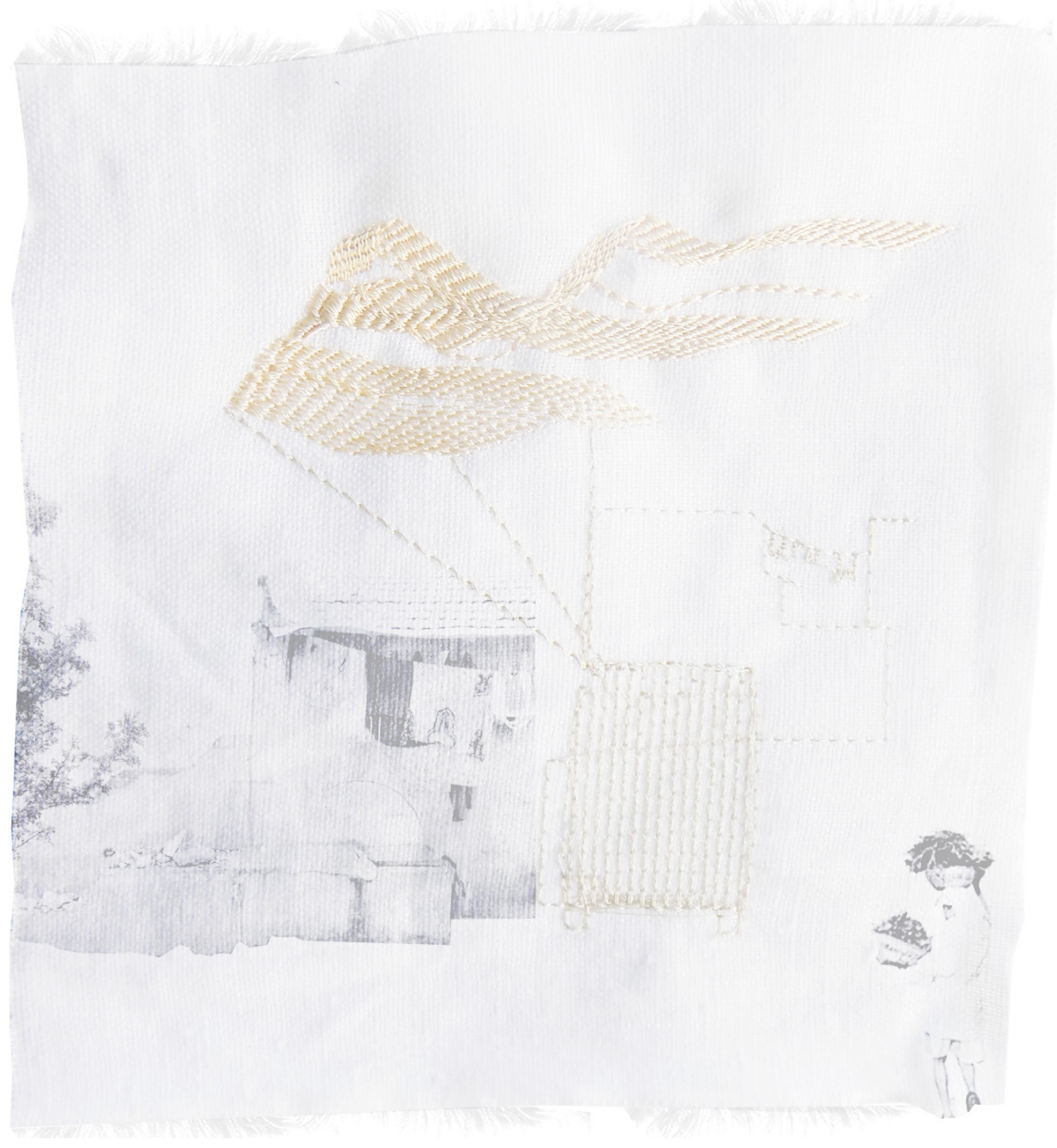

Figure 7.4: The Bus and Narrative Quilt Tethered Together Medium: Embroidery on Linen Scanned and Layered on Photo Images 


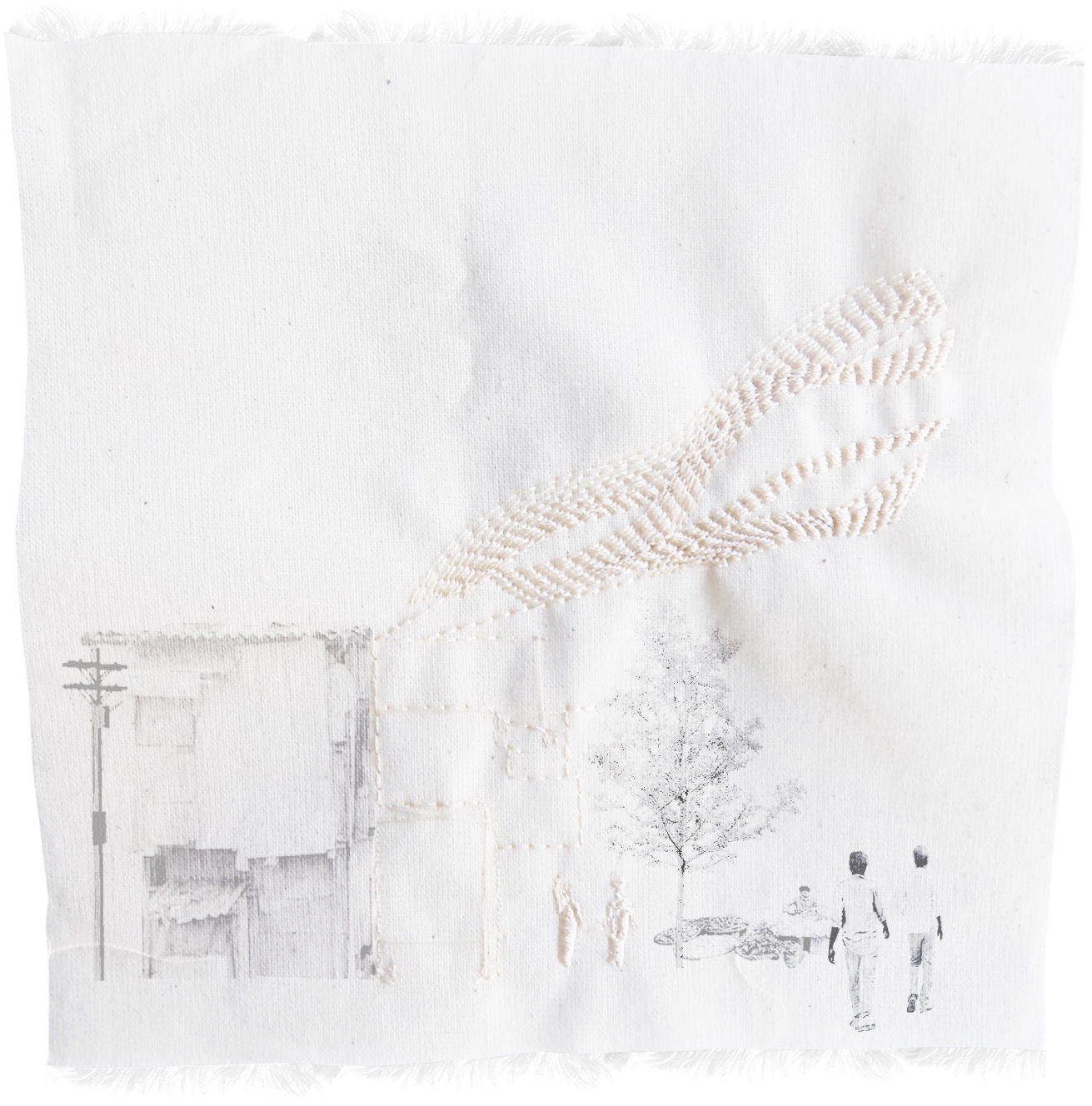

Figure 7.5: The Bus Tethered to the Narrative Quilt Medium: Embroidery on Cotton Scanned and Layered on Photo Images 

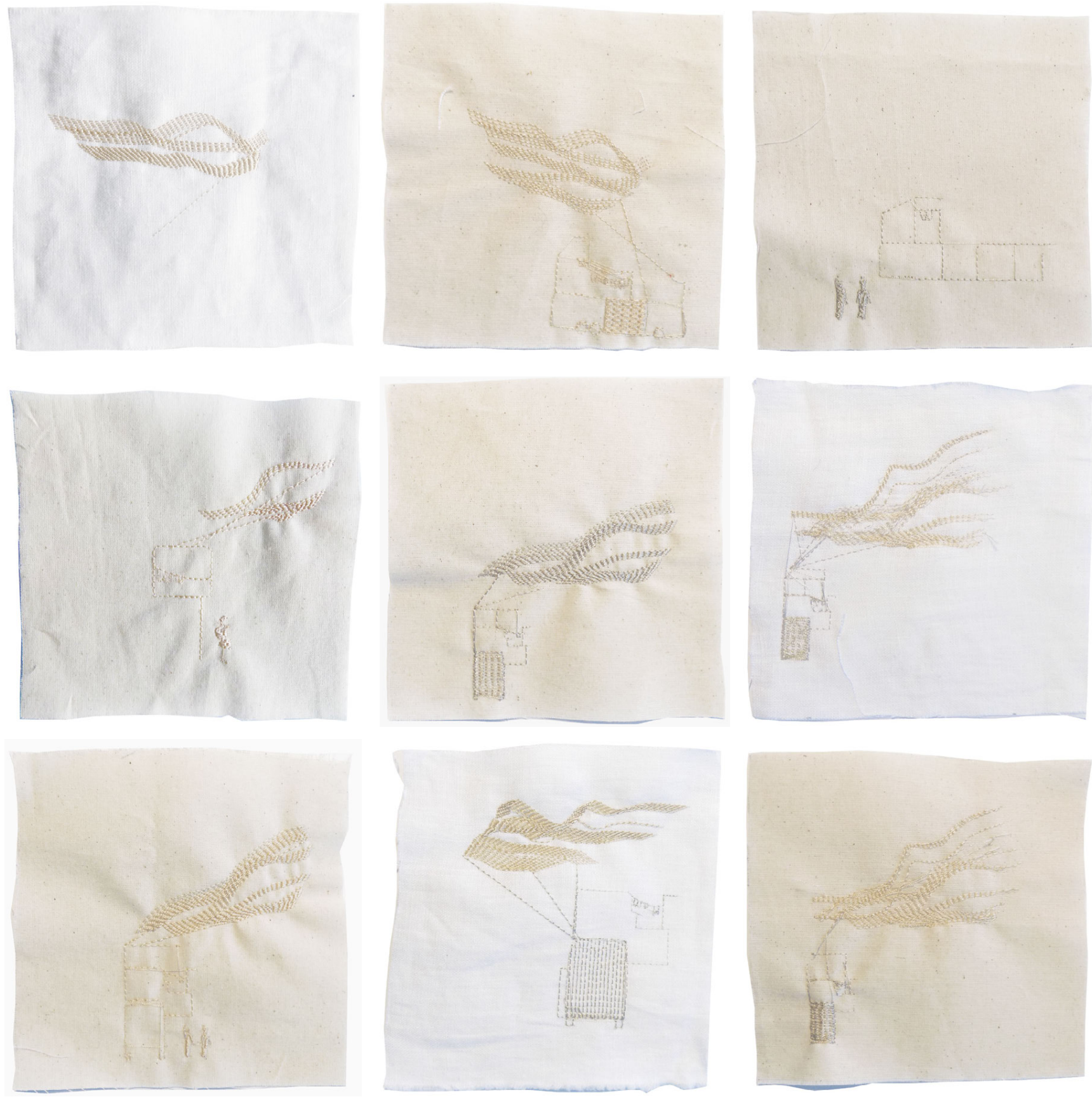

Figure 7.6: Narrative Quilt of the Tethered Buses Medium: Digital Embroidery on Linen and Cotton 

at home. It feels good, now he respects me."

"Then there were the young boys and men around, they would look at us. How were we

"Babies are born because of it and this is all I know."

"We don't come to the temple during menstruation. The elders and the family believe that during this time our prayers are never heard no matter how hard you pray."

"I can't say the words $\cdots$ I'm too shy."

"Girls find it difficult to buy it from the shops because there are a lot of men around. If they find out that a women is selling these things it will be easier for them."

"Women are the base of any society. And women are more powerful but they don't recognize themselves. They don't know how much power they have and what they can do."

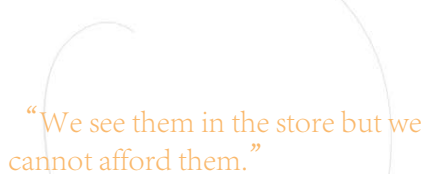
cannot afford them." supposed to change in front of them?"

"We just find whatever we can at home $\cdots$ In the evening when no one is around, we throw them away right here $\cdots$ it's embarrassing."

\section{I had to change it quite often, which meant I had to leave frequently.}

the cloth 1 used got wet quickly, so
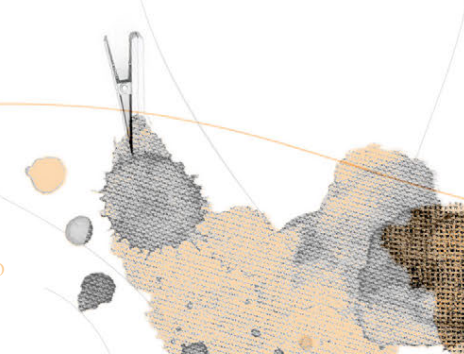

"It is something only God knows, it's the dirty blood that is released."

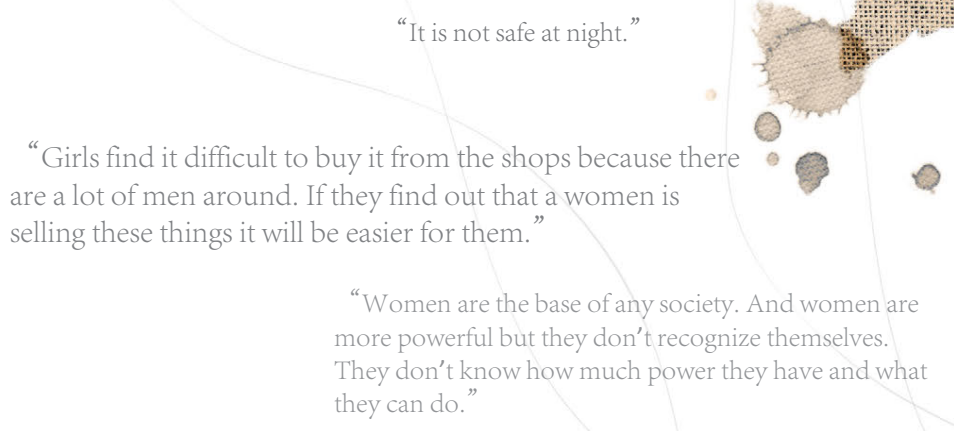

$\operatorname{tin}=$
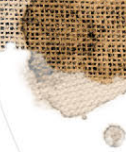

*

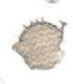

"We've worked very hard for women, so we want the women to rise and fly."
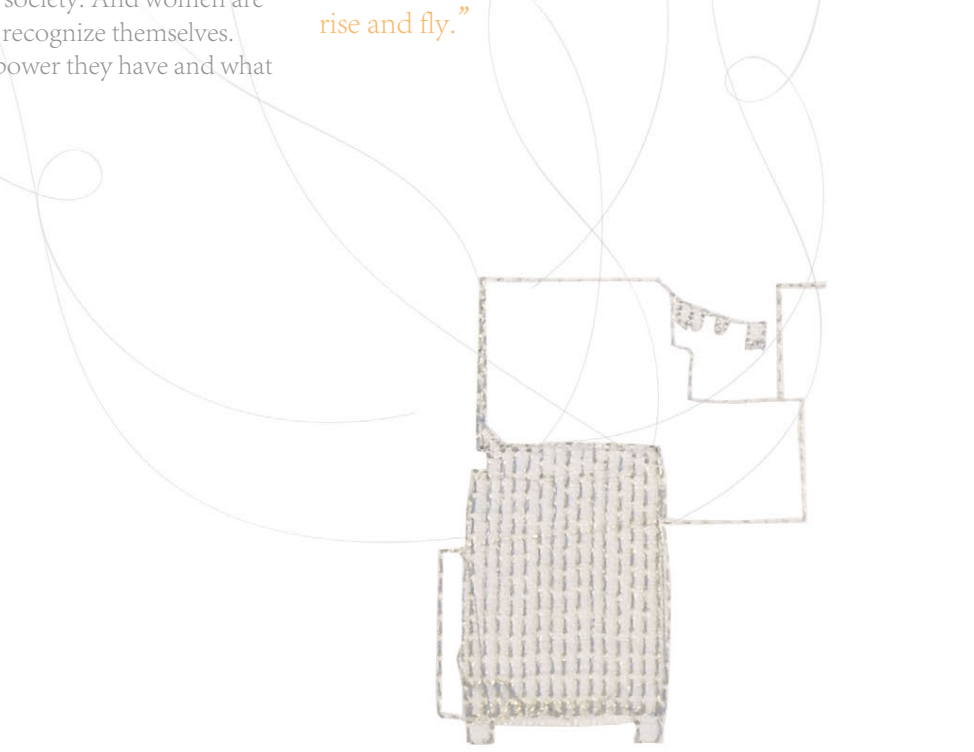

Figure 7.7: Narratives from Hapur District Imagined as the Magical Quilt 


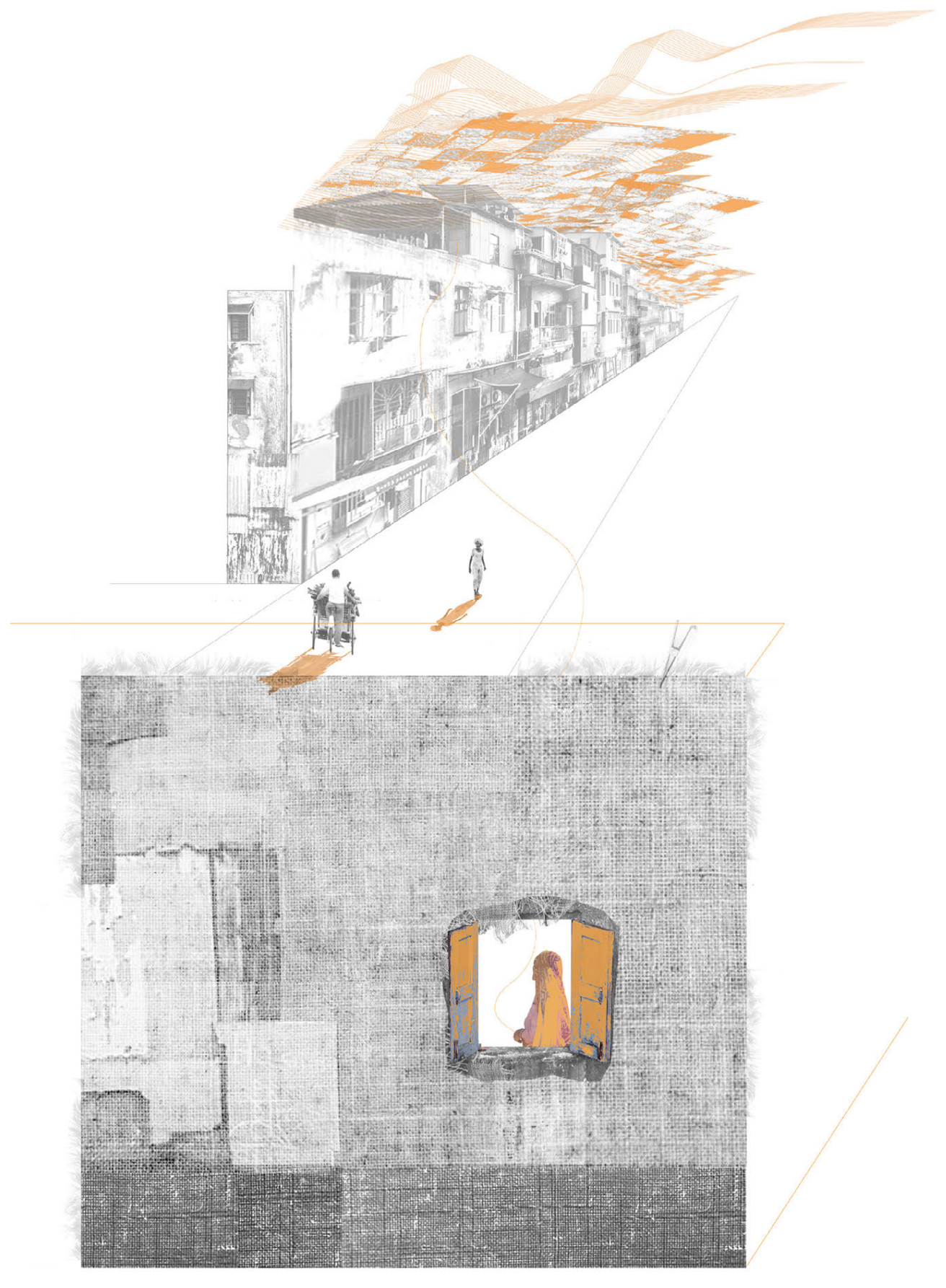

Figure 7.8: Magical Representation of Women Sewing Messages to the Narrative Quilt 


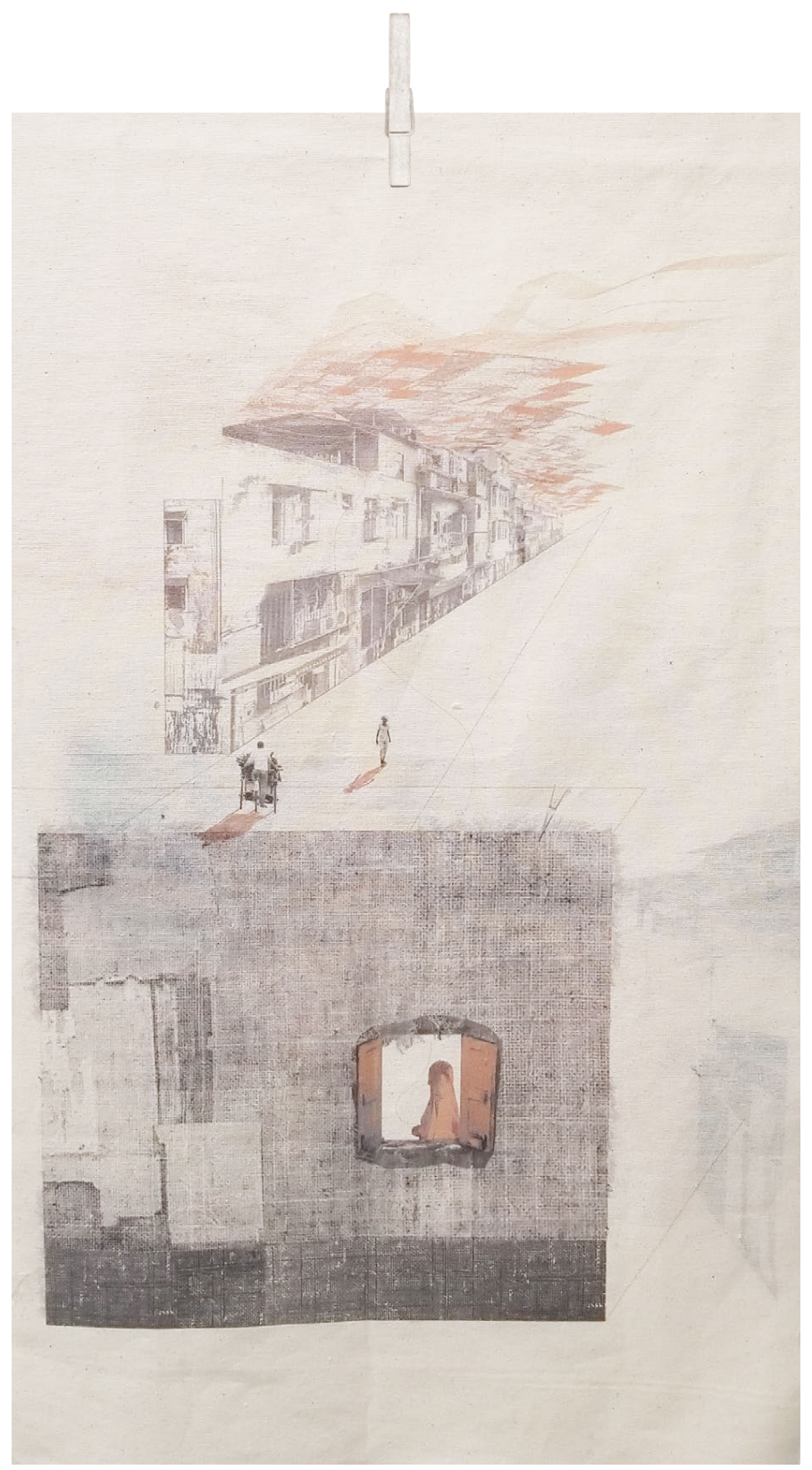

The image represents a woman using a piece of thread to sew her message to the larger quilt that hangs over the community. The quilt is stitched together with multiple narratives, perspectives, and stories shared by other women through this collaborative process. The goal is that by sharing her story, the social fabric will begin to mend itself.

Figure 7.9: Women Sewing Messages to the Narrative Quilt Medium: Substrate Printed on Cotton 


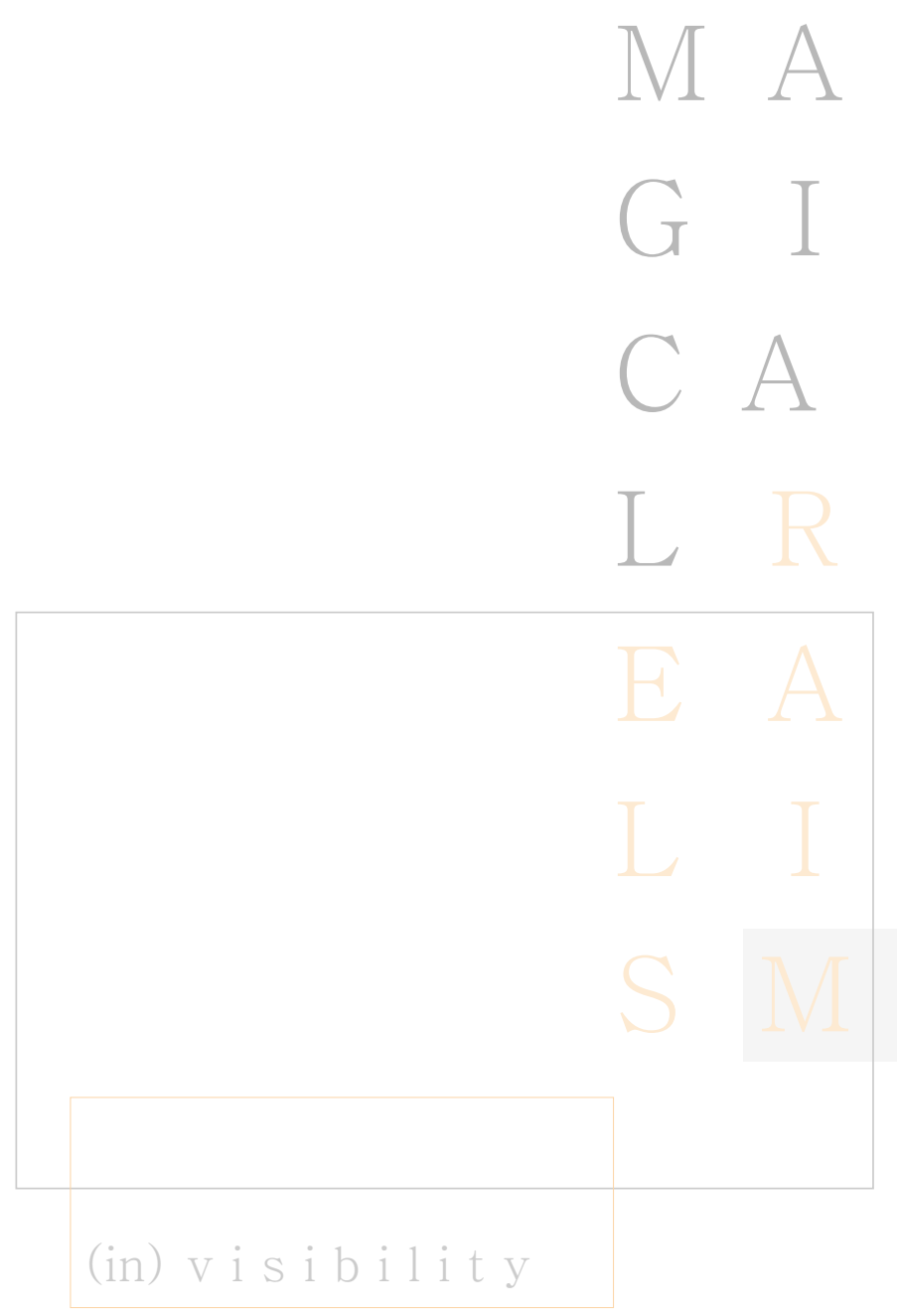




\section{Transposing Invisible Space}

A central theme in this project is visibility or more importantly, invisibility. In order for the project to be effective there needs to be a level

of invisibility, so as to not disrupt customary traditions and offer a degree of security for women. The re-use of the local transit system is a realworld ways in which the project tries to integrate into the neighbourhood and minimize attention.

With magical realism, the project can further push the boundary between visible and invisible. How does one represent invisible space? This question ultimately led to substrate printing the bus using white ink onto white linen. The white ink has a thickness to it--which was built up through multiple layers--and so, has a faint visibility at certain angles. The subtle shadows and lines that arise start to show the boundaries of the mobile clinic and the demarcation of space. Each fabric shows a different iteration of spatial arrangement to represent the bus's evolving, opensource design.

The linen is in keeping with the project's laundry and sewing themes but also represents a different medium to build upon. Similar to the sections, the fabric can be manipulated, stitched, or overlaid to adjust the bus's visibility and spatial arrangement, which illustrates its open 
source design.

The different bus designs printed onto the fabric are overlyexaggerated spaces to underscore the ad-hoc design. In addition, the towering and comically extended buses are meant to show the sliding scales of visibility. In a way, the bus is growing by absorbing the stigmatization on menstruation and the taboos around reproductive health. The scale of the bus directly correlates with the growing visibility and acceptability of women's health in the community. As women's health becomes more visible in society and everyday vernacular--through initiatives that empower women and normalize taboo topics--the mobile clinic becomes larger and more present.

The visibility of the project reflects the visibility of the subject matter in society and so, the project can be a barometer for changing attitudes. 

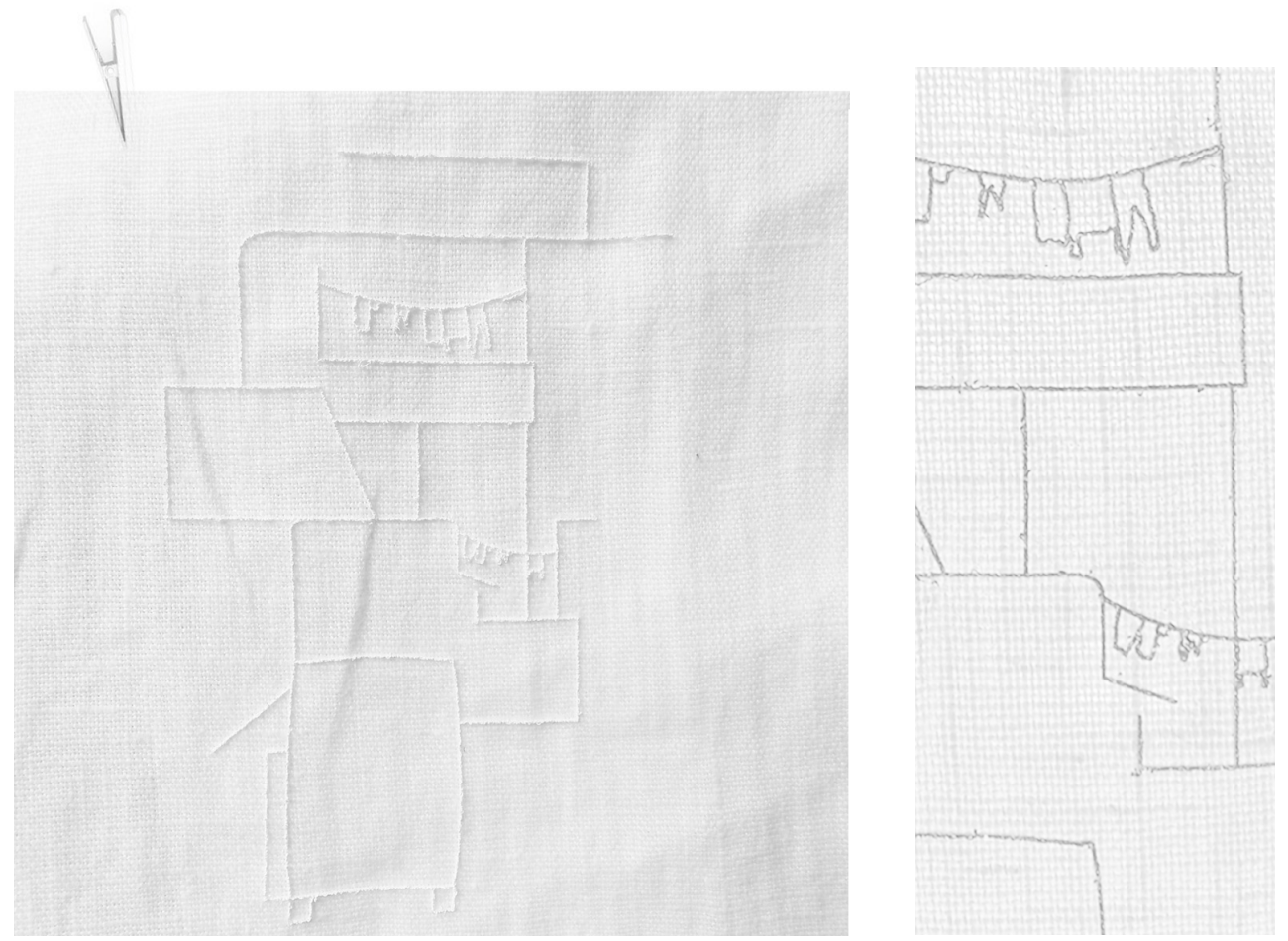

Figure 7.10: Magical Representation of the Bus's Space and Visibility Medium: Substrate Print on Linen 

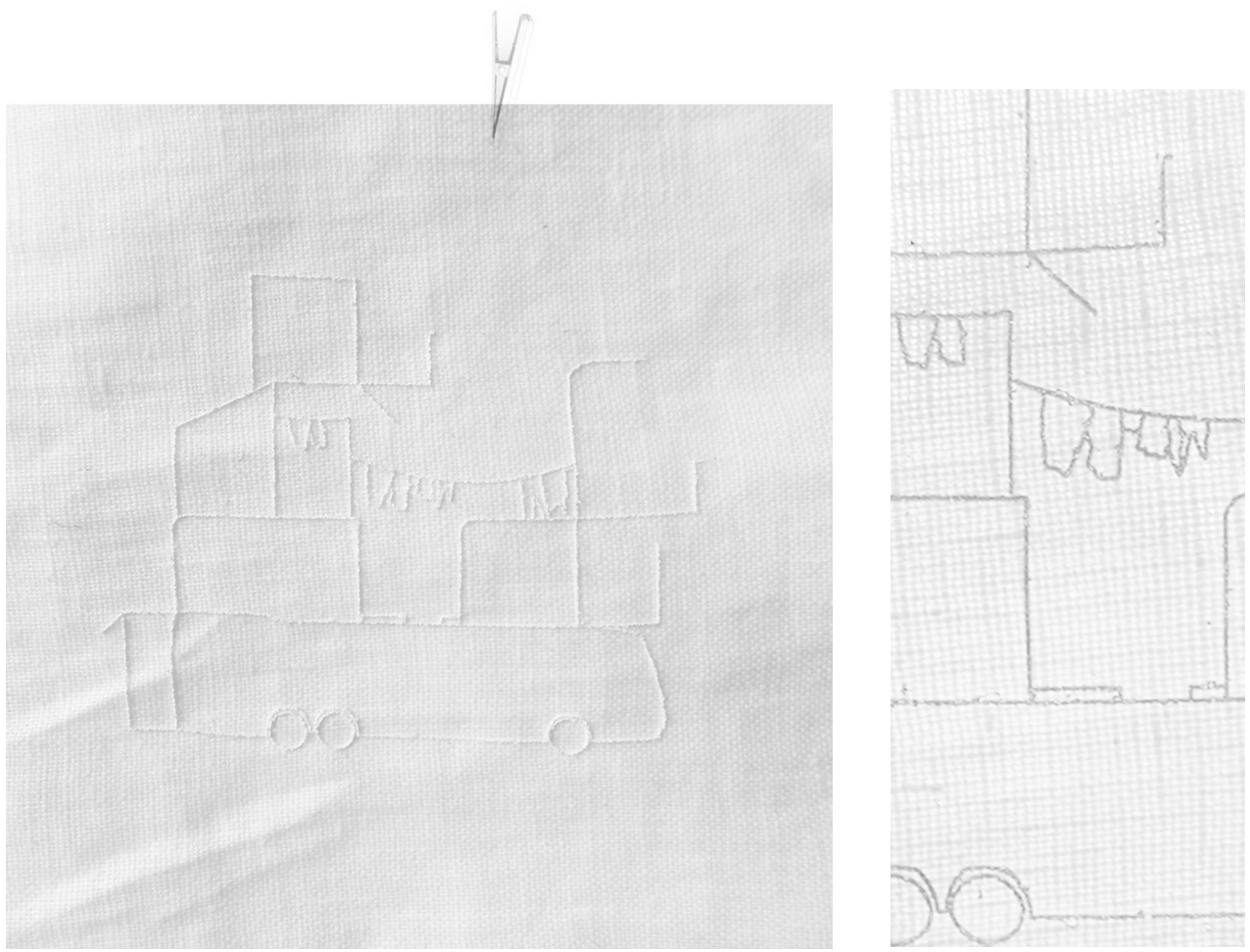

Figure 7.11: Magical Representation of the Bus's Space and Visibility Medium: Substrate Print on Linen 

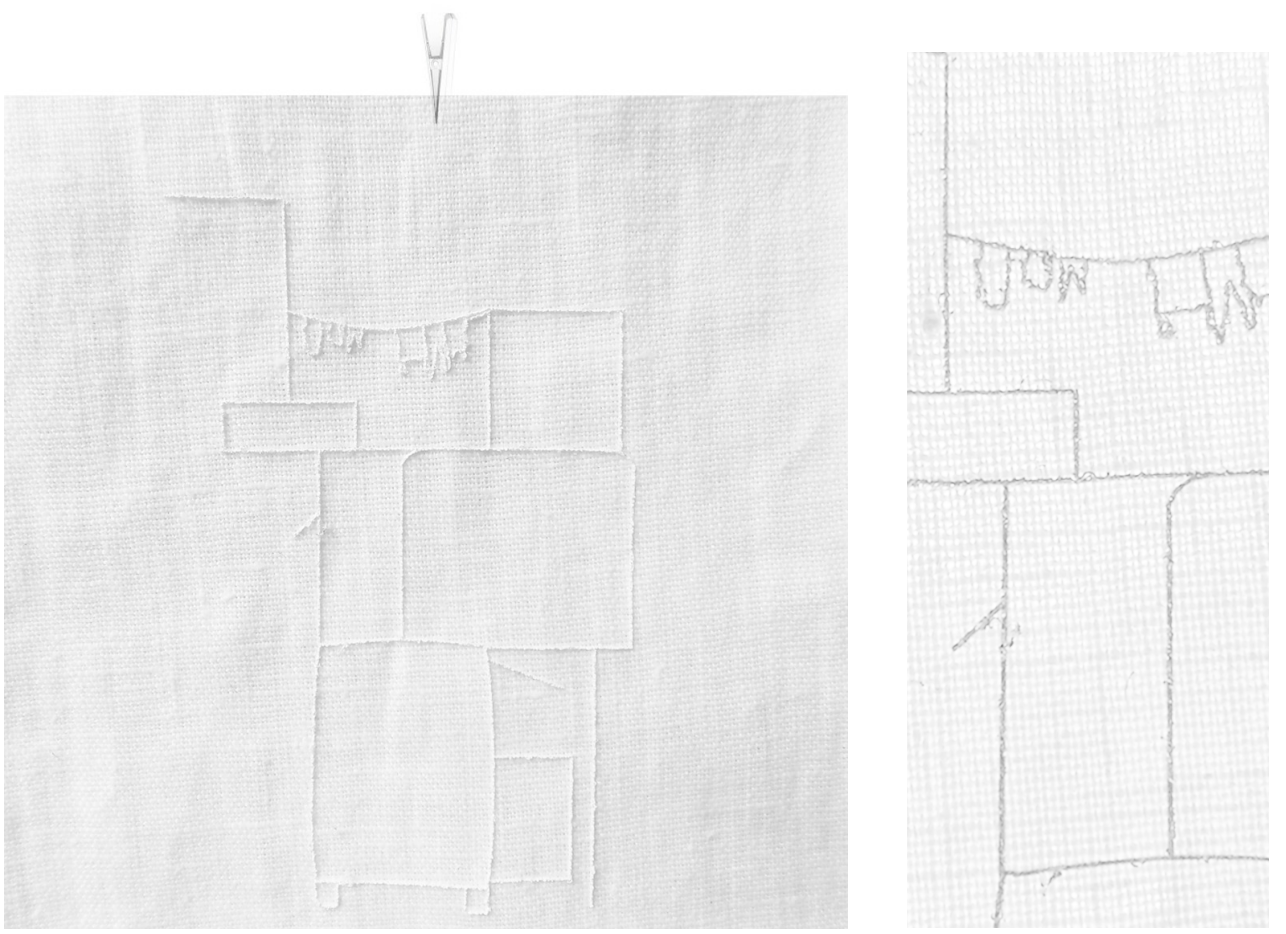

Figure 7.12: Magical Representation of the Bus's Space and Visibility Medium: Substrate Print on Linen 

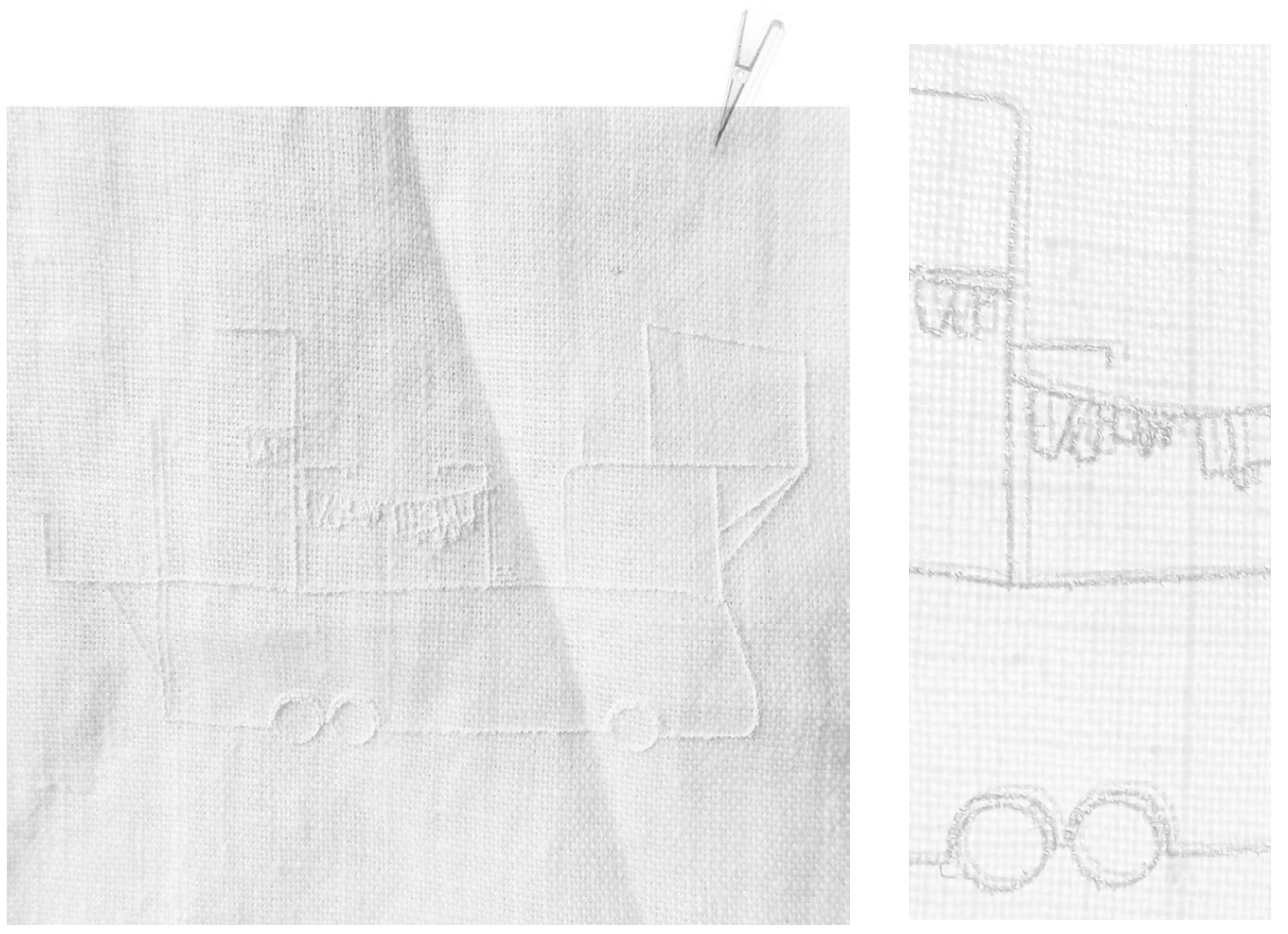

Figure 7.13: Magical Representation of the Bus's Space and Visibility Medium: Substrate Print on Linen 


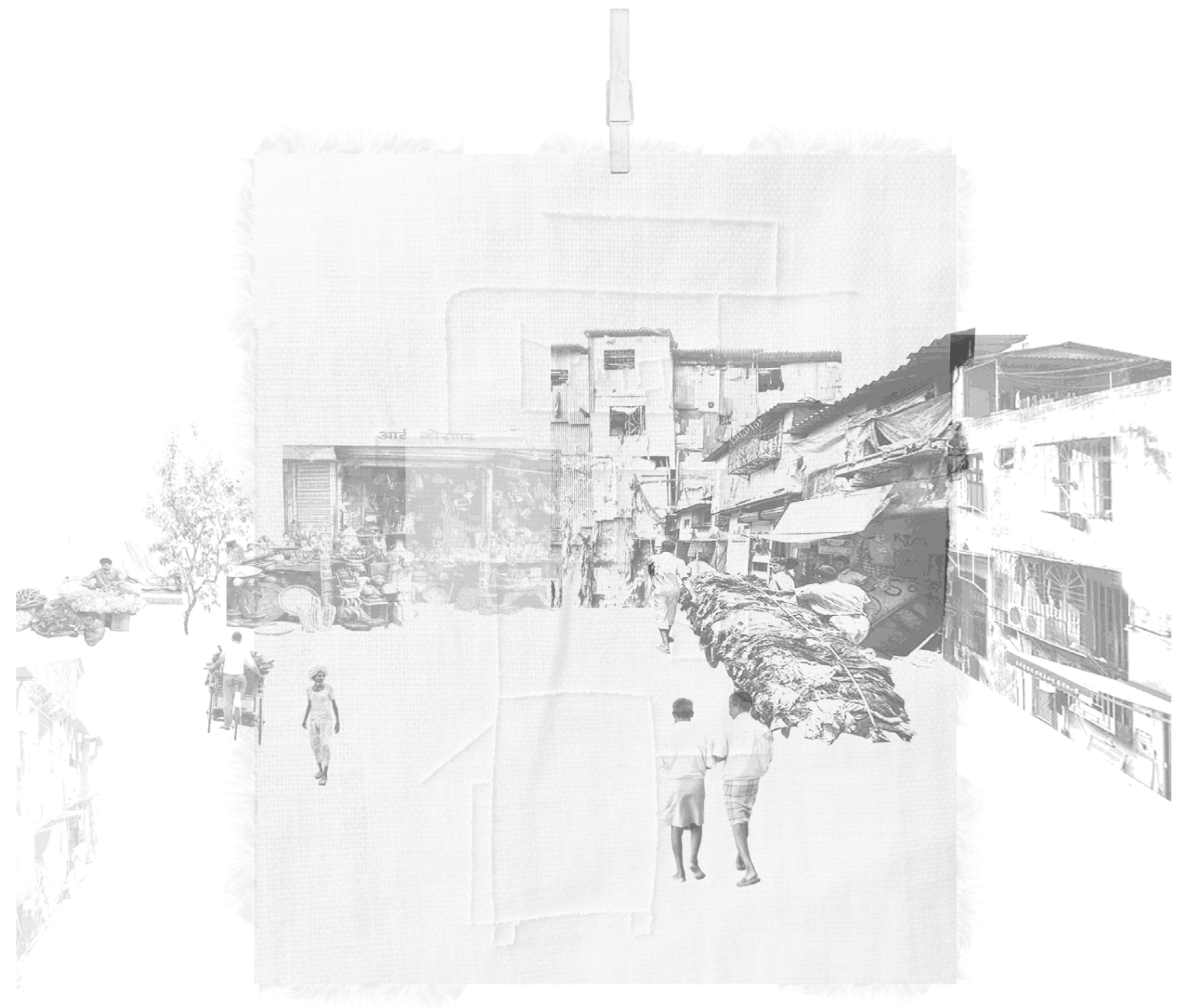

Figure 7.14: Magical Representation of the Bus Moving through a Bazaar Medium: Substrate Print on Linen Scanned and Layered on Photo Images 


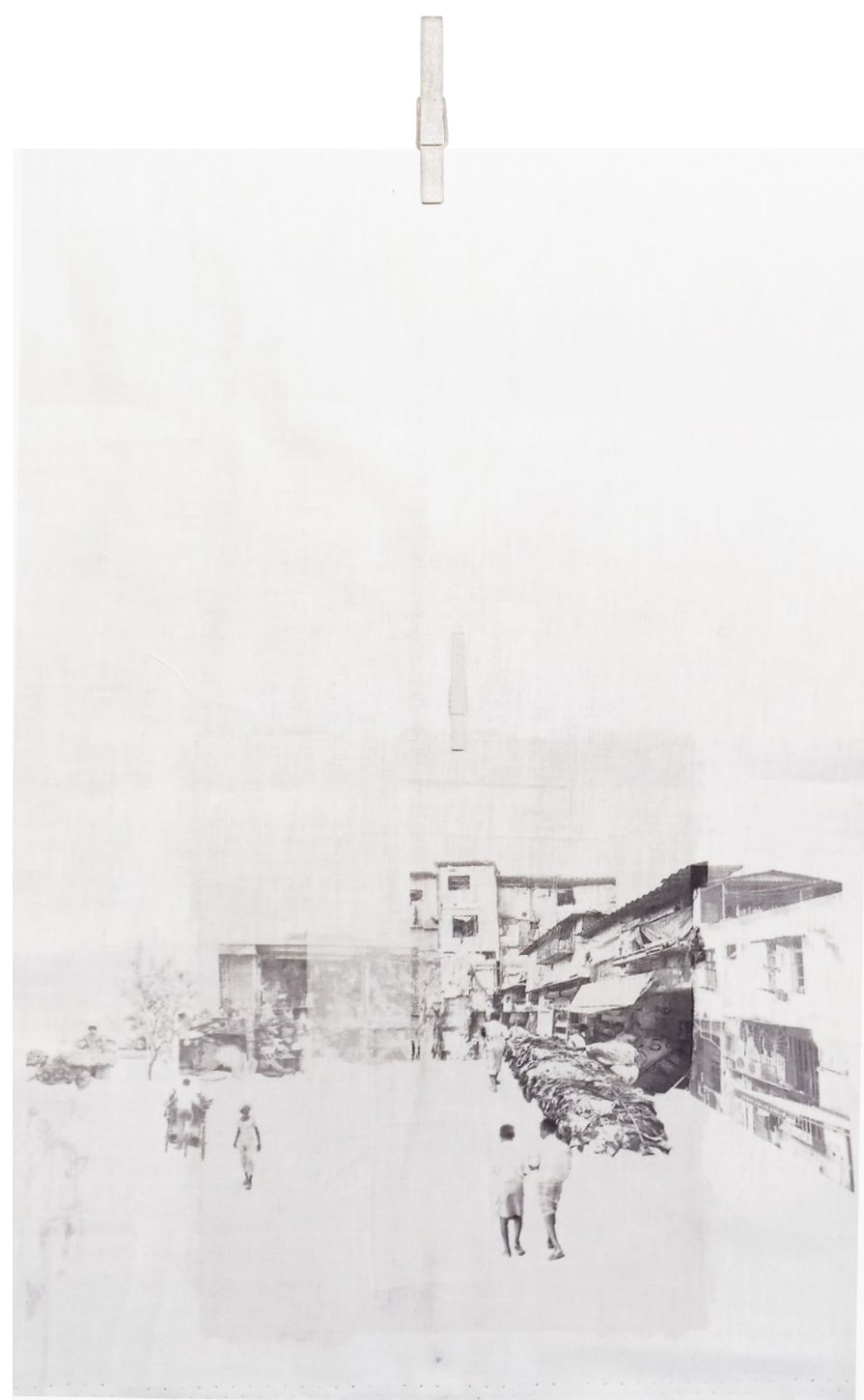

The image illustrates the two levels of visibility, the bus and the site, by using different methods of representation, photography images and linen. The bus was substrate printed on the linen and then overlaid onto the photos of the site to convey the bus's presence while also illuminating its invisibility in relation to its surroundings.

Figure 7.15: Bus Moving through a Bazaar in Dharavi Medium: Substrate Printed on Cotton 


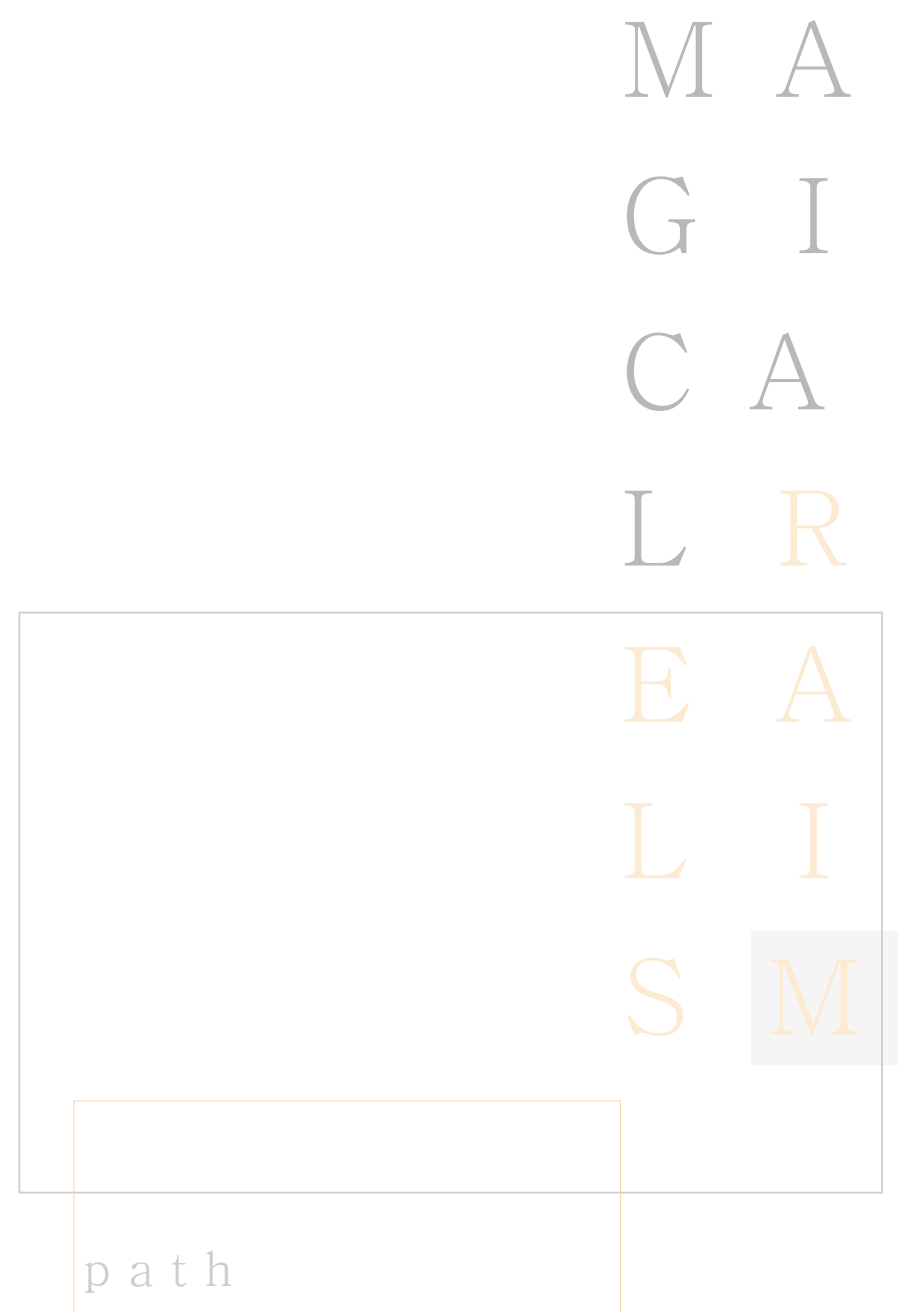




\section{Moving Boundaries}

In "Soak: Mumbai in an Estuary," Mathur and Cunha write how the separation of water and land "found its most powerful instrument in the European enterprise of mapping that would make the land-sea separation not just a commonly accepted reality, but a stark divide, represented by a firm line.” 161

This mode of representation, the line or border, is used to mark edges or routes but remains a symbol that does not exist in reality. So, symbolic borders, such as gendered boundaries that exclude women from accessing certain areas could be an equally real concept on a map if represented by a line. These areas of exclusion could be businesses, schools, places of worship or public spaces because of gendered norms or discriminatory practices that weaponize women's health and menstruation.

The path could circle the metaphoric boundaries women face each day in Dharavi, which would be invisible to those who do not share in similar experiences. Mathur and Cunha write about how once an edge is defined it then influences how society reacts to said edge. ${ }^{162}$ They uses the estuary as an example and how the walls signify a war against the sea

161 Mathur and Cunha 2009: 6

162 Mathur and Cunha 2009: 4 
and the privileging of land. ${ }^{163}$ Likewise, there are gendered forces acting in Dharavi that build imaginary walls between men and women, privileging the men. The hope is that through a magical lens more attention could be drawn to the walls through a less prescriptive but more experiential route.

The use of women's experiences is a layer of mapping that once existed but has since become less prevalent. Mathur and Cunha write that "in the sixteenth and seventeenth centuries, makers of sea charts used observations and sketches from ship journals to constitute the line of the west coast, supporting their drawing of it, with plans of harbours, elevation profiles of land, data of winds and currents, and instructions from experience of what to expect and look out for.” 164 They note how these maps were of "cumulative experience, representing the accumulation of more observations than any one person could make in a lifetime.” 163

It could be worthwhile to re-introduce the experiential quality of mapping based on women's momentary experience or exclusion of space, as a way to highlight the barriers on site.

163 Mathur and Cunha 2009: 4

164 Mathur and Cunha 2009: 21

165 Mathur and Cunha 2009: 21 


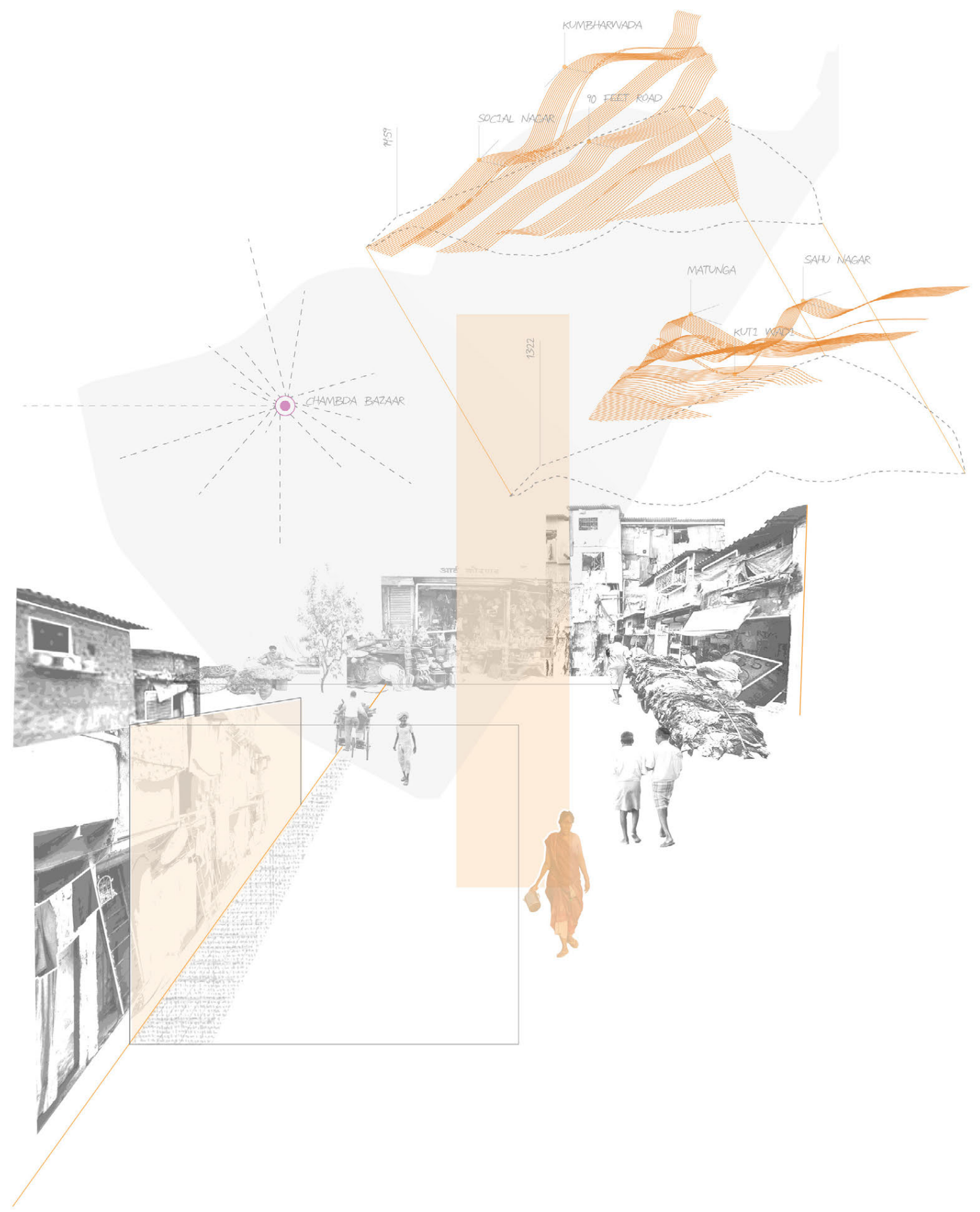

Figure 7.16: Magical Representation of Path Moving through Places of Exclusion 


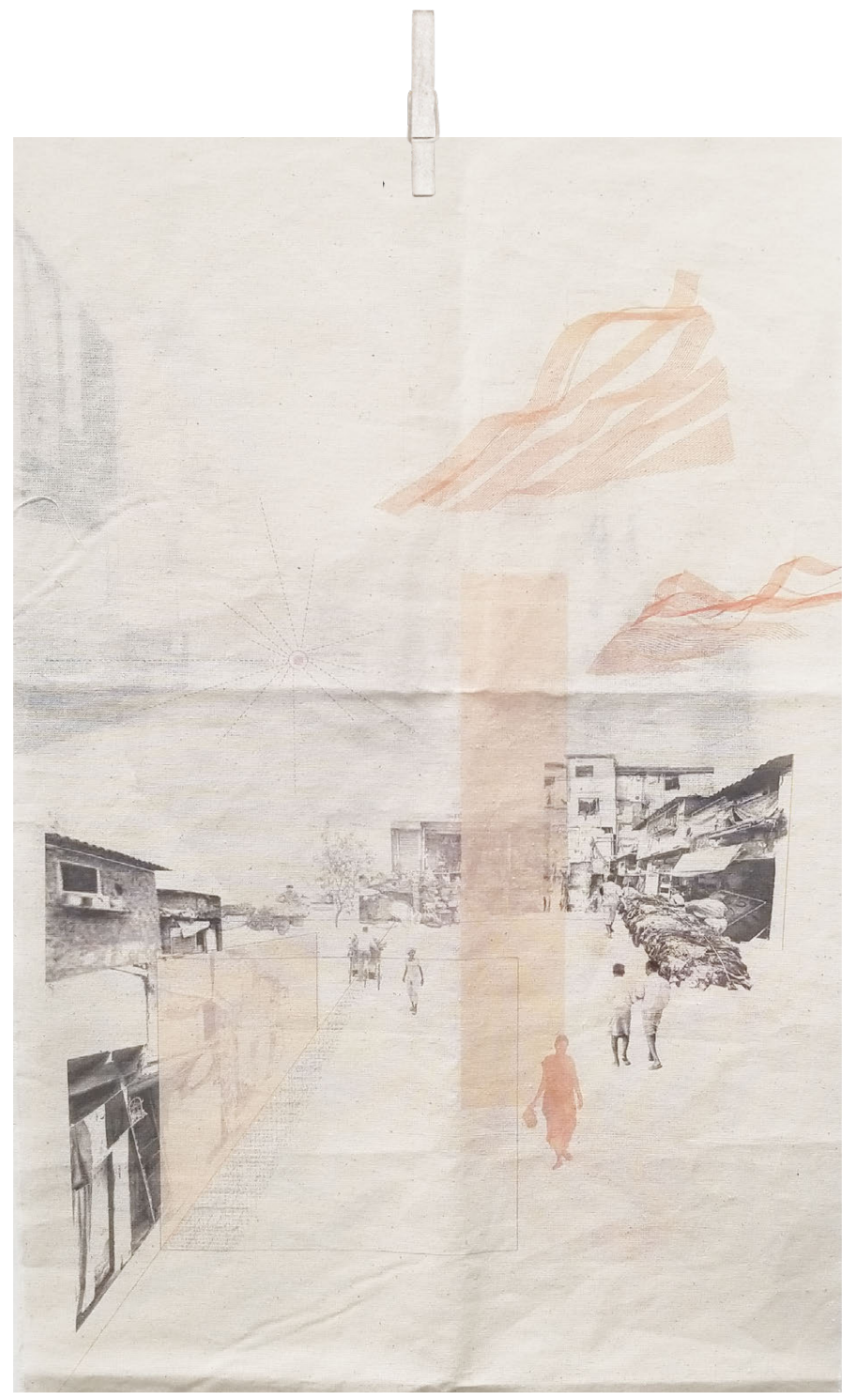

The image shows a bazaar, which represents a place of commerce that women may be excluded from. The curved lines represent the fabric of Dharavi women, which is impacted--either lifted or depressed--as a way of visually representing the momentary experiences of exclusion. As a woman experiences gendered bias, the fabric shifts and the bus's route changes to mark the invisible boundary.

Figure 7.17: Women Excluded from Commerce Activity Medium: Substrate Printed on Cotton 
Conclusion
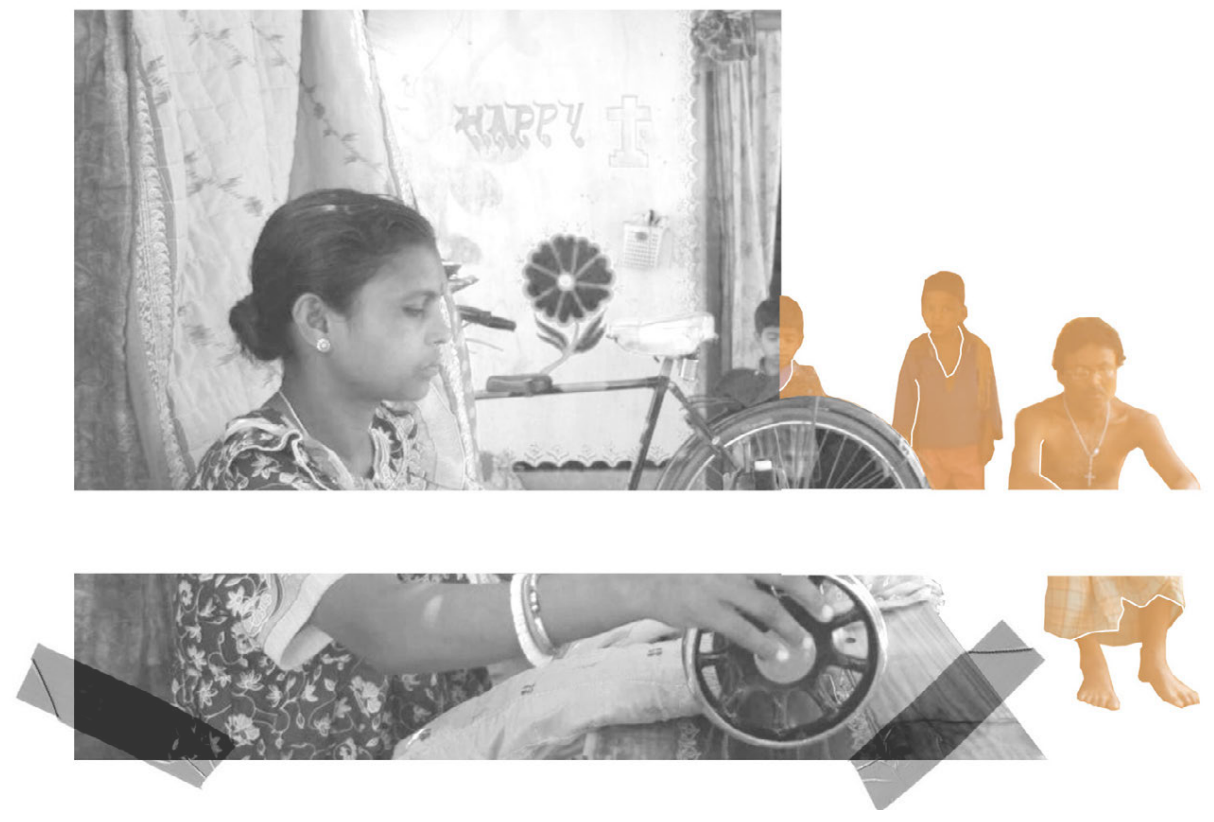

magic in the design process to allow multiple narratives to exist within the project without subverting one another. By obscuring reality in the representation, the project can preserve some indefiniteness and malleability for the women to shape.

Using a narrative tool like magical realism was meant to highlight the real boundaries on site and overcome them in a magical way but also to reflect the importance of narration. The space is meant to promote menstrual health and hygiene through conversation and identifying the condition. Hopefully, by making menstruation visible through the project's use, it can also lead to higher visibility for women in other realms.

The project's quilt represents the joining together of different stories and experiences, into a fabric that is only visible to the participating women. In the drawings, the narratives and health-related advice are metaphorically being woven into the quilt sky in real-time and evolving over time. Again, the sky is a neutral plane for the women to claim, can also help orient the scale of the problem, and mimics a growing canopy asserting its presence onto the site. 
The hope is that the research, ethnographic data, and writing can justify the project's feasibility and acceptability on site. Even though design considerations were made, they are meant to maintain a level of abstraction to anticipate further engagement.

The intent was to not be overly prescriptive but rather propose a framework that could be applied on site and be continuously adapted by women. For far too long women have been told how to feel about their reproductive health and the project does not wish to reinforce the patriarchal narrative. Period. 
The thesis defence was presented in room 402 B on Wednesday, April 17th, 2019. The defence was divided into two formats for two different audience members. The first section was presented as if speaking to an NGO and the second section as if speaking to the community members in Dharavi.

As such, the presentation had two different modes of delivery. The first part was a standing presentation next to the printed drawings, displaying the technical elements of the project, along with a concise speech outlining its feasibility. The second part was presented at the table, seated, while questions were asked and the drawings printed on fabric were passed around, as a way of engaging the community and forming a collaborative construction of the project. A stop motion animation of coloured threads layering onto one another was projected onto fabric hanging from the ceiling--this was to symbolize the narrative quilt and its growing stories over Dharavi. 


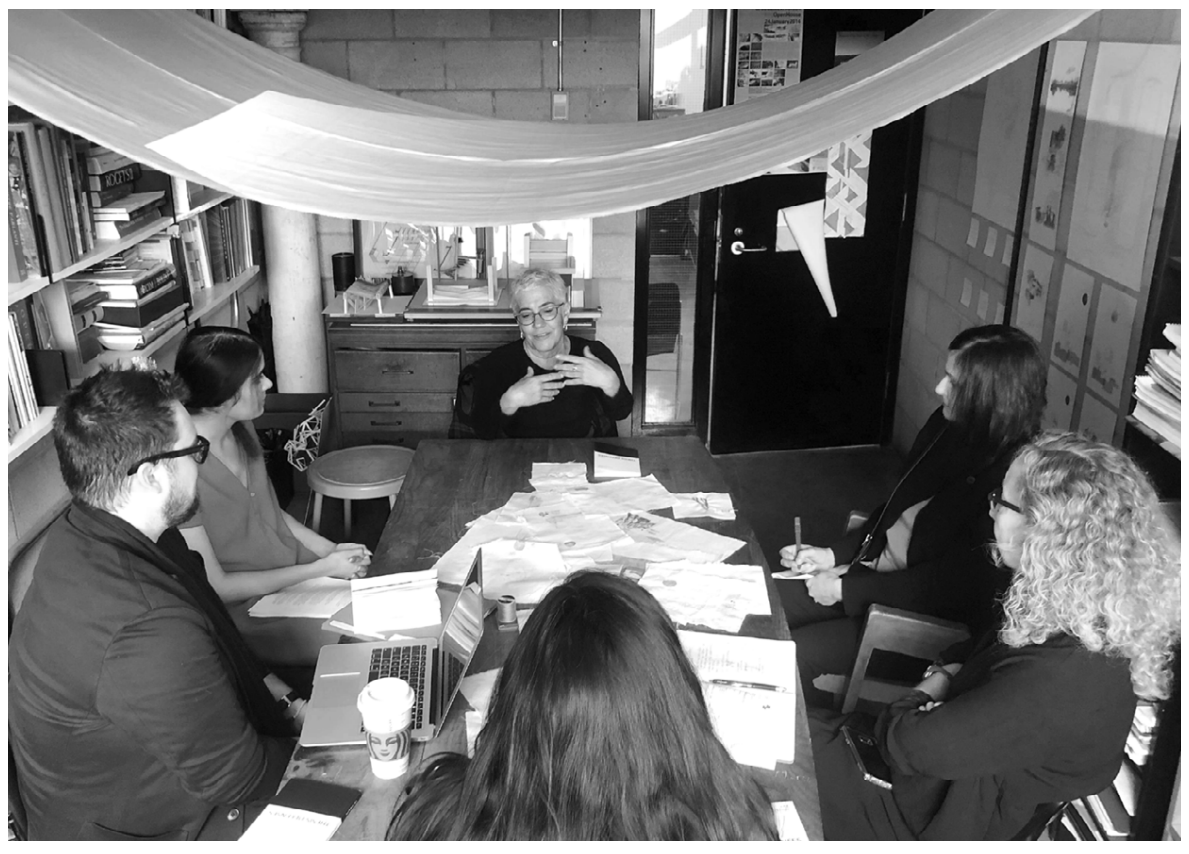




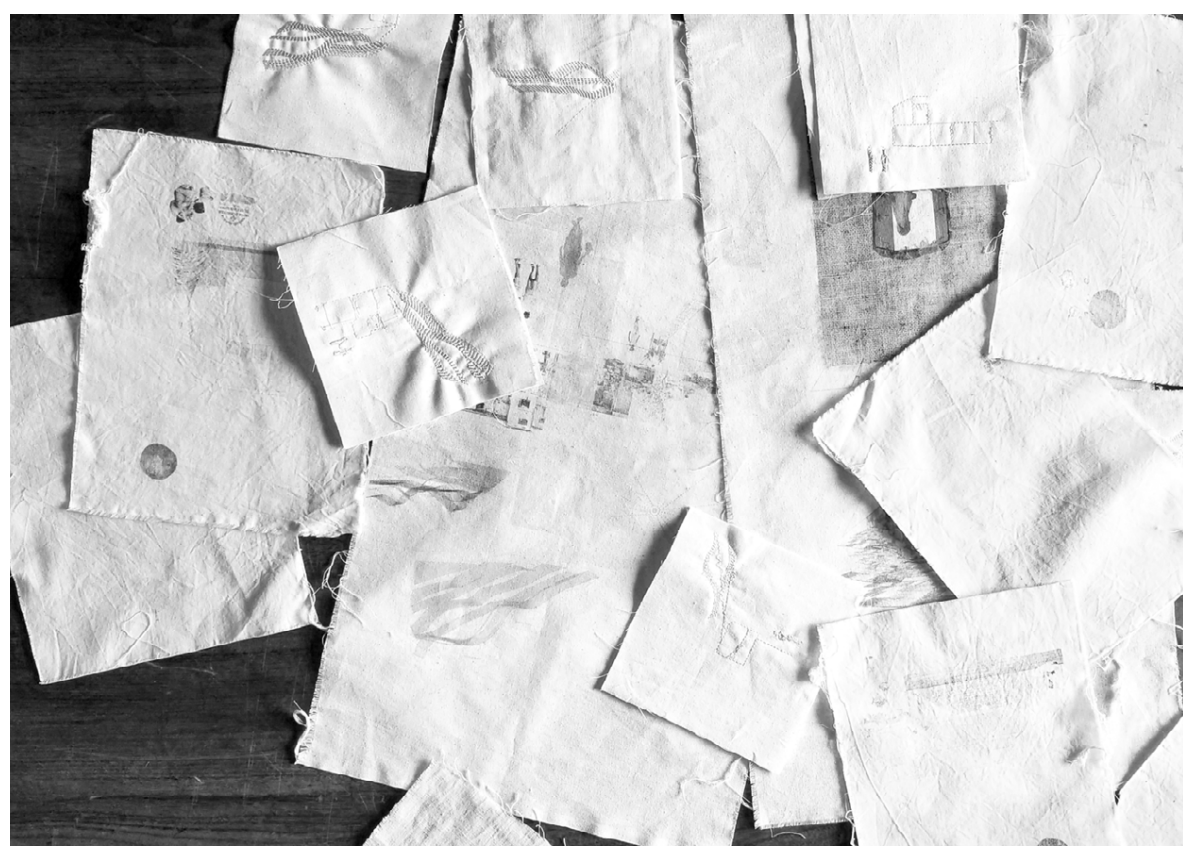



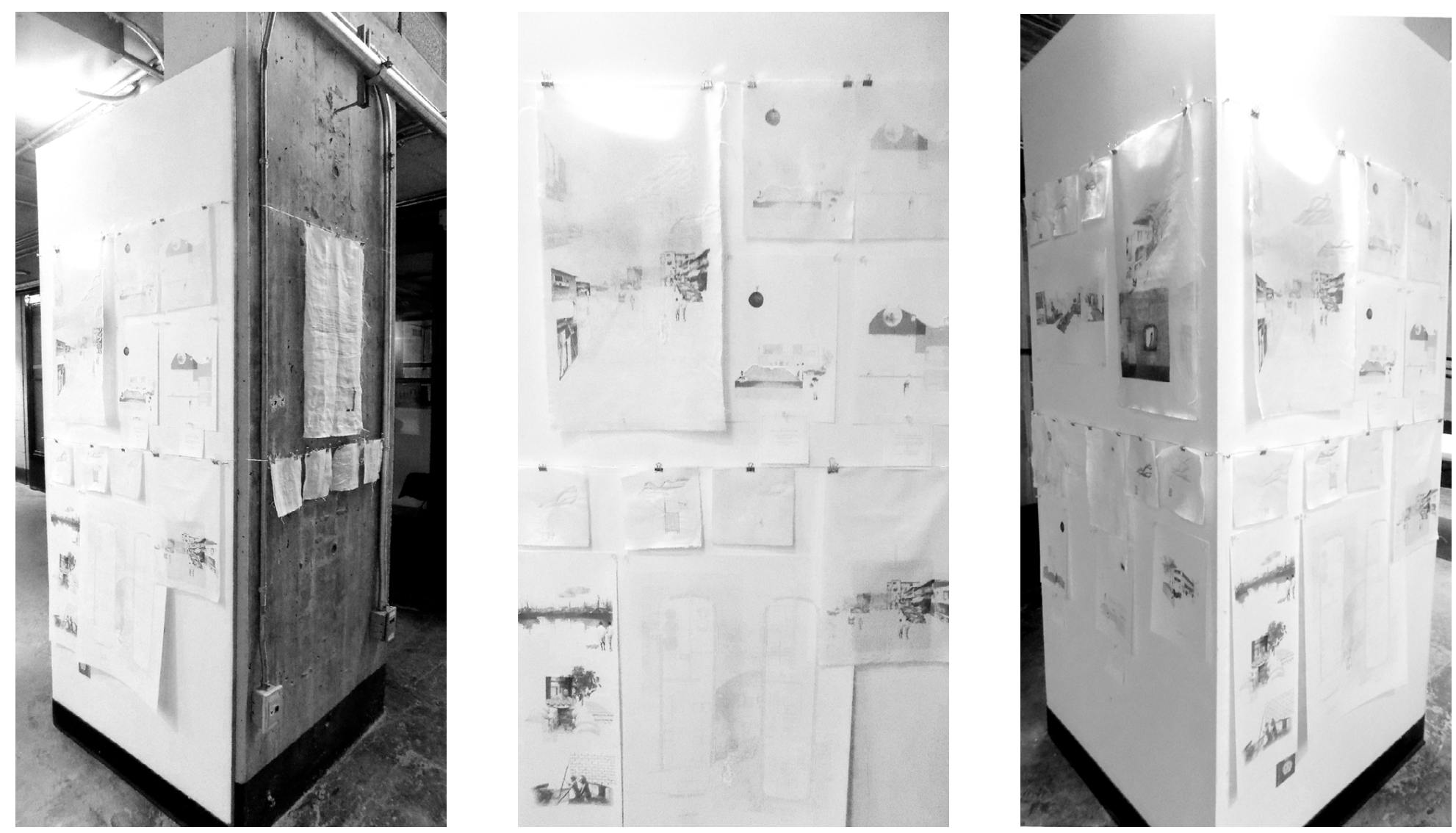

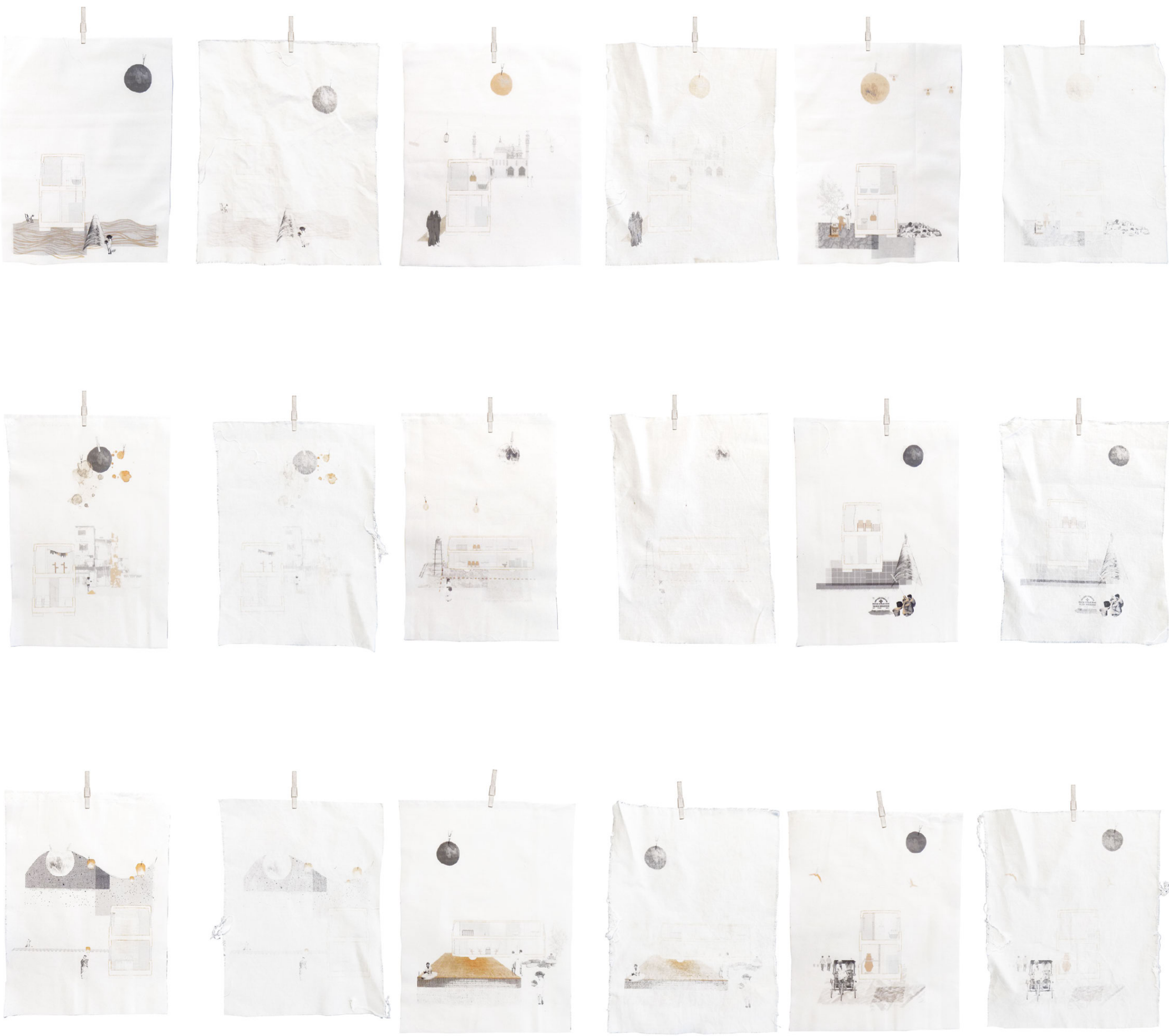
Ansari, F. (2017). Scenario of some waterborne diseases in slums of Mumbai city. International Journal of Multidisciplinary Research and Development, 4(7). Retrieved from http://www.allsubjectjournal.com/ archives/2017/vol4/issue7/4-7-143

Assainar, R. (2014). At the heart of Dharavi are 20,000 mini-factories. Retrieved from https://www.theguardian.com/cities/2014/nov/25/ dharavi-mumbai-mini-factories-slum

BBC. (2017). India washing machine launched. Retrieved from https:// www.bbc.com/news/business-39176358

Bhartiya, A. (2013). Menstruation, Religion and Society. International Journal of Social Science and Humanity 3(6), 523-527. doi: 10.7763/ IJSSH.2013.V3.296

Brown, W. (2017). Mumbai's slumdog recycling works surprisingly well--unless you're one of its workers. Retrieved from https:// www.citymetric.com/fabric/mumbai-s-slumdog-recycling-workssurprisingly-well-unless-you-re-one-its-workers-3096

Bobhate, P. S., Shrivastava S. R. (2011). A Cross Sectional Study of Knowledge and Practices about Reproductive Health among Female Adolescents in An Urban Slum of Mumbai. Journal of Family and Reproductive Health, 5(4), 117-123.

CARE. (2017). Dignified work in Asia impact report 2017. Retrieved from https://www.care.at/wp-content/uploads/2017/12/Made-byWomen_Dignified-Work-in-Asia-Impact-Report-2017.pdf 
Carr, C. (2015). Health in Indian slums: inside Mumbai's busiest public hospital. Retrieved from https://www.theguardian.com/globaldevelopment-professionals-network/2015/oct/30/health-in-indianslums-inside-mumbais-busiest-public-hospital

Chandran, R. (2016). What's a slum? In India, Dharavi's thriving informal economy defies the label. Retrieved from https://in.reuters. com/article/india-landrights-slum-idINKCN12B1KY

Daruwalla, N., Fernandez, A., Salam, J., Shaikh, N., \& 1 and Osrin, D. (2009). Conflict, crisis, and abuse in Dharavi, Mumbai: Experiences from six years at a centre for vulnerable women and children. PLOS Med, 6(7). Doi: 10.1371/journal.pmed.1000088

Das, M., Angeli, F., Krumeich, A. J., \& Schayck, O. C. (2018). Patterns of illness disclosure among Indian slum dwellers: A qualitative study. BMC International Health and Human Rights, 18(1). doi:10.1186/s12914018-0142-x

Das, S. (2017). Washing a city. Retrieved from https://maptia.com/ sanjitdas/stories/washing-a-city

Dey, S. (2018). The circular economy of Dharavi: Making building materials from waste (Master's Thesis). The Pennsylvania State University, State College.

Dovey, K., Tomlinson, R. (2012). Dharavi: Informal Settlements and Slum Upgrading. Retrieved from http://www.placeresearch.net/pdf/ DHARAVI\%20report.pdf

Fernando, B. (2014). The bamboo basket weavers at Mahim station. Retrieved from https://dharavibiennale.wordpress.com/2014/01/25/ the-bamboo-basket-weavers-mahim-station/ 
Gandy, M. (2008). Landscapes of disaster: water, modernity, and urban fragmentation in Mumbai. Environment and Planning, 40(1), 108-130. doi:10.1068/a3994

Gartenberg, I. (2011). Mapping exercise of home based workers in Maharashtra. (LEARN). Retrieved from http://learn-india.org/

Ghoshal, R. (2016). What ails India's two-tiered healthcare system? A philosophical enquiry. Indian Journal of Medical Ethics, 12 (1), 25. Retrieved from http://ijme.in/articles/what-ails-indias-two-tieredhealthcare-system-a-philosophical-enquiry/

Gupta, I., \& Guin, P. (2015). Health Status and Access to Health Services in Indian Slums. Health, 7(02), 245-255. doi:10.4236/ health.2015.72029

ICC Ventilation. (2019). Low profile rotary fan ventilator for van, bus, caravan. Retrieved from https://www.incarconnections.co.uk/vanventilation-van-roof-vents-van-vent/low-profile-rotary-van-ventilatorfor-van-bus-caravan-plastic-roof-vent.html

International Health Care System Profiles. (2017). The Indian Health Care System. Retrieved from https://international.commonwealthfund. org/countries/india/

Kapadia-Kundu, N., \& Kanitkar, T. (2002). Primary Healthcare in Urban Slums. Economic and Political Weekly, 37(51), 5086-5089. Retrieved from http://www.jstor.org.proxy.library.carleton.ca/stable/4412981

Karn, S., \& Harada, H. (2002). Field survey on water supply, sanitation and associated health impacts in urban poor communities - a case from Mumbai City, India. Water Science and Technology, 46(11), 269275. 
P.183

Mathur, A., \& Cunha, D. (2009). Soak: Mumbai in an Estuary. New Delhi: Rupa Publications.

McFarlane, C. (2007). Sanitation in Mumbai's informal settlements: state, 'slum', and infrastructure. Environment Planning, 40, 88-107. doi:10.1068/a39221

Mehotra, R. (2008). Negotiating the static and kinetic cities: The emergent urbanism of Mumbai. In A. Huyssen (Ed.), Other cities other worlds: Urban imaginaries in a globalizing age (p. 205-218). London: Duke University Press.

Meleis, A., Birch, E., \& Wachter, S. (Eds.). (2011). Women's Health and the World's Cities. University of Pennsylvania Press. Retrieved from http://www.jstor.org/stable/j.ctt3fh73p

Mingwei, L. (2017). The mending project. http://www.leemingwei. com/projects.php\# Ministry of Home Affairs, Government of India. (2001). 2001 census data religion. Retrieved from http://censusindia.gov.in/Census_And_ You/religion.aspx

Ministry of Home Affairs, Government of India. (2001). 2001 census data gender composition. Retrieved from http://censusindia.gov.in/ Census_And_You/gender_composition.aspx

Mitra, B. (2016). Dhobi ghat uses 78k litres of drinking water every day. Retrieved from https://timesofindia.indiatimes.com/city/kolkata/ dhobi-ghat-uses-drinking-water/articleshow/52536924.cms

Myna Mahila Foundation. (2018). The Myna Mahila Foundation model. Retrieved from https://mynamahila.com/ 
Pandey, S., \& Bajpai, P. (2014). Exaptive urbanism:

Symbiotic regeneration of Mahalaxmi Dhobighat, Mumbai.

Retrieved from https://www.symbioticcities.net/index.

cfm?id=64554\&modex=blogid\&modexval=18244\&blogid=18244

Phadke, M. (2017). For Dharavi's leather industry, troubles are more than skin-deep. Retrieved from https://theprint.in/economy/dharavisleather-industry-troubles/12316/

Press Trust of India. (2018). Bumpy ride ahead for Mumbai's BEST buses as losses mount to Rs 9.9 billion. Retrieved from https:// www.business-standard.com/article/pti-stories/bumpy-rideahead-for-mumbai-s-best-buses-as-losses-mount-to-rs-990-crorein-2016-17-118030400081_1.html

Pyati, A., \& Kamal, A. (2012). Rethinking community and public space from the margins: A study of community libraries in Bangalore's slums. Area, 44(3), 336-343. Retrieved from http://www.jstor.org. proxy. library.carleton.ca/stable/23251555

Rajagopal, S., \& Mathur, K. (2017). Breaking the silence around menstruation: experiences of adolescent girls in an urban setting in India. Gender \& Development, 25(1), 303-317. doi: 10.1080/13552074.2017.1335451

Saglio-Yatzimirsky, M. (2013). Dharavi, From Mega-Slum to Urban Paradigm. New Delhi: Abingdon Routledge.

Sengupta, A., \& Nundy, S. (2005). The private health sector in India. BMJ (Clinical research ed.), 331(7526), 1157-8.

Souza, N. (1998). Fabric Care. New Delhi: New Age International Limited Publishers. 
Svarer, C., Meiers, R., \& and Rothmeier, B. (2017). Empowering female workers in the apparel industry. (BSR 6/2017). Retrieved from https:// www.bsr.org/reports/BSR_Empowering_Female_Workers_in_the_ Apparel_Industry.pdf

Taubenböck, H., \& Kraff, N. (2014). The physical face of slums: A structural comparison of slums in Mumbai, India, based on remotely sensed data. Journal of Housing and the Built Environment, 29(1), 15-38. Retrieved from http://www.jstor.org.proxy.library.carleton.ca/ stable/43907251

Taylor, P. (2013). Extraordinary cities: Millenia of moral syndromes, world systems and city/state relations. Cheltenham: Edward Elgar Publishing Limited.

Time and Date. (2019). Sunrise, sunset, and daylength. Retrieved from https://www.timeanddate.com/sun/india/mumbai

Thapan, M. (1997). Linkages between Culture, Education and Women's Health in Urban Slums. Economic and Political Weekly, 32(43), WS83WS88. Retrieved from http://www.jstor.org. proxy.library.carleton.ca/ stable/4406011

The New York Times. (2011). An industrial slum at the heart of Mumbai. Retrieved from https://archive.nytimes.com/www.nytimes. com/interactive/2011/12/28/world/asia/an-industrial-slum-at-theheart-of-mumbai.html?ref=asia

United Nations Human Settlements Programme. (2006). The state of the world's cities report 2006/2007. Retrieved from https:// sustainabledevelopment.un.org/content/documents/11292101_alt. pdf 
United States Geological Survey. (2016). Water at home. Retrieved from https://water.usgs.gov/edu/qa-home-percapita.html

URBZ. (2018). Kumbharwada: A pottery village. Retrieved from https:// urbz.net/articles/kumbharwada-pottery-village

US Aid. (2016). Drinking Water Supply for Urban Poor: City of Mumbai. Retrieved from https://www.safewaternetwork.org/sites/default/files/ Safe\%20Water\%20Network_Mumbai\%20City\%20Report.pdf US Department of Energy. (2019). Storage water heaters. Retrieved from https://www.energy.gov/energysaver/water-heating/storagewater-heaters

Yardley, J. (2011). In Indian slum, misery, work, politics and hope. Retrieved from https://www.nytimes.com/2011/12/29/world/asia/inindian-slum-misery-work-politics-and-hope.html?mtrref=www.google. com\&gwh=1B5478761AADA5342A6FB6BBBF368A56\&gwt=pay

Zamora, L. P., \& Faris, W. B. (Ed.). (1995). Magical realism: Theory, history, community. Durham, N.C: Duke University Press.

Zehtabchi, R., Berton, M., Taback, L., Schiff, G. (Producers), \& Zehtabchi, R. (Director). (2018). Period. End of Sentence [film]. California: Netflix. 


\section{Images Cited}

Figure 2.1: WHO Health Expenditure Amongst Newly Industrialized Nations [Image]. (2015). Retrieved from https://www.aljazeera. com/indepth/interactive/2017/08/india-healthcare-private-publicsector-170831125534448.html

Figure 2.2: Public versus Private Healthcare Systems in India [Image]. (2014). Retrieved from https://www.aljazeera.com/indepth/interactive/2017/08/india-healthcare-private-public-sector-170831125534448. html

Figure 4.0: Times of India Map of Bombay, India c. 1895 [Image]. (2019). Retrieved from https://www.geographicus.com/P/AntiqueMap/ Bombay-times-1895

Figure 4.5: Map of Kumbharwada and its marked kilns [Image]. (2018). Retrieved from https://urbz.net/articles/kumbharwada-pottery-village

Figure 4.7: Routes by which Women in Crisis Approached the Centre 2003-2006 [Image]. (2009). Retrieved from https://www.ncbi.nlm.nih. gov/pmc/articles/PMC2699030/

Figure 5.0: Dr Franz Roh, “The Candle Duel of the Literary Man,” c. 1930. [Image]. (2019). Retrieved from https://www.ubugallery.com/gallery/artists/franz-roh/\#

Figure 6.1: Laundry at Dhobi Ghat in Mumbai, India [Image]. (2009). Retrieved from https://www.gettyimages.ca/detail/photo/laundry-atdhobi-ghat-in-mumbai-india-royalty-free-image/519962038

Figure 6.3: Population and Social Structure of the Dhobi Ghat, Mumbai [Image]. (2014). Retrieved from https://www.symbioticcities.net/index. cfm?id=64554\&modex=blogid $\&$ modexval $=18244 \&$ blogid $=18244$ 
Figure 6.16: A 17-Year-Old Nepali Woman Banished to a Chaupadi Hut during Menstruation [Image]. (2018). Retrieved from https://www. nytimes.com/2018/06/19/world/asia/nepal-women-menstruation-period.html

Figure 7.0: Lee Mingwei, “The Mending Project,” c. 2017 [Image]. (2018). Retrieved from http://annawu.com/

Figure 7.1: Cotton Fabric Drying in the Sun in Jaipur, Rajasthan [Image]. (2016). Retrieved from http://www.yannarthusbertrand2.org/collection/ earth-from-above/ 
